UNIVERSIDADE DE SÃO PAULO

ESCOLA DE ENGENHARIA DE SÃO CARLOS

MÁRIO ANGELO NUNES DE AZEVEDO FILHO

ANÁLISE DO PROCESSO DE PLANEJAMENTO DOS TRANSPORTES COMO CONTRIBUIÇÃO PARA A MOBILIDADE URBANA SUSTENTÁVEL 

MÁRIO ANGELO NUNES DE AZEVEDO FILHO

\section{ANÁLISE DO PROCESSO DE PLANEJAMENTO DOS TRANSPORTES COMO CONTRIBUIÇÃO PARA A MOBILIDADE URBANA SUSTENTÁVEL}

Tese apresentada à Escola de Engenharia de São Carlos da Universidade de São Paulo para obtenção do título de Doutor em Engenharia de Transportes.

Área de Concentração: Planejamento e Operação de Sistemas de Transportes

Orientador: Prof. Dr. Antônio Nélson

Rodrigues da Silva 
AUTORIZO A REPRODUÇÃO TOTAL OU PARCIAL DESTE TRABALHO, POR QUALQUER MEIO CONVENCIONAL OU ELETRÔNICO, PARA FINS DE ESTUDO E PESQUISA, DESDE QUE CITADA A FONTE.

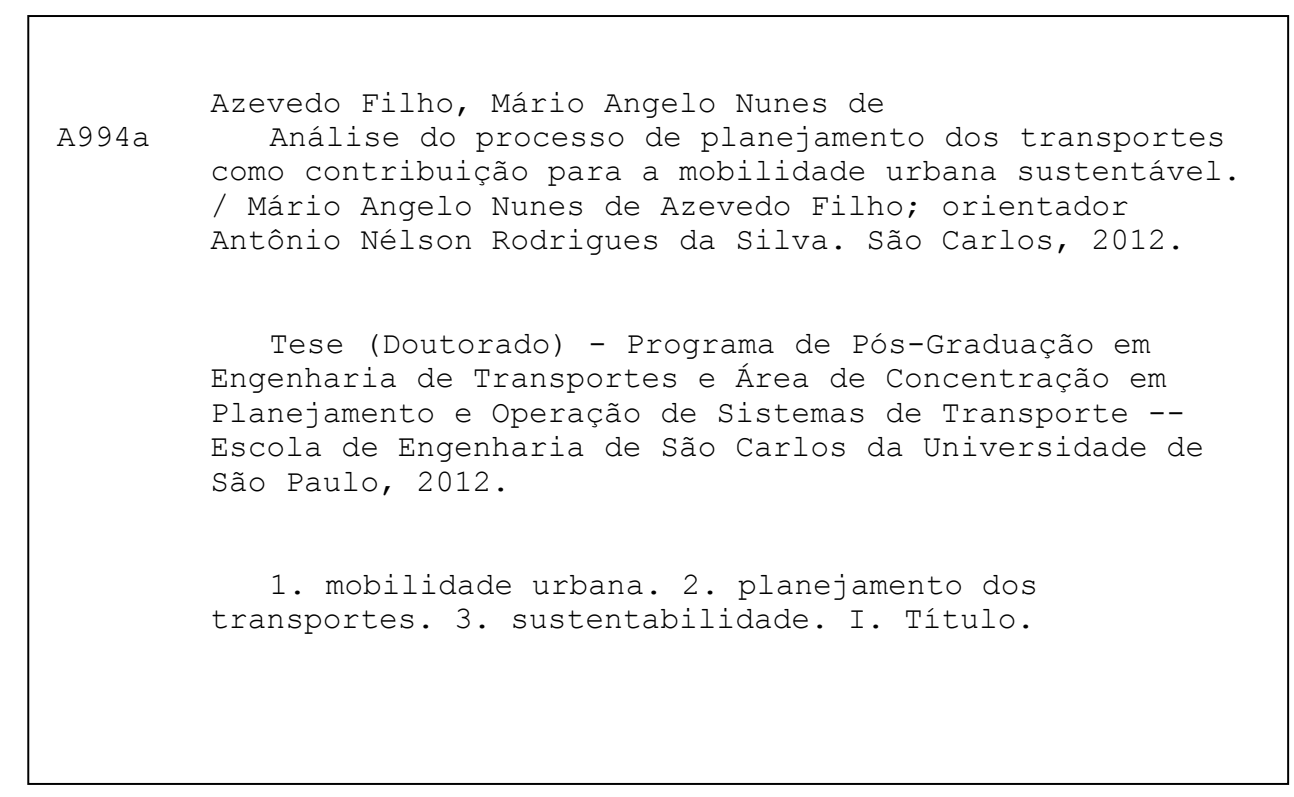




\section{FOLHA DE IULGAMENTO}

\section{Candidato: Engenheiro MÁRIO ANGELO NUNES DE AZEVEDO FILHO}

Título da tese: "Análise do processo de planejamento dos transportes como contribuição para a mobilidade urbana sustentável"

Data da defesa: 02/10/2012

\section{Comissão Julgadora:}

$\underline{\text { Resultado: }}$

Prof. Associado Antônio Nélson Rodrigues da Silva (Orientador)

(Escola de Engenharia de São Carlos/EESC)

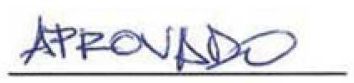

Prof. Dr. Carlos Felipe Grangeiro Loureiro

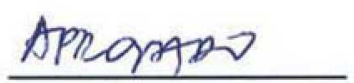

(Universidade Federal do Ceará/UFC)

Prof $^{\mathrm{a}} \mathrm{Dr}^{\mathrm{a}}$. Ana Maria Guerra Seráfico Pinheiro

APRONADO

(Universidade Federal de Pará/UFPA)

Prof. Dr. Rui António Rodrigues Ramos

APRONADO

(Universidade do Minho-Braga/Portugal)

Prof. Dr. Daniel Souto Rodrigues

(Universidade do Minho-Braga/Portugal)

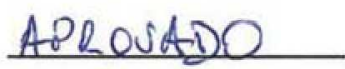

Coordenador do Programa de Pós-Graduação em Engenharia de Transportes:

Prof. Associado Antônio Nélson Rodrigues da Silva

Presidente da Comissão de Pós-Graduação:

Prof. Titular Denis Vinicius Coury 

A Rosina, Pedro e Lucas. 



\section{AGRADECIMENTOS}

Meu Deus, eu terminei! Muito obrigado!

À minha GRANDE família sempre tão atenta às minhas idas e vindas, me apoiando e doida para me ver de volta em casa.

Aos meus grandes amigos, colegas de apartamentos, David, Robson, Bruno e Samuel. Vou sentir saudades dessa minha família de São Carlos.

A Marília e Joana D'Arc, os anjos que me arrumaram asas.

Aos queridos amigos Expedito e Calimério, que sempre me perguntavam sobre o final desse meu doutorado e que foram embora antes de eu poder Ihes dar a boa notícia.

Aos meus colegas do Departamento de Engenharia de Transportes da Universidade Federal do Ceará.

To my former supervisors, Prof Anthony Wren and Dr Raymond Kwan, that did a good job trying to help me finish my research and thesis. Thanks also to Rahin, Margaret, Ann, Sarah, Colin, Paul and the other colleagues of the School of Computer Studies, University of Leeds.

From Anthony para o Antônio. Muito obrigado ao meu orientador, Prof. Antônio Nélson a quem eu acho que dei muito trabalho, ou melhor, eu tenho certeza disso. Grande exemplo de professor e orientador, que vou procurar seguir.

À CAPES pelo excelente apoio quando fui bolsista na Inglaterra e pelas várias chances que me deu para concluir esta jornada.

Aos professores Roberto Cláudio, Ícaro (in memorian) e Jesualdo, ex-reitores e atual reitor da UFC, e Barros Neto, diretor do Centro de Tecnologia, que sempre me apoiaram na tarefa de desatar este nó.

Aos professores Senna e Lindau (UFRGS), Yaeko (UnB) e Rômulo (UFRJ), que também se propuseram a me ajudar nesta tarefa.

Aos professores, funcionários e colegas do Departamento de Engenharia de Transportes da EESC/USP.

Aos meus muitos amigos brasileiros e de outras partes do mundo que eu conheci em Leeds, com os quais eu e minha família vivemos momentos felizes.

Aos professores Ana Seráfico e Marcus Seraphico e seus alunos e bolsistas do Instituto de Tecnologia da Universidade Federal do Pará, pelo apoio com a aquisição dos dados de Belém.

Ao pessoal da Biblioteca do Ministério dos Transportes pela enorme gentileza em digitalizar e me enviar por e-mail vários volumes de planos de transportes de Belém.

Finalmente, aos que eu por ventura tenha esquecido. Foi tanto tempo, tanta gente, ...

Muito obrigado a todos! 

Vida eterna, vida eterna

É a vida dos sonhos

Deus é o tempo

Sonhar é a salvação

O sonho de Leno morreu

O meu não

Zeca Baleiro, Felicidade pode ser qualquer coisa, 2012 

AZEVEDO FILHO, M. A. N. d. Análise do processo de planejamento dos transportes como contribuição para a mobilidade urbana sustentável. 2012. Tese (Doutorado) - Escola de Engenharia de São Carlos, Universidade de São Paulo, São Carlos, 2012.

Esta pesquisa tratou de uma avaliação do processo de planejamento de transportes urbanos e suas implicações para o funcionamento das cidades. Foi feita inicialmente uma revisão dos métodos mais consagrados de planejamento, aqui chamados de "tradicionais", contrastando-os com abordagens alternativas que visam a mobilidade urbana sustentável. Alguns planos de transportes e de mobilidade, principalmente referentes a casos brasileiros, foram analisados e, a partir daí, foi selecionada para estudo de caso a Região Metropolitana de Belém - RMB. Para esta região foram desenvolvidos nove estudos de transportes no período de 1978 a 2010. Nas propostas destes estudos percebe-se, de maneira geral, um viés de favorecimento dos modos de transportes motorizados. Mesmo com o grande número de estudos, a mobilidade urbana em Belém não chegou a ser considerada como boa durante a investigação. Isso foi verificado com o cálculo do índice de Mobilidade Urbana Sustentável para diferentes cenários, centrados nos anos de 1980, 1991, 2001 e 2011. Outro experimento envolveu a avaliação dos possíveis impactos das medidas propostas nos estudos caso fossem implantadas. Os estudos melhor avaliados foram os Planos Diretores de Transportes Urbanos concluídos em 1991 e 2001. Embora a preocupação com os impactos ambientais causados pelo sistema de transportes esteja presente em todos os estudos, as propostas não contemplaram bem esta questão. O discurso de melhoria do meio ambiente começou de maneira mais moderada nos primeiros planos e foi ganhando mais força ao longo do tempo, até mesmo pelas exigências, cada vez maiores, da legislação nacional e local. Apesar disso, no conjunto dos planos, o Domínio "Aspectos Ambientais" foi, comparativamente, o menos importante. A ideia de que, na medida em que as pessoas melhoram de condição econômica elas deixam de utilizar o transporte público e passam para o automóvel, parece levar a um problema sem solução. Não são consideradas medidas que restrinjam o uso do automóvel, o que poderia levar a melhores soluções. Outros fatores que impedem a implantação de um sistema de transportes mais adequado é a inexistência de uma estrutura de gerência metropolitana e os entraves para alterar o arranjo atual das empresas de transporte coletivo e suas áreas exclusivas de operação. Embora não tenha aqui sido feita uma avaliação detalhada de outros casos, as práticas observadas no caso de Belém são seguramente muito próximas do que ocorre em outras cidades e regiões metropolitanas brasileiras. Por outro lado, a entrada em vigor em 2012 da lei que estabelece as diretrizes para a Política Nacional de Mobilidade Urbana abre perspectivas para uma mudança nos procedimentos de planejamento visando a mobilidade sustentável.

Palavras chave: mobilidade urbana, planejamento dos transportes, sustentabilidade. 

AZEVEDO FILHO, M. A. N. d. Analysis of the transportation planning process as a contribution to a sustainable urban mobility. 2012. Thesis (DSc) - Escola de Engenharia de São Carlos, Universidade de São Paulo, São Carlos, 2012.

The research dealt with the process of urban transportation planning and its consequences on the cities' functioning. It started with a literature review, which was carried out for comparing the well established planning methods, here named as "traditional", with the ones that propose an alternative approach aiming at a sustainable urban mobility. Some transportation or mobility plans, mainly from Brazilian cities, were thoroughly examined thereafter. Their inspection led to the selection of the RMB (which is the abbreviation of Belém Metropolitan Area, in Portuguese), as a case study. From 1978 to 2010, nine transportation studies or plans had been produced for that region. In general, most proposals found in these studies are biased towards motorized transport modes. Despite all these studies the mobility of Belém did not receive good grades along the investigation. This was assessed with the estimation of a Index of Sustainable Urban Mobility - I_SUM for different scenarios in the years 1980, 1991, 2001 and 2010. Another experiment consisted of an evaluation of the potential impact of the solutions proposed in the reports. As a result, the better ranked studies were the Urban Transportation Master Plans developed in 1991 and 2001. Even though concerns about the environmental impacts of the transportation system had been found in all studies, this question was far from being solved. The arguments in favor of environmental improvements started with moderate emphasis in the first plans and grew stronger toward the recent plans, in part due to local and national legislation. Nevertheless, the set of plans performed poorly in the "Environmental Aspects" Domain. The idea that improvements on people financial condition leads to a modal shift from transit to cars seems to produce an unsolvable problem. Restrictions on motoring would possibly open space for better solutions, but they were never effectively considered in those plans. The lack of a metropolitan institution in charge of the mobility management and the present setting of bus companies' exclusive operational areas also make difficult the implementation of better transportation system. Even though detailed analyses for other cases were not conducted here, the practice observed in Belém is surely quite similar to other Brazilian cities and metropolitan areas. However, a federal law establishing the guidelines for a National Policy for Urban Mobility was recently passed, what opens prospects of changes on the planning procedures aiming at a sustainable mobility.

Keywords: urban mobility, transportation planning, sustainability. 



\section{LISTA DE FIGURAS}

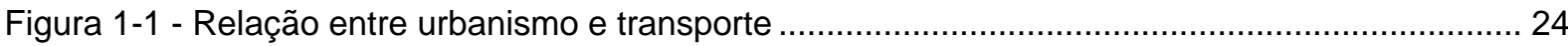

Figura 2-1 - Processo de previsão da demanda - Método de "4 Etapas" ............................................. 30

Figura 2-2 - Estrutura de Domínios e Temas do Índice de Mobilidade Urbana Sustentável, incluindo seus respectivos pesos. 41

Figura 2-3 - Temas e Indicadores do Domínio "Acessibilidade" do IMUS ............................................. 42

Figura 4-1 - Municípios que formam a Região Metropolitana de Belém............................................ 53

Figura 5-1 - Valores calculados para o IMUS, incluindo valor superior e inferior, considerando os dados de todos os indicadores para cada um dos cenários. 62 Figura 5-2 - Contribuição de cada um dos domínios para a formação do IMUS dos cenários

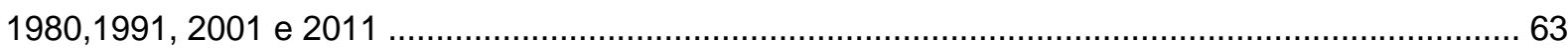

Figura 6-1 - Classificação dos Domínios, incluindo valor normalizado da soma das notas ponderadas pelos pesos. 



\section{LISTA DE TABELAS}

Tabela 2-1 - Diferenças entre o procedimento tradicional de planejamento dos transportes e aquele voltado para a mobilidade sustentável. 32

Tabela 2-2 - Problemas e consequências negativas principais do planejamento de transportes tradicional nos países em desenvolvimento. 32

Tabela 2-3 - Problemas dos modelos de planejamento de transporte e sugestões de melhorias....... 34

Tabela 2-4 - Domínios do IMUS e quantidades de temas e indicadores .......................................... 40

Tabela 2-5 - Estrutura do Índice de Mobilidade Sustentável ................................................................. 43

Tabela 4-1 - População dos municípios da Região Metropolitana de Belém ........................................ 53

Tabela 4-2 - Relação dos planos e estudos de transportes da Região Metropolitana de Belém.......... 54

Tabela 5-1 - Resultados do cálculo do IMUS para Belém e para outras regiões.................................. 64

Tabela 5-2 - Resultados da aplicação do método do Estudo Mobilize, para Belém e outras capitais . 65

Tabela 5-3 - Resultados da aplicação do método do Estudo Mobilize, para os cenários de Belém, com

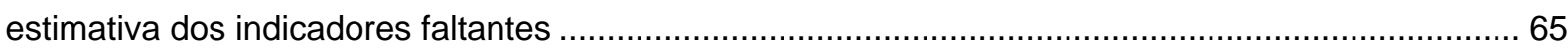

Tabela 5-4 - Resultado da aplicação do método do Índice de Mobilidade Sustentável ....................... 66

Tabela 5-5 - Comparando o IMS para a RMB (cenário 2011) com os municípios da Região

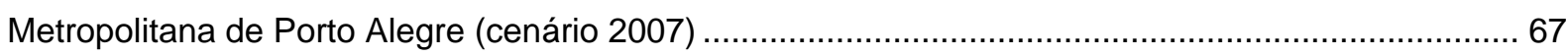

Tabela 6-1 - Avaliação dos estudos e planos de transportes para a RMB .......................................... 70 



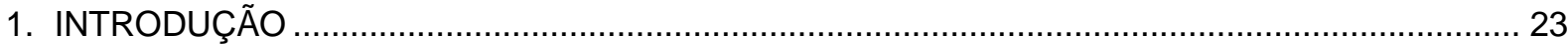

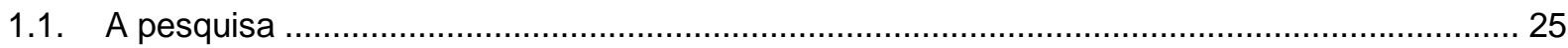

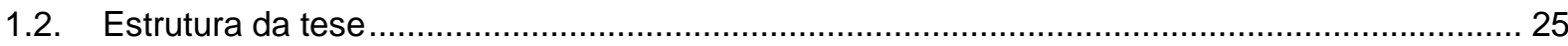

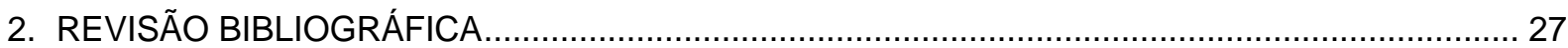

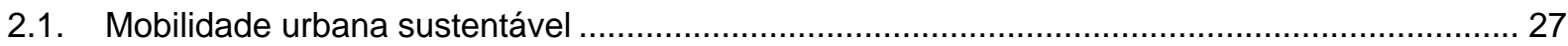

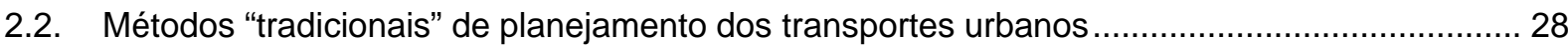

2.3. Novas abordagens para o planejamento da mobilidade urbana …........................................... 33

2.3.1. O Caderno de Referência para Elaboração do PlanMob....................................................... 35

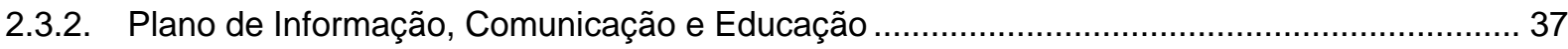

2.4. Uso de indicadores para o planejamento e gestão da mobilidade urbana................................. 38

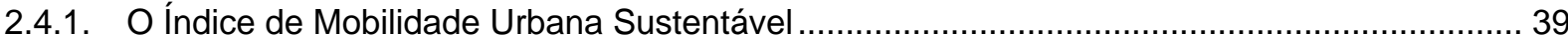

2.4.2. Outros casos de uso de indicadores para avaliação da mobilidade sustentável em cidades

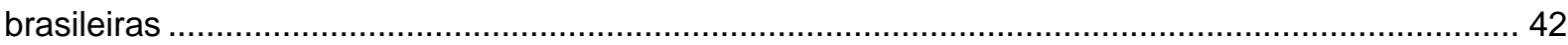

2.4.3. Uso de um índice de mobilidade sustentável para análise de PGVs.................................. 43

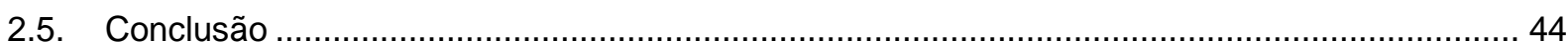

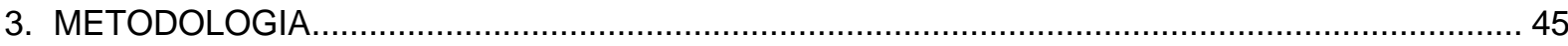

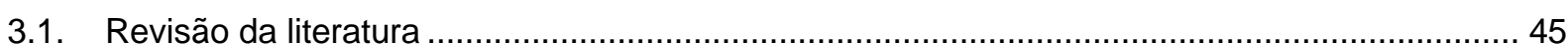

3.2. Levantamento de planos de transportes e seleção da localidade ............................................. 45

3.3. Caracterização e avaliação da informação disponível ......................................................... 46

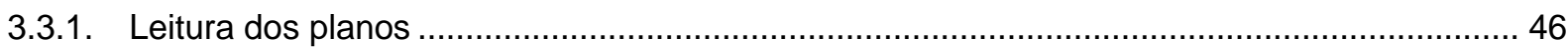

3.3.2. Levantamento da disponibilidade e qualidade dos dados para a situação atual..................... 47

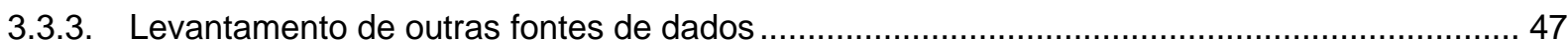

3.4. Estimativa da qualidade da mobilidade urbana sustentável................................................... 47

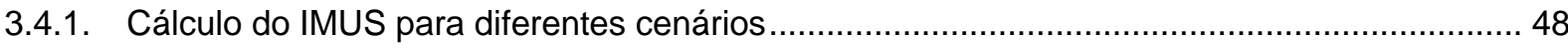

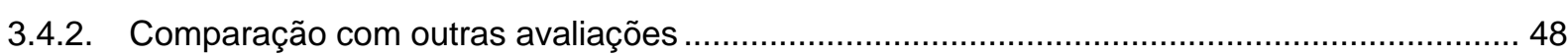

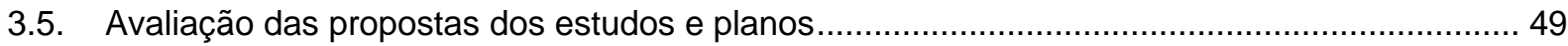

3.6. Considerações sobre o processo de planejamento da mobilidade .......................................... 49

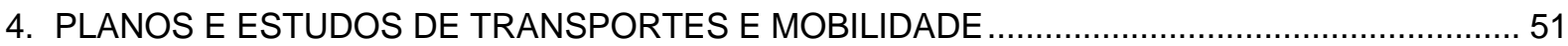

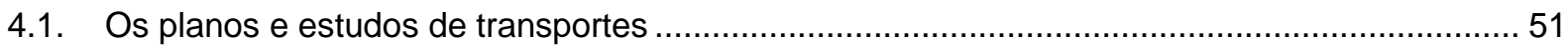

4.2. Caracterização da localidade escolhida e seus planos de transportes...................................... 52

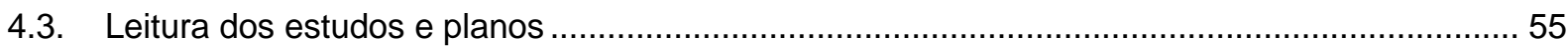

4.4. Outros estudos tratando da mobilidade urbana de Belém ..................................................... 57

5. AVALIAÇÃO DA MOBILIDADE URBANA SUSTENTÁVEL PARA OS DIFERENTES CENÁRIOS 59

5.1. Escolha e caracterização dos cenários e coleta de dados ......................................................... 59

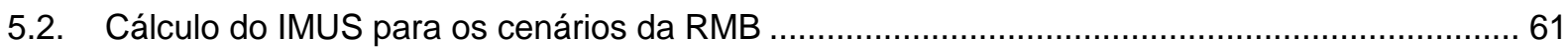




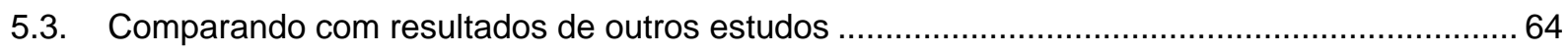

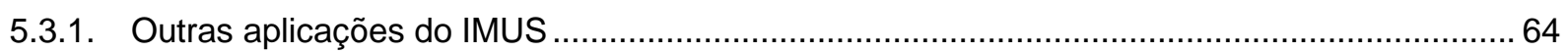

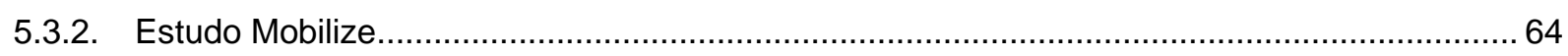

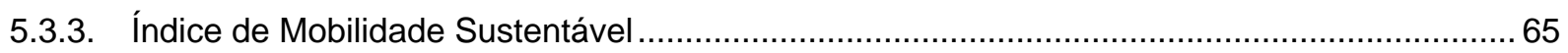

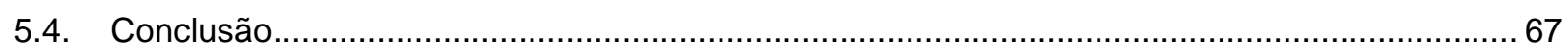

6. AVALIAÇÃO DO PROCESSO DE PLANEJAMENTO DA MOBILIDADE URBANA........................69

6.1. Comparando a contribuição potencial de cada projeto para a melhoria da mobilidade urbana

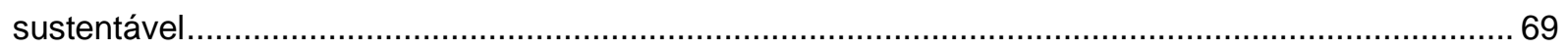

6.1.1. As propostas do conjunto de estudos e planos e o efeito nos Domínios do IMUS.................. 71

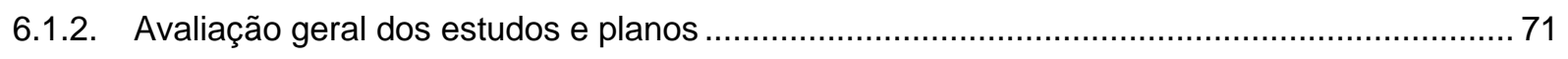

6.2. O processo de planejamento de transportes e a mobilidade urbana sustentável ..................... 73

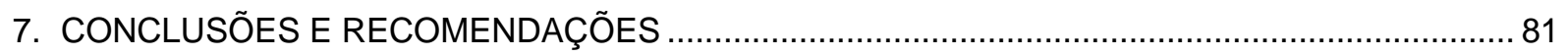

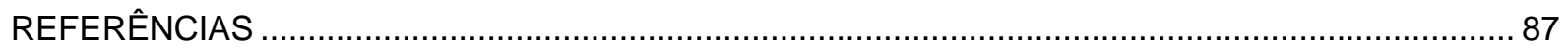

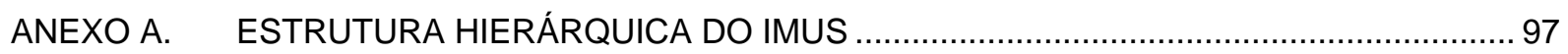

ANEXO B. RELAÇÃO DE ESTUDOS REALIZADOS PELO GEIPOT ......................................... 99

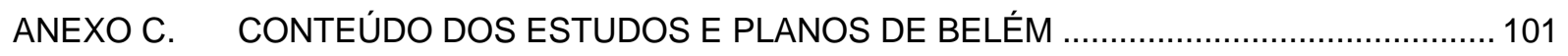

ANEXO D. RESUMO DOS INDICADORES CALCULADOS PARA O IMUS - RMB..................... 139

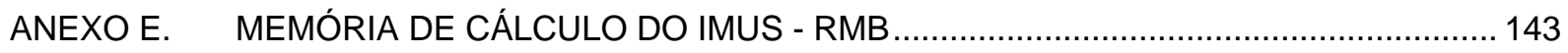




\section{INTRODUÇÃO}

O sistema de transportes de uma cidade está constantemente na pauta da imprensa e não raro é assunto de conversa entre indivíduos. Aparentemente, ele é mal gerido pelas autoridades, já que dificilmente se encontram opiniões favoráveis. São inúmeras as "receitas" para resolver os problemas do setor. Essas pessoas, leigas no assunto, normalmente consideram apenas o sistema de transportes, esquecendo que ele está dentro de um sistema maior, a cidade. Um problema maior é quando técnicos e autoridades, responsáveis pelo sistema, adotam o mesmo tipo de análise. Surge daí soluções que quase sempre apontam para a ampliação da infraestrutura, notadamente aquela destinada aos deslocamentos dos automóveis.

Também nos meios técnicos e acadêmicos, o processo de planejamento de transportes urbanos é questão que rende discussões há muitos anos (PLOWDEN, 1972; OWENS, 1995; BUCHANAN, 2004; BANISTER, 2005; RODRIGUES DA SILVA; COSTA; MACEDO, 2008; SEIXAS, 2010). Contrapondo-se aos processos de elaboração de "Planos Diretores de Transportes", concebidos desde as décadas de 60 e 70 do século passado, surgiu, mais recentemente, a proposta dos "Planos de Mobilidade", os quais são elaborados tendo em vista princípios de sustentabilidade. Existem manuais preparados por instituições governamentais, que estabelecem diretrizes e visam orientar, principalmente as administrações locais, para a maneira de se elaborar esses planos no Brasil e em outros países (MCIDADES, 2007h; PORTUGAL, 2010b, a).

O processo "tradicional" de planejamento segue o que Owens (1995) chama de "prever e prover" (do inglês, "predict and provide"), isto é, verifica-se o valor das demandas atuais, faz-se previsão dos valores futuros e, a partir daí, recomenda-se a ampliação ou criação de infraestruturas. A viabilidade econômica dos projetos baseia-se, quase sempre, na redução de custos operacionais e de tempo de viagem. Raramente são considerados custos de mensuração mais complexa como é o caso de impactos ambientais e da alteração do valor do solo (BANISTER, 2002). No entanto, Owens (1995) questiona se a abordagem não deveria ser a de "prever e prevenir" (do inglês, "predict and prevent").

Em muitos livros que tratam do planejamento dos transportes, encontram-se fluxogramas parecidos com o apresentado na Figura 1-1, que ilustra um ciclo de ocorrências interligadas do sistema de transportes e da cidade. Quando não existe o controle adequado do uso do solo, a tendência é que as soluções tenham vida curta, logo aparecendo novas demandas. A melhoria da infraestrutura agrega valor aos terrenos próximos e isto leva o proprietário a intensificar o uso da sua parcela de solo, repartindo esse novo valor com um número maior de clientes. Essa lógica da especulação imobiliária, em conjunto com a força de vendas da indústria automobilística, acaba influenciando as 
decisões e dificultando a aplicação de medidas de controle. Os tomadores de decisão também têm dificuldade para agir no sentido, por exemplo, de impor restrições ao uso do automóvel para favorecer modalidades que tragam benefícios para uma parcela maior e menos favorecida da população (MIRANDA et al., 2009).

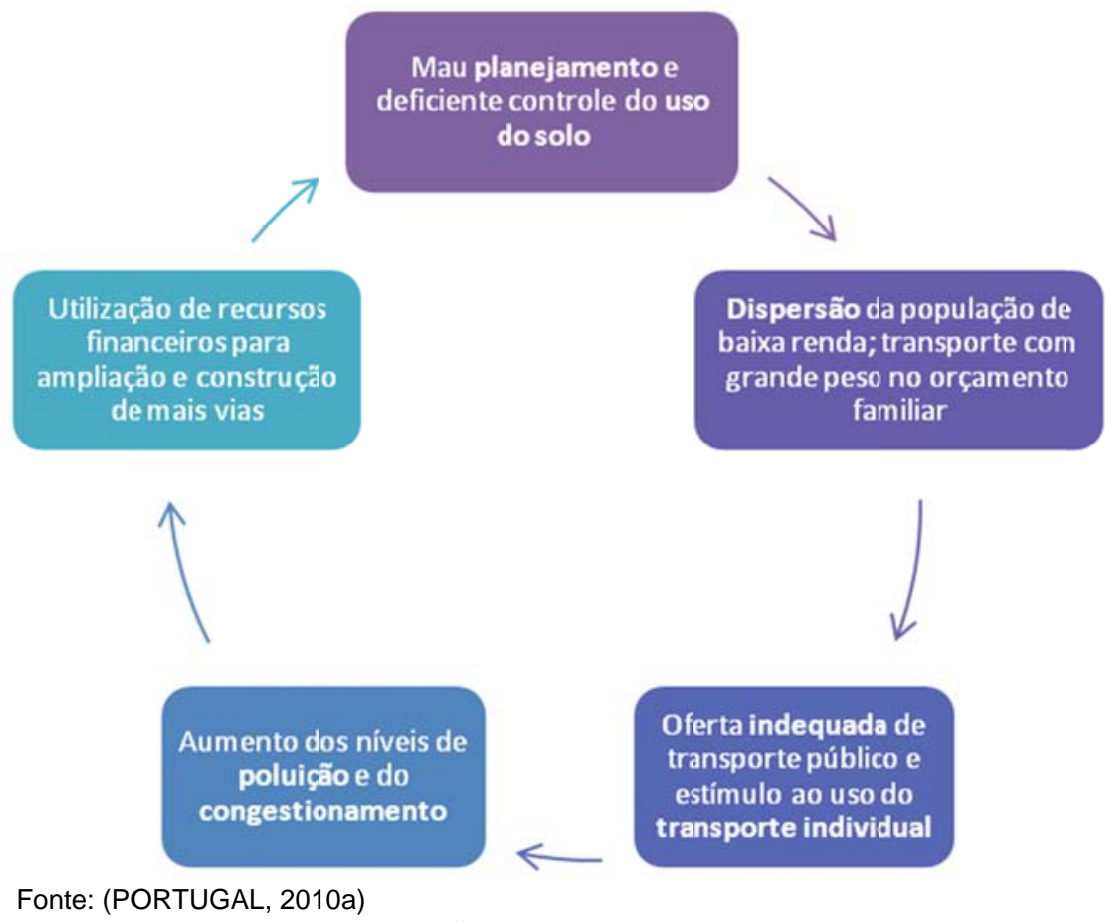

Figura 1-1 - Relação entre urbanismo e transporte

Diversos estudos foram desenvolvidos considerando o paradigma da mobilidade sustentável (AGYEMAN; EVANS, 2003; MACARIO; CARVALHO; FERMISSON, 2005; BANISTER, 2007, 2008; CURTIS, 2008; BLACK, 2010; COHEN, 2010; HICKMAN et al., 2010; RODRIGUES DA SILVA; COSTA; RAMOS, 2010). Este conceito deriva daquele do desenvolvimento sustentável, colocado no Relatório Brundtland (WCED, 1987) como sendo o que "atende às necessidades do presente sem comprometer a habilidade das gerações futuras de atender suas próprias necessidades" (tradução do autor). Poli (2011) questiona este conceito de mobilidade sustentável ou, pelo menos, a maneira como ele é utilizado.

Por facilidade, pela experiência acumulada, ou mesmo por outros interesses políticos ou financeiros, pode ser que as instituições acabem por utilizar os mesmo procedimentos, ou alguns semelhantes, que produzam o mesmo tipo de solução que, a princípio, se queria evitar. Em alguns casos, ocorre apenas a mudança do nome do plano, trocando o termo transporte por mobilidade, o que não é, em absoluto, a questão fundamental.

Procurando entender melhor esse processo a avaliar os efeitos produzidos pelo planejamento dos transportes urbanos, ou da mobilidade urbana, desenvolveu-se a pesquisa cuja concepção e estrutura são apresentadas a seguir. 


\subsection{A pesquisa}

Baseando-se na revisão preliminar da literatura, e na própria experiência do autor e seu orientador nas áreas de planejamento e operação de sistemas de transportes, chegou-se à seguinte Questão de Pesquisa:

O processo tradicional de planejamento de transportes proporciona condições para uma mobilidade urbana sustentável ou apenas reforça um ciclo vicioso de ampliação e ocupação da capacidade da infraestrutura das cidades?

Analisando-se esta questão e considerando que novas abordagens prometem melhores condições de atingir esta mobilidade sustentável, foi estabelecida com Hipótese de Pesquisa a de que o processo de planejamento de transportes urbanos, ou da mobilidade urbana, pode gerar propostas sustentáveis para os problemas dos movimentos de pessoas e bens nas áreas urbanas. Isso levou ao Objetivo Geral da Pesquisa que é o de "avaliar o processo de planejamento de transportes à luz do conceito de mobilidade urbana sustentável". Para detalhar a forma de atingir este objetivo geral, foram então definidos os seguintes Objetivos Específicos:

- Estudar os métodos propostos para o planejamento dos transportes urbanos e a sua evolução, tanto aqueles que são classificados como tradicionais como os que seguem novas abordagens.

- Examinar planos de transportes, alguns atualmente chamados de planos de mobilidade, de diferentes períodos das últimas décadas, procurando avaliar o tipo de proposta e, se possível, alguns resultados.

- Selecionar uma cidade ou região e realizar estudo de caso, procurando avaliar a qualidade da mobilidade à luz das informações apresentadas em planos diretores de transportes urbanos, planos de mobilidade urbana e similares.

- Preparar uma síntese dos estudos realizados nas etapas anteriores da pesquisa, procurando caracterizar o estado da prática do processo de planejamento de transportes, possíveis deficiências e caminhos mais promissores, com vistas à sustentabilidade.

Como Contribuições da Pesquisa pode se destacar a análise do processo de planejamento com a caracterização de possíveis omissões, ou abordagens equivocadas, que acabam dificultando a materialização da mobilidade sustentável. Os resultados podem alertar para a necessidade de mudanças culturais de quem toma decisões e faz a gerência da mobilidade urbana e da própria população em geral, que é quem gera os problemas e sofre com eles, e que deveria participar da solução dos mesmos.

\subsection{Estrutura da tese}

A partir desta Introdução, a tese continua com um capítulo de "Revisão Bibliográfica" que se concentra, principalmente, no processo de planejamento dos transportes urbanos e, seguindo tendências mais recentes, da mobilidade urbana sustentável. Também são revistos trabalhos sobre 
avaliação da mobilidade e sobre o uso de ferramentas de manuseio de informação que facilitem esse processo. O capítulo 3 constitui-se de uma descrição detalhada dos métodos utilizados nesta pesquisa. Os três capítulos seguintes tratam da aplicação da metodologia e da obtenção dos resultados, desde a análise dos planos de transportes e mobilidade, a seleção de uma localidade para o estudo de caso, a caracterização das informações disponíveis e a avaliação propriamente dita. Este bloco termina com uma análise mais geral sobre o processo de planejamento da mobilidade urbana sustentável. Fechando a tese vem o capítulo de "Conclusões e Recomendações", a relação das referências bibliográficas utilizadas e quatro anexos com informações complementares à pesquisa. 


\section{REVISÃO BIBLIOGRÁFICA}

Apresenta-se aqui uma revisão da literatura que trata de métodos de planejamento dos transportes e da mobilidade urbana. O ponto de partida são os métodos que aqui se convencionou chamar de "tradicionais". Estes, apesar de criticados, provavelmente ainda são os mais utilizados na prática. Esses métodos foram largamente utilizados, no caso brasileiro, na preparação dos Planos Diretores de Transportes Urbanos - PDTUs. Muitos estudos foram desenvolvidos no sentido de aperfeiçoar o método tradicional, notadamente na busca da melhor modelagem do comportamento dos usuários e, consequentemente, da demanda. Banister (2002) descreve essa evolução, mas ressalta que essas novas abordagens tendem a ficar restritas ao ambiente acadêmico, sem muitas aplicações na prática, ou seja, na preparação dos planos contratados pelos governos.

As preocupações com o meio ambiente são cada vez maiores, e o sistema de transportes é um dos principais causadores de impactos negativos. Com o passar do tempo, ficou mais nítido o fato de que o procedimento tradicional de planejamento alimenta o ciclo de ampliação e ocupação da capacidade da infraestrutura. Existem críticas a essa abordagem há várias décadas (ver Plowden (1972), por exemplo), mas nos últimos 10 a 20 anos os problemas começaram a se tornar mais aparentes levando a proposição de novas abordagens. Estas seguem a linha do planejamento da mobilidade urbana sustentável. Nas próximas seções são revistos conceitos e métodos de planejamento dos transportes e da mobilidade urbana.

\subsection{Mobilidade urbana sustentável}

O conceito de mobilidade urbana pode ser considerado subjetivo e de difícil compreensão quanto às suas definições, já que deve representar os mais diferentes espaços geográficos como os municípios ou aglomerados destes. Ainda é comum associar-se o conceito de mobilidade somente ao transporte, sobretudo aos modos motorizados. Restringe-se a análise, de forma equivocada, quase que apenas à circulação de automóveis e ao uso de transporte coletivo. Não existe a mesma preocupação com o deslocamento dos pedestres que constituem grande parte das viagens. Com planejamento adequado poder-se-ia atender uma parcela maior das necessidades com as pessoas se deslocando a pé ou usando bicicletas.

Um arranjo de uso do solo e uma mobilidade urbana sustentável devem assegurar o acesso a bens e serviços de maneira eficiente para todos os habitantes da área urbana, resguardando o meio ambiente, o patrimônio cultural e ecossistemas para a presente geração sem, no entanto, limitar as oportunidades das gerações futuras (BLACK; PAEZ; SUTHANAYA, 2002). 
Um dos motivos que levou o conceito de sustentabilidade a ser adicionado ao de mobilidade urbana foi a sua ligação com a eficiência da gestão da cidade e à necessidade do uso racional dos recursos. Por ser essencial às necessidades humanas e, até mesmo, envolver mudança de cultura, este passou a ser associado a conceitos como a gestão participativa e a sustentabilidade ambiental. Isto ampliou sua relevância, transformando-o em parâmetro para guiar a utilização de vias e espaços urbanos de forma eficiente e dinâmica, com a minimização dos impactos negativos (COSTA; RODRIGUES DA SILVA, 2006; MACEDO; RODRIGUES DA SILVA; COSTA, 2008). No Brasil, o desenvolvimento do conceito de mobilidade urbana, sob essa nova ótica, têm sido fomentado essencialmente por ações governamentais (RODRIGUES DA SILVA; COSTA; MACEDO, 2008).

Parte disso pode ser explicado pelo fato das ações para o desenvolvimento da política urbana serem recentes, tendo sido previstas na atual Constituição Federal (BRASIL, 1988) e em leis posteriores, como o Estatuto da Cidade (BRASIL, 2001) e a Lei de Diretrizes da Política Nacional de Mobilidade Urbana (BRASIL, 2012). Com o propósito de atender a esses dispositivos legais, o Ministério das Cidades estimula os municípios, com populações a partir de 20 mil habitantes, a preparar seus Planos de Mobilidade Urbana, o que representa uma evolução na política urbana brasileira. No entanto, apesar de existirem estudos acadêmicos sobre o tema, bem como ferramentas de avaliação e guias para a criação de Planos de Mobilidade Urbana (MCIDADES, 2006, 2007h), falta no Brasil know-how para elaboração e implantação de projetos seguindo essas novas abordagens.

Mais forte do que essa falta desse conhecimento para mudar os procedimentos pode ser a própria resistência à mudança, rompendo com um modelo que se sustenta em grandes interesses de especulação imobiliária e da indústria automobilística. A promoção da mobilidade sustentável depende da conscientização sobre estes novos conceitos não apenas dos gestores públicos, mas da população em geral. O processo envolve mudança de cultura e é essencial que o conceito de sustentabilidade faça parte das análises técnicas, introduzindo ou ampliando a utilização de modos de transportes não poluentes e/ou coletivos, em um mesmo espaço viário. Isso tende a propiciar um novo desenho urbano e uma nova maneira de pensar e planejar os espaços públicos voltados à mobilidade. Segundo alguns autores (como BOARETO, 2008, por exemplo), a percepção corrente é voltada quase que apenas para a expansão do uso do automóvel, através de um planejamento urbano que concebe cidades sem limites para expansão. Neste cenário, cada habitante teria, um dia, o seu próprio automóvel. Se esta for, de fato, a percepção partilhada por técnicos e gestores, a preparação de planos e, principalmente, a efetivação de ações voltadas à mobilidade urbana sustentável podem se tornar muito difíceis.

\subsection{Métodos "tradicionais" de planejamento dos transportes urbanos}

A análise da demanda é parte fundamental do processo de planejamento dos transportes. De acordo com Martin e McGuckin (1998) a previsão da demanda já era praticada há mais de 35 anos, em estudos das décadas de 50 e 60 do século passado. Certamente, a preocupação com a relação entre a oferta e a demanda nos transportes já havia sido pensada há muito mais tempo, mas ali começaram os estudos e aplicações mais sistemáticas. Trata-se de um processo que teve início nos 
Estados Unidos e, desde então, vem passando por constantes aperfeiçoamentos. Segundo os mesmos autores, o grande aumento da aplicação dessas técnicas ocorreu com o surgimento dos microcomputadores e isto "mudou dramaticamente o meio-ambiente nas áreas nas quais essas análises foram realizadas". A facilidade de aplicação das técnicas, com o acesso a software e hardware de menor custo, fez surgir um número maior de aplicações, além daquelas iniciais, que tratavam de grandes planos de investimentos em infraestrutura para longos períodos.

De uma maneira simples, os métodos se destinam à criação de um modelo que explique o funcionamento atual de um determinado sistema de transportes, baseando-se na ocupação do solo das áreas de estudos e do tipo de atividade ali desenvolvidas. O modelo é calibrado para que represente a realidade atual, associando um determinado conjunto de variáveis socioeconômicas ao padrão de viagens verificado. Posteriormente, essas condições socioeconômicas são projetadas para um determinado ano-horizonte e alimentam o modelo o que possibilita a estimativa dos perfis da demanda futura de transportes. Podem ser então previstas as necessidades de alteração (normalmente expansão) da infraestrutura de transportes.

Na Figura 2-1 apresenta-se um fluxograma descrevendo as etapas do chamado "Processo de Previsão da Demanda em 4 Etapas" ou "Modelo de 4 Etapas". Essa nomenclatura pode gerar alguma confusão já que se trata de um modelo de previsão da demanda, que se divide em quatro etapas, cada uma das quais é representada por um ou mais modelos. As quatro etapas principais estão destacadas na figura e consistem da Geração de Viagens, Distribuição de Viagens, Escolha Modal e Alocação de Tráfego.

Ao longo dos anos foram muitas as aplicações desse método, com uma série de variações, aos quais se dedicaram e se dedicam muitos engenheiros e outros profissionais, tanto da área acadêmica, quanto de agências governamentais e empresas de consultoria. No entanto, segundo Boyce et al. (1970 apud VUCHIC, 2005) "o resultado da maioria dos estudos de previsão de demanda tem pouca confiabilidade, e para poucos estudos houve uma verificação da precisão das projeções após a rede de transportes ter sido implantada".

Vuchic (2005) destaca que, para entender as previsões de demanda geradas por esses modelos, é necessário ter em mente que:

i. A previsão da demanda futura só pode ser tão precisa quanto a previsão do desenvolvimento futuro: aumento (ou diminuição) da população, desenvolvimento econômico, atividades sociais, etc.

ii. O procedimento de planejamento é baseado em modelos representando a situação e as relações atuais. A aplicação será válida se assumir-se que as relações continuarão válidas no futuro.

iii. O volume de viagens não é afetado apenas por fatores de influência externos, mas pelo próprio tipo de sistema de transportes que é ofertado. Isso mostra a necessidade de algum tipo de retroalimentação durante o processo de planejamento.

\footnotetext{
${ }^{1}$ Boyce, D. E., N. D. Day, and C. MacDonald. 1970. Metropolitan Plan Making. Philadelphia: Regional Science Research Institute.
} 
iv. Em virtude do aspecto anterior, um sistema de transportes não pode ser planejado, apenas, como consequência de desenvolvimentos independentes, porque ele mesmo tem a capacidade de gerar mais viagens e de influenciar na mudança do padrão de uso do solo e outros desenvolvimentos.

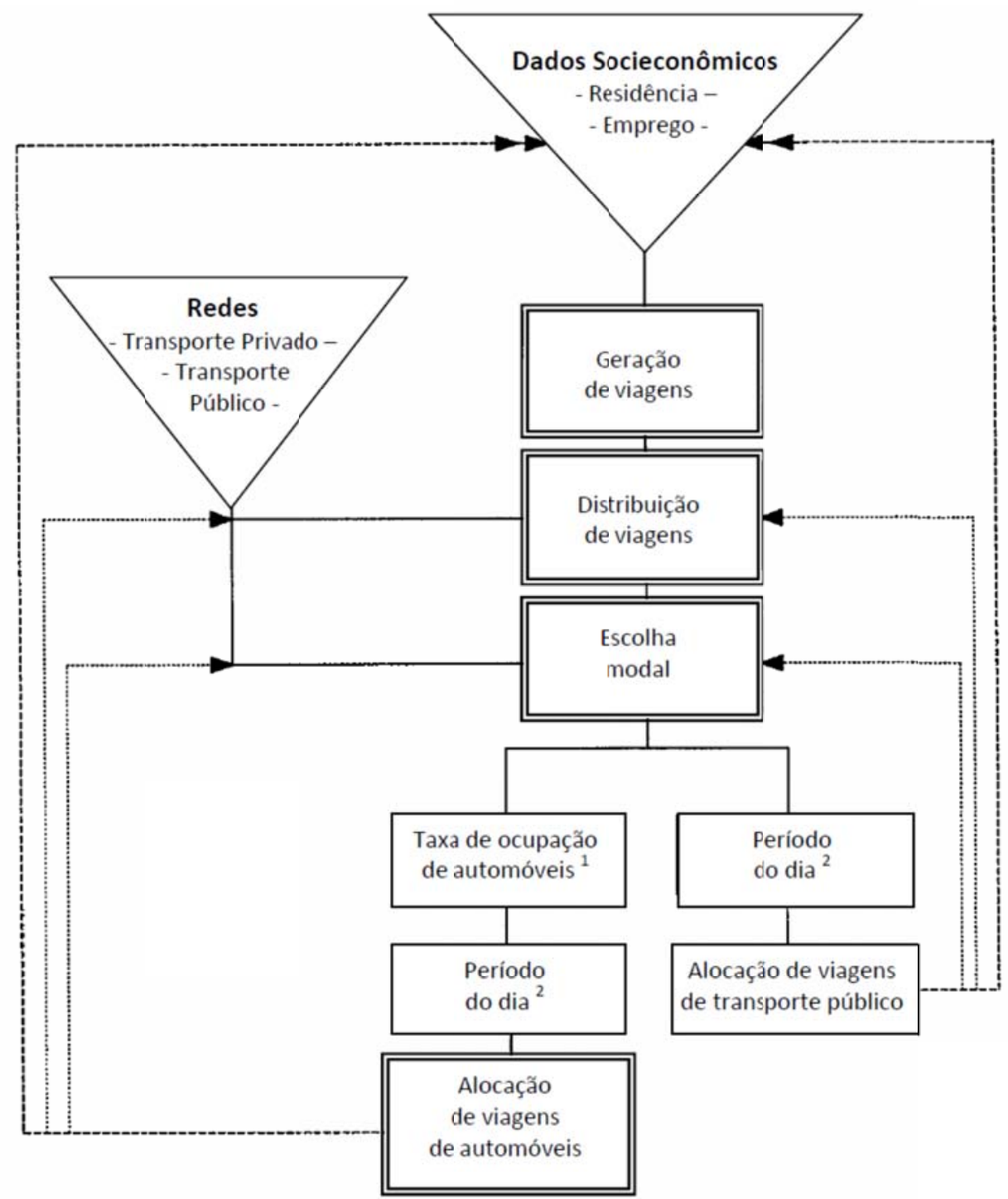

${ }^{1}=$ Taxa de ocupação de automóveis pode ser parte da escolha modal

$2^{2}=$ Para alocações no período de pico

= Circuito de retro alimentação

] = Procedimento tradicional de quatro etapas

= Outros submodelos

$=$ Dados de entrada

= Iteração comum

= Iteração desejável

Fonte: (Martin e McGuckin, 1998)

Figura 2-1 - Processo de previsão da demanda - Método de "4 Etapas"

O tratamento agregado das variáveis em zonas de tráfego, utilizado em alguns dos métodos, é um dos primeiros pontos fracos, mesmo considerando que o tratamento das viagens é feito de maneira separada (trabalho, estudo, lazer, etc.). O argumento para a crítica é de que se trata de escolhas 
feitas por pessoas, que podem ter comportamentos diferentes umas das outras. Para representar melhor esse "comportamento individual" foram introduzidos os modelos desagregados ou de escolha discreta.

Outra questão muito estudada é o custo de viagem, que no princípio era constituído apenas do comprimento dos caminhos utilizados. Foi preciso o desenvolvimento de modelos mais sofisticados, que consideram o tempo de viagem e a capacidade do sistema. Na medida em que aumenta a demanda de um determinado trecho de via, mudam as condições de tráfego, o que pode alterar o "custo". Assim, foram propostos métodos que utilizam retroalimentação, nos quais existem iterações até que haja um equilíbrio da rede. Vuchic (2005) destaca também a existência de abordagens que buscam resolver as três últimas das quatro etapas simultaneamente, utilizando programação não linear.

As críticas ao uso desses métodos de planejamento de transportes surgiram na medida de sua aplicação. Conforme relata Banister (2002), "O otimismo dos primeiros estudos de transportes foi derrubado, no início da década de 1970, com um movimento contra o planejamento dos transportes e programas de construção de vias em larga escala. O processo já não era mais visto como uma aplicação da técnica de especialistas e as suas recomendações não podiam ser aceitas automaticamente".

Plowden (1972) cita o manual ${ }^{2}$ publicado pelo Ministério do Transporte de Guerra, em 1946, no qual se pode ler "All traffic demands should be met", isto é, "Todas as demandas de tráfego devem ser atendidas" (tradução do autor). Nesta época, os procedimentos de previsão da demanda se limitavam a análises de séries históricas e à aplicação de taxas de crescimento do fluxo de tráfego. Embora o conjunto de ferramentas utilizado atualmente permita um conhecimento mais preciso do comportamento da demanda, o tipo de recomendação dos estudos atuais pode continuar na mesma linha desse manual editado há 66 anos, naquilo que Owens (1995) chama de um processo de "prever e prover". A autora questiona essa abordagem e se o caminho correto não seria o de buscar "prever e prevenir". Schiller, Brunn e Kenworthy (2010) apresentam uma relação de pontos que definem a diferença de abordagem do procedimento tradicional, classificado pelos autores como "business as usual" (em tradução livre, "à maneira usual"), e aquele com o objetivo de promover o transporte sustentável (Tabela 2-1). Vasconcellos (2000) também analisa esse processo, mas com foco nos sistemas de transportes de cidades de países em desenvolvimento. Neste trabalho, o autor relaciona problemas e consequências negativas do processo tradicional de planejamento de transportes (Tabela 2-2).

\footnotetext{
${ }^{2}$ Design and Layout of Roads in Built-up, HMSO, 1946.
} 
Tabela 2-1 - Diferenças entre o procedimento tradicional de planejamento dos transportes e aquele voltado para a mobilidade sustentável

\begin{tabular}{ll}
\hline \multicolumn{1}{c}{ Procedimento tradicional } & \multicolumn{1}{c}{ Transporte Sustentável } \\
\hline $\begin{array}{l}\text { Enfatiza a mobilidade e a quantidade (mais viagens, } \\
\text { mais rápido) }\end{array}$ & $\begin{array}{l}\text { Enfatiza a acessibilidade e a qualidade (mais } \\
\text { próximo e melhor) }\end{array}$ \\
\hline Enfatiza um modo (unimodalidade, uso do automóvel) & Enfatiza a pluralidade (multimodalidade) \\
\hline É comum faltarem conexões entre modos & Enfatiza as interconexões (intermodalidade) \\
\hline Acomoda e aceita tendências & Procura interromper e reverter tendências ruins \\
\hline $\begin{array}{l}\text { Planeja e constrói baseado em previsões da demanda } \\
\text { (prever e prover) }\end{array}$ & $\begin{array}{l}\text { Trabalha no sentido contrário, de uma visão da } \\
\text { situação preferencial para proceder ao planejamento } \\
\text { e à provisão (deliberar e decidir) }\end{array}$ \\
\hline $\begin{array}{l}\text { Expandir o sistema viário para atender à demanda } \\
\text { Ignorinistrar a demanda dos transportes e da } \\
\text { mobilidade }\end{array}$ \\
\hline $\begin{array}{l}\text { Incorpora todos os custos no planejamento e } \\
\text { provisão }\end{array}$ \\
\hline $\begin{array}{l}\text { O planejamento de transporte ocorre de maneira } \\
\text { isolada das áreas do meio ambiente, social e outras }\end{array}$ & $\begin{array}{l}\text { Enfatiza o planejamento integrado, combinado os } \\
\text { transportes com outras áreas relevantes }\end{array}$ \\
\hline
\end{tabular}

Fonte: (SCHILLER; BRUNN; KENWORTHY, 2010)

Tabela 2-2 - Problemas e consequências negativas principais do planejamento de transportes tradicional nos países em desenvolvimento.

\begin{tabular}{|c|c|c|}
\hline Área & Fator & Consequência \\
\hline \multirow{5}{*}{ Técnica } & Falta de dados confiáveis & Erros graves de previsão \\
\hline & Instabilidade social e econômica & Resultados absurdos nas previsões \\
\hline & Padrões complexos de transporte & Análise deficiente da demanda \\
\hline & Maioria das pessoas sem escolha & $\begin{array}{l}\text { Uso limitado da análise da escolha modal } \\
\text { Irrealismo dos pressupostos }\end{array}$ \\
\hline & $\begin{array}{l}\text { Várias imperfeições do mercado } \\
\text { Não trata transporte não motorizado } \\
\text { Não trata transporte por ônibus }\end{array}$ & Modos essenciais negligenciados \\
\hline \multirow[b]{2}{*}{ Estratégica } & Falta de técnicos treinados & Modelagem em "caixa preta" \\
\hline & Ambiente político instável & $\begin{array}{l}\text { Impossibilidade de trabalho continuado } \\
\text { Propostas irrealistas }\end{array}$ \\
\hline \multirow{3}{*}{ Política } & Fechamento do sistema político & $\begin{array}{l}\text { Decisões distorcidas } \\
\text { Espaço para lobby tecnológico }\end{array}$ \\
\hline & Diferenças sociais e econômicas & $\begin{array}{l}\text { Negligência do transporte público e do } \\
\text { transporte não motorizado }\end{array}$ \\
\hline & Influência privilegiada da classe média & Apoio indevido ao transporte individual \\
\hline \multirow[t]{2}{*}{ Ideológica } & Ideologia da mobilidade como progresso & $\begin{array}{l}\text { Negligência do transporte não motorizado } \\
\text { Negligência do transporte público } \\
\text { Apoio ao automóvel }\end{array}$ \\
\hline & Ideologia dos modelos como "neutros" & $\begin{array}{l}\text { Apoio ao automóvel } \\
\text { Negligência das externalidades }\end{array}$ \\
\hline \multirow{2}{*}{ Avaliação } & Grande diferença nos salários & Avaliação distorcida \\
\hline & Valor desconhecido das externalidades & Avaliação irrealista \\
\hline
\end{tabular}

Fonte: (VASCONCELLOS, 2000) 
Deve-se ressaltar que não se trata, necessariamente, de deficiências do processo de modelagem da demanda, mas do mau uso que pode ser feito dos resultados obtidos. A concepção do modelo deve envolver uma análise criteriosa da informação disponível para cada caso e a escolha adequada de ferramentas. Diferentes cidades, em diferentes países, com diferentes culturas, podem apresentar comportamentos diversos dos seus moradores. Deve-se também levar em consideração as limitações dos modelos. Afinal, de acordo com Derman (2011), os modelos são "metáforas que comparam os seus objetos de atenção com alguma outra coisa a qual eles se assemelham. Semelhança é sempre algo parcial e, assim, os modelos, necessariamente, simplificam as coisas e reduzem as dimensões do mundo". Cabe a técnicos e tomadores de decisão entender o comportamento do sistema e definir caminhos mais racionais para a sua evolução. Também faz parte do trabalho a compreensão das interfaces do sistema de mobilidade com os demais sistemas urbanos. Algumas causas, e também soluções, de parte dos problemas do sistema de transportes podem estar fora dele.

\subsection{Novas abordagens para o planejamento da mobilidade urbana}

Transportes ou Mobilidade? Conforme dito anteriormente, existe uma tendência de se utilizar o termo mobilidade no lugar de transportes. Os antigos "Planos Diretores de Transportes Urbanos" agora se chamam "Planos de Mobilidade Urbana". Não parece ser uma transição muito fácil, já que alguns os chamam de "Plano de Transportes e da Mobilidade", ou algo similar, como é o caso do plano elaborado para o Distrito Federal (GDF, 2010). No Ministério das Cidades, essa área é de

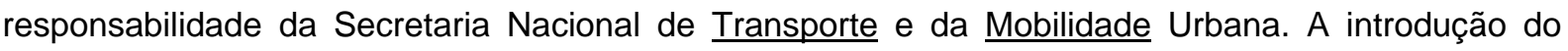
novo conceito pode servir, também, como símbolo de uma mudança de paradigma. A mudança permite a abertura de um espaço maior para o transporte não motorizado, já que se trata de alternativa importante para a realização de parcela do conjunto de viagens e não deve se limitar ao papel de complemento das viagens motorizadas. Na Tabela 2-3 são apresentados alguns dos problemas dos modelos de planejamento, relacionados em VTPI (2011), acompanhados de recomendações para que sejam aperfeiçoados.

Poli (2011) critica o predomínio de engenheiros civis na coordenação e desenvolvimento de uma grande parte das atividades dos estudos de transportes e trânsito. Segundo ele, os problemas do sistema de transportes, notadamente os congestionamentos das grandes cidades, estão aí há décadas e estes técnicos não conseguiram resolvê-lo. Afirma que até a própria sociedade, de uma maneira geral, foi cooptada e, quando enfrenta os problemas de transporte e trânsito no dia a dia, acaba demandando soluções de aumento da infraestrutura. A questão talvez não seja escolher uma ou outra categoria profissional como culpada para a atual situação. A crítica parece surgir da falta de visão da multidisciplinaridade das várias etapas do planejamento dos transportes. Não se trata, no entanto, de formar profissionais capazes de tratar adequadamente todas as questões, mas de reunir profissionais de diferentes formações, cada um preparado para tratar os diferentes aspectos da mobilidade urbana. 
Tabela 2-3 - Problemas dos modelos de planejamento de transporte e sugestões de melhorias

\begin{tabular}{|c|c|c|}
\hline Fator & Problemas dos modelos atuais & Correções propostas \\
\hline Acessibilidade & $\begin{array}{l}\text { A maioria dos modelos de transportes avalia mobilidade } \\
\text { (movimento), e falha em considerar a acessibilidade } \\
\text { (habilidade das pessoas em obter os produtos e chegar } \\
\text { aos locais desejados). }\end{array}$ & $\begin{array}{l}\text { Desenvolver modelos multimodais que considerem a } \\
\text { qualidade do transporte não motorizado e do transporte } \\
\text { público, e utilizem modelos de integração "transportes - } \\
\text { uso do solo", o que indica acessibilidade. }\end{array}$ \\
\hline $\begin{array}{l}\text { Modos } \\
\text { considerados }\end{array}$ & $\begin{array}{l}\text { A maioria dos modelos considera apenas automóveis e } \\
\text { transporte público. }\end{array}$ & $\begin{array}{l}\text { Expandir os modelos para que avaliem outros modos, } \\
\text { incluindo a pé e por bicicleta. }\end{array}$ \\
\hline Dados das viagens & $\begin{array}{l}\text { Os modelos atuais geralmente subestimam viagens } \\
\text { curtas, não motorizadas, fora do pico, etc. }\end{array}$ & $\begin{array}{l}\text { Melhorar as pesquisas de viagens para prover } \\
\text { informações mais abrangentes das atividades de } \\
\text { viagens. }\end{array}$ \\
\hline $\begin{array}{l}\text { Impactos para } 0 \\
\text { consumidor }\end{array}$ & $\begin{array}{l}\text { Muitos modelos de avaliação econômica analisam de } \\
\text { maneira superficial os impactos para o consumidor. Por } \\
\text { exemplo, consideram que a troca de dirigir o próprio } \\
\text { automóvel por um modo mais lento aumenta os custos. }\end{array}$ & $\begin{array}{l}\text { Usar análise do tipo excedente do consumidor para } \\
\text { medir o valor, para o usuário, dessas mudanças. } \\
\text { Reconhecer que troca por modos mais lentos, em } \\
\text { resposta a incentivos positivos, gera benefícios globais. }\end{array}$ \\
\hline Tempo de viagem & $\begin{array}{l}\text { A maioria dos modelos usa o mesmo valor do tempo de } \\
\text { viagem para todas as viagens, independente de } \\
\text { condições. }\end{array}$ & $\begin{array}{l}\text { Variar os valores dos tempos de viagem para que } \\
\text { reflitam as condições de viagem como, por exemplo, } \\
\text { desconforto e atraso. }\end{array}$ \\
\hline $\begin{array}{l}\text { Tráfego gerado e } \\
\text { indução de viagens }\end{array}$ & $\begin{array}{l}\text { Modelos de tráfego falham em levar em conta a } \\
\text { tendência da ampliação da infraestrutura viária em } \\
\text { gerar volumes adicionais de tráfego nos períodos de } \\
\text { pico e custos adicionais por viagens induzidas. }\end{array}$ & $\begin{array}{l}\text { Incorporar vários tipos de retroalimentação nos } \\
\text { modelos de tráfego. Desenvolver modelos de análise } \\
\text { econômica mais abrangentes que contabilizem os } \\
\text { impactos econômicos das viagens criadas. }\end{array}$ \\
\hline $\begin{array}{l}\text { Impactos } \\
\text { qualitativos }\end{array}$ & $\begin{array}{l}\text { Supervalorização de fatores quantitativos como } \\
\text { velocidade e custos monetários para os usuários e não } \\
\text { valorização de fatores qualitativos como conveniência e } \\
\text { conforto. Escalas de níveis de serviço existem para as } \\
\text { condições das vias, mas não para outros modos. }\end{array}$ & $\begin{array}{l}\text { Desenvolver escalas multimodais de níveis de serviço } \\
\text { para ajudar na avaliação das condições para caminhar, } \\
\text { pedalar e viajar de transporte público, com o objetivo de } \\
\text { identificar problemas e comparar as vantagens entre } \\
\text { automóveis e outros modos. }\end{array}$ \\
\hline $\begin{array}{l}\text { Viagens não- } \\
\text { motorizadas }\end{array}$ & $\begin{array}{l}\text { A maioria dos modelos de viagens não tratam de } \\
\text { maneira precisa as viagens não-motorizadas e, assim, } \\
\text { não valorizam melhorias nesses modos. }\end{array}$ & $\begin{array}{l}\text { Modificar os modelos existentes ou desenvolver } \\
\text { modelos especiais para avaliar melhorias no transporte } \\
\text { não-motorizado }\end{array}$ \\
\hline $\begin{array}{l}\text { Impactos } \\
\text { considerados }\end{array}$ & $\begin{array}{l}\text { Modelos atuais medem poucos impactos (tempo de } \\
\text { viagem e custos de operação dos veículos) }\end{array}$ & $\begin{array}{l}\text { Usar avaliações de impacto mais abrangente, incluindo } \\
\text { risco de acidentes, emissão de poluentes, atrasos para } \\
\text { os pedestres, impactos no uso do solo, etc. }\end{array}$ \\
\hline $\begin{array}{l}\text { Elasticidade do } \\
\text { transporte público }\end{array}$ & $\begin{array}{l}\text { A elasticidade do transporte público é baseada, em } \\
\text { grande parte, em estudos de curto e médio prazos e, } \\
\text { assim, subestimam impactos de longo prazo. }\end{array}$ & $\begin{array}{l}\text { Usar valores mais apropriados para avaliar impactos de } \\
\text { longo prazo das tarifas e da qualidade do serviço. }\end{array}$ \\
\hline $\begin{array}{l}\text { Profecias } \\
\text { autorrealizáveis }\end{array}$ & $\begin{array}{l}\text { Projeções de tráfego são, normalmente, descritas como } \\
\text { se fossem inevitáveis. Isso cria profecias } \\
\text { autorrealizáveis de aumento da capacidade viária, } \\
\text { aumento dos problemas de tráfego e espalhamento da } \\
\text { ocupação do solo. }\end{array}$ & $\begin{array}{l}\text { Relatar a demanda de tráfego como uma variável ("0 } \\
\text { volume de tráfego irá crescer } 20 \% \text { se as atuais políticas } \\
\text { continuarem, } 10 \% \text { se forem cobradas taxas médias de } \\
\text { estacionamento de R } \$ 2,00 \text { por dia, e } 0 \% \text { se essas } \\
\text { taxas tiverem valor médio de } \mathrm{R} \$ 6,00 \text { por dia") ao invés } \\
\text { de um valor fixo ("o volume de tráfego irá crescer } 20 \% \text { ") }\end{array}$ \\
\hline $\begin{array}{l}\text { Impactos das } \\
\text { obras }\end{array}$ & $\begin{array}{l}\text { Modelos econômicos normalmente falham em não } \\
\text { contabilizar os custos externos da atividade de } \\
\text { construção, tais como os congestionamentos e a } \\
\text { poluição. }\end{array}$ & $\begin{array}{l}\text { Levar em conta os atrasos dos congestionamentos } \\
\text { quando estiver avaliando o projeto e comparar a } \\
\text { expansão da capacidade com soluções do tipo TDM } \\
\text { (Transportation demand management ou gestão da } \\
\text { demanda de transportes - tradução do autor) }\end{array}$ \\
\hline $\begin{array}{l}\text { Diversidade de } \\
\text { opções de } \\
\text { transportes }\end{array}$ & $\begin{array}{l}\text { Muitos modelos subestimam os benefícios de se } \\
\text { melhorar as opções de viagens, particularmente } \\
\text { aquelas usadas por pessoas com algum tipo de } \\
\text { deficiência. }\end{array}$ & $\begin{array}{l}\text { Reconhecer os benefícios que resultam da melhoria } \\
\text { das opções de acessibilidade. }\end{array}$ \\
\hline $\begin{array}{l}\text { Impactos no uso } \\
\text { do solo }\end{array}$ & $\begin{array}{l}\text { Os modelos normalmente falham na identificação de } \\
\text { como as escolhas de transportes irão afetar os padrões } \\
\text { de uso do solo, como isso afeta a acessibilidade e os } \\
\text { objetivos estratégicos do planejamento. }\end{array}$ & $\begin{array}{l}\text { Desenvolver modelos de planejamento integrado de } \\
\text { transportes-uso do solo, os quais prevejam como as } \\
\text { decisões na área de transportes afetam os padrões de } \\
\text { uso do solo e como as decisões de ocupação do solo } \\
\text { afetam a acessibilidade. }\end{array}$ \\
\hline
\end{tabular}

Fonte: (VTPI, 2011) 
A argumentação de Poli (2011) não se prende apenas a isso, e avança por aspectos políticos, econômicos, lobbies de grandes empresas de construção e produção de veículos, etc. O processo de planejamento compreende, grosso modo, coleta de informações, diagnóstico, geração de alternativas de solução e seleção da mais adequada. Pela própria experiência do autor desta tese, conforme também destaca Poli (2011), é comum que as soluções já existam antes mesmo das informações serem levantadas e os problemas serem analisados. O mesmo autor não deixa de reconhecer a relevância, mas aponta os perigos do uso cada vez maior de relatórios e outras publicações do tipo "best practices" (pode-se traduzir por, "boas práticas"). O conhecimento das soluções encontradas por outras localidades para os seus problemas de transportes pode ajudar na geração de alternativas de solução, mas não pode e não deve evitar a consideração de soluções diversas.

A busca de soluções que aumentem a equidade de promoção da mobilidade dos vários segmentos da população passa pela efetiva participação dessas pessoas na definição das prioridades e no acompanhamento da implantação das medidas acordadas. Isto envolve um trabalho de comunicação e de educação, para que todos tenham condições de entender os problemas, para propor soluções compatíveis com as características locais.

Assim, uma nova abordagem deveria incorporar novos conhecimentos profissionais, tratando adequadamente todas as dimensões dos problemas e procurando eliminar os vieses que sempre favoreceram o transporte individual motorizado. O Caderno de Referência produzido pelo Ministério das Cidades (MCIDADES, 2007h) estabelece que o "Plano Diretor de Transporte e da Mobilidade" deve atender aos seguintes requisitos:

I. O transporte deve ser inserido em um contexto mais amplo, o da mobilidade urbana, que relaciona qualidade de vida, inclusão social e acesso às oportunidades da cidade;

II. A política de mobilidade deve estar crescentemente associada à política urbana, submetida às diretrizes do planejamento urbano expressas nos Planos Diretores Participativos;

III. O planejamento da mobilidade, tratado de forma ampliada e, em particular, considerando a sustentabilidade das cidades, deve dedicar atenção especial para os modos não motorizados e motorizados coletivos e observar as condições de acessibilidade universal;

IV. O planejamento da mobilidade deve ser realizado com a máxima participação da sociedade na elaboração dos planos e projetos, para garantir legitimação e sustentação política na sua implementação e continuidade.

Nas próximas seções serão apresentados o detalhamento das recomendações deste caderno de referência e a proposta do Plano de Informação, Comunicação e Educação de Poli (2011). Esse guia preparado pelo Ministério das Cidades representa um grande avanço para o planejamento da mobilidade urbana sustentável, mas ainda não se livra totalmente de todos os "vícios" do passado, problema para o qual Poli parece apontar uma saída.

\subsubsection{O Caderno de Referência para Elaboração do PlanMob}

O Caderno de Referência para Elaboração de Plano de Mobilidade Urbana (MCIDADES, 2007h) faz parte de um pacote de publicações que foi elaborado pelo Ministério das Cidades nos primeiros anos 
após a sua criação em 2003. Isso se deveu, provavelmente, à preocupação não apenas do Governo Federal, mas de outras instâncias de governo e da própria sociedade, com os rumos da mobilidade urbana. As publicações tratam da mobilidade urbana com forte ênfase nas questões dos modos não motorizados e do transporte público e da participação da comunidade no processo de planejamento. Dentre outros, foi também preparado um guia específico para o transporte por bicicleta (MCIDADES, 2007g), cadernos tratando da questão da acessibilidade (MCIDADES, 2007a, b, c, d, e, f) e uma publicação tratando da licitação e contratação de serviços de transporte coletivo (MCIDADES, 2007i). Também foram publicadas algumas cartilhas voltadas para um público mais amplo, explicando as questões da mobilidade urbana de modo menos técnico (MCIDADES, 2008b; MCIDADES; IBAM, 2008).

O Caderno do PlanMob foi estruturado de uma maneira que pode-se classificar de didática, com a fundamentação do conhecimento necessário à nova abordagem do planejamento da mobilidade, vinculando-a ao planejamento da cidade como um todo e à legislação que o regulamenta. Os cinco primeiros capítulos são utilizados para esta tarefa. O Capítulo 6 descreve cada componente a ser considerado no plano e, a seguir, trata especificamente da preparação do plano. O roteiro sugerido pode ser resumido como:

- Análise das condições da mobilidade

o Obtendo dados de campo

o Obtendo dados secundários

- Ouvindo a comunidade

- Utilizando métodos de planejamento de transporte

o Utilizando modelos de transporte

o Realizando estudos de projeção

o Analisando alternativas

- Análise de viabilidade

- Hierarquização das alternativas

Trata-se, na opinião do autor, de uma estrutura que permite a construção de planos dentro dos novos paradigmas da mobilidade urbana sustentável, mas pode perfeitamente abrigar os "velhos" planos diretores de transportes urbanos. Talvez por ser um documento que procura fazer a transição dos modelos de planejamento tradicionais para os novos, ele tenha ficado na fronteira. É interessante destacar dois trechos do texto, apresentados a seguir com grifos do autor.

No início do Capítulo 1 - Apresentação tem-se:

O Estatuto da Cidade determina que todas as cidades brasileiras com mais de 500 mil habitantes elaborem um plano de transportes e trânsito, rebatizado pela SeMob de Plano Diretor de Mobilidade, ou na expressão simplificada aqui usada, PlanMob.

Não é só uma mudança de nome, mas uma reformulação de conteúdo: a mobilidade urbana é um atributo das cidades, relativo ao deslocamento de pessoas e bens no espaço urbano, utilizando para isto veículos, vias e toda a infraestrutura urbana...

No Capítulo 7 - Construindo o Plano de Mobilidade: 


\subsubsection{Diretrizes e normas gerais para o planejamento integrado da gestão urbana e de transporte}

O Plano Diretor Municipal é o instrumento máximo de definição da política urbana e, como tal, deve ser a referência para a elaboração do Plano Diretor de Transporte e da Mobilidade que, por sua vez, deverá ser institucionalizado mediante decreto ou atos legislativos e normativos específicos que orientarão as políticas de mobilidade urbana.

Conforme já destacado, precisam ocorrer mudanças de comportamento tanto da população em geral quanto das equipes de planejamento e tomadores de decisão. O processo descrito na próxima seção parece tratar melhor destas questões.

\subsubsection{Plano de Informação, Comunicação e Educação}

Poli (2011) defende que a preparação de um Plano de Mobilidade Urbana - PMU deve ser precedida e acompanhada por um Plano de Informação, Comunicação e Educação - ICE. Este último seria uma importante ferramenta de comunicação bidirecional do poder público e equipe técnica com a população. A ênfase na característica bidirecional tem o sentido de reforçar a participação da sociedade. Não apenas as instituições públicas têm algo a informar aos cidadãos, mas estes também têm informações que querem e precisam passar para os primeiros. O autor argumenta que, se para atingir uma mobilidade urbana sustentável é preciso ocorrer mudanças de comportamento e que isso não surge da "mera manipulação de percepções", mesmo usando os melhores comunicadores. Ele recomenda que não se deve confundir "comunicação e educação com manipulação e padronização das mentes das pessoas". Considerando as diferentes necessidades de segmentos da população, ele chega a propor que se prepare um Plano de Mobilidades Urbanas. No caso, por exemplo, da redução do uso do automóvel, quando se estabelecem medidas para reduzir a quilometragem rodada, administra-se igual tratamento a pessoas com diferentes necessidades para uso desse modo. No entanto, este tipo de medida pode ser:

a) Muito pouco efetiva, porque só pode pedir pequenas reduções para todos;

b) Conservadora, porque ela leva a se repensar a política de tráfego e a projetar novas políticas de infraestrutura e mobilidade;

c) Possivelmente injusta, porque os cidadãos vão receber o mesmo tratamento embora possam estar em diferentes situações;

d) Esses problemas com injustiça e não efetividade irão, provavelmente, influenciar a tomada de decisão, porque podem fomentar protestos e oposição.

Se um plano ICE é adotado com ponto de partida da preparação de um PMU, deve-se considerar o seguinte:

- Não se devem ter expectativas não realistas sobre uma mudança rápida do comportamento dos cidadãos: o máximo que se pode esperar é que terá início um processo de mudança;

- Apesar do PMU destinar-se a toda a população, já se pode ficar satisfeito se ele for capaz de afetar apenas alguns segmentos dela;

- Apesar de ser possível prever uma situação final ótima, o plano deve ter foco em sequências de mudanças.

Assim, o plano serviria para acelerar mudanças sociais que já estão em andamento e, mais especificamente, aplicar medidas efetivas para conseguir melhorar rapidamente aspectos da 
mobilidade atual. O plano ICE seria um instrumento para ajudar na construção de consensos e é composto de três partes básicas:

- Dados (informação)

- Ferramentas de comunicação (interação)

- Ferramentas de construção de consensos (métodos e procedimentos de tomada de decisão)

As premissas seguidas para o PMU seriam então:

- $\quad$ O PMU é um plano estrutural que não implica construção, mas somente organização e ações do tipo "soft";

- Se o PMU é estrutural, isso implica que não deve ser esperada uma aceitação da situação atual como "gravada em pedra" (isto é, considerando tendências de crescimento, padrões atuais de mobilidade, preferências reveladas, etc.);

- Sendo um plano estrutural, um PMU tem o objetivo de produzir mudanças: pode-se assumir que essas mudanças sejam comportamentais, organizacionais e também físicas;

- É preciso mudar a estrutura da mobilidade sem construir novas estruturas físicas.

Trata-se de uma abordagem que certamente deve causar rejeição por boa parte dos técnicos e tomadores de decisão da área de gestão da mobilidade urbana, mas pode ser a saída para, não apenas conseguir melhores resultados na direção da mobilidade urbana sustentável, mas até mesmo produzir planos que tenham chances de ser implantados.

\subsection{Uso de indicadores para o planejamento e gestão da mobilidade urbana}

Gudmundsson (2003) coloca a seguinte questão: A busca pela mobilidade sustentável é um sucesso ou um fracasso? (tradução do autor). Isso depende até mesmo, segundo ele, de se chegar a um consenso sobre a implicação do conceito de mobilidade sustentável, o que considera um problema difícil de resolver. Ele afirma ainda que resolver esses problemas conceituais podem estar entre os menores desafios do estabelecimento de uma política de mobilidade, mas essas questões são muito importantes quando se trata de medir o sucesso ou fracasso desta política. Uma afirmação deste autor é utilizada por Black (2010) como epígrafe do capítulo 12, no qual trata de Planejamento Baseado em Indicadores (do inglês, Indicator-Based Planning).

To measure the performance of something, it has to be made operational, including concepts related to transport and mobility.

O que pode ser traduzido como "Para medir o desempenho de alguma coisa, incluindo conceitos relativos a transportes e mobilidade, ela tem que ser colocada em operação".

Segnestam (2002) trata do uso de indicadores para monitorar o meio ambiente e as condições de um desenvolvimento sustentável. A autora trata da concepção desses elementos e do processo, que pode incluir a agregação na forma de índices, até chegar à forma de informação utilizável. O trabalho de Black, Paez e Suthanaya (2002) já é específico da área de transportes urbanos e faz uma revisão de conceitos de sustentabilidade dos transportes urbanos e propõe possíveis indicadores e técnicas estatísticas, espaciais ou não, para o tratamento e apresentação das informações. Magalhães (2004) e Vilella et al. (2007) apresentam uma metodologia para seleção de indicadores para auxílio das 
atividades de planejamento de transportes. No Manual do PlanMob (MCIDADES, 2007h) existe a recomendação da concepção, implantação e manutenção, no âmbito do Plano de Mobilidade, de um "Sistema de Avaliação Permanente da Qualidade do Transporte Coletivo e de Indicadores de Trânsito". Velhos "vícios", talvez, tenham impedido a escolha de uma denominação mais adequada como, por exemplo, "Sistema de Avaliação Permanente da Qualidade da Mobilidade Urbana".

Costa (2008) relaciona um total de 52 índices propostos por diferentes entidades ao redor do mundo, com um número de indicadores variando de 8 a 319. Este aspecto contrasta um pouco com a proposta de Black (2010) que sugere que, na falta de outros indicadores, pode-se avaliar a sustentabilidade da mobilidade baseando-se em apenas um indicador, que seria quilometragem total percorrida por todas as pessoas da área de estudo em automóveis em um determinado período de tempo. Esta pode ser uma saída simples para aqueles locais nos quais essa informação seja coletada rotineiramente. Um índice composto de um número maior de indicadores pode tornar o processo mais dispendioso e inviabilizar a sua aplicação. Mais importante do que a escolha de quantos e de quais indicadores farão parte do índice, é a própria aplicação de uma ferramenta desse tipo, incluindo a organização para coleta e tratamento dos dados. A utilidade principal desse processo é o monitoramento constante da qualidade da mobilidade e os procedimentos devem ser inseridos nas rotinas normais de gestão. A simplicidade dos indicadores também ajuda a que mais entidades da sociedade civil façam o seu próprio controle. Dessa maneira elas terão melhores condições de discutir, com o poder público, a mobilidade que desejam. Apresentam-se a seguir algumas propostas brasileiras de índices de avaliação da mobilidade urbana sustentável.

\subsubsection{O Índice de Mobilidade Urbana Sustentável}

O Índice de Mobilidade Urbana Sustentável - IMUS foi concebido por Costa (2008) para combinar os principais Domínios e Temas necessários para o monitoramento da mobilidade urbana. Trata-se de uma ferramenta para dar suporte à gestão da mobilidade e à formulação de políticas públicas. A estrutura hierárquica do IMUS foi construída sobre um conjunto de indicadores que, tal como sugerido por Litman (2009), foram selecionados para refletir diversos impactos e perspectivas da mobilidade. De acordo com a autora, são indicadores baseados em dados de obtenção relativamente fácil e de cálculo direto. As principais características do Índice são:

- Segue uma hierarquia de critérios baseada em conceitos e elementos identificados por técnicos e gestores ligados ao planejamento urbano e de transportes de onze importantes cidades ou regiões metropolitanas brasileiras, conforme descrito em Rodrigues da Silva et al. (2008) e Costa (2008). 
- A hierarquia de critérios está associada a um sistema de pesos, os quais foram obtidos por meio de consulta a especialistas de diferentes países (Brasil, Portugal, Estados Unidos, Austrália e Alemanha). Esses pesos permitem não só identificar a importância relativa dos elementos e conceitos considerados no Índice, mas também avaliar o impacto de quaisquer alterações nos elementos que compõem o índice nas dimensões de sustentabilidade social, econômica e ambiental.

- A estrutura hierárquica adotada permite compensações (trade-offs) entre os 9 Domínios, 37 Temas e 87 Indicadores que compõem o índice (Tabela 2-4). Valores baixos nos pesos e escores de alguns dos elementos podem ser compensados por valores altos em outros elementos.

- É uma ferramenta de fácil entendimento e aplicação, não necessitando de programas específicos de computador ou de modelos matemáticos complexos para seu uso. Uma simples planilha eletrônica ou calculadora permite realizar todos os cálculos.

Tabela 2-4 - Domínios do IMUS e quantidades de temas e indicadores

\begin{tabular}{lcc}
\hline \multicolumn{1}{c}{ Domínio } & $\begin{array}{c}\text { Número de } \\
\text { temas }\end{array}$ & $\begin{array}{c}\text { Número de } \\
\text { indicadores }\end{array}$ \\
\hline Acessibilidade & 4 & 10 \\
\hline Aspectos Ambientais & 2 & 6 \\
\hline Aspectos Sociais & 5 & 5 \\
\hline Aspectos Políticos & 3 & 7 \\
\hline Infraestrutura de Transportes & 2 & 5 \\
\hline Modos Não-Motorizados & 3 & 9 \\
\hline Planejamento Integrado & 8 & 18 \\
\hline Tráfego e Circulação Urbana & 5 & 9 \\
\hline Sistemas de Transporte Urbano & 5 & 18 \\
\hline Total & 37 & 87 \\
\hline
\end{tabular}

Na Figura 2-2 se apresenta a estrutura do IMUS nos níveis de Domínios e Temas. Associados a cada um destes elementos encontram-se, entre parênteses, os valores dos pesos. No processo de estimativa do índice, os valores dos pesos dos Domínios não sofrem alteração, mas isso pode ocorrer com os pesos dos Temas, caso não existam dados para o cálculo de nenhum dos seus indicadores. Neste caso o peso daquele Tema não calculado é distribuído, proporcionalmente, entre os outros Temas do mesmo Domínio. No âmbito de um Tema também pode ocorrer a redistribuição dos pesos de indicadores, caso algum deles não seja calculado. A título de exemplo, o detalhamento do Domínio "Acessibilidade", com seus Temas e Indicadores, é apresentado na Figura 2-3.

O IMUS já foi calculado para as cidades de São Carlos (COSTA, 2008), Curitiba (MIRANDA, 2010; MIRANDA; RODRIGUES DA SILVA, 2012), Uberlândia (DA ASSUNÇÃO, 2012), Anápolis, São Paulo e para o Distrito Federal (PONTES, 2010), e está em processo de cálculo em várias outros locais. Azevedo Filho (2012) apresenta um mapa com a situação de cada local. 


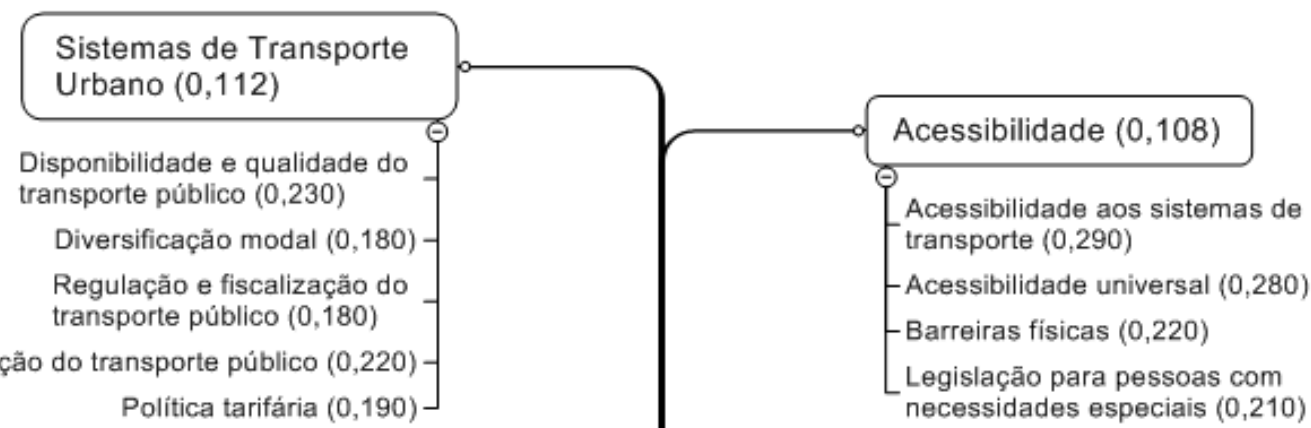

Integração do transporte público $(0,220)$ Política tarifária $(0,190)$ necessidades especiais $(0,210)$

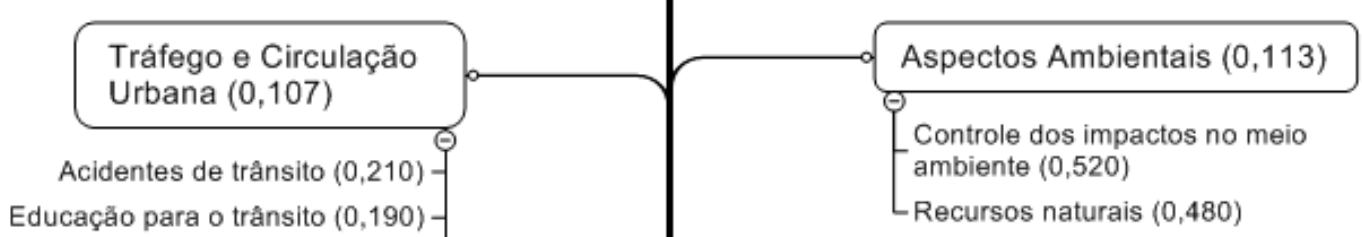

Educaçẵo para o trânsito $(0,190)-$

Fluidez e circulaçăo $(0,190)-$

Operação e fiscalização do trânsito $(0,200)-$

Transporte individual $(0,210)$

Planejamento Integrado $(0,108)$

Capacitação de gestores $(0,120)$

Áreas centrais e de interesse histórico $(0,110)$

Integraçăo regional $(0,120)-$

Transparência do processo de planejamento $(0,120)$

Planejamento e controle do uso e ocupação do solo $(0,140)$

Planejamento estratégico e integrado $(0,140)$

Planejamento da infraestrutura e equipamentos urbanos $(0,130)$

Plano Diretor e legislaçăo urbanística $(0,120)$

$$
\begin{array}{r}
\text { Modos Năo Motorizados }(0,110) \\
\text { Transporte cicloviário }(0,310) \\
\text { Deslocamentos a pé }(0,340) \\
\text { Reduçăo das viagens }(0,350)
\end{array}
$$

Recursos naturais $(0,480)$

Aspectos Sociais $(0,108)$

- Apoio ao cidadão $(0,210)$

- Inclusão social $(0,200)$

- Educação e cidadania $(0,190)$

- Participaçāo popular $(0,190)$

Qualidade de vida $(0,210)$

Aspectos Políticos $(0,113)$

- Integração de ações políticas $(0,340)$

Captação e gerenciamento de recursos $(0,330)$

- Política de mobilidade urbana $(0,330)$

Fonte: Adaptado de (COSTA, 2008)

Figura 2-2 - Estrutura de Domínios e Temas do Índice de Mobilidade Urbana Sustentável, incluindo seus respectivos pesos. 


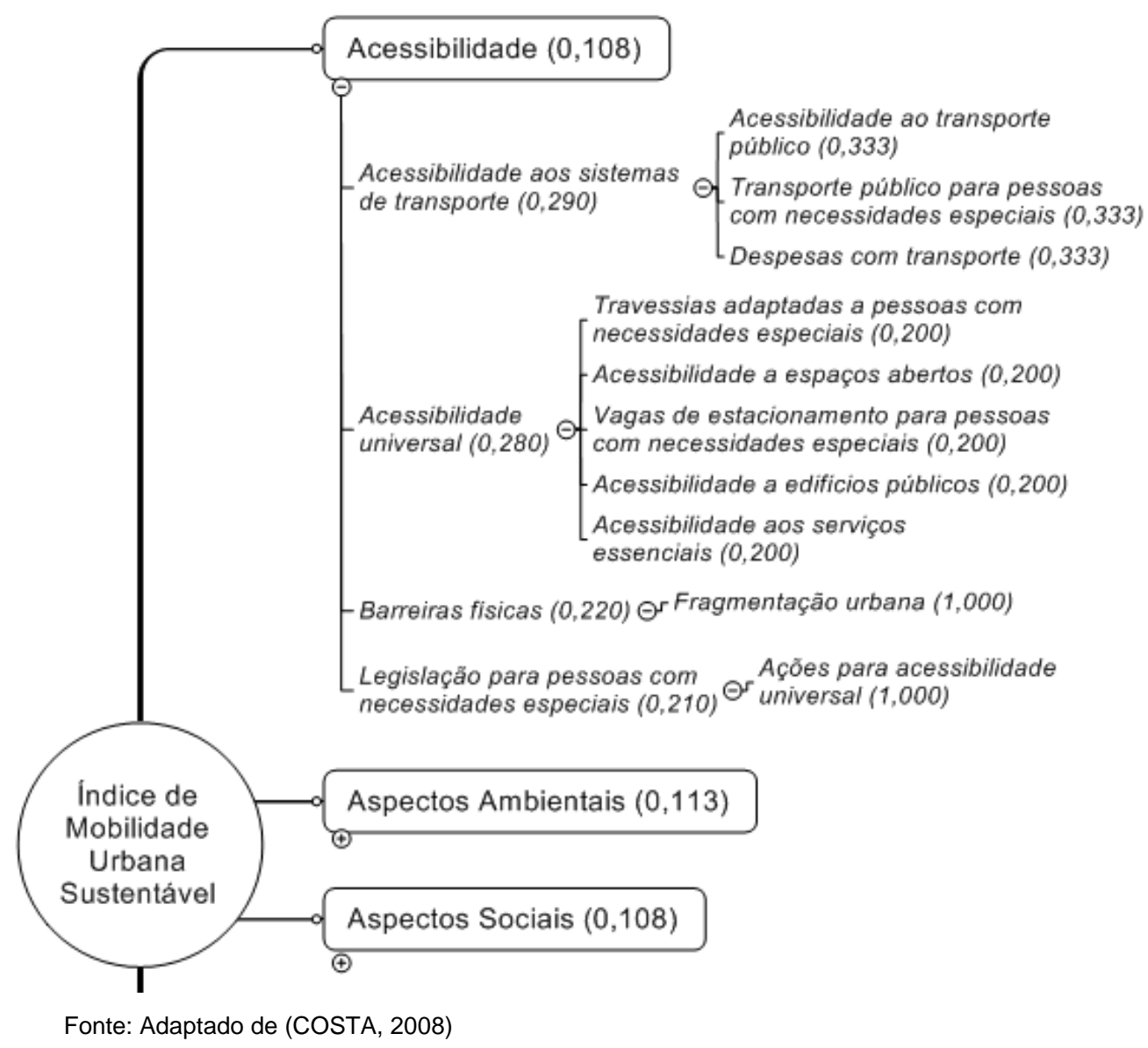

Figura 2-3 - Temas e Indicadores do Domínio "Acessibilidade" do IMUS

\subsubsection{Outros casos de uso de indicadores para avaliação da mobilidade sustentável em cidades brasileiras}

Dentre o variado conjunto de índices e processos de avaliação da mobilidade urbana sustentável, foram selecionados dois deles, propostos por pesquisadores brasileiros, para serem apresentados em maior detalhe. O método proposto por Mobilize (2011) consiste da formação de uma nota constituída da média da avaliação de cinco indicadores muito semelhantes aos utilizados no IMUS, mas a sua utilização tem o objetivo claro de comparar um conjunto de localidades ou cenários. Para cada um dos indicadores é atribuída nota dez no caso daquele na melhor situação e nota zero para o de pior desempenho. As notas atribuídas às situações intermediárias são calculadas proporcionalmente no intervalo entre os dois extremos. Os indicadores utilizados são os seguintes:

- Porcentagem de ônibus municipais adaptados a pessoas com deficiência física;

- Mortos em acidentes de trânsito (por 100.000 habitantes);

- Extensão de vias adequadas ao trânsito de bicicletas em relação à extensão do sistema viário;

- Razão entre a renda média mensal e a tarifa simples de ônibus urbano;

- Razão entre o número de viagens por modos individuais motorizados de transporte e o número total de viagens. 
Já no caso do Índice de Mobilidade Sustentável - IMS, proposto por Machado (2010), adota-se uma abordagem mais parecida com a do IMUS. A formação do índice é feita a partir de três dimensões, cada uma delas composta por três temas e seus respectivos indicadores (Tabela 2-5). As dimensões e os indicadores possuem pesos, que foram ajustados mediante resultado de consulta aos técnicos das administrações locais. O método utiliza ainda o conceito que os autores chamam de "direção" do indicador. São atribuídos sinais positivo (aumentar) ou negativo (diminuir) aos pesos dos indicadores, representando a "contribuição positiva" ou "negativa" de cada um. O valor de cada indicador é calculado, o conjunto de valores é padronizado, e os novos escores são então multiplicados pelos pesos do próprio indicador e da dimensão a que está associado. A somatória dos resultados desta operação, dentro de cada dimensão, resulta nos valores dos subíndices. O IMS é obtido pela soma dos três subíndices.

Tabela 2-5 - Estrutura do Índice de Mobilidade Sustentável

\begin{tabular}{|c|c|c|c|}
\hline Dimensão & Tema & Indicador & Direção \\
\hline \multirow{3}{*}{$\begin{array}{l}\text { Social } \\
(0,44)\end{array}$} & Acidentes com mortes & $\begin{array}{l}\text { Percentual de mortes em acidentes de } \\
\text { trânsito / frota de veículos }(0,36)\end{array}$ & Diminuir \\
\hline & Oferta de transporte coletivo & $\begin{array}{l}\text { Passageiros transportados per capita } \\
(0,34)\end{array}$ & Aumentar \\
\hline & Intermodalidade & Número de estações intermodais $(0,30)$ & Aumentar \\
\hline \multirow{3}{*}{$\begin{array}{l}\text { Econômica } \\
\qquad(0,29)\end{array}$} & Orçamento gasto em transporte (tarifa) & $\begin{array}{l}\text { Valor médio da tarifa*mês / valor do } \\
\text { salário mínimo }(0,40)\end{array}$ & Diminuir \\
\hline & Eficiência do transporte coletivo & $\begin{array}{l}\text { Índice de passageiros por km (IPK) } \\
(0,31)\end{array}$ & Aumentar \\
\hline & $\begin{array}{l}\text { Investimentos públicos no setor } \\
\text { transportes }\end{array}$ & $\begin{array}{l}\text { Percentual de gastos em transportes / } \\
\text { PIB }(0,29)\end{array}$ & Aumentar \\
\hline \multirow{3}{*}{$\begin{array}{c}\text { Ambiental } \\
(0,27)\end{array}$} & Taxa de motorização & $\begin{array}{l}\text { Número de veículos em circulação per } \\
\text { capita }(0,45)\end{array}$ & Diminuir \\
\hline & Consumo de combustíveis fósseis & $\begin{array}{l}\text { Venda de (gasolina + diesel) per capita } \\
(0,33)\end{array}$ & Diminuir \\
\hline & Consumo de combustíveis alternativos & $\begin{array}{l}\text { Venda de álcool hidratado per capita } \\
(0,22)\end{array}$ & Diminuir \\
\hline
\end{tabular}

Obs.: Os valores entre parênteses representam os pesos das dimensões e dos indicadores.

Fonte: (MACHADO; DOMINGUEZ, 2012)

\subsubsection{Uso de um índice de mobilidade sustentável para análise de PGVs}

Um dos grandes problemas enfrentados na gestão da mobilidade urbana é a avaliação e licenciamento de Polos Geradores de Viagens - PGVs. Empreendimentos como shopping-centers, hipermercados, igrejas, escolas, dentre outros, geram grandes quantidades de viagens e a implantação de um deles, normalmente, acarreta grandes impactos na vizinhança. O Estatuto da Cidade (BRASIL, 2001) já determina que sejam criadas leis municipais para regular a implantação e funcionamento desse tipo de empreendimento, com a definição de regras para obrigatoriedade de preparação de um Estudo de Impacto de Vizinhança - EIV. Assim, como os Planos de Mobilidade, esses estudos podem cair na mesma tradicional abordagem de tratar o problema pelo lado do transporte motorizado e, neste caso, mais centrados ainda no automóvel. Uma das principais preocupações é o número de vagas de estacionamento para estes veículos. 
Santos (2011) propõe a utilização de Medidas de Mobilidade Urbana Sustentável - MMUS para auxiliar no processo de licenciamento de PGVs e "... subsidiar análises e soluções de projeto mais focadas nos modos não motorizados". A autora propôs um conjunto de 37 indicadores que foram submetidos à avaliação de especialistas da área. A consulta resultou em aceitações superiores a $50 \%$ dos entrevistados para 34 indicadores (89\%), com média de 69\% de aprovação. As ações associadas aos indicadores com maiores percentuais de aprovação foram:

- Promover acessibilidade para pessoas com necessidades especiais - 97\%

- Apresentar calçadas largas, livre de obstáculos e completas, o que inclui: faixa de mobiliário, faixa de circulação livre e faixa de acesso ao lote - $97 \%$

- Implementar ciclofaixas e ciclovias - 93\%

- Promover a conectividade de ruas e espaços de circulação - 93\%

- Prever tratamento adequado e seguro ao pedestre nas entradas de garagem - 90\%

- Promover sinalização reforçada quanto à presença de pedestres e ciclistas, em especial nas regiões de conflito com travessias e interseções - 90\%

- Promover iluminação dedicada às calçadas e áreas de pedestres - 90\%

No outro extremo, aquelas com menor aprovação foram:

- Apresentar edifícios de uso misto, com andar térreo destinado a comércio e serviços - 33\%

- Dispor atividades de forma compacta, densa, compatibilizando residências, comércio e serviços numa área de 200 × 200 metros - 23\%

- Promover estacionamento ao longo da via (dando suporte às atividades lindeiras; atuando na redução da velocidade dos carros e servindo de barreira de proteção para o pedestre) - 10\%

\subsection{Conclusão}

Neste capítulo foi feita uma revisão e análise de conceitos e modelos de planejamento de transportes e da mobilidade que seguem diferentes abordagens e prioridades. Também se discutiu a utilização de instrumentos que auxiliam na caracterização e diagnóstico da situação de um determinado cenário de mobilidade e no monitoramento da implantação das medidas propostas. Pelo que foi descrito é possível perceber que se trata de um problema complexo com um variado conjunto de prescrições de tratamento. A continuação da pesquisa consiste da coleção e análise de estudos e planos de transportes e/ou mobilidade que tenham sido desenvolvidos para cidades brasileiras. Destas será selecionada uma para estudo de caso, com avaliação do tipo de abordagem utilizada e dos seus diagnósticos e propostas de soluções. A análise será complementada por uma estimativa da qualidade da mobilidade urbana em cenários representando diferentes períodos de tempo. 


\section{METODOLOGIA}

Apresenta-se neste capítulo a metodologia utilizada no desenvolvimento da pesquisa. O trabalho teve início com uma revisão da literatura na área de planejamento da mobilidade, sobre a qual se estabeleceu o conjunto de métodos a ser utilizado na produção e análise dos resultados, procurando verificar a hipótese de pesquisa e responder à questão que deu início a este trabalho. O primeiro passo consiste da caracterização e organização dos documentos disponíveis, da leitura destes documentos e da identificação de uma localidade apropriada para o estudo de caso. A partir desta seleção, se inicia a caracterização e avaliação das informações disponíveis e a busca de outras fontes de dados. O estudo segue com duas etapas de avaliação mais quantitativa. Na primeira, são definidos cenários correspondentes a diferentes períodos de planejamento da localidade selecionada e, para cada um deles, se calcula o valor do Índice de Mobilidade Urbana Sustentável. Esse resultado é comparado com outros índices similares. Na próxima etapa se utiliza a estrutura do mesmo índice, mas agora para avaliação prospectiva dos possíveis efeitos das propostas de cada plano nas condições da mobilidade urbana sustentável. Finalmente, é possível tecer considerações, de caráter mais geral, sobre o processo de planejamento da mobilidade, partindo-se da análise do estudo de caso. Cada uma dessas etapas será detalhada nas seções a seguir.

\subsection{Revisão da literatura}

A tarefa de consultar a literatura referente à matéria de que trata a pesquisa é a primeira a ter início e uma das últimas a ser concluída. Mesmo na finalização da redação da tese ainda cabem consultas para dar suporte a um ou outro argumento ou conclusão. A literatura tratando do planejamento dos transportes e da mobilidade urbana e do desenvolvimento sustentável é bastante ampla e variada. $\mathrm{O}$ conjunto final de referências bibliográficas deste trabalho também contém um bom número de relatórios de planos e estudos de transportes e mobilidade para diferentes localidades, além de peças de legislação. As leis e outras normas de caráter federal, estadual ou municipal servem, muitas vezes, para dar garantias mínimas de um rumo sustentável à mobilidade e ao desenvolvimento urbano.

\subsection{Levantamento de planos de transportes e seleção da localidade}

Embora tenham sido consultados alguns planos desenvolvidos para cidades no exterior, procurou-se concentrar os estudos em planos desenvolvidos para cidades ou regiões metropolitanas brasileiras. No Brasil, a principal fase de planejamento dos transportes urbanos teve início na década de 1970, 
incentivado pelo governo federal e sua Empresa Brasileira de Planejamento de Transportes GEIPOT. As atividades eram desenvolvidas em conjunto com órgãos locais e seguiam um esquema de encadeamento de estudos que possibilitaria a implantação e a obtenção de resultados já em curto prazo, sem que se precisasse aguardar um estudo de dois anos ou mais (Plano Diretor) para tratar do problema. As coletas de dados, muitas vezes incluindo pesquisas domiciliares, serviam tanto às "Recomendações para Implantação Imediata", quanto para estudos mais detalhados, como os de Transporte Coletivo - TRANSCOL e os Planos Diretores de Transporte Urbano - PDTU. Boa parte desses estudos, realizados até o final dos anos 1980, pode ser encontrada na Biblioteca do Ministério dos Transportes, que abriga o acervo da Biblioteca do GEIPOT desde que a empresa foi extinta.

Planos de transportes continuaram a ser produzidos, na sua maioria para servir de base para estudos de viabilidade de sistemas de transporte público de alta capacidade. O acesso aos seus relatórios é mais difícil já que, ao contrário dos mais antigos, não se encontram armazenados em uma única biblioteca. A situação melhora para os estudos mais recentes, aproximadamente nos últimos cinco anos, pois as instituições responsáveis pela contratação desses estudos começam a publicar os relatórios na Internet, para promover a chamada "transparência administrativa" e facilitar a participação ou, pelo menos, a informação da população.

Após a coleta e uma primeira análise dos relatórios disponíveis, procedeu-se à escolha de uma localidade para a realização de um estudo de caso. Buscou-se uma localidade que dispusesse de uma quantidade razoável de estudos e planos distribuídos ao longo de um período em torno de 20 ou 30 anos, o que permitiria observar mudanças na configuração do sistema de mobilidade urbana, avaliando-se a sua evolução.

\subsection{Caracterização e avaliação da informação disponível}

Este estudo se baseia na investigação de trabalhos técnicos elaborados para a localidade selecionada. Partiu-se da ideia de se caracterizar e analisar a mobilidade urbana deste local para períodos nos quais os estudos foram preparados. Em um primeiro momento, o esforço foi concentrado na reunião dos documentos disponíveis e na leitura dos mesmos dos mesmos, vindo a seguir a busca de outras fontes de informação que pudessem complementar a montagem dos cenários.

\subsubsection{Leitura dos planos}

A partir de uma leitura e análise criteriosa, procurou-se sintetizar o conteúdo dos relatórios, anotando os diagnósticos e propostas de solução apresentadas. Esses destaques foram separados nas áreas de transportes não motorizados, transporte público, transporte individual e sistema viário. Neste aspecto, o trabalho foi facilitado, pois esta é a organização normalmente adotada nos documentos analisados. Parte-se aqui da ideia de que uma mobilidade urbana sustentável normalmente requer uma maior atenção para o transporte público e os modos não motorizados. Isso ocorre em contraponto à "tradicional" divisão de recursos que favorece mais os investimentos no sistema viário, que beneficiam mais o transporte motorizado no geral e, particularmente, o automóvel. 


\subsubsection{Levantamento da disponibilidade e qualidade dos dados para a situação atual}

Esta etapa tratava do levantamento da disponibilidade e qualidade dos dados para a avaliação de uma situação presente. Seguindo o método proposto por Costa (2008) e já utilizado por outros autores (MIRANDA, 2010; PONTES, 2010; DA ASSUNÇÃO, 2012), preparou-se uma tabela com os indicadores do IMUS que foram, a seguir, avaliados em dois aspectos, conforme estrutura a seguir.

i. Disponibilidade do dado:

- CP - curto prazo - estimado como um período menor do que um ano.

- MP - médio prazo - estimado como o período de uma gestão municipal (quatro anos).

- LP - longo prazo - estimado como períodos maiores do que quatro anos.

ii. Qualidade do dado:

- A - alta - o dado existe é de levantamento recente, proveniente de fonte confiável.

- M - média - existe o dado, mas é de um período mais antigo e precisa de ajustes.

- B - baixa - o dado será obtido através de estimativas com informações mais antigas ou com a utilização de modelos preparados para outras localidades,

A partir deste levantamento é possível mapear as fontes de dados e identificar a necessidade de alguns levantamentos a serem feitos diretamente.

\subsubsection{Levantamento de outras fontes de dados}

O conjunto de informações necessário para o cálculo do IMUS abrange alguns dados além daqueles normalmente associados a planos e projetos de transportes urbanos. Além disso, nem todas as informações inerentes ao próprio sistema de transportes são consideradas ou disponibilizadas nos relatórios consultados. Assim, a disponibilidade de dados em sítios da Internet é fundamental para a ampliação do conjunto de informações disponíveis para este trabalho. As informações para cenários mais recentes têm melhor qualidade e são mais fáceis de serem encontradas.

Os problemas de mobilidade urbana afetam uma grande quantidade de pessoas e estão sempre em discussão e, assim, é de se esperar que existam outros estudos acadêmicos tratando do problema. Esses trabalhos podem agregar informações e dar apoio às análises aqui desenvolvidas.

\subsection{Estimativa da qualidade da mobilidade urbana sustentável}

A localidade selecionada deverá ser aquela contemplada com um número razoável de planos de transportes e mobilidade. Um dos objetivos deste trabalho é avaliar se a existência desses planos afetou a mobilidade urbana sustentável. Assim, nesta etapa do trabalho foi feita uma avaliação, utilizando o IMUS, da situação da mobilidade ao longo do tempo, caracterizada em alguns cenários. Os resultados desta avaliação são comparados com aqueles obtidos em outras localidades e, também, com os resultados de índices similares calculados com dados dos mesmos cenários. 


\subsubsection{Cálculo do IMUS para diferentes cenários}

De uma maneira pioneira para esta ferramenta, ela é utilizada para avaliar cenários passados que podem ser comparados entre si, verificando o que melhorou ou piorou dentro da ótica da mobilidade sustentável. Considerando a disponibilidade decenal de dados de censos demográficos como, no caso brasileiro, os do IBGE (IBGE, 2001, 2011a), os cenários foram estabelecidos com o agrupamento de estudos e planos em torno dos anos destes eventos.

Algumas informações têm caráter espacial e, para cálculo dos escores, se recomenda a utilização de algum software do tipo Sistema de Informação Geográfica - SIG. Neste trabalho foram utilizados o TransCAD (Caliper, 2007) e o Quantum GIS (QGIS, 2011). Outros indicadores têm caráter predominantemente qualitativo e o estabelecimento do escore ocorre segundo escalas estabelecidas por Costa (2008). Para facilitar o cálculo e aplicação dos pesos referentes a cada Domínio, Tema e Indicador do IMUS, utilizou-se um software de planilha eletrônica.

No cálculo dos indicadores os dados são convertidos em escores e estes são posteriormente normalizados. Isso ocorre porque os valores dos diferentes escores não são comparáveis entre si, pois tratam de diferentes dimensões. Para resolver este problema, procede-se a normalização dos valores dos escores, representando-os em uma escala comum, neste caso, variando de 0 a 1. Após a normalização dos escores de cada indicador, estes são multiplicados pelos pesos dos próprios indicadores e dos respectivos tema e domínio. No caso de indicadores e temas, os valores dos pesos são redistribuídos, em caso de falta de dados, entre aqueles para os quais existem as informações. A redistribuição dos pesos dos indicadores ocorre dentro de um mesmo tema, e a dos temas ocorre dentro de um mesmo domínio. O resultado da multiplicação dos pesos pelo valor do escore normalizado constitui a parcela do IMUS referente a cada indicador. O índice é então calculado pela somatória de todas as parcelas.

A redistribuição de pesos, descrita acima, é interessante para que se possa calcular o valor do IMUS mesmo sem o conjunto completo de dados, mas ela dificulta a comparação de valores do índice para localidades ou situações diferentes. Portanto, acrescentou-se mais uma avaliação do IMUS para os cenários na qual se considera apenas os indicadores comuns, ou seja, aqueles que estão com dados disponíveis para todos os cenários. Desta maneira, são considerados pesos iguais para os mesmos elementos de cada cenário.

\subsubsection{Comparação com outras avaliações}

Embora a aplicação principal do IMUS não seja a de estabelecer um padrão para comparação entre diferentes localidades, fez-se uma comparação com os valores obtidos em outros estudos, para as cidades de São Carlos (COSTA, 2008), Curitiba (MIRANDA, 2010), Distrito Federal (PONTES, 2010) e Uberlândia (DA ASSUNÇÃO, 2012). Além disso, os mesmos dados dos cenários foram adaptados e processados conforme as metodologias propostas por Mobilize (2011) e Machado (2010). Neste caso, o objetivo foi o de verificar se existe uma mesma tendência de evolução da qualidade da mobilidade entre os cenários. 


\subsection{Avaliação das propostas dos estudos e planos}

Nesta nova avaliação procurou-se aferir o efeito das propostas dos planos e estudos, na qualidade da mobilidade urbana sustentável, caso fossem implantadas. O método se constituiu da atribuição, pelo autor, de notas variando de 2 a -2 a cada um dos projetos, considerando os Temas do IMUS. A pontuação seguiu o seguinte critério:

- 2 - as propostas poderiam contribuir muito para a melhoria da avaliação do Tema;

- 1 - as propostas poderiam contribuir para a melhoria da avaliação do Tema;

- 0 - sem propostas que afetariam a avaliação do Tema;

- -1 - as propostas poderiam piorar a avaliação do Tema;

- -2 - as propostas poderiam piorar muito a avaliação do Tema.

A seguir, procedendo-se a somatória dos pontos de cada projeto, foi possível ter uma avaliação do impacto em possíveis melhorias dos valores dos indicadores do IMUS, o que implicaria em proporcionar uma melhor mobilidade urbana sustentável.

Em outra análise, verificou-se como a estimativa do valor da parcela de cada domínio do IMUS seria afetada, caso as propostas do conjunto de planos fossem implantadas. Foram utilizadas as mesmas notas e o conjunto de pesos dos temas e domínios do índice. Cada nota foi multiplicada pelos pesos do tema e do domínio a que se refere e, em seguida, foi feita a somatória de todos os valores para cada domínio. O resultado constituiu um conjunto de valores que representou a importância, ou ênfase, dos estudos referentes a cada domínio. Para melhor comparação, esses valores foram normalizados e ordenados.

\subsection{Considerações sobre o processo de planejamento da mobilidade}

De posse do conhecimento acumulado ao longo das etapas anteriores, foi possível fazer uma análise sobre o efeito dos planos e estudos sobre a qualidade da mobilidade urbana sustentável da localidade estudada, ou melhor, da pertinência e da efetivação das medidas propostas. Outro aspecto importante da avaliação foi a própria caracterização dos problemas, já que aqui também pode ser encontrado algum viés contrário à sustentabilidade da mobilidade. Isso pode ser, por exemplo, uma ênfase muito grande dada ao problema do congestionamento de tráfego e do insuficiente espaço viário. Do estudo de caso foi possível avaliar, de forma mais geral, o próprio processo de planejamento e gestão da mobilidade urbana. 



\section{PLANOS E ESTUDOS DE TRANSPORTES E MOBILIDADE}

Conforme amplamente discutido na literatura, o planejamento dos transportes urbanos é estudado e realizado há décadas. Existem diferentes abordagens, metodologias, programas de computador, etc., tudo para facilitar esse processo. No entanto, existe um descompasso entre a elaboração dos planos, quando são propostas intervenções, e a efetiva implantação das mesmas. Neste capítulo resume-se o trabalho de levantamento da disponibilidade de planos de transportes e de mobilidade urbana, realizado para esta pesquisa. O propósito desta compilação é possibilitar foi o de analisar as características dos métodos utilizados ao longo do tempo e, também, identificar um local que apresentasse um conjunto de planos que possibilitasse a comparação das medidas propostas com o sistema real, para os diferentes cenários.

\subsection{Os planos e estudos de transportes}

Nesta etapa, deu-se preferência aos planos preparados para cidades brasileiras, embora tenha ocorrido a análise de alguns documentos referentes ao planejamento da mobilidade em Portugal (CML, 2005; COSTA; SOARES, 2007; PORTUGAL, 2010a, b, 2011). No caso brasileiro pode-se afirmar que, à exceção dos estudos dos metrôs de São Paulo e do Rio de Janeiro, a elaboração de Planos Diretores de Transportes Urbanos teve início com aqueles preparados pelo GEIPOT. Criado como Grupo Executivo para Implantação da Política de Transportes, o GEIPOT foi posteriormente transformado na Empresa Brasileira de Planejamento de Transportes, mas manteve a sigla original. Esta dispunha de escritórios regionais em várias capitais brasileiras e coordenou a realização de um grande número de estudos de transportes, parcialmente relacionados no Anexo B. Além de liderar esse processo de planejamento, a instituição atuou na área de formação de recursos humanos, capacitando os técnicos das administrações locais para a gestão dos transportes urbanos. O instrumento principal neste caso foi uma série de cursos de especialização, realizados em conjunto com as universidades locais.

A tarefa de promover o planejamento dos transportes urbanos, principalmente nas regiões metropolitanas e grandes cidades, foi transferida do GEIPOT para a Empresa Brasileira de Transportes Urbanos - EBTU, na segunda metade da década de 1980. Em 1991, a EBTU foi extinta pelo governo federal e alguns anos mais tarde foi iniciada a extinção do GEIPOT, que foi completada em 2002. A essa altura, os grandes municípios já dispunham de condições de preparar os seus próprios planos de transportes urbanos, mas o ritmo da realização desse tipo de estudo diminuiu 
bastante. Normalmente, os estudos foram desenvolvidos apenas quando necessários para dar base a projetos de implantação de um novo sistema de transporte público de alta capacidade. O governo federal passou a incentivar novamente esse tipo de processo com a criação, em 2003, do Ministério das Cidades, que contou desde o início com a Secretaria Nacional do Transporte e da Mobilidade Urbana. Desta secretaria partiram diretrizes para o (re)início de implantação de uma política nacional de mobilidade urbana, inclusive com a produção de manuais para a orientação, tanto dos técnicos locais quanto da própria população (MCIDADES, 2006, 2007e, g, h). A lei que instituiu as diretrizes da Política Nacional de Mobilidade Urbana (BRASIL, 2012), sancionada em 2012, obriga a preparação de planos de mobilidade urbana para aqueles municípios com população acima de 20.000 habitantes, caso queiram se credenciar a receber recursos federais para sistemas de mobilidade urbana.

A maior parte dos relatórios dos estudos coordenados pelo GEIPOT estava disponível em sua biblioteca. Com a sua extinção, o acervo foi repassado à Biblioteca do Ministério dos Transportes, em Brasília. Embora geograficamente distante, sabia-se que existia um local para consulta dos trabalhos, já que estes ainda não foram digitalizados e disponibilizados em base com acesso pela Internet.

A consulta de planos mais recentes é um pouco mais fácil, pois as prefeituras e agências estaduais (responsáveis pelas áreas metropolitanas) têm disponibilizado relatórios em seus sítios na Internet. Da nova safra de planos que, em tese, deveriam seguir diretrizes que visam proporcionar uma mobilidade urbana sustentável, foi possível ter acesso a alguns relatórios de Belém (JICA, 2010), Belo Horizonte (BHTRANS, 2007, 2008, 2009, 2010a, b), Curitiba (IPPUC, 2008, 2010), Distrito Federal (GDF, 2010), Recife (PR, 2010a, b, 2011, 2012) e Uberlândia (PMU, 2010). Embora o estudo de Belém tenha sido uma atualização do plano diretor elaborado em 2001 (JICA, 2001), esta cidade se destacou pelo número de estudos realizados nas últimas três décadas e pelo acesso que o autor teve a esse material. Assim, a cidade de Belém, juntamente com sua região metropolitana, foi escolhida para o estudo de caso desta tese. Pesou também a favor desta escolha o fato de existir a colaboração de dois professores da Universidade Federal do Pará em projeto que envolve a avaliação da mobilidade urbana sustentável em cinco cidades brasileiras. Este projeto é coordenado pelo orientador deste trabalho de doutoramento, o que facilitou a troca de informações e foi benéfico para na preparação dos dois estudos.

Nas próximas seções apresenta-se a caracterização da Região Metropolitana de Belém, a análise dos seus estudos e planos de transportes e alguns trabalhos acadêmicos que também tratam da mobilidade urbana para a mesma área.

\subsection{Caracterização da localidade escolhida e seus planos de transportes}

A Região Metropolitana de Belém - RMB está localizada na região norte do Brasil e é composta dos municípios de Belém, Ananindeua, Marituba, Benevides e Santa Bárbara do Pará (Figura 4-1). Até 1996, apenas os dois primeiros faziam parte da RM. O município de Belém, capital do estado do 
Pará, apresenta uma população de 1.393.399 habitantes, segundo o Censo 2010 (IBGE, 2011a). Agregando-se os demais municípios da RMB, chega-se a 2.042.417 habitantes (Tabela 4-1) . $^{3}$

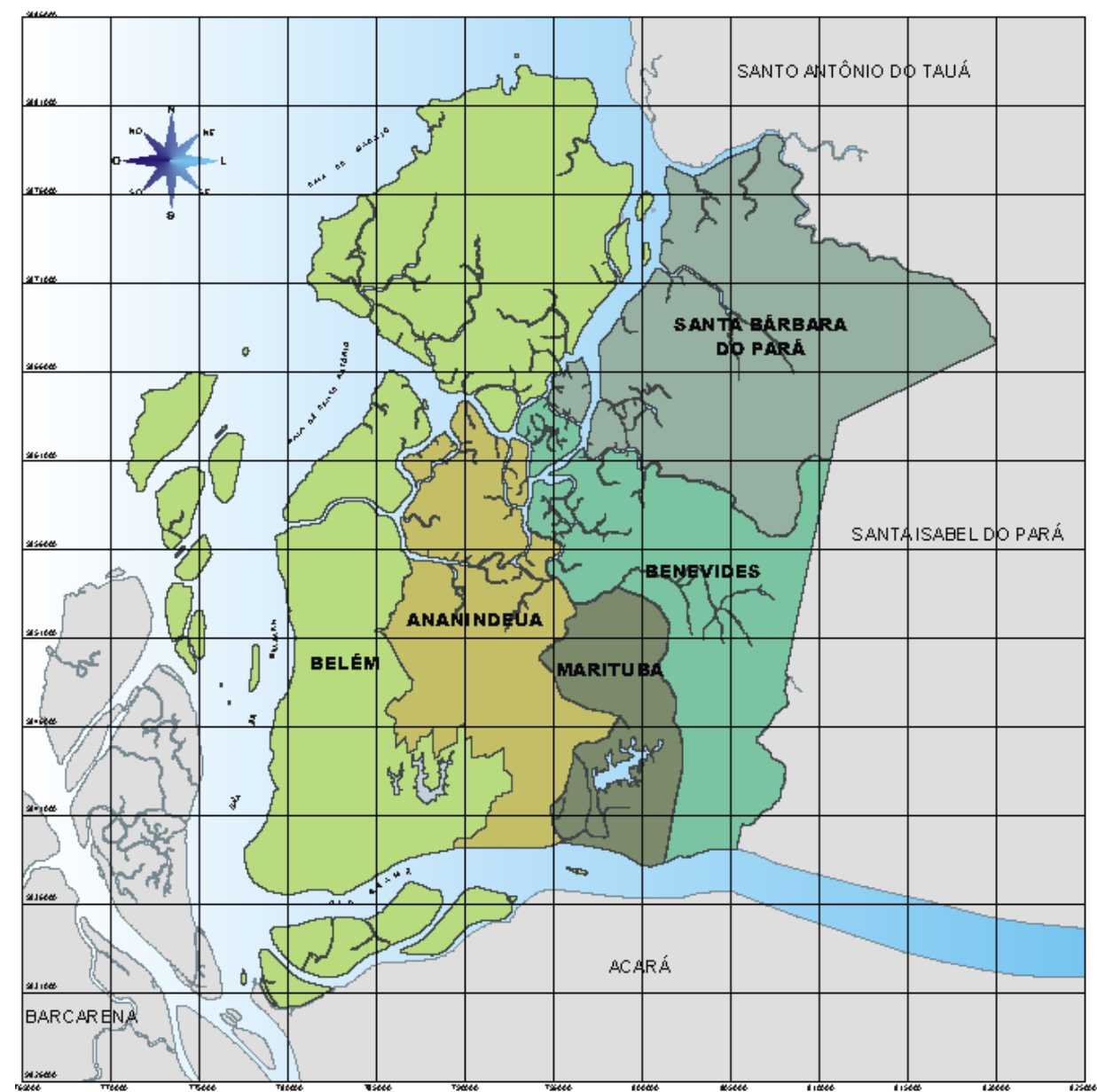

Fonte: (PMB, 2012b)

Figura 4-1 - Municípios que formam a Região Metropolitana de Belém

Tabela 4-1 - População dos municípios da Região Metropolitana de Belém

\begin{tabular}{lr}
\hline \multicolumn{1}{c}{ Município } & \multicolumn{1}{c}{ População } \\
\hline Ananindeua & 471980 \\
\hline Belém & 1393399 \\
\hline Benevides & 51651 \\
\hline Marituba & 108246 \\
\hline Santa Bárbara do Pará & 17141 \\
\hline Total & 2042417 \\
\hline
\end{tabular}

Fonte: (IBGE, 2011a)

\footnotetext{
3 Para efeito de realização do censo, o IBGE (2011a) classificou, também, como integrante da Região Metropolitana de Belém o município de Santa Isabel do Pará, com 59.466 habitantes.
} 
Conforme relatado na seção anterior, este aglomerado urbano foi selecionado para esta investigação por contar com um grande número de planos e estudos de transportes (Tabela 4-2) num período de três décadas, cujos relatórios estavam acessíveis ao autor da tese. No entanto, a percepção geral é a de que a qualidade da mobilidade da RMB é ruim, apesar de todos esses trabalhos e outros, de menor porte ou menos específicos da área, que não foram aqui analisados. Na realidade, a maior parte das propostas dos estudos e planos parece nunca ter saído do papel.

Tabela 4-2 - Relação dos planos e estudos de transportes da Região Metropolitana de Belém

\begin{tabular}{|c|c|c|}
\hline Título do plano/estudo & Ano & Instituições \\
\hline $\begin{array}{l}\text { Recomendações para Implantação Imediata para o Sistema } \\
\text { de Transportes Urbanos da Região Metropolitana de Belém } \\
\text { (GEIPOT, 1978) }\end{array}$ & 1978 & \multirow{4}{*}{$\begin{array}{l}\text { Empresa Brasileira de Planejamento de } \\
\text { Transportes - GEIPOT. }\end{array}$} \\
\hline TRANSCOL - Ciclovia da BL-01 (GEIPOT, 1979). & 1979 & \\
\hline $\begin{array}{l}\text { Estudo de Transportes Coletivos - TRANSCOL / Região } \\
\text { Metropolitana de Belém (GEIPOT, 1980) }\end{array}$ & 1980 & \\
\hline $\begin{array}{l}\text { Estudo de Racionalização do Transporte Coletivo da Região } \\
\text { Metropolitana de Belém (GEIPOT, 1986) }\end{array}$ & 1986 & \\
\hline $\begin{array}{l}\text { Plano Diretor de Transportes Urbanos da Região } \\
\text { Metropolitana de Belém (JICA, 1991) }\end{array}$ & 1991 & \multirow{3}{*}{$\begin{array}{l}\text { Governo do Estado do Pará. Agência de } \\
\text { Cooperação Internacional do Japão - JICA. }\end{array}$} \\
\hline $\begin{array}{l}\text { Plano Diretor de Transporte Urbano da Região } \\
\text { Metropolitana de Belém (JICA, 2001) }\end{array}$ & 2001 & \\
\hline $\begin{array}{l}\text { Estudo de Viabilidade Econômica de Projetos para o } \\
\text { Melhoramento do Sistema de Transporte na Região } \\
\text { Metropolitana de Belém na República Federativa do Brasil } \\
\text { (JICA, 2003) }\end{array}$ & 2003 & \\
\hline $\begin{array}{l}\text { Diretrizes de Ordenamento Territorial para a Região } \\
\text { Metropolitana de Belém (PARÁ, 2006) }\end{array}$ & 2006 & $\begin{array}{l}\text { Governo do Estado do Pará. Secretaria } \\
\text { Executiva de Desenvolvimento Urbano e } \\
\text { Regional - SEDURB. }\end{array}$ \\
\hline $\begin{array}{l}\text { Estudo Preparatório para o Projeto de Sistema de } \\
\text { Transporte de ônibus da Região Metropolitana de Belém na } \\
\text { República Federativa do Brasil (JICA, 2010) }\end{array}$ & 2010 & $\begin{array}{l}\text { Governo do Estado do Pará. Agência de } \\
\text { Cooperação Internacional do Japão - JICA. }\end{array}$ \\
\hline
\end{tabular}

Embora todos os estudos, a exceção das "Diretrizes de Ordenamento Territorial para a Região Metropolitana de Belém" (PARÁ, 2006), tenham focalizado o sistema de transportes, foram usadas várias abordagens e diferentes foram os graus de intervenção propostos para o sistema. Alguns trabalharam com uma quantidade menor de dados e propuseram apenas medidas para racionalizar 0 sistema de transportes públicos. Outros tiveram levantamento intensivo de dados, o que permitiu fazer um diagnóstico abrangente e propor medidas mais efetivas de estruturação do sistema de transportes da RMB. Outros ainda consistiram de detalhamento, em termos de projeto de engenharia, das medidas propostas nos planos diretores, sempre acompanhados de estudos de viabilidade econômica e financeira.

Os problemas de mobilidade urbana afetam uma grande quantidade de pessoas e estão sempre em debate, inclusive no meio acadêmico. Portanto, era de se esperar que existissem outros estudos tratando das questões da mobilidade da população da RMB. A leitura desses trabalhos, como os de Klautau (1993), Goto (2000), Mercês (2004), Tobias (2004), Pedro e Neves (2012), Rocha, Ribeiro e Goto (2012), ajuda na tarefa de avaliar o planejamento e a gerência da mobilidade urbana da RMB. O trabalho de Klautau (1993), por exemplo, trata de parte dos estudos e planos considerados neste 
estudo de caso. Ele consiste de uma análise crítica do planejamento realizado no período que vai de 1975 a 1991. O autor também inclui a avaliação do Plano de Desenvolvimento da Grande Belém (PMB, 1975 apud KLAUTAU, 1993) ${ }^{4}$ e do Plano de Estruturação Metropolitana (PMB, 1979 apud KLAUTAU, 1993) ${ }^{5}$.

\subsection{Leitura dos estudos e planos}

O primeiro estudo apreciado, as Recomendações para Implantação Imediata, do Estudo de Transportes Urbanos da RMB (GEIPOT, 1978), consistia de análises dos problemas e propostas de soluções de rápida implantação, procurando trazer melhorias para a qualidade do sistema de transportes. Deveria servir ainda como subsídio para estudos mais detalhados que levariam à proposição e implantação de medidas mais efetivas de ordenação do sistema. Apesar do foco exagerado no transporte por automóvel, as propostas de organização e correção da geometria do conjunto de vias, de alguma maneira, favoreceram o transporte público e o não motorizado.

A seguir veio o TRANSCOL - Ciclovia da BL-01 (GEIPOT, 1979), que tratou do adiantamento de alguns resultados de projeto mais amplo, o TRANSCOL (GEIPOT, 1980), para atender a uma solicitação da administração local. Foi um anteprojeto de uma ciclovia ligando áreas residenciais e industriais, acompanhando a rodovia que liga o distrito de Icoaraci a Belém. Este foi um dos estudos pioneiros no Brasil, seguindo padrões adequados para um bom projeto de ciclovia. A razão para a preparação de um estudo desse tipo, não usual para a época, pode ter sido a presença na equipe do projeto de dois entusiastas desse modo de transportes. O coordenador do projeto, Engenheiro José Carlos A. Ary, e o chefe da equipe em Belém, Arquiteto Antônio C. M. Miranda, são conhecidos pela participação em vários estudos e publicações sobre transporte cicloviário (BASTOS, 1983; ARY, 1984; BASTOS, 1984b, a; GEIPOT, 2001b, a; MCIDADES, 2007g; MIRANDA; ARY, 2012). Pode-se caracterizar a iniciativa como um auspicioso passo rumo a uma mobilidade sustentável, mas, conforme será visto a seguir, a ideia não prosperou.

O Estudo de Transporte Coletivo, do Estudo de Transportes Urbanos da RMB - TRANSCOL (GEIPOT, 1980), concluído no ano seguinte, tinha o objetivo de promover a reorganização e otimização do sistema de transporte público por ônibus, incluindo medidas de prioridade no sistema viário e adequação do serviço à demanda. Aqui já foram utilizados os dados de pesquisa domiciliar realizada em 1978, que atingiu 13.000 habitações. Havia a preocupação em atender a população de novas áreas da RMB, cuja ocupação era mais recente. Considerando os recursos empregados na realização das pesquisas de campo e os problemas apontados, poderiam ser esperadas propostas mais efetivas para resolver os problemas sem a preocupação em preservar a estrutura do sistema de transportes públicos da época.

Pela lógica de organização dos estudos do GEIPOT, o próximo estudo deveria ser o Plano Diretor de Transportes Urbanos, mas o que acabou sendo feito foi uma espécie de atualização do TRANSCOL, provavelmente, porque poucas das propostas anteriores foram implantadas. O Estudo de

\footnotetext{
${ }^{4}$ Plano de Desenvolvimento da Grande Belém - Prefeitura Municipal de Belém - 1975.

${ }^{5}$ Plano de Estruturação Metropolitana - PEM - Prefeitura Municipal de Belém - 1979.
} 
Racionalização do Transporte Coletivo da Região Metropolitana de Belém (GEIPOT, 1986) apresentou propostas pouco ambiciosas, menos até que o TRANSCOL, e praticamente mantinha o modo corrente de operação do sistema de transportes públicos.

Finalmente, em 1991, foi finalizado o Plano Diretor de Transportes Urbanos da RMB (JICA, 1991), já sem a participação do GEIPOT, que estava em processo de extinção. O estudo foi realizado mediante convênio da Agência de Cooperação Internacional do Japão - JICA com o Governo do Estado do Pará, com a interveniência dos governos brasileiro e japonês. Foram feitos os levantamentos de dados e adotados os procedimentos padrão do processo de planejamento de transportes, configurando-se este um estudo mais abrangente do que os realizados anteriormente. Foram realizados levantamentos detalhados sobre a situação existente, inclusive uma pesquisa domiciliar, que permitiram estimar os desejos de viagem da população da $\mathrm{RMB}^{6}$. O estudo se enquadra dentro da metodologia tradicional de planejamento de transportes, isto é, a previsão de uma demanda crescente e a proposta de medidas que atendam a ela. Por mais que a concentração de atividades no centro de Belém seja apontada como problema, são muito tímidas as propostas para reverter a situação. Pelo contrário, as medidas propostas tendem a reforçar esse aspecto.

Depois de 10 anos do primeiro PDTU-RMB (JICA, 1991) e, praticamente, sem nenhuma das propostas implantadas, preparou-se mais o Plano Diretor de Transporte Urbano da RMB (JICA, 2001). Aqui começaram a ganhar um pouco mais de destaque as preocupações com o transporte não motorizado e os impactos ambientais. Tratou-se de um trabalho de atualização do PDTU de 1991, mas muitas das pesquisas foram feitas novamente, já que mudaram as características de ocupação do território e da demanda dos transportes.

Embora mantenha a característica de apresentar soluções conservadoras, este plano representa um avanço, pois conclui pela necessidade de um sistema que dê maior prioridade ao transporte público, incluindo faixas exclusivas para ônibus e a implantação de integração física e tarifária. Nos planos anteriores isto era sempre deixado para o "futuro". Outra novidade são as propostas para uma integração com o transporte hidroviário, uma necessidade evidente considerando-se as características locais. No entanto, não são apresentados detalhes ou anteprojetos específicos para esse modo.

O Estudo de Viabilidade Econômica de Projetos para o Melhoramento do Sistema de Transporte na $\underline{R M B}$ (JICA, 2003) atualiza algumas informações do PDTU-2001 (JICA, 2001) e prepara melhores detalhamentos das propostas e das análises relativas a impactos ambientais e à viabilidade econômica dos projetos. As propostas de infraestrutura para o transporte por bicicleta também foram melhoradas.

As Diretrizes de Ordenamento Territorial para a Região Metropolitana de Belém (PARÁ, 2006) não tratam apenas da área de mobilidade, mas considerou-se importante a inclusão do estudo nesta pesquisa. No documento são apresentadas avaliações de aspectos do uso e ocupação do solo em

\footnotetext{
${ }^{6}$ Deve-se ressaltar que, para os estudos do GEIPOT também foram realizadas pesquisas bem abrangentes, mas os resultados não foram utilizados completamente.
} 
conjunto com as infraestruturas de transportes e de saneamento básico. O Governo Federal, através de leis como o Estatuto das Cidades (Brasil, 2001) e de ações do próprio Ministério das Cidades, obriga os municípios a prepararem seus Planos Diretores Municipais. A ideia dessas "Diretrizes" é a de promover a consonância das propostas contidas nos planos dos municípios da RMB. É interessante que a mobilidade urbana seja tratada dentro de um mesmo "pacote" onde estejam uso e ocupação do solo, localização de polos geradores de viagens, sistemas de drenagem, localização de habitações e áreas industriais. Todos esses aspectos afetam e/ou são afetados pelas operações de transportes.

Considerando que as propostas dos estudos e planos anteriores não foram implantadas, foi preparada mais uma atualização parcial do PDTU, na forma do Estudo Preparatório para o Projeto de Sistema de Transporte de Ônibus da RMB (JICA, 2010). O conjunto de intervenções anteriormente proposto precisou ser reduzido, pois a capacidade de endividamento do governo local não possibilita o financiamento de todas as medidas previstas. Constata-se que, com o passar do tempo, o cenário muda, inclusive com a implantação de novas infraestruturas, mas isso não afeta significativamente as propostas. Todavia, os problemas vão ficando maiores e, provavelmente, mais complexos. Duas questões merecem ser destacadas no relatório final deste estudo. A primeira diz respeito à previsão de divisão modal, que aponta percentuais quase iguais para os modos transporte público e automóvel no horizonte de 2025, algo que parece impossível de ser operado. A segunda diz respeito à continuação da operação do sistema convencional, em paralelo ao novo sistema tronco-alimentador. O primeiro seria reduzido ao longo do tempo, mas não se previu integração, tarifária principalmente, entre os dois.

Ao longo da leitura foram anotados os principais aspectos de cada documento e feitas análises preliminares. Essas anotações podem ser consultadas no Anexo C.

\subsection{Outros estudos tratando da mobilidade urbana de Belém}

A crítica de Klautau (1993) aos planos analisados fica explícita na expressão que aparece no título da sua dissertação e se repete na maioria dos capítulos, "papel aguenta tudo!". Com essas palavras o autor procura ressaltar o descolamento de algumas ou muitas das propostas da realidade da RMB. Goto (2000) analisa a acessibilidade ao sistema de transportes para pessoas das diferentes classes de renda. Este trabalho, que se baseou em dados do PDTU 1991 (JICA, 1991) e do novo plano (JICA, 2001), em andamento na época, ajuda na caracterização do cenário daquele período.

A tese de Mercês (2004) focaliza os aspectos institucionais e a relação entre o poder público, responsável pela gestão da mobilidade urbana, e os operadores do sistema de transporte público e a população da RMB. Como na maioria das cidades brasileiras, o sistema de transporte coletivo é operado há décadas pelas mesmas empresas ou por outras originadas de fusões ou divisões das primeiras. Isso torna difícil politicamente, algumas vezes legalmente, propor alterações no sistema que mexam com as parcelas de mercado de cada uma delas. $O$ trabalho de Tobias (2004) apresenta a evolução da área urbana da RMB, do seu sistema de transportes e das instituições que ao longo do tempo tiveram a responsabilidade da sua gestão. 
Tobias e Peixeira (2005) analisam a demanda do transporte por bicicletas na RMB. Este modo de transporte também é o foco de um trabalho mais recente, de Rocha, Ribeiro e Goto (2012), que avalia o potencial do uso das bicicletas em parte das viagens e relaciona algumas diretrizes que deveriam ser seguidas para proporcionar melhores condições aos usuários atuais e atrair novos ciclistas.

O mesmo livro no qual se encontra o trabalho anterior, traz um capítulo de Pedro e Neves (2012), que trata da integração do modo hidroviário ao sistema de transporte público da RMB. As autoras discutem esta integração como uma necessidade para aquelas pessoas que moram nas áreas insulares da RMB e que não têm a opção da ligação rodoviária e, também, como uma alternativa sustentável para o transporte de parte dos usuários do sistema de transportes rodoviário. A RMB é contemplada com vários cursos d'água que podem ser aproveitados para este tipo de transporte. 


\section{AVALIAÇÃO DA MOBILIDADE URBANA SUSTENTÁVEL PARA OS DIFERENTES CENÁRIOS}

Neste capítulo apresenta-se o relatório da avaliação da mobilidade urbana sustentável para diferentes cenários do sistema de transportes da RMB. Desde o princípio, esperava-se obter maior quantidade e melhor qualidade de dados para os cenários mais recentes. Isto se confirmou, mas a tarefa não foi tão simples quanto o esperado. De maneira geral, o foco principal de todos os estudos foi o transporte motorizado, com preocupações quase que equilibradas entre o modo público coletivo e o privado individual. Informações que hoje são consideradas importantes para a avaliação da sustentabilidade da mobilidade, como é o caso do uso dos transportes não motorizados, quase não aparecem nos estudos mais antigos, mesmo que os dados tenham sido levantados nas pesquisas de campo, o que é bastante provável. Um exemplo deste tipo de situação aparece em um dos estudos da JICA (1991). Ao tratar da divisão modal, o estudo se refere a um modo denominado "a pé e motocicleta". O cômputo das viagens neste caso compreendeu, pela definição, o conjunto das viagens realizadas a pé, por motocicleta ou bicicleta. Isso pressupõe a coleta dos valores das viagens para cada um dos três modos, mas a forma de divulgação dos dados não permite a recuperação das informações originais.

A maior parte das análises se baseou nos relatórios finais dos estudos e planos, em formato impresso ou arquivo digital (tipo PDF). Deve-se ressaltar a preciosa colaboração de funcionários da Biblioteca do Ministério dos Transportes (MT, 2012), que digitalizaram todos os relatórios finais dos estudos do GEIPOT para Belém $(1978,1979,1980,1986)$ e os enviaram por correio eletrônico para os autores. No caso do PDTU-2001 (JICA, 2001) foi possível também ter acesso a planilhas, textos e arquivos de dados georreferenciados, o que facilitou o cálculo de alguns indicadores.

\subsection{Escolha e caracterização dos cenários e coleta de dados}

A primeira tarefa foi a escolha dos períodos que corresponderiam aos cenários de análise, com a separação de quais estudos ou planos seriam as fontes de dados para cada um. Um dos aspectos considerados foi a proximidade dos anos nos quais foram realizados censos demográficos, já que estes constituem fonte de informações muito confiável. Coincidentemente, os estudos mais detalhados datavam de anos próximos a estes censos. Foram então definidos quatro cenários, caracterizados a seguir: 
Cenário 1980 - Para este cenário são utilizadas informações dos estudos do GEIPOT que foram concluídos entre 1978 e 1986 (GEIPOT, 1978, 1979, 1980, 1986). Embora o último deles tenha sido concluído em 1986, parte das informações se refere ao levantamento de dados da década anterior. Entre as pesquisas de campo realizadas figura uma pesquisa domiciliar para levantamento das origens, destinos e outras características das viagens da população. Desta pesquisa resultam informações preciosas para a análise da mobilidade, mas o autor teve acesso apenas aos relatórios finais, com dados já tratados e agregados, muitas vezes apresentados na forma de gráficos. Conforme já estabelecido acima, a preocupação principal não era a mobilidade urbana sustentável. Os dados provenientes do censo demográfico de 1980, realizado pelo IBGE, são poucos e de difícil acesso.

Cenário 1991 - Neste caso existe apenas o Plano Diretor de Transportes Urbanos (JICA, 1991), mas o relatório final apresenta uma quantidade um pouco maior de dados de interesse para esta pesquisa, ao contrário dos estudos anteriores que eram mais ricos em anteprojetos de engenharia. Para este plano também foi realizada uma pesquisa domiciliar para caracterizar as viagens dos residentes da RMB. A disponibilidade de dados do censo demográfico de 1991 é melhor. Essa melhor disponibilidade está muito ligada ao fato dessas informações aparecerem em maior quantidade em documentos disponíveis em sítios da Internet. Aqueles documentos que apresentam séries históricas de dados, como o Anuário Estatístico da ANP (2001), já trazem informações do ano de 1991.

Cenário 2001 - Um novo PDTU (JICA, 2001) e um estudo detalhando as propostas (JICA, 2003) dão base a este cenário. As pesquisas, mais uma vez, incluíram uma pesquisa domiciliar. Neste caso, o autor teve acesso a um conjunto de planilhas e arquivos geográficos com dados desagregados. Não se tratou do conjunto completo de informações, mas facilitou o trabalho. Outra novidade foi a qualidade muito melhor das informações disponíveis do censo demográfico (IBGE, 2001), do qual estão disponíveis dados ao nível de setores censitários em mapas georreferenciados. A partir daqui, são encontradas estatísticas sobre acidentes de trânsito (DENATRAN, 2002), embora este anuário tenha sido encontrado em outro sítio ${ }^{7}$ da Internet e não no portal do Departamento Nacional de Trânsito - DENATRAN. Até onde o autor conseguiu se informar, em algum momento dos últimos anos a administração deste departamento decidiu retirar os relatórios da Internet por considerar as estatísticas pouco confiáveis. Embora isso ultrapasse o escopo do presente estudo, poder-se-ia contra-argumentar que é melhor ter alguma informação pouco confiável do que nenhuma. De toda forma, o que importa aqui é que os dados foram obtidos, ainda que não da fonte "oficial". Além disso, em virtude da relativa proximidade com o cenário atual, parte dos dados foi estimada considerando a situação presente.

Cenário 2011 (Atual) - Este cenário foi o mais rico em informações, embora tenha sido o único a não contar com a ajuda de uma pesquisa domiciliar. Além da análise dos estudos mais recentes (PARÁ, 2006; JICA, 2010), foram utilizados dados da pesquisa que envolve a avaliação da mobilidade urbana sustentável em cinco localidades brasileiras incluindo Belém (AZEVEDO FILHO et al., 2011). Dois professores, e seus bolsistas de graduação, do Instituto de Tecnologia da Universidade Federal do

\footnotetext{
${ }^{7}$ http://www.vias-seguras.com/content/download/884/5272/file/Denatran\%20acidentes\%202001.zip
} 
Pará - ITEP-UFPA cuidaram do levantamento de boa parte dos dados necessários à avaliação deste cenário. Houve uma profícua colaboração entre o autor e esta equipe local, na identificação da fonte e produção de alguns dos indicadores. A quantidade de informação disponível na Internet é bem maior e inclui aspectos da população (IBGE, 2011a), sobre acidentes de trânsito (DETRAN-PA, 2010, 2011a), serviços de saúde e educação (DATASUS, 2012; INEP, 2012), legislação urbanística (PMB, 2006a, 2011b, 2012b; SEMMA, 2012) e mobilidade urbana (ANTP, 2010a, 2011a, b, 2012). Entram aqui outras ferramentas úteis, hoje disponíveis para qualquer usuário com acesso à Internet, tais como o Google Maps (GOOGLE, 2012) e o OpenStreetMap (OSMF, 2012) que provêm mapas e outros arquivos geográficos adequados a esse tipo de estudo. Um aspecto curioso é o fato do anuário estatístico preparado pela Prefeitura de Belém (PMB, 2011a) trazer uma grande quantidade de dados, incluindo o número de passageiros desembarcando em Belém em voos nacionais ou internacionais, mas sem qualquer informação sobre o número de passageiros transportados no sistema de transporte coletivo por ônibus.

A partir dos dados obtidos das fontes descritas acima, foi possível calcular parte dos indicadores para estimativa do IMUS para cada cenário. Os resultados desta tarefa são descritos a seguir.

\subsection{Cálculo do IMUS para os cenários da RMB}

Não foi possível calcular todos os indicadores que compõem o IMUS de cada cenário, pois faltaram dados principalmente para os cenários mais antigos. Dos 87 indicadores, foram calculados 39 para o cenário "1980", 44 para o "1991", 58 para o "2001" e 64 para o "2011". Através destes indicadores foram obtidos os valores apresentados na Figura 5-1, na qual cada cenário é representado por três valores. O valor intermediário é o IMUS propriamente dito. O valor superior foi obtido considerando a melhor situação possível (escore igual a um) para aqueles indicadores que não se conseguiu calcular. A atribuição dos piores valores possíveis a estes mesmos indicadores (escore igual a zero) possibilita a estimativa do limite inferior. A descrição dos domínios, temas e indicadores do IMUS, com os respectivos pesos, encontra-se no Anexo A. No Anexo $D$, se apresenta um resumo da situação do cálculo dos indicadores para cada cenário, cujas memórias de cálculo se encontram no Anexo E.

A diminuição da qualidade para o cenário atual pode ser creditada a valores ruins de indicadores dos domínios "Infraestrutura de Transportes", "Transporte Não Motorizado" e "Tráfego e Circulação Urbana" (refletida no gráfico situado na parte superior da Figura 5-2). Aqui existe o efeito da redistribuição de pesos por conta da falta de dados para certos indicadores. Para o caso da infraestrutura, dois dos indicadores para os quais existiam as informações para 2011 ("Sinalização viária" e "Vias para transporte coletivo") estão com avaliação zero. Os cenários "1991" e "2001" também são mal avaliados para o indicador "Vias para transporte coletivo", mas possuem melhor avaliação para "Vias pavimentadas". No caso de "Tráfego e Circulação Urbana" pesou o aumento das taxas de "Acidentes de trânsito" e de "Acidentes com pedestres e ciclistas", além da diminuição da "Velocidade média de tráfego" e a alta do "Índice de motorização". O efeito da redistribuição de pesos voltou a aparecer para o caso do domínio "Sistemas de Transporte Urbano". O cenário 2011 é o único para o qual se obteve informação para o indicador "Transporte clandestino". Com a estimativa de 25\% 
da demanda atendida por esse tipo de transporte, piorou a avaliação do tema "Regulação e fiscalização do transporte público".

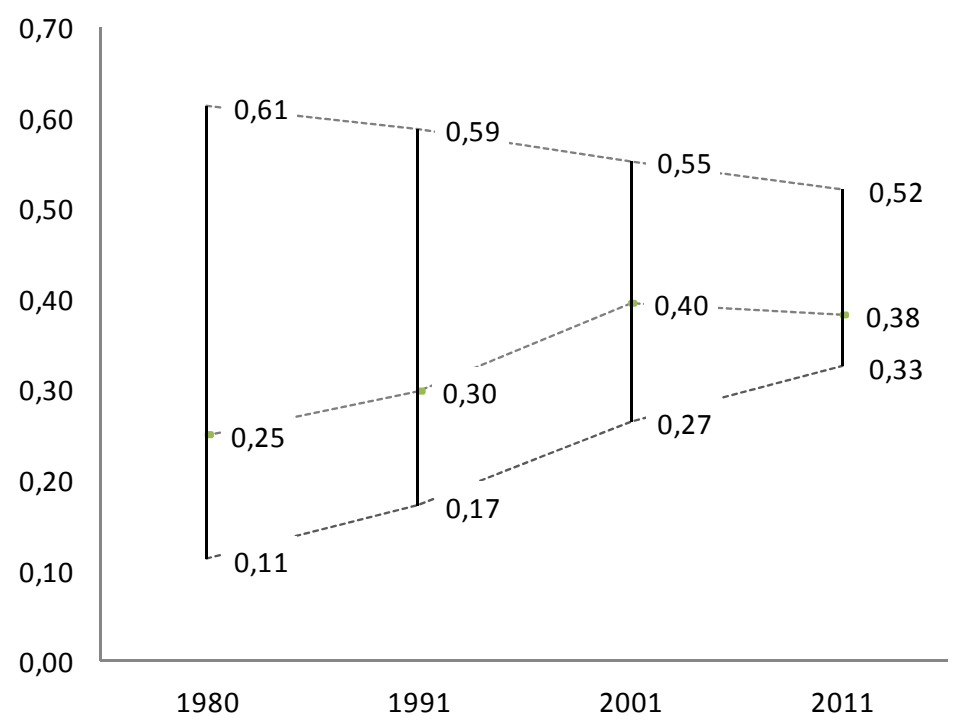

Figura 5-1 - Valores calculados para o IMUS, incluindo valor superior e inferior, considerando os dados de todos os indicadores para cada um dos cenários.

Para retirar o efeito da maior ou menor quantidade de indicadores calculados para cada cenário, foi feita nova estimativa do IMUS, neste caso, considerando apenas o conjunto de indicadores calculados para todos os cenários. Essa diferença pode ser avaliada comparando-se os gráficos da Figura 5-2. No gráfico superior, apresentam-se os valores do IMUS, separando-se as parcelas relativas a cada domínio, incluindo todos os indicadores calculados. Para o segundo gráfico foram considerados apenas indicadores comuns a todos os cenários (Ver Anexo D).

Existe um total de 36 indicadores nessa condição e a nova configuração mostra uma tendência de melhoria da mobilidade a cada década. Configuram-se dois patamares, ocorrendo uma espécie de "salto de qualidade" entre o par 1980-1991 e o par 2001-2011. Aqui, os domínios que se destacam são "Acessibilidade", "Aspectos Ambientais" e "Aspectos Sociais". No primeiro caso, a melhoria se explica pelo maior cuidado, por parte do poder público, em adotar medidas que refletem positivamente nos indicadores "Transporte público para pessoas com necessidades especiais", "Travessias adaptadas para pessoas com necessidades especiais" e "Ações para acessibilidade universal". Deve-se destacar que parte dessas medidas é "incentivada" pela obrigatoriedade estabelecida em leis. Os indicadores "Informação disponível ao cidadão" e "Participação na tomada de decisão", fizeram a diferença na melhoria da avaliação do domínio "Aspectos Sociais". Outra obrigação legal que ajudou a melhorar o julgamento do cenário "2011" foi referente ao indicador "Estudos de Impacto Ambiental" do domínio "Aspectos Ambientais".

Cabe ressaltar que, mesmo que exista a tendência de crescimento do valor do IMUS, valores como os alcançados representam uma mobilidade muito aquém das necessidades da população de Belém e região metropolitana. Na próxima seção, os resultados obtidos para a RMB são comparados com 
valores do IMUS estimados para outras localidades brasileiras e com os valores obtidos pela aplicação de outros dois métodos de avaliação da mobilidade sustentável.
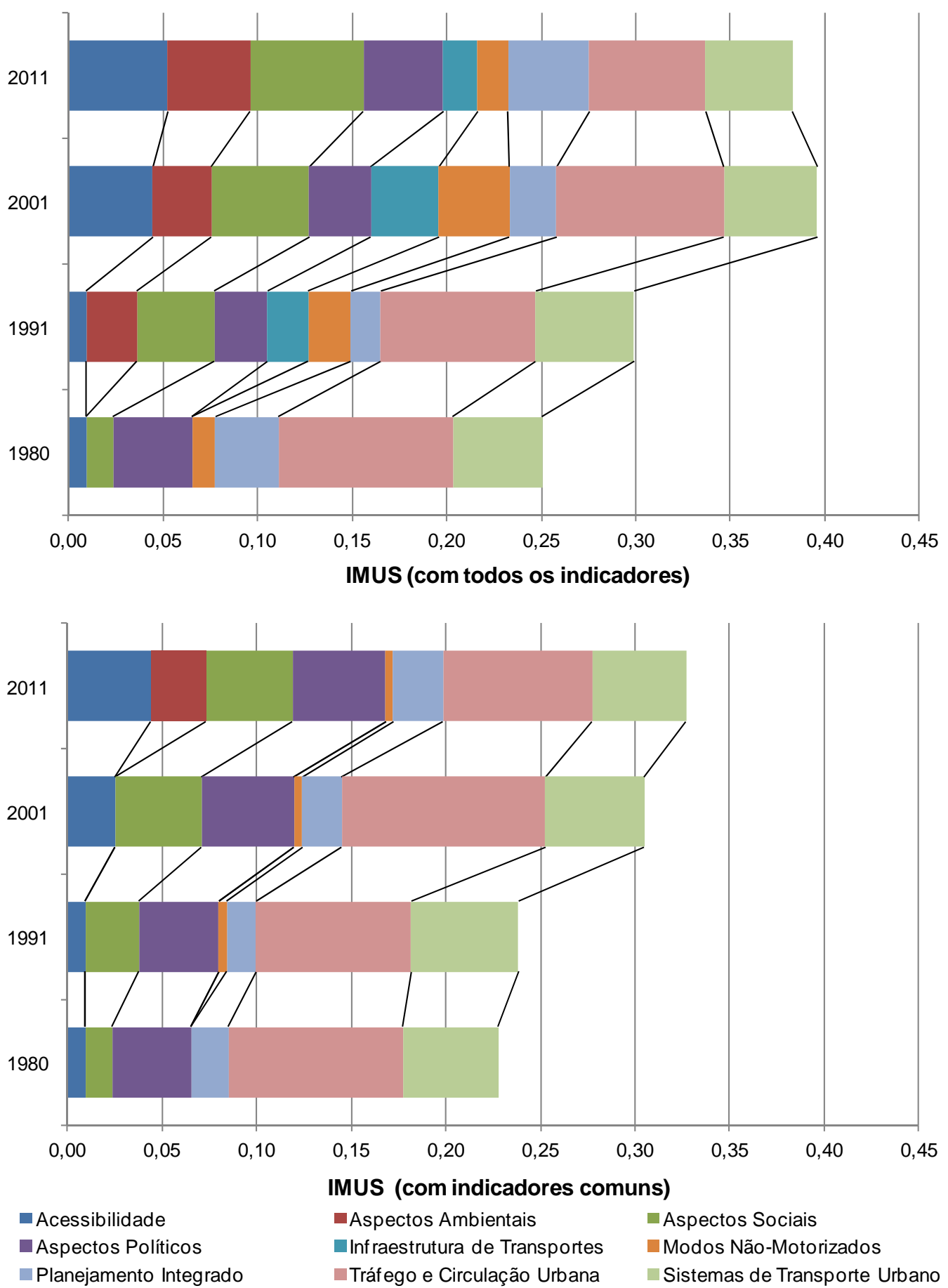

Figura 5-2 - Contribuição de cada um dos domínios para a formação do IMUS dos cenários 1980,1991, 2001 e 2011 


\subsection{Comparando com resultados de outros estudos}

Conforme destacado por Black (2010) o uso de indicadores tem utilidade principal no controle da evolução no sentido de uma mobilidade sustentável para um mesmo local. Eles são mais úteis como ferramentas de auxílio à tomada de decisão do que representando "certificados de qualidade". Todavia, foram feitas algumas comparações para saber como a mobilidade urbana da RMB estaria quando colocada ao lado de outras localidades para as quais foi calculado o IMUS. Na medida da disponibilidade de dados, foram feitas mais duas avaliações, utilizando métodos similares ao IMUS, testando se a tendência de melhoria da qualidade da mobilidade urbana se repetiria. Esses experimentos são relatados a seguir.

\subsubsection{Outras aplicações do IMUS}

Deve-se deixar claro que esta comparação foi feita com base em índices calculados por diferentes autores, para cidades com diferentes estruturas institucionais e, portanto, deve ser encarada com os devidos cuidados. Na Tabela 5-1 são apresentados alguns resultados obtidos em outros estudos, juntamente com os obtidos para a RMB.

Tabela 5-1 - Resultados do cálculo do IMUS para Belém e para outras regiões

\begin{tabular}{|c|c|c|c|}
\hline local & população & $\begin{array}{l}\text { valor do } \\
\text { IMUS }\end{array}$ & $\begin{array}{c}\text { indicadores } \\
\text { calculados }\end{array}$ \\
\hline Belém - 1980 & $949.545^{1}$ & 0,25 & $39(44,8 \%)$ \\
\hline Belém - 1991 & $1.244 .689^{1}$ & 0,30 & $44(50,6 \%)$ \\
\hline Belém - 2001 & $1.279 .861^{1}$ & 0,40 & $58(66,7 \%)$ \\
\hline Belém - 2011 & $1.393 .399^{2}$ & 0,38 & $64(73,6 \%)$ \\
\hline Curitiba (MIRANDA, 2010) & $1.751 .907^{2}$ & 0,74 & $75(86,2 \%)$ \\
\hline Distrito Federal (PONTES, 2010) & $2.570 .160^{2}$ & 0,45 & $79(90,8 \%)$ \\
\hline Distrito Federal + RM (PONTES, 2010) & $3.725 .630^{3}$ & 0,31 & $39(44,8 \%)$ \\
\hline São Carlos (COSTA, 2008) & $212.956^{4}$ & 0,58 & $80(92,0 \%)$ \\
\hline Uberlândia (DA ASSUNÇÃO, 2012) & $604.013^{2}$ & 0,71 & $80(92,0 \%)$ \\
\hline
\end{tabular}

\subsubsection{Estudo Mobilize}

O índice proposto por Mobilize (2011) é constituído de cinco indicadores e procurou-se calcular o valor destes para os cenários de Belém. Não foram encontrados dados para calcular todos os indicadores para os quatro cenários. Faltaram os seguintes indicadores:

- Mortos em acidentes de trânsito (por 100.000 habitantes), para os cenários "1980" e "1991";

- Razão entre a renda média mensal e a tarifa simples de ônibus urbano, para o cenário "1980";

- Razão entre o número de viagens por modos individuais motorizados de transporte e o número total de viagens, para o cenário "2011". 
Foram feitas duas simulações. Na primeira (Tabela 5-2) as notas foram calculadas para os indicadores com dados disponíveis para a RMB. Na outra (Tabela 5-3), foram utilizados os mesmos valores dos indicadores de cenários mais próximos. Não foram atribuídos valores a indicadores faltantes de outras localidades. No primeiro experimento, os dois cenários mais recentes da RMB estariam bem colocados, sendo que na comparação mais justa, o caso atual, ele corresponderia à mediana. Quando se estabelecem os valores dos indicadores faltantes, a situação fica ainda melhor. O que interessa mais no caso desta pesquisa é a confirmação de que a mobilidade para os cenários da RMB melhorou de 1980 a 2001 e ocorreu uma queda do valor do escore para o cenário 2011. Este é o mesmo comportamento observado com a utilização do IMUS para o conjunto completo de indicadores.

Tabela 5-2 - Resultados da aplicação do método do Estudo Mobilize, para Belém e outras capitais

\begin{tabular}{|c|c|c|c|c|c|c|c|c|c|c|c|c|}
\hline \multirow[b]{2}{*}{ local } & \multirow[b]{2}{*}{ média } & \multirow[b]{2}{*}{ ord } & \multicolumn{2}{|c|}{$\begin{array}{c}\text { ônibus } \\
\text { acessíveis }\end{array}$} & \multicolumn{2}{|c|}{$\begin{array}{l}\text { mortes no } \\
\text { trânsito }\end{array}$} & \multicolumn{2}{|c|}{$\begin{array}{l}\text { estrutura } \\
\text { cicloviária }\end{array}$} & \multicolumn{2}{|c|}{$\begin{array}{l}\text { tarifa de } \\
\text { ônibus }\end{array}$} & \multicolumn{2}{|c|}{$\begin{array}{c}\text { viagens } \\
\text { motorizadas }\end{array}$} \\
\hline & & & $\%$ & nota & ind & nota & $\%$ & nota & ind & nota & $\%$ & nota \\
\hline Belém - 1980 & 0,2 & 13 & 0,0 & 0,0 & - & - & 0,00 & 0,0 & - & - & 28 & 0,6 \\
\hline Belém - 1991 & 1,9 & 12 & 0,0 & 0,0 & - & - & 0,00 & 0,0 & 371,6 & 0,0 & 17 & 7,5 \\
\hline Belém - 2001 & 6,2 & 3 & 10,0 & 1,1 & 4,8 & 10,0 & 1,05 & 4,0 & 685,7 & 5,7 & 13 & 10,0 \\
\hline Belém - 2011 & 4,4 & 7 & 42,0 & 4,7 & 7,9 & 7,7 & 1,33 & 5,1 & 376,8 & 0,1 & - & - \\
\hline Belo Horizonte & 4,3 & 8 & 69,9 & 7,8 & 11,0 & 5,3 & 0,40 & 1,5 & 627,6 & 4,6 & 25 & 2,5 \\
\hline Brasília & 5,7 & 4 & 24,1 & 2,7 & 18,0 & 0,0 & 2,61 & 10,0 & 924,5 & 10,0 & - & - \\
\hline Cuiabá & 2,9 & 11 & 44,9 & 5,0 & 12,0 & 4,5 & 0,81 & 3,1 & 462,7 & 1,6 & 29 & 0,0 \\
\hline Curitiba & 7,0 & 2 & 90,0 & 10,0 & 5,2 & 9,7 & 2,51 & 9,6 & 615,5 & 4,4 & 27 & 1,3 \\
\hline Natal & 4,5 & 6 & 20,7 & 2,3 & 8,2 & 7,4 & - & - & 482,9 & 2,0 & 19 & 6,3 \\
\hline Porto Alegre & 4,0 & 10 & 43,1 & 4,8 & 10,1 & 6,0 & 0,28 & 1,1 & 678,3 & 5,5 & 25 & 2,5 \\
\hline Rio de Janeiro & 8,1 & 1 & 60,0 & 6,7 & 5,4 & 9,5 & 2,54 & 9,7 & 617,1 & 4,4 & 13 & 10,0 \\
\hline Salvador & 4,6 & 5 & 44,8 & 5,0 & 9,9 & 6,1 & 0,36 & 1,4 & 421,5 & 0,9 & 14 & 9,4 \\
\hline São Paulo & 4,2 & 9 & 43,6 & 4,8 & 12,1 & 4,5 & 0,21 & 0,8 & 515,9 & 2,6 & 16 & 8,1 \\
\hline
\end{tabular}

Fonte: À exceção de Belém, os dados de todas as demais cidades são provenientes de Mobilize (2011).

Tabela 5-3 - Resultados da aplicação do método do Estudo Mobilize, para os cenários de Belém, com estimativa dos indicadores faltantes

\begin{tabular}{ccccccccccccc} 
& & & \multicolumn{2}{c}{$\begin{array}{c}\text { Ônibus } \\
\text { acessíveis }\end{array}$} & \multicolumn{2}{c}{$\begin{array}{c}\text { mortes no } \\
\text { trânsito }\end{array}$} & \multicolumn{2}{c}{$\begin{array}{c}\text { estrutura } \\
\text { cicloviária }\end{array}$} & \multicolumn{2}{c}{$\begin{array}{c}\text { tarifa de } \\
\text { onnibus }\end{array}$} & \multicolumn{2}{c}{$\begin{array}{c}\text { viagens } \\
\text { motorizadas }\end{array}$} \\
\hline local & média & ord & $\%$ & nota & ind & nota & $\%$ & nota & ind & nota & $\%$ & nota \\
\hline Belém - 1980 & 2,1 & 13 & 0,0 & 0,0 & 4,8 & 10,0 & 0,00 & 0,0 & 371,6 & 0,0 & 28 & 0,6 \\
\hline Belém - 1991 & 3,5 & 11 & 0,0 & 0,0 & 4,8 & 10,0 & 0,00 & 0,0 & 371,6 & 0,0 & 17 & 7,5 \\
\hline Belém - 2001 & 6,2 & 3 & 10,0 & 1,1 & 4,8 & 10,0 & 1,05 & 4,0 & 685,7 & 5,7 & 13 & 10,0 \\
\hline Belém - 2011 & 5,5 & 5 & 42,0 & 4,7 & 7,9 & 7,7 & 1,33 & 5,1 & 376,8 & 0,1 & 13 & 10,0 \\
\hline
\end{tabular}

\subsection{3. Índice de Mobilidade Sustentável}

O IMS (MACHADO, 2010) não se presta à avaliação de uma única localidade ou cenário, já que os valores dos indicadores são padronizados considerando média e desvio padrão de um conjunto de dados. O método foi utilizado de duas maneiras. Na primeira foram considerados apenas os cenários 
da RMB (Tabela 5-4). Na segunda foram utilizados os dados do cenário 2011 e Belém foi comparada com as dez cidades da Região Metropolitana de Porto Alegre, cenário 2007, conforme os dados disponíveis em Machado (2010).

Tabela 5-4 - Resultado da aplicação do método do Índice de Mobilidade Sustentável

\begin{tabular}{|c|c|c|c|c|}
\hline Cenário & 1980 & 1991 & 2001 & 2011 \\
\hline SOC1 - num de mortes em acidentes / frota & $0,075^{\star}$ & $0,075^{*}$ & 0,059 & 0,075 \\
\hline Valor padronizado & 0,487 & 0,487 & $-1,500$ & 0,525 \\
\hline Valor multiplicado pelo peso e pela direção & $-0,175$ & $-0,175$ & 0,540 & $-0,189$ \\
\hline SOC2 - passageiros transportados / população & 0,708 & 0,975 & 1,037 & 0,595 \\
\hline Valor padronizado & $-0,572$ & 0,693 & 0,985 & $-1,106$ \\
\hline Valor multiplicado pelo peso e pela direção & $-0,194$ & 0,236 & 0,335 & $-0,376$ \\
\hline SOC3 - número de estações intermodais & 0,000 & 0,000 & 0,000 & 0,000 \\
\hline \multicolumn{5}{|l|}{ Valor padronizado } \\
\hline \multicolumn{5}{|l|}{ Valor multiplicado pelo peso e pela direção } \\
\hline SOC - dimensão social & $-0,163$ & 0,026 & 0,385 & $-0,249$ \\
\hline ECO1 - valor da tarifa / valor do salário mínimo & $0,003^{*}$ & 0,003 & 0,004 & 0,003 \\
\hline Valor padronizado & $-0,813$ & $-0,813$ & 1,235 & 0,390 \\
\hline Valor multiplicado pelo peso e pela direção & 0,325 & 0,325 & $-0,494$ & $-0,156$ \\
\hline ECO2 - índice de passageiros por km (IPK) & 4,130 & 5,150 & 2,740 & 2,800 \\
\hline Valor padronizado & 0,367 & 1,248 & $-0,834$ & $-0,782$ \\
\hline Valor multiplicado pelo peso e pela direção & 0,114 & 0,387 & $-0,258$ & $-0,242$ \\
\hline \multicolumn{5}{|l|}{ ECO3 - gastos em transportes / PIB } \\
\hline \multicolumn{5}{|l|}{ Valor padronizado } \\
\hline \multicolumn{5}{|l|}{ Valor multiplicado pelo peso e pela direção } \\
\hline ECO - dimensão econômica & 0,127 & 0,207 & $-0,218$ & $-0,116$ \\
\hline AMB1 - número de veículos / população & 0,059 & 0,061 & 0,082 & 0,133 \\
\hline Valor padronizado & $-0,728$ & $-0,652$ & $-0,049$ & 1,429 \\
\hline Valor multiplicado pelo peso e pela direção & 0,328 & 0,294 & 0,022 & $-0,643$ \\
\hline AMB2 - gasolina+diesel / população & $356,595^{\star}$ & 356,595 & 362,135 & 444,942 \\
\hline Valor padronizado & $-0,542$ & $-0,542$ & $-0,414$ & 1,497 \\
\hline Valor multiplicado pelo peso e pela direção & 0,179 & 0,179 & 0,137 & $-0,494$ \\
\hline AMB3 - álcool / população & 0,000 & 50,075 & 6,832 & 9,047 \\
\hline Valor padronizado & $-0,726$ & 1,478 & $-0,425$ & $-0,328$ \\
\hline Valor multiplicado pelo peso e pela direção & 0,160 & $-0,325$ & 0,094 & 0,072 \\
\hline AMB - dimensão ambiental & 0,180 & 0,040 & 0,068 & $-0,288$ \\
\hline IMS - Índice de Mobilidade Sustentável & 0,144 & 0,273 & 0,235 & $-0,652$ \\
\hline
\end{tabular}

* Indicador sem dados. Foram adotados valores de cenários correspondentes à pior situação

Para a comparação entre os cenários, não foi possível obter dados para o indicador ECO03, que avalia os gastos efetuados pelo poder público com relação ao Produto Interno Bruto local. O indicador SOC03 (número de estações intermodais) não teve qualquer influência no cálculo do índice, porque a 
situação é a mesma para todos os cenários, isto é, estas estações nunca existiram. Da comparação dos valores do IMS, verifica-se uma situação diversa da observada nos casos anteriores. O cenário "1991" seria o melhor e o cenário atual seria o pior.

No segundo experimento com o IMS, quando se coloca a RMB em conjunto com os municípios da RMPA, foram obtidos os resultados apresentados na Tabela 5-5, o que coloca a RMB na segunda colocação, mas a uma distância grande com relação à cidade de Porto Alegre no primeiro posto. Comparando-se as dimensões que compõem o IMS, Porto Alegre ficou em primeiro lugar nas dimensões social e econômica, e em nono lugar na dimensão ambiental. A RMB ficou com a sexta colocação na dimensão social e na segunda colocação nas dimensões econômica e ambiental.

Tabela 5-5 - Comparando o IMS para a RMB (cenário 2011) com os municípios da Região Metropolitana de Porto Alegre (cenário 2007)

\begin{tabular}{|c|c|c|c|}
\hline & local & IMS & ordem \\
\hline \multirow{10}{*}{ 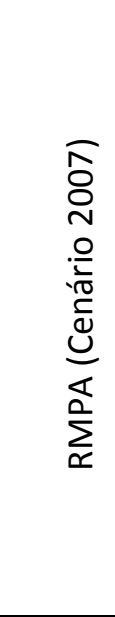 } & Alvorada & 0,202 & 4 \\
\hline & Cachoeirinha & 0,356 & 3 \\
\hline & Canoas & $-0,145$ & 6 \\
\hline & Eldorado do Sul & $-0,247$ & 8 \\
\hline & Esteio & $-0,199$ & 7 \\
\hline & Gravataí & $-0,326$ & 10 \\
\hline & Guaíba & $-0,296$ & 9 \\
\hline & Porto Alegre & 0,721 & 1 \\
\hline & Sapucaia do Sul & $-0,442$ & 11 \\
\hline & Viamão & $-0,030$ & 5 \\
\hline \multicolumn{2}{|c|}{ RMB (cenário 2011) } & 0,406 & 2 \\
\hline
\end{tabular}

Fonte: os dados da RMPA são provenientes de Machado (2010)

Mais uma vez é bom destacar as condições da comparação, com dados de diferentes períodos e aplicação de um método avaliado, a princípio, apenas para a aplicação da RMPA. Tratou-se de um exercício para balizar o experimento principal desta tese.

\subsection{Conclusão}

De uma maneira geral, a obtenção de uma grande parte dos dados depende da cooperação de pessoas de vários órgãos municipais e, algumas vezes, estaduais ou federais. Cidades maiores, com maiores problemas, normalmente dispõem de estruturas administrativas mais sofisticadas e tendem à produção de mais informações. No entanto, para que isto se reverta em benefício para o cálculo do índice, é preciso que haja uma organização para coleta de dados e manutenção de uma base de indicadores não apenas de mobilidade, mas de todas as áreas que afetam a qualidade de vida e a sustentabilidade das cidades. Várias rotinas de controle do sistema de transportes, por exemplo, geram dados secundários que são úteis quando recebem o tratamento adequado. É o caso, por exemplo, dos sistemas de bilhetagem eletrônica e de rastreamento dos veículos de transporte 
coletivo. Estes sistemas já estão em operação em várias cidades, com funções de controle da arrecadação e de segurança dos operadores e usuários. Vários indicadores podem ser obtidos daí como, por exemplo, velocidades de operação, pontualidade, duração e frequência das viagens.

Do conjunto de 87 indicadores, 15 não foram calculados para nenhum dos cenários (ver Anexo D). Alguns dependem de pesquisas mais sofisticadas (pesquisa domiciliar para levantamento do padrão de viagens, por exemplo) ou dependem de instrumentos mais caros de coleta, como é o caso dos indicadores dos teores de $\mathrm{CO}$ e $\mathrm{CO}_{2}$ da atmosfera. Existem alguns que representam novos conceitos para uma parte dos técnicos da área de mobilidade, como os que envolvem a distribuição de recursos do orçamento, dinâmicas da ocupação urbana e existência e cumprimento de normas urbanísticas. A maior parte desses indicadores depende da sistematização da captação de informações existentes. É preciso envolver as várias instituições e criar rotinas que "automatizem" a atualização e disponibilização desses dados.

A comparação dos resultados da RMB com outras localidades, utilizando o próprio IMUS ou os dois outros métodos aqui relatados, permite ter uma ideia da qualidade da mobilidade urbana sustentável desta com relação às outras localidades. No entanto, existe um risco nesse procedimento, pois o cálculo dos indicadores das diferentes localidades, apesar de ter sido feito seguindo os mesmos métodos, foi preparado por equipes técnicas diferentes, sem uma padronização de critérios para as avaliações de caráter subjetivo. Isto ocorre no caso da falta de dados ideais quando são feitas estimativas utilizando dados mais antigos ou situações análogas, quase sempre produzindo informações de pior qualidade. 


\section{AVALIAÇÃO DO PROCESSO DE PLANEJAMENTO DA MOBILIDADE URBANA}

We talk the talk but we don't walk the walk.

(TOLLEY, 2003)

Neste capítulo apresenta-se uma avaliação dos efeitos potenciais das propostas dos vários estudos e planos desenvolvidos para a RMB. Estima-se também o impacto do conjunto de trabalhos sobre a avaliação de cada domínio do IMUS. Além dessas duas avaliações de caráter mais quantitativo, é possível fazer uma análise qualitativa. Esta leva em conta, além desses resultados, a experiência do autor e as análises desenvolvidas por outros autores para o problema da mobilidade urbana da RMB. Ao final, é possível fazer uma análise do processo de planejamento da mobilidade urbana, de maneira mais geral, destacando os principais problemas e suas possíveis soluções.

\subsection{Comparando a contribuição potencial de cada projeto para a melhoria da mobilidade urbana sustentável}

Aqui são analisadas as propostas dos estudos e planos segundo método proposto pelo autor e descrito no capítulo de metodologia. Foram atribuídas notas a cada um dos planos ou estudos, baseados no impacto positivo ou negativo que estes poderiam causar nos requisitos considerados pelos Temas do IMUS (Tabela 6-1). Conforme se observa, a soma dos pontos dos planos e estudos mais antigos é bem mais baixa do que a dos mais recentes. Isso se deve ao fato de que os primeiros trabalhos apresentavam um conjunto menor de propostas, que eram muito direcionadas para a melhoria e ampliação do sistema viário. Klautau (1993) avalia tais propostas como sendo quase que exclusivamente na área da engenharia de tráfego. Como a análise presente segue um roteiro que visa à mobilidade urbana sustentável, ocorreu que dos quatro planos mais antigos o que melhor pontuou foi o TRANSCOL - Ciclovia (GEIPOT, 1979). Um projeto que favorece o transporte não motorizado, aumentando a sua participação na divisão modal e melhorando a segurança da circulação dos ciclistas, afeta positivamente vários Temas do IMUS.

A pontuação total poderia variar de -74 (37 Temas todos com nota -2) a 74 (37 Temas todos com nota 2). Nos quatro primeiros estudos a avaliação variou de 3 a 8. Nos estudos do período de 1991 a 2010, a variação foi de 20 a 27. A maior pontuação foi do PDTU-2001 (JICA, 2001) que, dessa maneira, foi considerado pelo autor como o que apresentou o conjunto de propostas que traria o melhor impacto na melhoria da mobilidade urbana sustentável. É interessante observar que ocorreu 
uma queda significativa da pontuação entre o PDTU-2001 e o estudo mais recente (JICA, 2010). Por questões orçamentárias e também políticas, houve um enfraquecimento da proposta de um sistema integrado de transportes, prejudicando assim a avaliação.

Tabela 6-1 - Avaliação dos estudos e planos de transportes para a RMB

IMUS

\begin{tabular}{|c|c|c|c|c|c|c|c|c|c|c|}
\hline \multicolumn{2}{|r|}{ IMUS } & \multirow{2}{*}{$\begin{array}{l}\infty \\
\stackrel{\infty}{\sigma} \\
\stackrel{-}{-1} \\
1 \\
\dot{m} \\
\sum_{\propto}^{\prime} \\
\frac{1}{\bar{\alpha}}\end{array}$} & \multirow{2}{*}{$\begin{array}{l}9 \\
\stackrel{9}{0} \\
\stackrel{-}{-1} \\
1 \\
-1 \\
0 \\
1 \\
1 \\
0 \\
\frac{\sigma}{2} \\
\frac{0}{0} \\
\frac{0}{0}\end{array}$} & \multirow{2}{*}{ 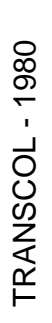 } & \multirow{2}{*}{ 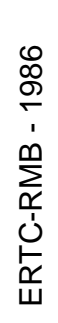 } & \multirow[b]{2}{*}{ 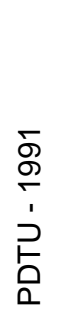 } & \multirow[b]{2}{*}{ 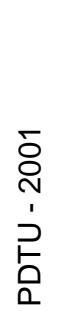 } & \multirow{2}{*}{ 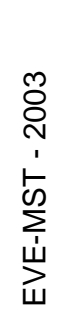 } & \multirow{2}{*}{ 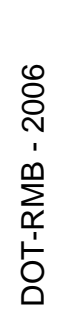 } & \multirow{2}{*}{ 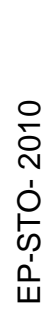 } \\
\hline Domínio & Tema & & & & & & & & & \\
\hline \multirow{4}{*}{ Acessibilidade } & Acessibilidade aos sistemas de transporte & 1 & 0 & 1 & 1 & 1 & 2 & 2 & 2 & 1 \\
\hline & Acessibilidade universal & 0 & 0 & 0 & 0 & 0 & 0 & 0 & 0 & 0 \\
\hline & Barreiras físicas & 0 & 0 & 0 & 0 & 0 & 0 & 0 & 0 & 0 \\
\hline & Legisl. para pessoas com necessidades especiais & 0 & 0 & 0 & 0 & 0 & 1 & 1 & 1 & 1 \\
\hline \multirow{2}{*}{$\begin{array}{l}\text { Aspectos } \\
\text { Ambientais }\end{array}$} & Controle dos impactos no meio ambiente & 0 & 0 & 0 & 0 & 0 & 1 & 2 & 2 & 1 \\
\hline & Recursos naturais & 0 & 0 & -1 & -1 & -1 & -1 & -1 & -1 & -2 \\
\hline \multirow{5}{*}{$\begin{array}{l}\text { Aspectos } \\
\text { Sociais }\end{array}$} & Apoio ao cidadão & 0 & 0 & 0 & 0 & 1 & 1 & 1 & 1 & 1 \\
\hline & Inclusão social & 0 & 1 & 1 & 1 & 1 & 1 & 1 & 1 & 1 \\
\hline & Educação e cidadania & 0 & 0 & 0 & 0 & 0 & 0 & 0 & 0 & 0 \\
\hline & Participação popular & -1 & -1 & -1 & -1 & -1 & -1 & -1 & -1 & -1 \\
\hline & Qualidade de vida & 1 & 1 & 1 & 1 & 1 & 1 & 1 & 1 & 1 \\
\hline \multirow{3}{*}{$\begin{array}{l}\text { Aspectos } \\
\text { Políticos }\end{array}$} & Integração de ações políticas & 0 & 0 & 0 & 0 & 1 & 1 & 1 & 1 & 1 \\
\hline & Captação e gerenciamento de recursos & 0 & 1 & 1 & 1 & 2 & 2 & 2 & 1 & 1 \\
\hline & Política de mobilidade urbana & 1 & 1 & 1 & 1 & 2 & 2 & 1 & 1 & 1 \\
\hline \multirow{2}{*}{$\begin{array}{l}\text { Infraestrutura } \\
\text { de Transportes }\end{array}$} & Provisão e manutenção da infraest. de transportes & 0 & 0 & 0 & 0 & 1 & 2 & 2 & 1 & 1 \\
\hline & Distribuição da infraestrutura de transporte & 0 & 0 & 1 & 0 & 1 & 2 & 2 & 1 & 2 \\
\hline \multirow{3}{*}{$\begin{array}{l}\text { Modos Não } \\
\text { Motorizados }\end{array}$} & Transporte cicloviário & 0 & 2 & 0 & 0 & 1 & 2 & 2 & 1 & 2 \\
\hline & Deslocamentos a pé & 0 & 0 & 1 & 0 & 1 & 1 & 1 & 1 & 1 \\
\hline & Redução de viagens & 0 & 1 & 0 & 0 & 0 & 0 & 0 & 0 & 0 \\
\hline \multirow{8}{*}{$\begin{array}{l}\text { Planejamento } \\
\text { Integrado }\end{array}$} & Capacitação de gestores & 0 & 0 & 0 & 0 & 1 & 1 & 1 & 1 & 1 \\
\hline & Áreas centrais e de interesse histórico & 0 & 0 & 0 & 0 & 0 & 0 & 0 & 0 & 0 \\
\hline & Integração regional & 0 & 0 & 0 & 0 & 1 & 1 & 1 & 1 & 2 \\
\hline & Transparência do processo de planejamento & 0 & 0 & 0 & 0 & 0 & 0 & 0 & 0 & 0 \\
\hline & Planejamento e controle do uso e ocupação do solo & 0 & 0 & 0 & 0 & 1 & 1 & 1 & 2 & 1 \\
\hline & Planejamento estratégico e integrado & 0 & 0 & 0 & 0 & 1 & 1 & 1 & 1 & 1 \\
\hline & Planejamento da infraest. urbana e equip. urbanos & 0 & 0 & 0 & 0 & 0 & 0 & 0 & 0 & 0 \\
\hline & Plano diretor e legislação urbanística & 0 & 0 & 0 & 0 & 0 & 0 & 0 & 2 & 0 \\
\hline \multirow{5}{*}{$\begin{array}{l}\text { Tráfego e } \\
\text { Circulação } \\
\text { Urbana }\end{array}$} & Acidentes de trânsito & 1 & 1 & 1 & 0 & 1 & 1 & 1 & 1 & 1 \\
\hline & Educação para o trânsito & 0 & 0 & 0 & 0 & 0 & 0 & 0 & 0 & 0 \\
\hline & Fluidez e circulação & 1 & 0 & 1 & 1 & 2 & 2 & 2 & 2 & 2 \\
\hline & Operação e fiscalização de trânsito & 0 & 0 & 0 & 0 & 0 & 0 & 0 & 0 & 0 \\
\hline & Transporte individual & 0 & 0 & 0 & 0 & -1 & -1 & -1 & -1 & -2 \\
\hline \multirow{6}{*}{$\begin{array}{l}\text { Sistemas de } \\
\text { Transporte } \\
\text { Urbano }\end{array}$} & Disponibilidade e qualidade do transporte público & 0 & 0 & 1 & 1 & 2 & 2 & 2 & 2 & 2 \\
\hline & Diversificação modal & 0 & 1 & 0 & 0 & 0 & 1 & 1 & 1 & 1 \\
\hline & Regulação e fiscalização do transporte público & 0 & 0 & -1 & -1 & -1 & -1 & -1 & -1 & -1 \\
\hline & Integração do transporte público & 0 & 0 & -1 & -1 & 1 & 1 & 1 & 1 & 1 \\
\hline & Política tarifária & 0 & 0 & 0 & 0 & 1 & 1 & 0 & 0 & 0 \\
\hline & Soma dos pontos & 4 & 8 & 6 & 3 & 20 & 27 & 26 & 25 & 21 \\
\hline
\end{tabular}


Todos os projetos pontuaram mal no Tema "Participação Popular", pois não há registro de que esta tenha ocorrido. Klautau (1993) coloca esse como um dos principais problemas dos planos por ele analisados. Mercês (2004) relata a importância e as conquistas de movimentos populares na área de mobilidade, mas isso em problemas mais imediatos e não nas atividades de planejamento. Outro Tema em que todos os estudos foram mal avaliados foi o referente ao "Transporte Individual". Apesar de sempre ser citado o problema do excesso de automóveis e dos congestionamentos das vias, não se apontam medidas para restringir esse modo de transporte. No caso do Tema "Recursos Naturais" avalia-se a redução do consumo de gasolina e o uso de combustíveis menos poluentes. Quase não existiram propostas que pudessem afetar positivamente estes indicadores.

\subsubsection{As propostas do conjunto de estudos e planos e o efeito nos Domínios do IMUS}

Com base nas mesmas notas da Tabela 6-1, procedeu-se ao cálculo de um indicador que representasse o provável efeito, ainda segundo a metodologia de avaliação aqui preconizada, das propostas do conjunto de planos e estudos sobre cada Tema do IMUS. Primeiramente, cada uma das notas foi multiplicada pelos valores dos pesos dos respectivos Domínios e Temas (para valores dos pesos, ver Anexo A), conforme exemplo a seguir:

- Domínio "Acessibilidade": peso = 0,108

- Tema "Acessibilidade aos sistemas de transporte": peso = 0,290

- Projeto "RII-RMB": nota $=1$

- Valor do peso $=0,108 \times 0,290 \times 1=0,031$

A seguir, procedeu-se a somatória de todos esses valores para o conjunto de notas de cada Domínio. No caso do Domínio "Acessibilidade" o valor resultante foi 0,467 . Para facilitar a comparação entre os Domínios, os valores obtidos foram normalizados, sendo atribuído o valor $\underline{0,000}$ para o pior caso e 1,000 para o melhor, isto é, o Domínio que representaria o impacto mais positivo.

O Domínio que traria a melhor contribuição seria o dos "Aspectos Políticos" vindo, logo em seguida, "Infraestrutura de Transportes". Todos os projetos pontuaram mal no Domínio "Aspectos Ambientais" e este acabou ficando em último lugar na escala. Os resultados para todos os Domínios são apresentados na Figura 6-1.

\subsubsection{Avaliação geral dos estudos e planos}

Todos os planos e estudos foram elaborados com a participação de equipes mistas com técnicos locais, de outras partes do país e do exterior. Quando esses projetos se baseiam em "boas práticas" de outras cidades e utilizam métodos desenvolvidos para realidades diversas, corre-se o risco de ignorar características importantes da situação local. Klautau (1993) cita a frase de um professor de uma universidade local que, comentando as propostas do PDTU-1991 (JICA, 1991), diz “... - Os japoneses podem saber mais que a gente, mas ignoram a nossa realidade - ...". É uma estória comum. Uma cidade tem estudos e propostas de solução de seus problemas elaboradas por técnicos das instituições locais. Em determinado momento se contrata consultoria externa para estudar os 
mesmos problemas e esta chega a diagnóstico e proposta de soluções semelhantes ou, no pior caso, são sugeridas intervenções que não condizem com a realidade local.

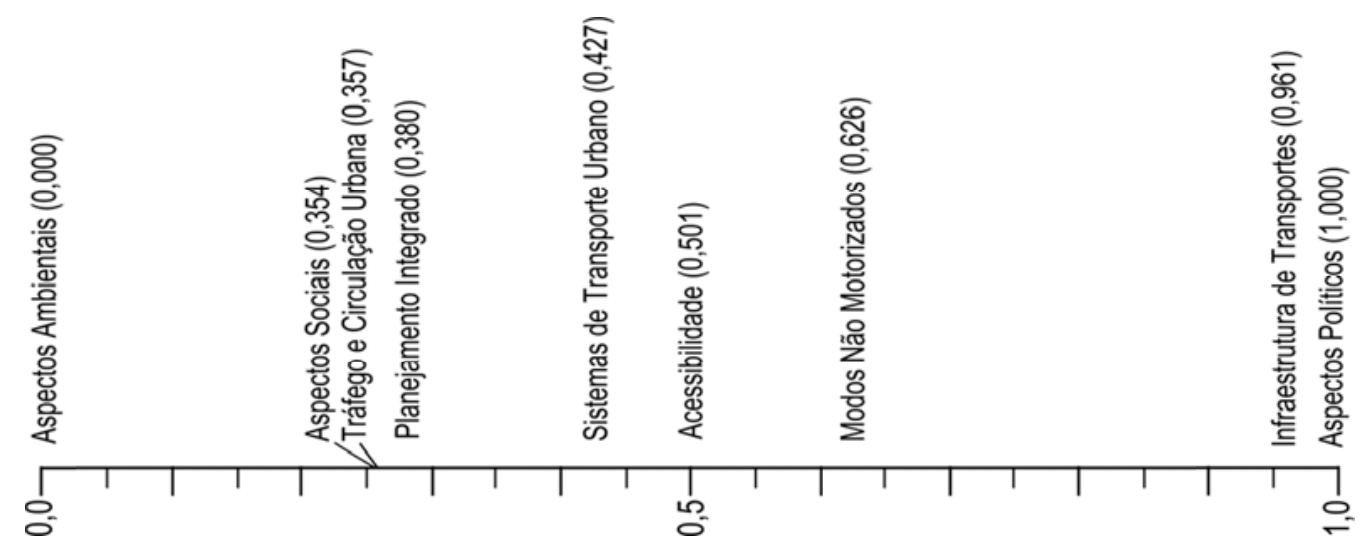

Figura 6-1 - Classificação dos Domínios, incluindo valor normalizado da soma das notas ponderadas pelos pesos.

Uma questão que surge naturalmente neste ponto da análise é: porque as soluçães propostas não foram de fato implantadas na RMB? Além dos custos de construção de vias e terminais e aquisição de equipamentos, existem, aparentemente, dois problemas que dificultam a implantação destas. $O$ primeiro é a inexistência de uma gerência institucionalizada para a mobilidade urbana da região metropolitana. Dentro do período considerado nesta pesquisa, foi criada e extinta a Empresa Metropolitana de Transportes Urbanos - EMTU. Algumas das atribuições desta empresa foram transferidas para a CTBel - Companhia de Transportes do Município de Belém (MERCÊS, 2004). O estudo de 2010 (JICA, 2010) traz uma proposta detalhada para a criação de um "Consórcio Público" para ser a entidade gestora do sistema de transportes da RMB. O outro problema é o não enfrentamento da questão da organização e regularização do conjunto de empresias operadoras do transporte coletivo, incluindo as devidas licitações. A tese de Mercês (2004) faz um relato extenso das relações entre os órgãos concedentes e os operadores. Existem interesses políticos e econômicos em jogo e a legislação dá margem a interpretações que impedem, nos tribunais, o poder público de tomar medidas que impliquem alterar as reservas de mercado das empresas de ônibus.

Apesar de quase todos os estudos destacarem o problema da excessiva concentração de atividades no centro da cidade de Belém e sugerirem que sejam desenvolvidas outras centralidades, as propostas são tímidas frente a um problema difícil de ser resolvido apenas pelo lado da oferta de transportes. É sempre aceita a inevitabilidade do crescimento da demanda de transportes e o consequente carregamento dos corredores, ao ponto de atingir a capacidade máxima de quase todas as opções de modos de transporte. No último estudo (JICA, 2010) chega-se a uma previsão de divisão modal com parcelas quase iguais para as viagens por transporte coletivo e por automóvel para o horizonte de 2025. Na prática, muito provavelmente, essas previsões não irão se concretizar, mas neste rumo se pode esperar grandes problemas de mobilidade. 
O foco principal é sempre o transporte motorizado por ônibus ou automóvel. Em uma cidade situada às margens de grandes rios com parte do território constituído de ilhas, praticamente se ignora 0 modo hidroviário. Não se pensa em alternativas não motorizadas, mesmo que seja para uma parcela menor das viagens. No relatório do PDTU-2001 (JICA, 2001) encontra-se a seguinte sentença: "Embora não esteja considerado na previsão de demanda futura, o modo bicicleta merece especial atenção dada a sua participação na divisão modal, 7,52 \% do total dos deslocamentos". Pode-se questionar que, se o modo merece atenção, e existe no presente, como a demanda desaparece no futuro? Não se percebe o mesmo cuidado em tratar da viagem completa, quando se trata do transporte não motorizado. Com a implantação das medidas propostas, a situação das calçadas e das vias para bicicletas melhoraria muito nos corredores principais. No entanto, a maior parte das viagens não inicia ou termina nesses corredores. Faltam propostas, mesmo que não sejam na forma de projetos ou anteprojetos detalhados, para melhorar as condições dos deslocamentos para além das novas estruturas dos corredores.

\subsection{O processo de planejamento de transportes e a mobilidade urbana sustentável}

Essa seção tem o objetivo de comentar, de modo geral, aspectos do planejamento da mobilidade urbana no Brasil. Para iniciá-la, parece conveniente analisar alguns trechos do Plano Diretor de Transporte Urbano e Mobilidade do Distrito Federal e Entorno (GDF, 2010), como segue (os grifos são do autor).

Do capítulo em que trata da modelagem da demanda:

Também é importante citar que em relação aos modos de viagem, a geração de viagens considerou apenas aquelas realizadas por modos que efetivamente ocupam espaço viário, desprezando-se as viagens realizadas por modos que não ocupam espaço viário de modo significativo. Assim, foram considerados os seguintes modos de viagem:

- Metrô;

- Ônibus;

- Micro-ônibus;

- Transporte de vizinhança;

- Van;

- Transporte fretado;

- Condutor de automóvel;

- Passageiro de automóvel;

- Táxi.

Por não ocuparem espaço significativo no sistema viário, não foram considerados os seguintes modos:

- Mototáxi;

- Moto;

- Passageiro de moto;

- Bicicleta;

- A pé;

- Outros.

Do capítulo intitulado "Recomendações Especiais para Melhoria da Mobilidade e Acessibilidade":

Os estudos e pesquisas efetuadas no âmbito do Plano Diretor de Mobilidade e Transporte Urbano evidenciam que: 
- os deslocamentos não motorizados (a pé e por bicicleta) constituem uma parcela significativa do total de viagens realizadas, sobretudo nos municípios do Entorno imediato (23\% no DF e $47 \%$ no Entorno);

- as viagens realizadas por modo individual pelos moradores do DF tem um peso importante - 50\% - no total de viagens motorizadas e, dado o crescimento da renda e da taxa de motorização na próxima década, esses percentuais manter-se-ão elevados;

Com base nisso, o Plano Diretor recomenda a adoção de medidas de curto, médio e longo prazo, contemplando os modos não motorizados, o transporte coletivo, o trânsito e o sistema viário.

$\cdots$

Em relação ao transporte não motorizado (pedestres e ciclistas), recomenda-se a adoção de medidas que visem o conforto e a segurança do cidadão, inclusive daquele com dificuldade de locomoção. Essas medidas, de baixo custo e curto prazo, contemplam construção de calçadas e ciclovias, implantação de passarelas e faixas de pedestres, além da adequação física dos espaços urbanos e edificações às normas de acessibilidade universal.

Quanto ao trânsito, em face do crescimento acentuado do volume de veículos, identifica-se a necessidade de preservar o funcionamento do sistema viário arterial em condições aceitáveis. Para isso, prevê-se investimentos nas vias de ligação, aumentando a capacidade operacional das mesmas ou criando trajetos alternativos. Nas vias urbanas, dadas as limitações óbvias de expansão da infraestrutura existente, propõe-se a realização de intervenções de modo a eliminar descontinuidades e os gargalos eventualmente existentes. É imperativo, também, otimizar o uso do sistema viário existente, o que exige a adoção de políticas de operação e fiscalização de trânsito, e o uso de recursos mais eficazes, tais como o a implantação do controle de tráfego por área e a supervisão da operação a partir de um Centro de Controle Operacional. Não menos importante é a definição e implantação de políticas de segurança de trânsito, estacionamento e movimentação de cargas, garantindo a melhor utilização do sistema existente e a minimização dos seus impactos. Todavia, face à impossibilidade de ampliação do sistema viário, sobretudo em áreas urbanas, pode vir a ser necessário adotar medidas restritivas para o tráfego geral.

A sigla adotada para este estudo de Brasília foi PDTU e isso é bem apropriado, pois o plano é muito semelhante aos antigos planos diretores de transportes. Aparecem conceitos novos, tratando de mobilidade e sustentabilidade, mas eles claramente não têm influência nas propostas finais. O Plano de Mobilidade de Belo Horizonte (BHTRANS, 2007, 2008, 2009, 2010a, b), por outro lado, seguiu uma linha diferente. $\mathrm{O}$ autor não tem informação sobre o processo de elaboração do mesmo e, desta forma, não se pode afirmar se houve um envolvimento da sociedade na identificação dos problemas e na proposta de soluções, ou se foi concebido e elaborado por um grupo de "déspotas esclarecidos", segundo classificação de Poli (2011). No diagnóstico encontra-se o seguinte texto:

O diagnóstico consolidado do sistema de mobilidade urbana de Belo Horizonte foi elaborado com o intuito de analisar as condições atuais dos diversos aspectos envolvidos em cada uma das componentes do sistema de mobilidade, relacionando-as com a configuração sócio-econômica e espacial da cidade.

- Nos últimos anos, o poder público de Belo Horizonte vem propondo algumas ações no sentido de tentar reverter a tradicional lógica de criação de facilidades para a utilização do automóvel. Dentre as medidas adotadas com o intuito de estimular o uso do transporte coletivo e dos modos não motorizados, pode-se destacar:

- A ampliação significativa das integrações físicas e tarifárias, inclusive com modalidades gerenciadas em outros níveis governamentais;

- As intervenções na rede de caminhamento (especialmente na Área Central);

- A criação de programa de incentivo ao uso de bicicleta como modo de transporte.

- Belo Horizonte tem plenas condições de reverter significativamente a lógica de seu sistema de mobilidade, desde que medidas efetivas sejam implementadas no sentido de incentivar a utilização de sistemas de transporte público e dos modos não motorizados. 
- Para a efetiva configuração de um sistema de mobilidade urbana, muitos problemas ainda terão de ser enfrentados, tanto no que se refere ao aspecto institucional, quanto em relação às questões físicas e operacionais do sistema.

No volume que trata do "Plano de Gerenciamento da Demanda e Diretrizes para Melhoria da Oferta" se encontram as propostas apresentadas a seguir.

\section{Divisão Modal:}

Embora seja um aspecto de fundamental importância para o sistema de mobilidade da cidade, a divisão modal requer ações específicas sobre cada uma das componentes do sistema. As metas associadas à divisão modal em Belo Horizonte apontam para uma maior racionalização da matriz de transportes do Município.

- Metas:

o Inverter a tendência observada em nível nacional de modo a, pelo menos, manter a participação atual do modo coletivo na matriz de viagens de Belo Horizonte e aumentar a participação dos modos não motorizados;

o Diminuir a participação do modo motorizado individual, especialmente nas viagens a trabalho e estudo.

- Política:

- As políticas deverão estar direcionadas para cada um dos componentes do sistema de mobilidade urbana.

\section{Automóvel Particular:}

Ultimamente, em função do preço e, particularmente, pela facilidade de crédito, a taxa de motorização tem apresentado tendência de elevado crescimento. A meta associada à utilização do automóvel particular consiste, portanto, em reduzir sua utilização na matriz de transporte do Município.

- Meta:

o Reduzir a utilização do automóvel, especialmente nas áreas mais congestionadas da cidade.

- Política:

o Implantar medidas de restrição ao uso do automóvel, especialmente na Área Central, que poderão incluir redução da capacidade do sistema viário destinado ao tráfego geral, redução do número de vagas de estacionamento disponíveis, rodízio de placas e taxa de uso da do sistema viário (pedágio urbano).

\section{Deslocamentos à Pé:}

Em relação à rede de caminhamento a pé, deverão ser criadas facilidades para os deslocamentos em todas as regiões da cidade, especialmente no que se refere à segurança e conforto.

- Metas:

- Criar facilidades para os deslocamentos a pé em toda a cidade;

- Fiscalizar o cumprimento das regras de acessibilidade (ABNT NBR 9050:2004) e do Código de Posturas do Município (Lei no 8.616 de 14 de julho 2003).

- Políticas:

- Propor melhorias nas calçadas, passeios, acessos às estações de metrô e BRT e nos pontos de travessia através do aumento do tempo de verde para os pedestres;

- Elevar os níveis de conforto e segurança para os pedestres (policiamento e iluminação pública) levando em conta os portadores de mobilidade reduzida;

- Propor medidas de moderação do tráfego e incentivar a expansão das áreas ambientais. 


\section{Bicicleta:}

A rede cicloviária atual de Belo Horizonte ainda é muito restrita. A implantação das novas rotas tenderá a estimular o crescimento da utilização deste modo, tanto como um sistema para deslocamentos entre sub-centros quanto para a alimentação do transporte coletivo.

- Metas:

- Elevar a participação do modo bicicleta para patamares compatíveis com a extensão da rede proposta para cada cenário. Segundo dados da pesquisa O/D de 2002, a participação atual é da ordem de 0,5\% em relação ao total de viagens realizadas diariamente, sendo que a média nacional é de $2,8 \%$ e a de cidades com mais de um milhão de habitantes é 0,9\%;

- Aumentar a integração com o transporte coletivo (do total de viagens realizadas por bicicleta em Belo Horizonte, somente em 1,73\% são realizadas integrações com o sistema de transporte coletivo por ônibus) e prever a implantação de paraciclos e esquemas de sinalização.

- Política:

- Propor a implantação de uma rede de ciclovias e ciclofaixas em todas as áreas do município, especialmente como modo alimentador dos sistemas de alta e média capacidade, prevendo a implantação de bicicletários junto às estações de integração.

\section{Estacionamento:}

Também os estacionamentos deverão ser utilizados como instrumentos para racionalização da matriz de transportes da cidade.

- Meta:

- Utilizar a oferta e o preço dos estacionamentos como instrumento de desestímulo ao uso do automóvel.

- Políticas:

- Eliminar ou restringir significativamente o número de vagas do estacionamento rotativo na Área Central e, se necessário, sobretaxar os estacionamentos privados nesta região da cidade.

Embora as propostas descritas acima fiquem restritas a Metas e Políticas diretamente ligadas ao sistema de transportes, não se pode negar que elas apontam para um caminho diferente daquele seguido pelos planos da RMB e do Distrito Federal. Infelizmente, parece que a maior parte dos planos acaba ficando mais para o formato daqueles preparados para essas duas últimas localidades. Uma leitura mais atenta do "Caderno de Referência para Elaboração de Plano de Mobilidade Urbana" (MCIDADES, 2007h) permite descobrir inclusive que mesmo este manual pode levar à preparação de "Planos de Mobilidade" que não diferem muito dos "Planos Diretores de Transportes Urbanos" de 30 anos atrás. Ele representa um avanço, mas faz concessões e deixa margem para abordagens que, muito provavelmente, não passavam pela mente de quem trabalhou na preparação do documento.

A comparação de exemplos positivos com exemplos negativos e mesmo com diretrizes para um novo modelo de planejamento que reproduzem ou reforçam falhas do planejamento tradicional aponta para algumas questões gerais, que devem ser aqui evidenciadas e discutidas. De maneira geral (e, portanto, para além do caso de Belém), os seguintes pontos podem ser destacados em uma análise crítica de natureza essencialmente qualitativa: 


\section{Os profissionais da área}

A formação de boa parte dos profissionais da área de transportes do Brasil tem origem no GEIPOT, na EBTU e em instituições estaduais ou municipais, como a Companhia de Engenharia de Tráfego de São Paulo, as companhias dos metrôs de São Paulo e Rio de Janeiro e a colaboração com algumas grandes universidades. A partir da formação de um grupo maior e da colaboração com instituições de outros países foi possível consolidar a área e, mesmo, planejar seus próprios rumos. O modelo de planejamento de transportes "tradicional" ainda está forte na cultura dos técnicos da área.

\section{Boas práticas?}

Outro aspecto importante diz respeito à questão do financiamento para a preparação dos planos e, principalmente, da implantação das propostas. Existe uma interferência forte das agências internacionais (BIRD, BID, JICA, ...) $)^{8}$ para que o os estudos sejam feitos de acordo com os seus manuais. Antes de seguir a carreira acadêmica, o autor teve a oportunidade de trabalhar na Prefeitura de Fortaleza, sede de uma das maiores regiões metropolitanas brasileiras. Ele participou de discussões em que a equipe local teve que aceitar soluções impostas por consultores que pouco entendiam do problema local. Mesmo a relação com a EBTU não era das melhores, já que as soluções "vindas de Brasília", às vezes, não faziam muito sentido. Na época, Curitiba era o grande sucesso e as "boas práticas" de lá eram sempre citadas. No entanto, nem tudo em Curitiba era perfeito. Evidentemente, os erros não deveriam ser copiados e, infelizmente, isto nem sempre ocorria.

\section{O automóvel}

Banister (2002, 2005), Poli (2011), Owens e Cowell (2011), entre vários outros autores tratam da dificuldade de reduzir a participação do automóvel no transporte das pessoas. Enquanto existem iniciativas mais ou menos tímidas, de instituições governamentais e não governamentais, no sentido de alertar a sociedade para o uso exagerado do automóvel, do outro lado, a máquina de publicidade da indústria automobilística nem se incomoda. As propagandas mostram o automóvel como um símbolo de tudo que há de bom. A maioria dos planos acaba caindo no caso do PDTU do Distrito Federal recomendando que "pode vir a ser necessário" adotar algum tipo de restrição ao seu uso. Esta é, no entanto, uma medida antipática, o que é particularmente relevante se observado que os ditos "formadores de opinião" são frequentemente usuários do modo automóvel.

A questão do uso do veículo individual privado aparece até quando se faz o estudo de viabilidade econômica. No caso da RMB, e isso é mais regra do que exceção, a principal parcela dos benefícios gerados por um determinado projeto é aquela proveniente da redução do custo do tempo de viagem. O valor do tempo das pessoas é calculado com base na renda média das mesmas. As pessoas de famílias que possuem um ou mais automóveis têm renda mais alta. Assim o tempo dessas pessoas é mais valioso. Consequentemente, os projetos que beneficiam a circulação dos automóveis, melhorando a fluidez, têm maior chance de produzir uma boa relação benefício-custo.

\footnotetext{
${ }^{8}$ BIRD - Banco Internacional para Reconstrução e Desenvolvimento que juntamente com a Associação Internacional de Desenvolvimento (AID) compõem o Banco Mundial.

BID - Banco Interamericano de Desenvolvimento

JICA - Agência de Cooperação Internacional do Japão
} 
É preciso ficar claro que não existem recursos (dinheiro, espaço, ambiente, ...) para que todas as pessoas utilizem o automóvel para todas as suas atividades. No momento, parece que os técnicos locais encontraram uma forma de transferir a responsabilidade no que diz respeito ao aumento da frota de veículos particulares motorizados. O problema seria a redução de impostos e melhoria das condições de financiamento promovidas pelo Governo Federal que, além disso, parece ter sido associada um aumento da renda média da população. O resultado é que mais pessoas conseguem comprar um automóvel e ampliam os congestionamentos das vias. Existe, é claro, uma correlação entre posse e uso do veículo, mas também existe o direito das pessoas de adquirir o bem que desejarem e que estiver dentro de sua capacidade financeira. Basta que técnicos e tomadores de decisão locais trabalhem para prover uma estrutura de mobilidade que privilegie os modos não motorizados e o transporte público e deixem de dedicar tanto tempo ao problema da circulação dos automóveis. Com o tempo, se eles fizerem o que Ihes cabe, as pessoas nem vão se interessar tanto na compra de um automóvel.

\section{A participação da população}

A participação efetiva da sociedade no processo de planejamento da mobilidade é fundamental para que se chegue a um produto aceito, se não por todos, pelo menos pela maioria. Isso garante, em boa parte, o sucesso do plano que não seria o plano deste ou daquele prefeito ou governador ou instituição. Seria fruto da negociação com a participação de todos. O Manual do PlanMob (MCIDADES, 2007h), por exemplo, enfatiza bem essa necessidade. Poli (2011), por outro lado, chega a questionar a validade da aprovação desse tipo de plano baseada na vontade da autoridade que detém, naquele momento, a maioria do poder. A justificativa é a de que as decisões tomadas terão efeito que ultrapassam o período de mandato dessas pessoas e, na opinião daquele autor, deve-se sempre procurar um consenso.

A análise de um problema e a busca de uma solução de consenso, reunindo pessoas com as mais variadas formações e interesses, não é, no entanto, um processo fácil. Especialistas não podem esperar que todos entendam ou utilizem o jargão próprio das suas áreas de atuação. Para alguns, parece um tempo desperdiçado, mas isso contribui para a qualidade do que vai ser produzido. Além disso, existem, com certeza, outras etapas que vão demandar muito mais tempo.

Muitas vezes o que se chama de participação se caracteriza como um trabalho de convencimento da população de que o grupo que preparou o plano sabe quais são as necessidades dela e as melhores soluções. São reuniões e audiências públicas em que se trava uma luta desigual entre um lado com todas as informações e capacidade de mostrar um "produto" atraente e o outro que, basicamente, sabe dos problemas que enfrenta no dia a dia. A produção da informação tem um custo, geralmente alto, mas é quase sempre produzida com recursos públicos. Nada mais correto do que a disponibilização desses dados para todos. Isso possibilita o acompanhamento das propostas e resultados e, com o tempo, facilita o entendimento e a proposta de melhores soluções. 


\title{
$\underline{\text { Monitoramento }}$
}

Do "Relatório Etapa 5 - Plano de Implantação, Gestão e Monitoramento" do PlanMob-BH (BHTRANS, 2010a) tem-se:

\begin{abstract}
Mais importante que o monitoramento do andamento do processo de implantação das intervenções propostas para cada cenário, uma vez que estas dependem de diversos fatores muitos dos quais estão fora do controle dos planejadores do sistema de mobilidade da cidade, é o acompanhamento do grau em que os objetivos traçados para o sistema vão sendo alcançados em função da implantação das medidas propostas.

$\cdots$

Portanto, o sistema de monitoramento proposto toma como referência cada um dos objetivos estratégicos traçados para o Sistema de Mobilidade de Belo Horizonte, buscando avaliar, através dos indicadores propostos, o grau de alcance de cada um dos objetivos estratégicos definidos para o sistema de mobilidade urbana.
\end{abstract}

Monitorar os resultados e corrigir os rumos de um plano como esse pode ser um dos aspectos que pode garantir o sucesso da implantação das medidas propostas e atingir as metas desejadas. Foram propostos 28 indicadores que, logicamente, são muito semelhantes àqueles dos métodos utilizados nesta pesquisa (COSTA, 2008; MACHADO, 2010; MOBILIZE, 2011). Provavelmente não existe um índice, ou conjunto de indicadores, ideal para avaliar a mobilidade urbana sustentável. Black (2010) chega a sugerir que, na falta de mais indicadores, bastaria utilizar a quantidade total de milhas percorridas pelo conjunto dos veículos da área analisada. É o que, no Brasil, alguns autores chamam de momento de transportes (veículo $\times \mathrm{km}$ ). Segundo aquele autor, este indicador teria uma considerável correlação com vários outros indicadores normalmente utilizados. A ação de monitoramento já representa muito. O conjunto de indicadores pode ser ajustado ao longo do próprio processo.

\section{A "mão invisível" do mercado}

Nas últimas décadas espalhou-se a ideia de que a iniciativa privada teria condições muito melhores de operar serviços públicos, como o de transportes, inclusive reduzindo custos. A participação do Estado deveria ser mínima. O poder público não se preocuparia nem mais em saber quando custa a produção do serviço. Este seria contratado em leilões, nos quais vencem as empresas que apresentam uma proposta de tarifa mais baixa ou algo similar. Surgem também as Parcerias PúblicoPrivadas que, para alguns, pode ser o remédio para todos os males.

No sistema de transporte público, por exemplo, existem parcerias público-privadas há décadas. As empresas que operam os serviços de ônibus nas cidades brasileiras são privadas, na sua imensa maioria. O que o poder público não pode fazer é abrir mão de um rigoroso controle do serviço que é prestado. Isso inclui, na opinião deste autor, o conhecimento de quanto custa o serviço. A chamada "mão invisível do mercado" não tem dado conta de equilibrar preços e tornar as relações mais justas.

\section{O uso do solo}

A geração de viagens está ligada diretamente às atividades que se desenvolvem no território de uma cidade. Para acontecerem, essas atividades precisam de infraestrutura, que pode crescer dentro de 
certos limites físicos, econômicos e ambientais. Sem controle, o uso do solo entra no círculo vicioso apresentado na Figura 1-1, o que caracteriza, no caso dos transportes, o "prever e prover" sem fim. Dado que os recursos são finitos, isso tem que ter um fim. Parece, no entanto, que muitos não sabem, ou não se importam com isso.

As grandes cidades apresentam maiores problemas e, consequentemente, mais recursos são destinados à tentativa de resolvê-los, o que acaba por torná-las, mesmo que temporariamente, mais atrativas. As pessoas mudam para essas cidades em busca de melhores condições de vida e, aos poucos, esse processo congestiona os serviços, que voltam a piorar. Nessas cidades moram milhões de eleitores e um importante indicador de sucesso de um administrador é conseguir se reeleger ou conseguir a vitória de um correligionário. Nesse aspecto, no Brasil, as capitais dos estados padecem mais deste problema, pois constituem palco para a disputa de eleições, tanto municipais quanto estaduais.

\section{Tendências}

Ao contrário do que alguns possam acreditar, em virtude das desigualdades que afetam a mobilidade urbana, é quase impossível desenvolver um processo em que todos ganhem. Se o sistema está desequilibrado, a busca do equilíbrio sempre vai produzir ganhadores e perdedores. Considerando o problema de um ponto de vista otimista, pode-se argumentar que esses "perdedores" estarão trocando, por exemplo, as vantagens do uso de um automóvel pelo privilégio de viver em um mundo mais equilibrado, menos poluído. A ideia é a de que, neste caso, muitos dos usuários deixarão de sentir a necessidade da posse de um automóvel ou, pelo menos, do seu uso para todos os deslocamentos. O caminho deve passar por um processo de negociação, onde cada grupo consiga expressar sua percepção do problema e defender suas propostas de solução. Todos os cuidados devem ser tomados para garantir equilíbrio na oportunidade de defesa dos interesses. Como lembra Napier (2003), em uma referência à capacidade do poder econômico para influenciar as decisões, “... money talks". Além do "poder do dinheiro", o autor cita os interesses políticos e profissionais.

É cada vez maior o número de autores propondo uma abordagem que, ao contrário de tentar prever o futuro, estabeleça uma proposta de um "futuro desejável" (BANISTER, 2005; BANISTER; HICKMAN; STEAD, 2008; MANCINI, 2011; POLI, 2011). A ideia é a de projetar cenários futuros, com alguma variação do conjunto de expectativas, mas buscando um consenso do que seria o desejável para a sociedade local. O Plano de Mobilidade seria desenvolvido sobre propostas de medidas para direcionar o sistema para a configuração desejada. Essa abordagem livra a equipe de planejamento da tarefa nada simples de prever o futuro, o que ocorre nos processos de "prever e prover". Além disso, conforme destaca Poli (2011), o procedimento de montagem dos cenários ajuda a tornar mais explícitos os interesses de cada grupo. Um exemplo deste tipo de abordagem é o projeto Vision2030 (2012), que trabalha a visão de um futuro com mobilidade sustentável. No seu sítio da Internet podese ler:

O envolvimento da população no processo de visualizar o futuro é prioridade chave, e uma coleção de ferramentas de participação possibilitará às pessoas narrarem suas próprias estórias com ou sem a visão de especialista, assim, abrindo a possibilidade de um conjunto de visões rico e extenso, apoiado em experiências reais. (tradução do autor) 


\section{CONCLUSÕES E RECOMENDAÇÕES}

Ao final desta pesquisa, pode-se afirmar que ela respondeu algumas perguntas e abriu muitas outras. Foi possível agregar novos conhecimentos à experiência do autor, o que serviu para derrubar um ou outro preconceito, confirmar velhas ideias e trazer outras novas. Foi um longo trabalho de leitura das muitas publicações existentes sobre o assunto, nem todas elas citadas na lista da próxima seção. A disponibilidade da Internet facilita muito o trabalho, mas também gera uma dose excessiva de informação. O estudo teórico dos métodos de planejamento foi complementado com a análise dos relatórios de planos de transportes de cidades ou regiões metropolitanas brasileiras, com uma menor parcela do tempo dedicado à leitura de planos e manuais portugueses.

Os métodos de planejamento de transportes, aqui denominados "tradicionais", existem desde as décadas de 1950/1960 e apresentaram grande evolução dos procedimentos utilizados para coleta e tratamento de informações, diagnóstico, geração de alternativas e proposição de soluções. Quase tão antigas quanto esses métodos são as críticas quanto a maneira como tratam o problema e o tipo de resultado que pode vir de suas propostas. A publicação de um trabalho como o relatório Traffic in Towns (REINO UNIDO, 1963) ${ }^{9}$, que chegou a ser editado e vendido em formato popular, gerou uma resposta no formato do livro Towns Against Traffic (PLOWDEN, 1972). Este último é considerado como um dos primeiros a analisar o problema antepondo os conceitos de "prever e prover" e "prever e prevenir". Esta seria a crítica fundamental ao modelo tradicional de planejamento que, grosso modo, analisa o comportamento atual da demanda, relacionando-a com um determinado cenário socioeconômico, projeta este cenário em um determinado horizonte e, a partir dele, avalia a necessidade ou não de ampliação da infraestrutura. O problema é que sempre aparece a necessidade de ampliar a infraestrutura quando se adota o transporte motorizado, principalmente o automóvel, como principal elemento do sistema.

Nas últimas três décadas, a sociedade vem cada vez mais se preocupando com a questão do meio ambiente. $\mathrm{O}$ assunto é polêmico e quase todas as pessoas têm alguma ideia do que se trata e alguma proposta de ação. Com essa preocupação passa a chamar a atenção o sistema de transportes, um dos grandes responsáveis pela poluição ambiental e consumo de recursos não renováveis. Todos concordam que é preciso mudar, mas como fazer isso?

\footnotetext{
9 Este trabalho também é conhecido como "Relatório Buchanan", considerando o engenheiro e arquiteto britânico Colin Buchanan, que foi o membro da equipe técnica que recebeu maior destaque.
} 
Surgem então propostas de mudanças nos procedimentos de planejamento dos transportes. Alguns autores passam a usar mobilidade no lugar de transportes, justificado pela maior abrangência da abordagem dos problemas e propondo a ênfase na análise das necessidades das pessoas e não no reforço da infraestrutura de transportes. O uso desses termos acaba gerando certa confusão. Poli (2011) chega dizer que o certo seria tratar de planos de acessibilidade. Pelo menos no Brasil, a palavra acessibilidade está mais ligada à parte física de acesso a veículos e edificações, com foco principal nas pessoas com deficiências (ou, de maneira mais geral, com restrições de mobilidade). 0 termo acessibilidade também pode ser usado para avaliar a distância que uma pessoa se encontra do serviço de transporte público.

No caso brasileiro, a mudança de paradigma para o planejamento da mobilidade urbana foi assumida e liderada, por algum tempo, pelo Ministério das Cidades que, conforme apresentado no Capítulo 2, editou uma série de cadernos de referência para incentivar e orientar a preparação dos novos planos. Estes documentos reforçam as ideias de sustentabilidade e da participação da população no processo de planejamento, mas aquele que trata da preparação de planos de mobilidade urbana (MCIDADES, 2007h) acaba deixando abertura para que sejam seguidas suas orientações e se produza um plano tradicional. Permanece nele o conceito de "prever e prover".

Para qualquer que seja a maneira de planejar, é preciso que o sistema seja constantemente monitorado para verificar os resultados e compará-los com o previsto. Assim, detectam-se necessidades de correção de rumo e se mantém atualizada uma base de informações para quando for necessária uma revisão do plano. Para isso, é fundamental que se estabeleça um conjunto de indicadores para avaliação dos vários aspectos da mobilidade. A revisão da literatura incluiu a análise de algumas propostas de utilização de indicadores para a avaliação da mobilidade urbana sustentável. Uma das propostas desta pesquisa foi a utilização desse tipo de ferramenta para a avaliação da mobilidade de uma cidade em cenários representando diferentes períodos de tempo.

A localidade selecionada foi a Região Metropolitana de Belém, no norte do Brasil. Estavam disponíveis para a análise relatórios de nove estudos relativos ao sistema de transportes, cobrindo o período de 1978 a 2010. Apesar de todos esses estudos e planos, a população da RMB tem muitas reclamações quanto à qualidade da mobilidade urbana. A etapa de análise dos estudos e identificação dos dados disponíveis compreendeu, além da leitura dos relatórios, uma visita a Belém e interação com a equipe de professores e alunos da UFPA que se ocupou, principalmente, da obtenção de dados relativos à situação presente.

Da leitura dos planos pode-se verificar o uso de métodos tradicionais de planejamento, com algumas variações quanto ao tratamento dos modos não motorizados. $\mathrm{Na}$ base de vários desses estudos estão extensos levantamentos de dados, incluindo três pesquisas domiciliares para levantamento de padrões da demanda. Os planos mais recentes repetem propostas dos mais antigos, pois estas não "saíram do papel". O uso do exemplo das "boas práticas" faz com que, aparentemente, as soluções copiadas de Curitiba ou Bogotá já estejam estabelecidas antes mesmo do levantamento dos problemas. Todavia, para se copiar uma dessas duas cidades é preciso mexer com o arranjo operacional das empresas de ônibus e isto nunca ocorre, o que acaba levando a propostas tímidas 
para resolver os grandes problemas. O produto termina por se caracterizar mais como um estudo de racionalização da operação do transporte público e do trânsito, do que um instrumento para tratar de modo eficaz as deficiências da mobilidade urbana. Falta também uma entidade de gestão metropolitana, para compatibilizar as ações das administrações municipais e do Governo do Estado, que dividem a responsabilidade pela provisão da mobilidade urbana.

A partir do conjunto de estudos e de um primeiro levantamento de dados, organizou-se um conjunto de quatro cenários centralizados nos anos de 1980, 1991, 2001 e 2011. Para cada um deles foi estimado o valor do Índice de Mobilidade Urbana Sustentável - IMUS (COSTA, 2008). Não foi possível obter dados para o cálculo de todos os indicadores (87) para os cenários, mesmo para o cenário "2011" do qual se calculou 64 indicadores. O valor do IMUS, que pode variar de 0 a 1, neste estudo foi de 0,25 para 1980, 0,30 para 1991, 0,40 para 2001 e 0,38 para 2011, quando considerados todos os indicadores de cada cenário. Para fazer uma comparação mais justa, o cálculo foi refeito considerando apenas os 36 indicadores para os quais se dispunha de dados em todos os cenários. Deste modo, os valores obtidos foram $0,23,0,24,0,30$ e 0,33 , respectivamente. Verifica-se uma melhoria contínua da qualidade da mobilidade urbana sustentável, mas os resultados são ruins, quando comparados com valores obtidos para outras cidades brasileiras. Os dados dos cenários foram avaliados usando dois métodos semelhantes. O método do Mobilize (2011) produziu resultados que repetem a tendência da primeira aplicação do IMUS, isto é, a melhoria contínua, mas a queda para o último cenário. No caso do IMS (MACHADO, 2010) o cenário melhor avaliado foi o "1991". Esses dois métodos utilizam um conjunto menor de indicadores e a falta de um ou outro deles pode afetar bastante o resultado.

A próxima análise considerou as propostas dos planos. Para avaliar o possível efeito na qualidade da mobilidade urbana, o autor atribuiu notas a elas, considerando a estrutura de Domínios e Temas do IMUS. Em um primeiro momento, foi feita a comparação entre os planos utilizando as notas totais. A pontuação foi crescendo desde o primeiro deles (GEIPOT, 1978) até chegar aos Planos Diretores (JICA, 1991, 2001). A seguir, nas atualizações do PDTU-2001, ocorreu um retrocesso, não em termos tecnológicos, mas de integração geral do sistema e a nota diminuiu. Em seguida, foi feito o exame das contribuições do conjunto de estudos para atender os requisitos dos Domínios do IMUS. Verificou-se que os maiores ganhos seriam aqueles referentes ao Domínio "Aspectos Políticos", com valor normalizado igual a 1, vindo a seguir "Infraestrutura de Transportes", com 0,961. A pior contribuição se refere ao Domínio "Aspectos Ambientais".

No caso do retrocesso observado após o PDTU-2001, a questão da integração do transporte público assumiu importância fundamental. As estratégias operacionais evoluíram gradativamente dos sistemas tradicionais (linhas radiais, diametrais e circulares) para propostas de sistemas troncoalimentados, passando por simples linhas troncais. Na última proposta se optou pela operação conjunta, não integrada, de um sistema tronco-alimentado e um convencional. A existência destes dois subsistemas pode ser benéfica, até porque a cobertura do primeiro não abrange toda a área da RMB. O que falta, no entanto, é a possibilidade de integração tarifária entre os dois. Isso poderia trazer ganhos de qualidade do serviço para os usuários e aumento da demanda, já que um sistema 
com melhor integração abre novas possibilidades de viagens a preços acessíveis. Mais ainda, com os recursos tecnológicos hoje disponíveis, a implantação de esquemas de integração tarifária nem mesmo exigiria a adoção de uma tarifa única.

Na comparação entre Domínios, a primeira colocação para o Domínio "Aspectos Políticos" reflete a atenção dada à melhor organização das ações voltadas para o sistema de transportes, incluindo a cooperação entre os diferentes níveis de governo e o setor privado. A maior parte dos recursos financeiros previstos nos estudos e planos diz respeito à melhoria ou implantação de infraestrutura, principalmente, vias. Nessas mesmas vias, as obras incluem a melhoria ou implantação de calçadas e ciclovias, o que coloca em uma boa posição o Domínio "Modos Não Motorizados". Deve-se destacar a posição intermediária dos Domínios "Sistema de Transporte Urbano" e "Acessibilidade", porque eles tratam do transporte público, cuja melhoria é um dos principais objetivos declarados em praticamente todos os estudos. Embora a preocupação com os impactos ambientais causados pelo sistema de transportes esteja presente em todos os estudos, as propostas não contemplaram bem esta questão. O discurso de melhoria do meio ambiente começou de maneira mais moderada nos primeiros planos e foi ganhando mais força ao longo do tempo, até mesmo pelas exigências, cada vez maiores, da legislação nacional e local. Apesar disso, no conjunto dos planos o Domínio "Aspectos Ambientais" foi, comparativamente, o menos importante.

A falha em se apresentar propostas que viabilizem uma mobilidade mais sustentável ocorre, principalmente, pela resistência em se adotar medidas que limitem o uso do automóvel. A cultura, que se reflete até nos modelos de previsão de demanda utilizados, é a de que o aumento da renda da população implica em uma mudança do modo de transporte utilizado. Grosso modo, se a economia da localidade melhora e as pessoas passam a receber melhores salários, estima-se que uma parcela das que usam transporte público passará a usar automóvel.

O uso de um sistema de indicadores como IMUS se mostrou de grande utilidade para a avaliação das condições da mobilidade urbana sustentável dos diferentes cenários, com a possibilidade de identificação de pontos fortes e fracos. Verificou-se a necessidade de organização de processos de coleta, tratamento e disponibilização de dados para alimentar o cálculo dos indicadores. Alguns desses processos podem ser automatizados, mas é preciso investir nas instituições públicas que requerem instalações e pessoal qualificado para acompanhar a preparação do plano de mobilidade e a sua implantação.

\section{$\underline{\text { Recomendações }}$}

O caminho à frente parece recomendar a abordagem do "prever e prevenir" e a consideração mais cuidadosa da relação da mobilidade com as demais atividades urbanas. Nessa linha, encontra-se o uso de cenários para estabelecer um futuro desejável e a construção de planos para atingi-lo. Essa é uma das áreas que merece a dedicação de mais pesquisadores e a aplicação prática. A recémaprovada lei de diretrizes para a Política Nacional de Mobilidade Urbana (BRASIL, 2012) requer que todos os municípios com população maior do que 20.000 habitantes preparem seus Planos de Mobilidade Urbana. Isso pode produzir um excelente laboratório para avaliar novos métodos. É bom lembrar que não existem recursos financeiros para a produção de estudos tradicionais. 
Para baratear a obtenção de informações para o planejamento e o monitoramento da mobilidade, devem ser pesquisadas novas formas de levantamento de dados e, principalmente, de aproveitamento de dados secundários. Isso abrange o uso de ferramentas da estatística tradicional ou espacial, mineração de dados, sistema de informações geográficas, etc. Também é preciso que se encontrem maneiras acessíveis de avaliação de indicadores de poluição atmosférica e sonora, principalmente para as cidades maiores. Isto envolve até mesmo a avaliação dos efeitos provocados e de quais seriam as situações de equilíbrio. Algumas situações podem desafiar o senso comum. $O$ excesso de automóveis, normalmente um indicador negativo, pode crescer e chegar a níveis que o tornariam benéfico por determinados pontos de vista como, por exemplo, a poluição sonora, que tende a diminuir. O número e gravidade dos acidentes também seriam bastante reduzidos em situações de congestionamento.

Além da caixa de ferramentas numéricas acima, é preciso que se reforce o estudo e a aplicação de ferramentas de comunicação e de tomada de decisão que insiram, efetivamente, a sociedade no processo de planejamento da mobilidade. 



\section{REFERÊNCIAS}

AGYEMAN, J.; EVANS, T. Toward just sustainability in urban communities: Building equity rights with sustainable solutions. Annals of the American Academy of Political and Social Science, v. 590, n., p. 35-53, 2003.

ANP. Anuário Estatístico 2001. Agência Nacional de Petróleo, 2001. Disponível em: http://www.anp.gov.br/?pg=15280. Acesso em: 25/6/2012.

ANP. Anuário Estatístico 2010. Brasília: Agência Nacional de Petróleo, 2011.

ANTP. Maiores Cidades - Dados de 2007. São Paulo: Associação Nacional de Transportes Públicos, 2008. Disponível em: http://portal1.antp.net/site/simob/Downloads/Dados\%20maiores\%20G43\%20-\%202007.pdf. Acesso em: 26/06/2012

ANTP. Custos de Mobilidade - Dados de Março de 2010. São Paulo: Associação Nacional de Transportes Públicos, 2010a. Disponível em:

http://portal1.antp.net/site/simob/Downloads/Custos\%20da\%20Mobilidade\%20\%20mar\%C3\%A7o\%20de\%202010.pdf. Acesso em: 26/06/2012

ANTP. Maiores Cidades - Dados de 2009. São Paulo: Associação Nacional de Transportes Públicos, 2010b. Disponível em:

http://portal1.antp.net/site/simob/Downloads/Dados\%20maiores\%20G43\%20-\%202009.pdf. Acesso em: 26/06/2012

ANTP. Maiores Cidades - Dados de 2010. São Paulo: Associação Nacional de Transportes Públicos, 2011a. Disponível em:

http://portal1.antp.net/site/simob/Downloads/Dados\%20maiores\%20G45\%20-\%202010.pdf. Acesso em: 26/06/2012

ANTP. Relatório Geral 2010. São Paulo: Associação Nacional de Transportes Públicos, $2011 b$. Disponível em: http://portal1.antp.net/site/simob/Downloads/Relat\%C3\%B3rio\%20Geral\%202010.pdf. Acesso em: 26/06/2012

ANTP. Tarifas de 2005 a 2012. São Paulo: Associação Nacional de Transportes Públicos, 2012. Disponível em: http://portal1.antp.net/site/simob/Downloads/Tarifas\%20de\%202005\%20a\%202012.pdf. Acesso em: 26/06/2012

ARY, J. C. A. Instruções para Planejamento. Brasília: Empresa Brasileira de Planejamento de Transportes - GEIPOT, 1984. (Estudos de Transporte Cicloviário)

AZEVEDO FILHO, M. A. N. D. Índice de Mobilidade Urbana Sustentável - Google Map. 2012. Disponível em: http://goo.gl/maps/1FGR. Acesso em: 11/07/2012.

AZEVEDO FILHO, M. A. N. D.; PINHEIRO, A. M. G. S.; SORRATINI, J. A.; MACÊDO, M. H.; RODRIGUES DA SILVA, A. N. Disponibilidade e Qualidade dos Dados para Avaliação das Condições de Mobilidade Urbana Sustentável. In: XXV Congresso de Pesquisa e Ensino em Transportes, 2011, Belo Horizonte. ANPET, p. 1-12. 
BANISTER, D. Transport Planning. 2.ed. London: Taylor \& Francis, 2002. (Transport, Development and Sustainability)

BANISTER, D. Unsustainable Transport: City transport in the new century. London: Routledge, 2005. (Transport, Development and Sustainability)

BANISTER, D. Sustainable transport: challenges and opportunities. Transportmetrica, v. 3, n. 2, p. 91-106, 2007.

BANISTER, D. The sustainable mobility paradigm. Transport Policy, v. 15, n. 2, p. 73-80, 2008.

BANISTER, D.; HICKMAN, R.; STEAD, D. Looking over the horizon: visioning and backcasting. In: Perrels, A., Himanen, V., et al (Ed.). Building blocks for sustainable transport: obstacles, trends, solutions. Bingley: Emerald, 2008. p.25-53.

BASTOS, M. L. D. L. Tratamento de Interseções. Brasília: Empresa Brasileira de Planejamento de Transportes - GEIPOT, 1983. (Estudos de Transporte Cicloviário)

BASTOS, M. L. D. L. Estacionamento. Brasília: Empresa Brasileira de Planejamento de Transportes - GEIPOT, 1984a. (Estudos de Transporte Cicloviário)

BASTOS, M. L. D. L. Trechos Lineares. Brasília: Empresa Brasileira de Planejamento de Transportes - GEIPOT, 1984b. (Estudos de Transporte Cicloviário)

BHTRANS. Diagnóstico Preliminar do Sistema de Mobilidade Urbana de Belo Horizonte. Belo Horizonte: Prefeitura de Belo Horizonte. Empresa de Transportes e Trânsito de Belo Horizonte S.A., 2007.

BHTRANS. Diagnóstico e Prognóstico Preliminar. Plano de Mobilidade Urbana de Belo Horizonte. Belo Horizonte: Prefeitura de Belo Horizonte. Empresa de Transportes e Trânsito de Belo Horizonte S.A., 2008.

BHTRANS. Plano de Gerenciamento da Demanda e Diretrizes Para Melhoria da Oferta Revisão. Plano de Mobilidade Urbana de Belo Horizonte. Belo Horizonte: Prefeitura de Belo Horizonte. Empresa de Transportes e Trânsito de Belo Horizonte S.A., 2009.

BHTRANS. Plano de Implantação, Gestão e Monitoramento. Plano de Mobilidade Urbana de Belo Horizonte. Belo Horizonte: Prefeitura de Belo Horizonte. Empresa de Transportes e Trânsito de Belo Horizonte S.A., 2010a.

BHTRANS. Plano de Melhoria da Oferta. Plano de Mobilidade Urbana de Belo Horizonte. Belo Horizonte: Prefeitura de Belo Horizonte. Empresa de Transportes e Trânsito de Belo Horizonte S.A., 2010b.

BLACK, J. A.; PAEZ, A.; SUTHANAYA, P. A. Sustainable Urban Transportation: Performance Indicators and Some Analytical Approaches. Journal of Urban Planning and Development, v. 128, n. 4, p. 184-209, 2002.

BLACK, W. R. Sustainable Transportation: Problems and Solutions. 3.ed. New York: Guildorf, 2010.

BOARETO, R. A política de mobilidade urbana e a construção de cidades sustentáveis: Santa Maria, 2008, 73-92 p.

BRASIL. Constituição da República Federativa do Brasil. Brasília. 1988. Disponível em: http://www.planalto.gov.br/ccivil_03/constituicao/constitui\%C3\%A7ao.htm. Acesso em: 29/11/2011

BRASIL. Estatuto da Cidade, Lei $\mathbf{n}^{\circ}$ 10.257. Brasília. 2001. Disponível em:

http://www.planalto.gov.br/ccivil_03/leis/LEIS_2001/L10257.htm. Acesso em: 03/09/2011 
BRASIL. Lei $\mathrm{n}^{\circ}$ 12.587, de 03 de janeiro de 2012. Institui as diretrizes da Política Nacional de Mobilidade Urbana e dá outras providências. Brasília. 2012. Disponível em:

http://www.planalto.gov.br/ccivil_03/_Ato2011-2014/2012/Lei/L12587.htm. Acesso em: 06/01/2012

BUCHANAN, M. More or less traffic in towns? Proceedings of the Institution of Civil EngineersTransport, v. 157, n. 1, p. 27-41, 2004.

CALIPER (Ed.). TransCAD - Transportation Planning Software - Version 5.0 GIS User's Guide. Newton: Caliper Corporation, 2007.

CML. Lisboa: O desafio da mobilidade. Colecção de Estudos Urbanos - Lisboa XXI. Lisboa: Câmara Municipal de Lisboa. Licenciamento Urbanístico e Planeamento Urbano., 2005.

COHEN, M. J. Destination unknown: Pursuing sustainable mobility in the face of rival societal aspirations. Research Policy, v. 39, n. 4, p. 459-470, 2010.

COSTA, M. D. S. Um Índice de Mobilidade Urbana Sustentável. Tese (Doutorado). Escola de Engenharia de São Carlos, Universidade de São Paulo, São Carlos, 2008.

COSTA, M. D. S.; RODRIGUES DA SILVA, A. N. Caracterização da Mobilidade Urbana Sustentável em Contextos Distintos com Recursos de MCDA-C. In: XX Congresso de Pesquisa e Ensino em Transportes, 2006, Brasília. ANPET, p. 817-828.

COSTA, V.; SOARES, T. Estudo de Mobilidade da População Residente no Concelho de Braga Relatório Final. Braga: Transportes Urbanos de Braga, 2007.

CURTIS, C. Planning for sustainable accessibility: The implementation challenge. Transport Policy, v. 15, n. 2, p. 104-112, 2008.

DA ASSUNÇÃO, M. A. Indicadores de Mobilidade Urbana Sustentável para a Cidade de Uberlândia, MG. Dissertação (Mestrado). Faculdade de Engenharia Civil, Universidade Federal de Uberlândia, Uberlândia, 2012.

DATASUS. Informações de Saúde. Ministério da Saúde, 2012. Disponível em: http://www2.datasus.gov.br/DATASUS/index.php?area=02. Acesso em: 02/07/2012.

DENATRAN (Ed.). Anuário Estatístico de Acidentes de Trânsito - 2001. Brasília: Departamento Nacional de Trânsito, 2002.

DERMAN, E. Models Behaving Badly. Why Confusing Illusion with Reality can Lead to Disaster, on Wall Street and in Life. New York: Free Press, 2011.

DETRAN-PA. Relatório Estatístico de Trânsito no Estado do Pará e Município de Belém: Período 2007-2009. Belém: Departamento de Trânsito do Estado do Pará, 2010.

DETRAN-PA. Acidentes de Trânsito no Estado do Pará em 2010. Belém: Departamento de Trânsito do Estado do Pará, 2011a.

DETRAN-PA. Frota de Veículos no Estado do Pará. Belém: Departamento de Trânsito do Estado do Pará, 2011b.

ESPIRITO SANTO, R. B. D. A Logística como ferramenta eficaz no transporte urbano de passageiros: $O$ caso da empresa de transporte Metropolitano Belém Rio. Dissertação (Mestrado). Centro de Formação Acadêmica e Pesquisa, Escola Brasileira de Administração Pública e de Empresas. Fundação Getúlio Vargas, Rio de Janeiro, 2010.

GDF. Plano Diretor de Transporte Urbano e Mobilidade do Distrito Federal e Entorno - PDTU/DF - Relatório Final. Brasília: Governo do Distrito Federal. Secretaria de Estado de Transportes., 2010. 
GEIPOT. Recomendações para Implantação Imediata. Estudo de Transportes Urbanos da Região Metropolitana de Belém. Belém: Empresa Brasileira de Planejamento de Transportes, 1978.

GEIPOT. TRANSCOL - Ciclovia da BL-01. Estudo de Transportes Urbanos da Região Metropolitana de Belém. Brasília: Empresa Brasileira de Planejamento de Transportes, 1979.

GEIPOT. Estudo de Transportes Coletivos - TRANSCOL. Estudo de Transportes Urbanos da Região Metropolitana de Belém. Brasília: Empresa Brasileira de Planejamento de Transportes, 1980.

GEIPOT. Estudo de Racionalização do Transporte Coletivo da Região Metropolitana de Belém. Brasília: Empresa Brasileira de Planejamento de Transportes, 1986.

GEIPOT. Manual de Planejamento Cicloviário. 3a.ed. Brasília: Empresa Brasileira de Planejamento de Transportes, 2001a.

GEIPOT. Planejamento Cicloviário: Diagnóstico Nacional. Brasília: Ministério dos Transportes. Empresa Brasileira de Planejamento de Transportes, 2001b.

GEIPOT. Publicações - Transporte Urbano. Empresa Brasileira de Planejamento de Transportes, 2011. Disponível em: http://www.geipot.gov.br/publicacoes/urbano.htm. Acesso em: 30/09/2011.

GOOGLE. Google Earth. Google, 2011. Disponível em: http://www.google.com.br/int//ptBR/earth/index.html. Acesso em: 23/11/2011.

GOOGLE. Google Maps. Google, 2012. Disponível em: http://maps.google.com/. Acesso em: 20/08/2012.

GOTO, M. Uma análise de acessibilidade sob a ótica da eqüidade - o caso da Região Metropolitana de Belém. Dissertação (Mestrado). Escola de Engenharia de São Carlos, Universidade de São Paulo, São Carlos, 2000.

GUDMUNDSSON, H. Making concepts matter: sustainable mobility and indicator systems in transport policy. International Social Science Journal, v. 55, n. 2, p. 199-+, 2003.

HICKMAN, R.; SEABORN, C.; HEADICAR, P.; BANISTER, D. Planning for sustainable travel: Integrating spatial planning and transport. In: Givoni, M. e Banister, D. (Ed.). Integrated Transport: From Policy to Practice. London: Routledge, 2010. p.33-53.

IBGE. Censo Demográfico 2000. Instituto Brasileiro de Geografia e Estatística, 2001. Disponível em: http://www.ibge.gov.br/home/estatistica/populacao/default_censo_2000.shtm. Acesso em: 05/09/2011.

IBGE. Censo Demográfico 2010. Instituto Brasileiro de Geografia e Estatística, 2011a. Disponível em: http://www.ibge.gov.br/home/estatistica/populacao/censo2010/default.shtm. Acesso em: 05/09/2011.

IBGE. IBGE - Cidades@. Instituto Brasileiro de Geografia e Estatística, 2011b. Disponível em: http://www.ibge.gov.br/cidadesat/topwindow.htm?1. Acesso em: 05/09/2011.

IBGE. Séries Estatísticas \& Séries Históricas. Instituto Brasileiro de Geografia e Estatística, 2012. Disponível em: http://seriesestatisticas.ibge.gov.br/. Acesso em: 25/06/2012.

INEP. EDUDATABRASIL - Sistema de Estatísticas Educacionais. Instituto Nacional de Estudos e Pesquisas Educacionais Anísio Teixeira, 2012. Disponível em: http://www.edudatabrasil.inep.gov.br/. Acesso em: 02/07/2012.

IPPUC. Planos Setoriais: Relatório 2008. Plano Diretor de Curitiba. Curitiba: Prefeitura Municipal de Curitiba. Instituto de Pesquisa e Planejamento Urbano de Curitiba, 2008. 
IPPUC. Análise de desempenho e índice de desenvolvimento, 1970 a 2009: mobilidade urbana e transporte integrado. Plano Diretor de Curitiba. Curitiba: Instituto de Pesquisa e Planejamento Urbano de Curitiba, 2010.

JICA. Plano Diretor de Transportes Urbanos da Região Metropolitana de Belém, República Federativa do Brasil: Relatório Final. Belém: Governo do Estado do Pará. Agência de Cooperação Internacional do Japão, 1991.

JICA. Plano Diretor de Transporte Urbano da Região Metropolitana de Belém: Relatório Final. Belém: Governo do Estado do Pará. Agência de Cooperação Internacional do Japão, 2001.

JICA. Estudo de Viabilidade Econômica de Projetos para o Melhoramento do Sistema de Transporte na Região Metropolitana de Belém na República Federativa do Brasil: Relatório Final. Belém: Governo do Estado do Pará. Agência de Cooperação Internacional do Japão, 2003.

JICA. Estudo Preparatório para o Projeto de Sistema de Transporte de Ônibus da Região Metropolitana de Belém na República Federativa do Brasil: Relatório Final. Belém: Governo do Estado do Pará. Agência de Cooperação Internacional do Japão, 2010.

KLAUTAU, S. D. Estudos, Projetos e Planos: Papel Aguenta Tudo! - Avaliação Crítica das Metodologias Utilizadas nas Elaborações dos Estudos, Projetos e Planos de Transporte Coletivo Urbano, para a Região Metropolitana de Belém, no Período de 1975 a 1991. Dissertação (Mestrado). Mestrado em Transportes Urbanos, Universidade de Brasília, Brasília, 1993.

LITMAN, T. Sustainable Transportation Indicators: A Recommended Research Program For Developing Sustainable Transportation Indicators and Data. In: Transportation Research Board $88^{\text {th }}$ Annual Meeting, 2009, Washington, D.C. TRB, p. 1-14.

MACARIO, R.; CARVALHO, D.; FERMISSON, J. Achieving sustainable transport and land use with integrated policies. Urban Transport XI, v., n., p. 351-360, 2005.

MACEDO, M. H.; RODRIGUES DA SILVA, A. N.; COSTA, M. D. S. Abordagem Sistêmica da Mobilidade Urbana: Reflexões sobre o Conceito e suas Implicações. In: $3^{\circ}$ Congresso Luso Brasileiro para o Planejamento Urbano, Regional, Integrado e Sustentável - PLURIS, 2008, Santos. Santos: PLURIS, $p$.

MACHADO, I.; DOMINGUEZ, E. M. Índice de Mobilidade Sustentável: Uma ferramenta de auxílio ao planejamento urbano. In: PLURIS 2012 - Congresso Luso Brasileiro para o Planejamento Urbano, Regional, Integrado e Sustentável, 2012, Brasília. PLURIS, p. 1-12.

MACHADO, L. Índice de Mobilidade Sustentável para Avaliar a Qualidade de Vida Urbana Estudo de Caso: Região Metropolitana de Porto Alegre - RMPA. Dissertação (Mestrado). Faculdade de Arquitetura, Universidade Federal do Rio Grande do Sul, Porto Alegre, 2010.

MAGALHÃES, M. T. Q. Metodologia para Desenvolvimento de Sistemas de Indicadores: Uma Aplicação no Planejamento e Gestão da Política Nacional de Transportes. Dissertação (Mestrado). Faculdade de Tecnologia, Departamento de Engenharia Civil e Ambiental, Universidade de Brasília, 2004.

MANCINI, M. T. Planejamento urbano baseado em cenários de mobilidade sustentável. Dissertação (Mestrado). Escola de Engenharia de São Carlos, Universidade de São Paulo, São Carlos, 2011.

MARTIN, W. A.; MCGUCKIN, N. A. Travel Estimation Techniques for Urban Planning. National Cooperative Highway Research Program. Washington: Transportation Research Board - National Research Council, 1998.

MCIDADES (Ed.). Evolução das Tarifas de Ônibus Urbanos: 1994-2003. Brasília: Ministério das Cidades, Secretaria Nacional de Transporte e da Mobilidade Urbana - SeMob, 2004. 
MCIDADES. Gestão integrada da mobilidade urbana: Curso de capacitação. Brasília: Ministério das Cidades, Secretaria de Transporte e da Mobilidade Urbana - SeMob, 2006. (Mobilidade e desenvolvimento urbano)

MCIDADES. Caderno 1: Atendimento Adequado às Pessoas com Deficiência e Restrição de Mobilidade Brasília: Secretaria Nacional de Transporte e da Mobilidade Urbana. Ministério das Cidades, 2007a. (Brasil Acessível. Programa Brasileiro de Acessibilidade Urbana)

MCIDADES. Caderno 2: Construindo a Cidade Acessível Brasília: Secretaria Nacional de Transporte e da Mobilidade Urbana. Ministério das Cidades, 2007b. (Brasil Acessível. Programa Brasileiro de Acessibilidade Urbana)

MCIDADES. Caderno 3: Implementação do Decreto n 5.296/04 Brasília: Secretaria Nacional de Transporte e da Mobilidade Urbana. Ministério das Cidades, 2007c. (Brasil Acessível. Programa Brasileiro de Acessibilidade Urbana)

MCIDADES. Caderno 4: Implantação de Políticas Municipais de Acessibilidade Brasília: Secretaria Nacional de Transporte e da Mobilidade Urbana. Ministério das Cidades, 2007d. (Brasil Acessível. Programa Brasileiro de Acessibilidade Urbana)

MCIDADES. Caderno 5: Implantação de Sistemas de Transportes Acessíveis. Brasília: Secretaria Nacional de Transporte e da Mobilidade Urbana. Ministério das Cidades, 2007e. (Brasil Acessível. Programa Brasileiro de Acessibilidade Urbana)

MCIDADES. Caderno 6: Boas Práticas em Acessibilidade. Brasília: Secretaria Nacional de Transporte e da Mobilidade Urbana. Ministério das Cidades, 2007f. (Brasil Acessível. Programa Brasileiro de Acessibilidade Urbana)

MCIDADES. Caderno de Referência para Elaboração de Plano de Mobilidade por Bicicleta nas Cidades. Brasília: Ministério das Cidades, Secretaria Nacional de Transporte e da Mobilidade Urbana, 2007g.

MCIDADES. Caderno de Referência para Elaboração de Plano de Mobilidade Urbana. Brasília: Ministério das Cidades, Secretaria Nacional de Transporte e da Mobilidade Urbana - SeMob, 2007h. (PlanMob: Construindo a Cidade Sustentável)

MCIDADES. A licitação e contratação dos serviços de transportes públicos coletivos urbanos. Brasília: Ministério das Cidades. Secretaria Nacional de Transporte e da Mobilidade Urbana, 2007i.

MCIDADES (Ed.). Como andam Belém e Goiânia. Brasília: Ministério das Cidades, 2008a. (Como Andam as Regiões Metropolitanas. Coleção Estudos e Pesquisas do Programa Nacional de Capacitação das Cidades)

MCIDADES. Mobilidade urbana é desenvolvimento urbano (cartilha). Brasília: Ministério das Cidades. Secretaria Nacional de Transporte e da Mobilidade Urbana, $2008 \mathrm{~b}$.

MCIDADES; IBAM. A mobilidade urbana no planejamento da cidade (cartilha). 2a. .ed. Brasília: Ministério das Cidades. Secretaria Nacional de Transporte e da Mobilidade Urbana. Instituto Brasileiro de Administração Municipal, 2008.

MERCÊS, S. D. S. S. D. Transporte coletivo em Belém: mudança e continuidade. Tese (Doutorado). Faculdade de Arquitetura e Urbanismo, Universidade de São Paulo, São Paulo, 2004.

MIRANDA, A. C. D. M.; ARY, J. C. A. GEIPOT - Escola de Bicicleta. Escola de Bicicleta, 2012. Disponível em: http://www.escoladebicicleta.com.br/geipot.html. Acesso em: 16/02/2012.

MIRANDA, H. D. F. Mobilidade Urbana Sustentável e o Caso de Curitiba. Dissertação (Mestrado). Escola de Engenharia de São Carlos, Universidade de São Paulo, São Carlos, 2010. 
MIRANDA, H. D. F.; MANCINI, M. T.; AZEVEDO FILHO, M. A. N. D.; ALVES, V. F. B.; RODRIGUES DA SILVA, A. N. Barreiras para a Implantação de Planos de Mobilidade. In: XXIII ANPET - Congresso de Pesquisa e Ensino em Transportes, 2009, Vitória. ANPET, p. 1-12.

MIRANDA, H. D. F.; RODRIGUES DA SILVA, A. N. Benchmarking Sustainable Urban Mobility: The Case of Curitiba, Brazil. Transport Policy, v. 21, n., p. 141-151, 2012.

MOBILIZE. Estudo Mobilize 2011: Diagnóstico da Mobilidade Urbana Sustentável em Capitais Brasileiras. São Paulo: Associação Abaporu, 2011.

MORAES, E.; LARA, L.; TOGUCHI, L.; PINTO, A. Mapa de ruídos da zona comercial de Belém: Uma parcela do mapa de ruídos da cidade de Belém - Brasil. In: TecniAcústica, 2003, Bilbao. p.

MT. Biblioteca do Ministério dos Transportes. Ministério dos Transportes, 2012. Disponível em: http://www.transportes.gov.br/index/conteudo/id/37575. Acesso em: 20/07/2012.

MTE. Evolução do Salário Mínimo: Brasília: Ministério do Trabalho e Emprego, 2011, 2 p.

NAPIER, I. The walking economy. In: Tolley, R. (Ed.). Sustainable transport: Planning for walking and cycling in urban environments. Cambridge: Woodhead, 2003. p.159-171.

OSMF. OpenStreetMap: O Wiki de Mapas Livres. The OpenStreetMap Foundation, 2012. Disponível em: http://www.openstreetmap.org/. Acesso em: 20/08/2012.

OWENS, S. From 'Predict and Provide' to 'Predict and Prevent'?: Pricing and Planning in Transportation Policy. Transport Policy, v. 2, n. 1, p. 43-49, 1995.

OWENS, S.; COWELL, R. Land and Limits: Interpreting Sustainability in the Planning Process. 2.ed. London: Routledge, 2011. (RTPI Library Series)

PARÁ. Diretrizes de Ordenamento Territorial para a Região Metropolitana de Belém. Belém: Governo do Estado do Pará. Secretaria Executiva de Desenvolvimento Urbano e Regional SEDURB, 2006.

PEDRO, N. D. S.; NEVES, P. B. T. D. Integração do transporte hidroviário ao sistema de transporte público da Região Metropolitana de Belém. In: Silva, L. D. J. D. D. e Ponte, J. P. X. (Ed.).

Urbanização e ambiente: experiências de pesquisa na Amazônia Oriental. Belém: Paka-Tatu, 2012. p.221-238.

PLOWDEN, S. Towns Against Traffic. London: Andre Deutsch, 1972.

PMB. Código de Posturas. Lei no 7.055 de 30 de dezembro de 1977. Dá nova redação ao Código de Posturas do Município de Belém. Prefeitura Municipal de Belém. Belém. 1977. Disponível em: http://www.belem.pa.gov.br/segep/download/coletanea/PDF/n_urban_p/cod_post.pdf. Acesso em: $3 / 10 / 2011$

PMB. Lei $n^{\circ}$ 7.122, de 28 de dezembro de 1979. Dispõe sobre a organização do solo urbano do Município de Belém, e dá outras providências. Prefeitura Municipal de Belém. Belém. 1979.

Disponível em: Acesso em:

PMB. Lei das Edificações. Lei $n^{\circ} 7.400$ de 25 de janeiro de 1988. Dispõe sobre as edificações do Município de Belém e dá outras providências. Prefeitura Municipal de Belém. Belém. 1988a. Disponível em: http://www.belem.pa.gov.br/segep/download/coletanea/PDF/n_urban_p/edific.pdf. Acesso em: 3/10/2011

PMB. Lei $n^{\circ}$ 7.399, de 15 de janeiro de 1988. Dispõe sobre o parcelamento do solo urbano do Município de Belém. Prefeitura Municipal de Belém. Belém. 1988b. Disponível em: http://www.belem.pa.gov.br/semaj/app/Sistema/view_lei.php?id_lei=446. Acesso em: 30/05/2011 
PMB. Lei $n^{\circ} 7.603$ de 13 de janeiro de 1993. Dispõe sobre o Plano Diretor do Município de Belém e dá outras providências. Belém. 1993. Disponível em:

http://www.belem.pa.gov.br/segep/download/coletanea/PDF/n_urban_p/pdu_belem.pdf. Acesso em: 05/06/2012

PMB. Lei $n^{\circ} 7.684$, de 12 de janeiro de 1994. Dispõe sobre o plano diretor das ilhas do Caratateua e Mosqueiro e dá outras providências. Prefeitura Municipal de Belém. Belém. 1994a. Disponível em: http://www.belem.pa.gov.br/semaj/app/Sistema/view_lei.php?id_lei=1358. Acesso em: 05/06/2012

PMB. Lei $n^{\circ} 7.709$ de 18 de maio de 1994. Dispõe sobre a preservação e proteção do patrimônio histórico, artístico, ambiental e cultural do município de Belém e dá outras providências. Prefeitura Municipal de Belém. Belém. 1994b. Disponível em: http://www.belem.pa.gov.br/segep/download/coletanea/PDF/n_urban_p/patr_hist.pdf. Acesso em: $3 / 10 / 2011$

PMB. Lei $n^{\circ}$ 7.747, de 02 de janeiro de 1995, que autoriza o Poder Executivo a criar o Centro de Referência em Educação Ambiental - Escola Bosque "Professor Eidorfe Moreira", na llha de Caratateua, Distrito de Outeiro, Município de Belém e dá outras providências. Prefeitura Municipal de Belém. Belém. 1995. Disponível em:

http://www.belem.pa.gov.br/semaj/app/Sistema/view_lei.php?id_lei=1458. Acesso em: 3/10/2011

PMB. Lei $n^{\circ} 7.806$ de 30 de julho de 1996. Delimita as áreas que compõem os Bairros de Belém e dá outras providências. Prefeitura Municipal de Belém. Belém. 1996. Disponível em: http://www.belem.pa.gov.br/segep/download/coletanea/PDF/n_urban_p/bairros.pdf. Acesso em: $3 / 10 / 2011$

PMB. Lei Complementar $n^{\circ} 2$ de 19 de julho de 1999. Dispõe sobre o parcelamento, ocupação e uso do solo urbano do Município de Belém e dá outras providências. Prefeitura Municipal de Belém. Belém. 1999. Disponível em:

http://www.belem.pa.gov.br/segep/download/coletanea/PDF/n_urban_p/lccu.pdf. Acesso em: $3 / 10 / 2011$

PMB. Legislação Municipal. Prefeitura Municipal de Belém. , 2006a. Disponível em: http://www.belem.pa.gov.br/planodiretor/paginas/legislacaomunicipal.php. Acesso em: 05/06/2012.

PMB. Outras leis urbanísticas. Prefeitura Municipal de Belém. , 2006b. Disponível em: http://www.belem.pa.gov.br/planodiretor/paginas/outrasleisurba.php. Acesso em: 05/06/2012.

PMB. Lei ${ }^{\circ}$ 8.655, de 30 de julho de 2008. Dispõe sobre o Plano Diretor do Município de Belém, e dá outras providências. Prefeitura Municipal de Belém. Belém. 2008. Disponível em: http://www.belem.pa.gov.br/planodiretor/paginas/planodiretoratual.php. Acesso em: 26/6/2012

PMB. Anuário Estatístico do Município de Belém 2010. Belém: Prefeitura Municipal de Belém. Secretaria Municipal de Coordenação Geral do Planejamento e Gestão, 2011a.

PMB. Legislação Urbanística: Normas. Prefeitura Municipal de Belém. Secretaria Municipal de Coordenação Geral do Planejamento e Gestão, 2011b. Disponível em:

http://www.belem.pa.gov.br/segep/download/coletanea/normas.htm. Acesso em: 31/5/2011.

PMB. Diário Oficial do Município. Prefeitura Municipal de Belém. , 2012a. Disponível em: http://www.cinbesa.com.br/diario/conDiario/conDiario.php. Acesso em: 28/6/2012.

PMB. Legislação Urbanística: Mapas. Prefeitura Municipal de Belém. Secretaria Municipal de Coordenação Geral do Planejamento e Gestão, 2012b. Disponível em:

http://www.belem.pa.gov.br/segep/download/coletanea/mapas.htm. Acesso em: 28/6/2012.

PMB. Portal Transparência Belém. Prefeitura Municipal de Belém. , 2012c. Disponível em: http://www.belem.pa.gov.br/app/c2ms/v/?id=30. Acesso em: 28/6/2012. 
PMB. Secretaria Municipal de Coordenação Geral do Planejamento e Gestão. Prefeitura Municipal de Belém. , 2012d. Disponível em: http://www.belem.pa.gov.br/app/c2ms/v/index.php?id=2. Acesso em: 28/6/2012.

PMB; PMA. Protocolo que entre si celebram a Prefeitura Municipal de Belém e a Prefeitura Municipal de Ananindeua, com a finalidade de definir os limites territoriais dos dois municípios. Prefeitura Municipal de Belém. Prefeitura Municipal de Ananindeua. Belém. 1991. Disponível em: http://www.belem.pa.gov.br/planodiretor/pdfs_outras_normas_urb/protocolo.pdf. Acesso em: 30/05/2011

PMU. Plano Diretor de Transporte e Mobilidade Urbana de Uberlândia - Versão Preliminar. Uberlândia: Prefeitura Municipal de Uberlândia. Secretaria Municipal de Trânsito e Transportes, 2010.

POLI, C. Mobility and Environment - Humanists versus Engineers in Urban Policy and Professional Education. New York: Springer, 2011.

PONTES, T. F. Avaliação da Mobilidade Urbana na Área Metropolitana de Brasília. Dissertação (Mestrado). Faculdade de Arquitetura e Urbanismo, Universidade de Brasília, Brasília, 2010.

PORTUGAL. Manual de Boas Práticas para uma Mobilidade Sustentável. Projecto Mobilidade Sustentável. Amadora: Agência Portuguesa do Ambiente, Ministério do Ambiente e do Ordenamento do Território, 2010a.

PORTUGAL. Projecto Mobilidade Sustentável: Concepção, Principais Conclusões e Recomendações. Projecto Mobilidade Sustentável. Amadora: Agência Portuguesa do Ambiente, Ministério do Ambiente e do Ordenamento do Território, 2010b.

PORTUGAL. Projecto Mobilidade Sustentável. Agência Portuguesa do Ambiente, Ministério do Ambiente e do Ordenamento do Território, 2011. Disponível em: http://sniamb.apambiente.pt/mobilidade/. Acesso em: 03/01/2011.

PR. Plano Diretor de Transporte e Mobilidade Urbana: Diagnóstico. Recife: Prefeitura do Recife, 2010a.

PR. Plano Diretor de Transporte e Mobilidade Urbana: Diretrizes. Recife: Prefeitura do Recife, 2010b.

PR. Projeto de Lei No 12 / 2011. Institui o Plano Municipal de Transporte e Mobilidade. Prefeitura do Recife. Recife. 2011. Disponível em: http://www.recife.pe.gov.br/noticias/arquivos/4601.pdf. Acesso em: 19/08/2012

PR. Plano Diretor de Transporte e Mobilidade Urbana. Prefeitura do Recife, 2012. Disponível em: http://www2.recife.pe.gov.br/projetos-e-acoes/projetos/plano-diretor-de-transporte-e-mobilidadeurbana-2/. Acesso em: 19/08/2012.

QGIS. Quantum GIS - User Guide - Version 1.7.0 'Wroclaw'. http://www.qgis.org: Quantum GIS Development Team, 2011.

REINO UNIDO. Traffic in Towns: A study of the long term problems of traffic in urban areas. London: Ministry of Transport, 1963.

ROCHA, I. A.; RIBEIRO, P.; GOTO, M. O uso potencial de bicicletas na Região Metropolitana de Belém. In: Silva, L. D. J. D. D. e Ponte, J. P. X. (Ed.). Urbanização e ambiente: experiências de pesquisa na Amazônia Oriental. Belém: Paka-Tatu, 2012. p.201-220.

RODRIGUES DA SILVA, A. N.; COSTA, M. D.; MACEDO, M. H. Multiple Views of Sustainable Urban Mobility: The Case of Brazil. Transport Policy, v. 15, n. 6, p. 350-360, 2008. 
RODRIGUES DA SILVA, A. N.; COSTA, M. S.; RAMOS, R. A. R. Development and application of I_SUM - An index of Sustainable Urban Mobility. In: Transportation Research Board $89^{\text {th }}$ Annual Meeting, 2010, Washington, D.C. TRB, p.

SANTOS, D. V. D. C. Polos Geradores de Viagens Sustentáveis: Uma Proposta para o Licenciamento e a Análise de Projetos. Dissertação (Mestrado). Escola Politécnica, Universidade Federal da Bahia, Salvador, 2011.

SCHILLER, P. L.; BRUNN, E. C.; KENWORTHY, J. R. An introduction to sustainable transportation: Policy, planning and implementation. London: Earthscan, 2010.

SEGNESTAM, L. Indicators of Environment and Sustainable Development: Theories and Practical Experience. Washington: The International Bank for Reconstruction and Development The World Bank, 2002. (Environmental Economic Series)

SEIXAS, A. R. A cidade e a mobilidade na era do automóvel: a obra de Colin Buchanan (19581966). Tese (Doutorado). Departamento de Arquitetura e Urbanismo, Escola de Engenharia de São Carlos, Universidade de São Paulo, São Carlos, 2010.

SEMMA. Legislação. Prefeitura Municipal de Belém. Secretaria Municipal de meio Ambiente, 2012. Disponível em: http://www.belem.pa.gov.br/app/c2ms/v/?id=10\&conteudo=2722. Acesso em: 05/06/2012.

TOBIAS, M. S. G. Condicionantes Históricos da Evolução do Transporte Público na Região Metropolitana de Belém. In: XVIII Congresso de Pesquisa e Ensino em Transportes, 2004, Florianópolis. ANPET, p. 299-306.

TOBIAS, M. S. G.; PEIXEIRA, A. P. D. Alteração no perfil e na demanda cicloviária na Região Metropolitana de Belém: Repensando prioridades. In: $15^{\circ}$ Congresso Brasileiro de Transporte e Trânsito, 2005, Goiânia. ANTP, p. 1-9.

TOLLEY, R. Introduction: talking the talk but not walking the walk. In: Tolley, R. (Ed.). Sustainable transport: Planning for walking and cycling in urban environments. Cambridge: Woodhead, 2003. p.xv-xxi.

VASCONCELLOS, E. A. D. Transporte urbano nos países em desenvolvimento - reflexões e propostas. São Paulo: Annablume, 2000.

VILLELA, T. M. D. A.; MAGALHÃES, M. T. Q.; GOMES, H. A. D. S.; ARRUDA, B. D. L. D.; SILVEIRA, L. S. D. C. Metodologia para Desenvolvimento e Seleção de Indicadores para Planejamento de Transportes. In: XXI ANPET - Congresso de Pesquisa e Ensino em Transportes, 2007, Rio de Janeiro. ANPET, p. 1-12.

VISIONS2030. Visions of the role of walking and cycling in 2030. Universities of Leeds, Oxford, East Anglia, Salford and Manchester, 2012. Disponível em: http://visions2030.org.uk/. Acesso em: 25/08/2012.

VTPI. Transport Model Improvements: Improving Methods for Evaluating The Effects and Value of Transportation System Changes. Victoria Transport Policy Institute, 2011. Disponível em: http://www.vtpi.org/tdm/tdm125.htm. Acesso em: 25/10/2011.

VUCHIC, V. R. Urban transit: Operations, planning and economics. Hoboken: Wiley, 2005.

WCED. Our Common Future (The Brundtland Report). New York: World Commission on Environment and Development. United Nations, 1987. (A/42/427). 


\section{ANEXO A. ESTRUTURA HIERÁRQUICA DO IMUS}

\begin{tabular}{|c|c|c|}
\hline Domínio & Tema & Indicador \\
\hline \multirow{4}{*}{ 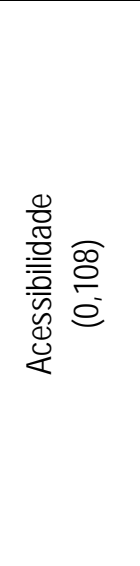 } & Acessibilidade aos sistemas de transporte $(0,29)$ & $\begin{array}{l}\text { - Acessibilidade ao transporte público }(0,333) \\
\text { - Transporte público para pessoas com necessidades especiais } \\
(0,333) \\
\text { - Despesas com transportes }(0,333) \\
\end{array}$ \\
\hline & Acessibilidade universal $(0,28)$ & $\begin{array}{l}\text { - Travessias adaptadas para pessoas com necessidades } \\
\text { especiais }(0,200) \\
\text { - Acessibilidade aos espaços abertos }(0,200) \\
\text { - Vagas de estacionamento para pessoas com necessidades } \\
\text { especiais }(0,200) \\
\text { - Acessibilidade a edifícios públicos }(0,200) \\
\text { - Acessibilidade aos serviços essenciais }(0,200)\end{array}$ \\
\hline & Barreiras físicas $(0,22)$ & - Fragmentação urbana $(1,00)$ \\
\hline & $\begin{array}{l}\text { Legislação para pessoas com necessidades } \\
\text { especiais }(0,21)\end{array}$ & - Ações para acessibilidade universal $(1,00)$ \\
\hline \multirow{2}{*}{ 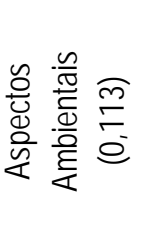 } & Controle dos impactos no meio ambiente $(0,52)$ & $\begin{array}{l}\text { - Emissões de } \mathrm{CO}(0,250) \\
\text { - Emissões de } \mathrm{CO}_{2}(0,250) \\
\text { - População exposta ao ruído de tráfego }(0,250) \\
\text { - Estudos de Impacto Ambiental - EIA }(0,250) \\
\end{array}$ \\
\hline & Recursos naturais $(0,48)$ & $\begin{array}{l}\text { - Consumo de combustível }(0,500) \\
\text { - Uso de energia limpa e combustíveis alternativos }(0,500)\end{array}$ \\
\hline \multirow{5}{*}{ 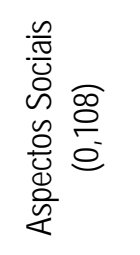 } & Apoio ao cidadão $(0,21)$ & - Informação disponível ao cidadão $(1,000)$ \\
\hline & Inclusão social $(0,2)$ & - Equidade vertical (renda) $(1,000)$ \\
\hline & Educação e cidadania $(0,19)$ & - Educação para o desenvolvimento sustentável $(1,000)$ \\
\hline & Participação popular $(0,19)$ & - Participação na tomada de decisão $(1,000)$ \\
\hline & Qualidade de vida $(0,21)$ & - Qualidade de vida $(1,000)$ \\
\hline \multirow{3}{*}{ 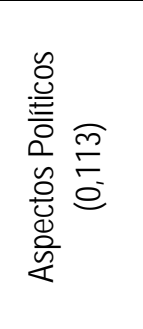 } & Integração de ações políticas $(0,34)$ & $\begin{array}{l}\text { - Integração entre níveis de governo }(0,500) \\
\text { - Parcerias público-privadas }(0,500)\end{array}$ \\
\hline & Captação e gerenciamento de recursos $(0,33)$ & $\begin{array}{l}\text { - Captação de recursos }(0,250) \\
\text { - Investimentos em sistemas de transporte }(0,250) \\
\text { - Distribuição dos recursos (coletivo x privado) }(0,250) \\
\text { - Distribuição dos recursos (motorizados x não-motorizados) } \\
\quad(0,250)\end{array}$ \\
\hline & Política de mobilidade urbana $(0,33)$ & - Política de mobilidade urbana $(1,00)$ \\
\hline \multirow[t]{2}{*}{ 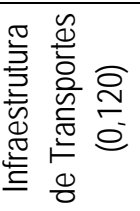 } & $\begin{array}{l}\text { Provisão e manutenção da infraestrutura de } \\
\text { transportes }(0,46)\end{array}$ & $\begin{array}{l}\text { - Densidade e conectividade da rede viária }(0,250) \\
\text { - Vias pavimentadas }(0,250) \\
\text { - Despesas com manutenção da infraestrutura }(0,250) \\
\text { - Sinalização viária }(0,250)\end{array}$ \\
\hline & Distribuição da infraestrutura de transporte $(0,54)$ & - Vias para transporte coletivo $(1,000)$ \\
\hline \multirow{3}{*}{ 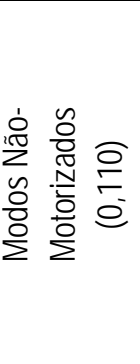 } & Transporte cicloviário $(0,31)$ & $\begin{array}{l}\text { - Extensão e conectividade de ciclovias }(0,333) \\
\text { - Frotas de bicicletas }(0,333) \\
\text { - Estacionamento de bicicletas }(0,333)\end{array}$ \\
\hline & Deslocamentos a pé $(0,34)$ & $\begin{array}{l}\text { - Vias para pedestres }(0,500) \\
\text { - Vias com calçadas }(0,500)\end{array}$ \\
\hline & Redução de viagens $(0,35)$ & $\begin{array}{l}\text { - Distância de viagem }(0,250) \\
\text { - Tempo de viagem }(0,250) \\
\text { - Número de viagens }(0,250) \\
\text { - Ações para redução do tráfego motorizado }(0,250)\end{array}$ \\
\hline
\end{tabular}

Fonte: Adaptado de Costa (2008). 


\begin{tabular}{|c|c|c|}
\hline Domínio & Tema & Indicador \\
\hline \multirow{8}{*}{ 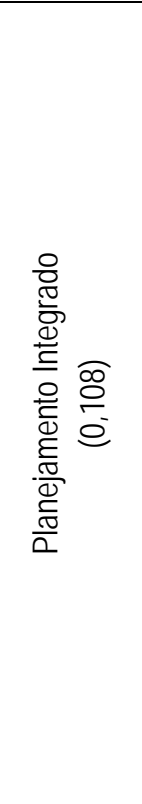 } & Capacitação de gestores $(0,12)$ & $\begin{array}{l}\text { - Nível de formação de técnicos e gestores }(0,500) \\
\text { - Capacitação de técnicos e gestores }(0,500)\end{array}$ \\
\hline & Áreas centrais e de interesse histórico $(0,11)$ & - Vitalidade do centro $(1,000)$ \\
\hline & Integração regional $(0,12)$ & - Consórcios intermunicipais $(1,000)$ \\
\hline & Transparência do processo de planejamento $(0,12)$ & - Transparência e responsabilidade $(1,000)$ \\
\hline & Planejamento e controle do uso e ocupação do solo $(0,14)$ & $\begin{array}{l}\text { - Vazios urbanos }(0,200) \\
\text { - Crescimento urbano }(0,200) \\
\text { - Densidade populacional urbana }(0,200) \\
\text { - Índice de uso misto }(0,200) \\
\text { - Ocupações irregulares }(0,200)\end{array}$ \\
\hline & Planejamento estratégico e integrado $(0,14)$ & $\begin{array}{l}\text { - Planejamento urbano, ambiental e de transporte } \\
\text { integrado }(0,500) \\
\text { - Efetivação e continuidade das ações }(0,500)\end{array}$ \\
\hline & $\begin{array}{l}\text { Planejamento da infraestrutura urbana e equipamentos } \\
\text { urbanos }(0,13)\end{array}$ & $\begin{array}{l}\text { - Parques e áreas verdes }(0,333) \\
\text { - Equipamentos urbanos (escolas) }(0,333) \\
\text { - Equipamentos urbanos (postos de saúde) }(0,333)\end{array}$ \\
\hline & Plano diretor e legislação urbanística $(0,12)$ & $\begin{array}{l}\text { - Plano diretor }(0,333) \\
\text { - Legislação urbanística }(0,333) \\
\text { - Cumprimento da legislação urbanística }(0,333)\end{array}$ \\
\hline \multirow{5}{*}{ 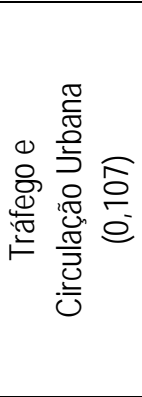 } & Acidentes de trânsito $(0,21)$ & $\begin{array}{l}\text { - Acidentes de trânsito }(0,333) \\
\text { - Acidentes com pedestres e ciclistas }(0,333) \\
\text { - Prevenção de acidentes }(0,333)\end{array}$ \\
\hline & Educação para o trânsito $(0,19)$ & - Educação para o trânsito $(1,000)$ \\
\hline & Fluidez e circulação $(0,19)$ & $\begin{array}{l}\text { - Congestionamento }(0,500) \\
\text { - Velocidade média do tráfego }(0,500)\end{array}$ \\
\hline & Operação e fiscalização de trânsito $(0,2)$ & - Violação das leis de trânsito $(1,000)$ \\
\hline & Transporte individual $(0,21)$ & $\begin{array}{l}\text { - Índice de motorização }(0,500) \\
\text { - Taxa de ocupação de veículos }(0,500)\end{array}$ \\
\hline \multirow{5}{*}{ 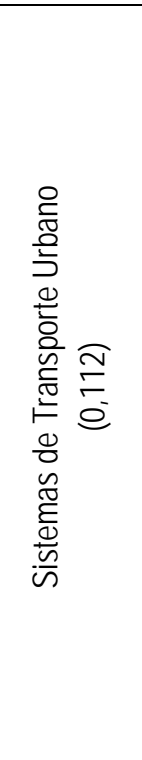 } & Disponibilidade e qualidade do transporte público $(0,23)$ & $\begin{array}{l}\text { - Extensão da rede de transporte público }(0,125) \\
\text { - Frequência de atendimento do transporte público }(0,125) \\
\text { - Pontualidade }(0,125) \\
\text { - Velocidade média do transporte público }(0,125) \\
\text { - Idade média da frota de transporte público }(0,125) \\
\text { - Índice de passageiros por quilômetro }(0,125) \\
\text { - Passageiros transportados anualmente }(0,125) \\
\text { - Satisfação do usuário com o serviço de transporte público } \\
(0,125)\end{array}$ \\
\hline & Diversificação modal $(0,18)$ & $\begin{array}{l}\text { - Diversidade de modos de transporte }(0,333) \\
\text { - Transporte coletivo x transporte individual }(0,333) \\
\text { - Modos não-motorizados x modos motorizados }(0,333)\end{array}$ \\
\hline & Regulação e fiscalização do transporte público $(0,18)$ & $\begin{array}{l}\text { - Contratos e licitações }(0,500) \\
\text { - Transporte informal }(0,500)\end{array}$ \\
\hline & Integração do transporte público $(0,22)$ & $\begin{array}{l}\text { - Terminais intermodais }(0,500) \\
\text { - Integração do transporte público }(0,500)\end{array}$ \\
\hline & Política tarifária $(0,19)$ & $\begin{array}{l}\text { - Descontos e gratuidades }(0,333) \\
\text { - Tarifas de transporte }(0,333) \\
\text { - Subsídios públicos }(0,333)\end{array}$ \\
\hline
\end{tabular}

Fonte: Adaptado de Costa (2008). 


\section{ANEXO B. RELAÇÃO DE ESTUDOS REALIZADOS PELO GEIPOT}

Esta relação foi preparada a partir de uma lista de publicações da Empresa Brasileira de Planejamento de Transportes - GEIPOT, encontrada na Internet (GEIPOT, 2011).

\begin{tabular}{|c|c|}
\hline Ano & Estudo \\
\hline 1974 & Estudo de Transportes Urbanos do Distrito Federal - I Programa Topics C Graphos \\
\hline \multirow{6}{*}{1976} & Estudo de Transportes Urbanos de Salvador - Recomendações para Implantação Imediata \\
\hline & Estudo de Transportes Urbanos do Recife - Recomendações para Implantação Imediata \\
\hline & Estudo de Trem Suburbano da Região Metropolitana de Porto Alegre TRENSURB \\
\hline & Estudo do Transporte Coletivo da Região Metropolitana de Porto Alegre \\
\hline & Plano Diretor de Transporte Urbano da Região Metropolitana de Porto Alegre \\
\hline & Plano Diretor de Transportes Urbanos do Distrito Federal, Brasília \\
\hline \multirow{4}{*}{1977} & $\begin{array}{l}\text { Estudo de Transportes Urbanos da Grande Florianópolis - Recomendações para Implantação } \\
\text { Imediata }\end{array}$ \\
\hline & $\begin{array}{l}\text { Estudo de Transportes Urbanos da Região Metropolitana do Recife - Estudo de Transportes } \\
\text { Coletivos do Recife TRANSCOL }\end{array}$ \\
\hline & Estudo de Transportes Urbanos de Maceió - Estudos Especiais - Bicicletas \\
\hline & Estudo de Transportes Urbanos de Maceió - Recomendações para Implantação Imediata \\
\hline \multirow{8}{*}{1978} & $\begin{array}{l}\text { Estudo de Transportes Urbanos da Grande Florianópolis - Estudo de Transporte Coletivo } \\
\text { TRANSCOL }\end{array}$ \\
\hline & Estudo de Transportes Urbanos da Grande Florianópolis - Plano Diretor de Transportes Urbanos \\
\hline & $\begin{array}{l}\text { Estudo de Transportes Urbanos da Região Metropolitana de Belém - Recomendações para } \\
\text { Implantação Imediata }\end{array}$ \\
\hline & $\begin{array}{l}\text { Estudo de Transportes Urbanos da Região Metropolitana de Fortaleza - Recomendações para } \\
\text { Implantação Imediata }\end{array}$ \\
\hline & $\begin{array}{l}\text { Estudo de Transportes Urbanos da Região Metropolitana de Salvador - Estudo de Transportes } \\
\text { Coletivos de Salvador TRANSCOL }\end{array}$ \\
\hline & Estudo de Transportes Urbanos de Caxias do Sul - Recomendações para Implantação Imediata \\
\hline & Estudo de Transportes Urbanos de Ipatinga - Recomendações para Implantação Imediata \\
\hline & Estudo de Transportes Urbanos de Pelotas - Recomendações para Implantação Imediata \\
\hline \multirow{3}{*}{1979} & Estudo de Transportes Urbano de Caxias do Sul; Recomendações de Médio Prazo \\
\hline & Estudo de Transportes Urbanos de Cuiabá, Recomendações para Implantação Imediata \\
\hline & Plano Diretor de Transportes Urbanos do Distrito Federal \\
\hline \multirow{7}{*}{1980} & Estudo de Transportes Urbanos da Região Metropolitana de Belém \\
\hline & Estudo de Transporte Urbano de Aracaju; Recomendações para Implantação Imediata \\
\hline & Estudo de Transporte Urbano de Campina Grande; Recomendações para Implantação Imediata \\
\hline & Estudo de Transportes Urbanos de Lages; Recomendações para Implantação Imediata \\
\hline & Estudo de Transportes Urbanos de Maceió; Estudo de Transporte Coletivo - TRANSCOL \\
\hline & Estudo de Transportes Urbanos de Montenegro; Recomendações para Implantação Imediata \\
\hline & Estudo de Transportes Urbanos para Cidades de Porte Médio - Bauru \\
\hline
\end{tabular}




\begin{tabular}{|c|c|}
\hline Ano & Estudo \\
\hline \multirow{7}{*}{1981} & Aglomerado Urbano de Cuiabá; Proposta Preliminar \\
\hline & $\begin{array}{l}\text { Estudo de Transportes Urbanos da Região Metropolitana de Fortaleza; Estudo de Transportes } \\
\text { Coletivos - TRANSCOL }\end{array}$ \\
\hline & Estudo de Transportes Urbanos de Barra Mansa; Recomendações para Implantação Imediata \\
\hline & $\begin{array}{l}\text { Estudo de Transportes Urbanos de Campina Grande; Estudos de Transportes Coletivos - } \\
\text { TRANSCOL }\end{array}$ \\
\hline & Estudo de Transportes Urbanos de Natal, Recomendações para Implantação Imediata \\
\hline & Estudo de Transportes Urbanos de Volta Redonda, Recomendações para Implantação Imediata \\
\hline & Estudo de Transportes Urbanos para Cidades Porte Médio - Montenegro \\
\hline \multirow{11}{*}{1982} & Estudo do Transporte Coletivo de Natal TRANSCOL \\
\hline & Estudio do Transporte Urbano de Asuncion; - Propuestas para Implantacion Imediata \\
\hline & Estudo de Transporte Urbano de Barra Mansa; Estudo de Transportes Coletivos TRANSCOL \\
\hline & $\begin{array}{l}\text { Estudo de Transportes Urbanos da Região Metropolitana de Recife; Plano Diretor de Transportes } \\
\text { Urbanos - PDTU }\end{array}$ \\
\hline & $\begin{array}{l}\text { Estudo de Transporte Urbano da Região Metropolitana de Salvador; Plano Diretor de Transporte } \\
\text { Urbano - PDTU }\end{array}$ \\
\hline & Estudo de Transportes Urbanos de Aracaju - Recomendação para Implantação a Médio Prazo \\
\hline & Estudo de Transportes Urbanos de Maceió; Plano Diretor de Transportes Urbanos - PDTU \\
\hline & Estudo de Transportes Urbanos de Natal; Estudo de Transporte Coletivo - TRANSCOL \\
\hline & Estudo de Transportes Urbanos de Volta Redonda; Estudo de Transportes Coletivos - TRANSCOL \\
\hline & Estudo de Transportes Urbanos para Cidades de Porte Médio - Sorocaba \\
\hline & Estudo de Transportes Urbanos para Cidades Industriais no Médio Vale do Paraíba \\
\hline \multirow{11}{*}{1983} & Estudo de Transporte Urbano de Manaus - Recomendações para Implantação Imediata \\
\hline & Estudo de Transportes Urbanos de Fortaleza; Plano Diretor de Transportes Urbanos - PDTU \\
\hline & Estudo de Transportes Urbanos de João Pessoa - Recomendações para Implantação a Médio Prazo \\
\hline & Estudo de Transportes Urbanos de João Pessoa - Recomendação para Implantação Imediata \\
\hline & Estudo de Transportes Urbanos de Ouro Preto - Recomendações para Implantação Imediata \\
\hline & Estudo de Transportes Urbanos de Pelotas - Recomendações de Médio Prazo \\
\hline & $\begin{array}{l}\text { Estudo de Transportes Urbanos Em Cidades de Porte Médio do Estado de Santa Catarina e Estudo } \\
\text { da Área Central }\end{array}$ \\
\hline & Estudo de Transportes Urbanos para Cidades de Porte Médio do Estado da Bahia \\
\hline & Estudo de Transportes Urbanos para Cidades de Porte Médio do Estado de Minas Gerais \\
\hline & Estudo de Transportes Urbanos para Cidades de Porte Médio do Estado do Paraná \\
\hline & Estudo de Transportes Urbanos para Cidades de Porte Médio do Estado do Rio Grande do Sul \\
\hline \multirow{2}{*}{1984} & Estudo de Transporte Urbano de Asunción; Estudo del Transporte Publico \\
\hline & Projeto de Racionalização do Transporte Coletivo Urbano - Aglomerado Urbano de Florianópolis \\
\hline \multirow{5}{*}{1985} & Estudo de Transporte Coletivo de Londrina \\
\hline & Estudo de Transportes Urbanos de João Pessoa; Plano Diretor de Transportes Urbanos - PDTU \\
\hline & Estudo de Transportes Urbanos de Natal; Plano Diretor de Transportes Urbanos - PDTU \\
\hline & Estudo do Sistema Viário Básico da Região Metropolitana de Curitiba \\
\hline & Plano Diretor de Transportes Urbanos de João Pessoa - PDTU - Relatório \\
\hline \multirow{2}{*}{1986} & Estudo de Racionalização do Transporte Coletivo da Região Metropolitana de Belém \\
\hline & Estudo de Transportes Urbanos de Cuiabá e Várzea Grande \\
\hline 1987 & $\begin{array}{l}\text { Estudo de Transportes Urbanos da Grande Florianópolis; Recomendações para Implantação } \\
\text { Imediata }\end{array}$ \\
\hline
\end{tabular}




\section{ANEXO C. CONTEÚDO DOS ESTUDOS E PLANOS DE BELÉM}

C.1. Estudo de Transportes Urbanos da Região Metropolitana de Belém / Recomendações para Implantação Imediata - RII-RMB (GEIPOT, 1978)

C.2. Estudo de Transportes Urbanos da Região Metropolitana de Belém / TRANSCOL - Ciclovia da BL-01 (GEIPOT, 1979). 106

C.3. Estudo de Transportes Urbanos da Região Metropolitana de Belém / Estudo de Transportes Coletivos - TRANSCOL (GEIPOT, 1980) 108

C.4. Estudo de Racionalização do Transporte Coletivo da Região Metropolitana de Belém - ERTCRMB (GEIPOT, 1986)

C.5. Plano Diretor de Transportes Urbanos - Região Metropolitana de Belém - República Federativa do Brasil - PDTU-RMB-91 (JICA, 1991)

C.6. Plano Diretor de Transporte Urbano da Região Metropolitana de Belém - PDTU-RMB-01 (JICA, 2001)

C.7. Estudo de Viabilidade Econômica de Projetos para o Melhoramento do Sistema de Transporte na Região Metropolitana de Belém na República Federativa do Brasil - EVE-MST-RMB (JICA, 2003) 126

C.8. Diretrizes de Ordenamento Territorial para a Região Metropolitana de Belém - DOT-RMB (PARÁ, 2006)

C.9. Estudo Preparatório para o Projeto de Sistema de Transporte de Ônibus da Região Metropolitana de Belém na República Federativa do Brasil - EP-STO-RMB (JICA, 2010). 134 



\section{C.1. ESTUDO DE TRANSPORTES URBANOS DA REGIÃO METROPOLITANA DE BELÉM / RECOMENDAÇÕES PARA IMPLANTAÇÃO IMEDIATA - RII- RMB (GEIPOT, 1978)}

Como o próprio título revela, o RII-RMB foi um plano que visava propor soluções de rápida implantação, procurando trazer melhorias para a qualidade do sistema de transportes e, mesmo, preparar o terreno para estudos mais detalhados que levariam à proposição e implantação de medidas mais efetivas de ordenação do sistema. Este é um esquema que foi muito utilizado pelo GEIPOT $^{10}$, ou seja, um encadeamento de estudos que possibilitaria a implantação e a obtenção de resultados já em curto prazo, sem que se precisasse aguardar um estudo de dois anos ou mais (Plano Diretor) para tratar do problema. Os levantamentos iniciais serviam tanto aos Relatórios para Implantação Imediata, quanto para estudos mais aprofundados como os de Transporte Coletivo TRANSCOL e os Planos Diretores de Transporte Urbano - PDTU. A seguir, se apresenta uma síntese do conteúdo de cada um dos capítulos do relatório final deste plano.

\section{RESUMO DO CONTEÚDO}

\begin{tabular}{|c|c|c|}
\hline & Capítulo & Conteúdo \\
\hline \multirow{2}{*}{\multicolumn{2}{|c|}{ A. Introdução }} & $\begin{array}{l}\text { Este capítulo trata de uma maneira geral dos problemas do sistema de transportes de } \\
\text { Belém e de suas possíveis causas. Diz que a Região Metropolitana de Belém, assim } \\
\text { como outras grandes cidades brasileiras, “... ressente-se da ausência de um } \\
\text { planejamento preventivo e, da insuficiência de recursos próprios, não apresentando } \\
\text { infraestrutura capaz de assimilar rapidamente os novos contingentes populacionais, } \\
\text { além de não atender às exigências dos novos costumes do mundo moderno". }\end{array}$ \\
\hline & & $\begin{array}{l}\text { São apresentadas duas listas. Uma com as consequências dessa falta de } \\
\text { planejamento e investimento em infraestrutura e outra com as principais causas dos } \\
\text { problemas do sistema. }\end{array}$ \\
\hline B. & Justificativas & $\begin{array}{l}\text { O texto se estende por apenas duas páginas e está centrado, basicamente, no } \\
\text { grande crescimento da população da cidade de Belém, que representava } 93 \% \text { do } \\
\text { total da RM, e nos problemas do sistema de transportes, principalmente do transporte } \\
\text { motorizado. Apresenta-se também uma pequena análise das estatísticas de } \\
\text { acidentes para o período de 1975/77. }\end{array}$ \\
\hline \multirow[t]{4}{*}{ C. } & $\begin{array}{l}\text { Objetivos do } \\
\text { Trabalho }\end{array}$ & $\begin{array}{l}\text { O objetivo geral do plano foi retirado, segundo o próprio texto, foi baseado nas metas } \\
\text { para o período 1980/85 do Plano Nacional de Transportes - PNT, que trata de “... } \\
\text { aumentar a produtividade, segurança e uso dos transportes coletivos e desestimular } \\
\text { a expansão da utilização do automóvel;..." }\end{array}$ \\
\hline & & $\begin{array}{l}\text { A partir daí, são apresentados três objetivos específicos que chegam, praticamente, } \\
\text { às soluções propostas. O primeiro deles é a melhoria do acesso à área central de } \\
\text { Belém, através da preparação de rotas (corredores) alternativas para o transporte } \\
\text { motorizado privado, desafogando os corredores principais (Av. Almirante Barroso e } \\
\text { Av. Nazaré / Av. Gov. José Malcher) para a utilização do transporte público. }\end{array}$ \\
\hline & & $\begin{array}{l}\text { Outro objetivo seria o de propor medidas de melhoria de calçadas e implantação de } \\
\text { sinalização adequada, visando melhorar as condições da circulação dos pedestres. }\end{array}$ \\
\hline & & $\begin{array}{l}\text { O terceiro objetivo seria a preparação da área central para esquemas futuros de } \\
\text { circulação que, no âmbito do projeto, consistiu da proposição da construção de um }\end{array}$ \\
\hline
\end{tabular}

10 “O GEIPOT foi criado pelo Decreto no 57.003, de 11 de outubro de 1965, com a denominação de Grupo Executivo de Integração da Política de Transportes e com sua direção superior formada pelo Ministro da Viação e Obras Públicas, Ministro de Estado da Fazenda, Ministro Extraordinário para o Planejamento e Coordenação Econômica e pelo Chefe do Estado Maior das Forças Armadas, conforme foi sugerido pelo Acordo de Assistência Técnica firmado naquele ano entre o governo brasileiro e o Banco Internacional para a Reconstrução e Desenvolvimento (BIRD)". Fonte: http://www.geipot.gov.br/ (acesso em 15/02/2012) 


\begin{tabular}{ll}
\hline \multicolumn{1}{c}{ Capítulo } & \multicolumn{1}{c}{ Conteúdo } \\
\hline & $\begin{array}{l}\text { anel viário que separaria a parte mais central, de uso mais intenso pelos pedestres, e } \\
\text { as vias de acesso que apresentam predominância de veículos motorizados. }\end{array}$ \\
\hline D. Área de Atuação & O texto fala de três possíveis abordagens para o estudo, das quais foi escolhida uma \\
& para ser desenvolvida: \\
& "Estudo das avenidas Nazaré e Almirante Barroso, criação de novos corredores \\
& destinados ao tráfego de passagem da periferia para o centro da cidade, \\
& desenvolvimento de estudos visando à proposição de obras que caracterizassem a \\
& formação de um anel viário para a Área Central e estudo de interseções \\
& problemáticas;". \\
& Segundo o relatório, esta alternativa apresentava "melhores perspectivas de \\
& integração com as fases futuras do projeto ...". \\
& Divididas em duas partes: \\
& - novos corredores, que inclui construção, alargamento e outras intervenções na \\
& geometria das vias; \\
E. Proposições de & - alteração do esquema de circulação, que recomenda alterações no sentido de vias \\
Âmbito Geral & e alteração da sinalização estatigráfica e semafórica.
\end{tabular}

F. Proposições de Segundo o relatório, "O tratamento dado às interseções e corredores, tem por Âmbito Específico objetivo assegurar uma circulação ordenada dos veículos, garantindo a segurança entre os diversos usuários do espaço viário: pedestres, condutores e passageiros de automóveis e ônibus, motoristas de caminhão, etc." Assim, as proposições constituem-se de:

- Dispositivos de canalização;

- Sinalização horizontal e vertical;

- Implantação ou remanejamento de semáforos;

- Regulamentação de estacionamento de veículos;

- Aumento da área de circulação de pedestres;

- Melhoria da pavimentação das ruas.

São apresentados projetos das várias intervenções, incluindo plantas detalhadas da via com a sinalização horizontal e vertical e um quadro com a estimativa de custos de implantação. As propostas cobrem os corredores, a área central e o anel viário próximo ao centro, conforme o estabelecido no capítulo dos objetivos, além das também citadas interseções isoladas. O relatório apresenta sempre, para cada projeto, a planta da situação atual e a da proposta.

\begin{tabular}{lll} 
G. Proposições & $\begin{array}{l}\text { Recomenda-se ainda, algumas medidas complementares para facilitar a implantação } \\
\text { das medidas centrais do plano. Elas dizem respeito tanto ao transporte motorizado, } \\
\text { com a melhoria da pavimentação de vias e rearranjo de itinerários de linhas de } \\
\text { ônibus, quanto à questão dos pedestres, com a proposta de criação de novas áreas } \\
\text { exclusivas, melhoria do acesso e das condições de conforto do terminal rodoviário. }\end{array}$ \\
\hline H. Custos - Resumo & $\begin{array}{l}\text { Aqui se apresenta um quadro com uma estimativa do custo total para a implantação } \\
\text { das medidas propostas no plano. }\end{array}$ \\
\hline
\end{tabular}

\section{COMENTÁRIOS}

Como ressaltado na seção anterior, este foi um plano com objetivo de dar uma resposta rápida aos problemas da população de Belém e a sua mobilidade. Embora o tratamento de região metropolitana, essa região era constituída do grande município de Belém e mais uma pequena cidade, Ananindeua. 
Apesar do foco exagerado no transporte por automóvel, refletindo a cultura da época11, as propostas de organização e correção da geometria do conjunto de vias, de alguma maneira favoreceram o transporte não motorizado. A seguir, trata-se do assunto, adotando uma classificação proposta para esta análise.

\section{Propostas para o transporte não motorizado}

As principais propostas do estudo dizem respeito à infraestrutura viária. Muitas das áreas tratadas eram constituídas de grandes espaços pavimentados, sem sinalização adequada para veículos, e pedestres tendo que enfrentar calçadas estreitas. A correção da geometria, estabelecendo as faixas de tráfego e as áreas de estacionamento, deixou "sobras" (áreas remanescentes) que foram destinadas a calçadas mais largas e mesmo áreas mais amplas para circulação dos pedestres. A melhor canalização dos veículos e a sinalização possibilitaram travessias mais seguras das vias.

O plano não trata do transporte por bicicleta.

\section{Propostas para o transporte público}

O plano não trata diretamente da operação do sistema de transporte público, mas procura favorecê-la com a ampliação e organização do sistema viário e a implantação de alguns trechos de vias exclusivas.

\section{Propostas para o transporte individual}

O transporte individual é o principal favorecido pelas propostas, mesmo se considerando as restrições de estacionamento e circulação em algumas áreas. Ele recebe, na área atingida pelo plano, um sistema de circulação organizado e adequadamente sinalizado.

\section{Propostas para o sistema viário}

Praticamente todas as propostas do plano se referem ao sistema viário.

\footnotetext{
${ }^{11}$ Deve-se ressaltar que propostas que favorecem o transporte motorizado individual continuam a existir nos dias atuais, mesmo considerando os avanços no sentido de incentivar os modos não motorizados.
} 


\section{C.2. ESTUDO DE TRANSPORTES URBANOS DA REGIÃO METROPOLITANA DE BELÉM I TRANSCOL - CICLOVIA DA BL-01 (GEIPOT, 1979)}

Este estudo foge um pouco do esquema do GEIPOT, já que se trata de uma proposta para implantação de um sistema isolado do conjunto do sistema de transportes. Trata-se de uma publicação em caráter preliminar, em virtude da "... solicitação do Exmo. Sr. Prefeito de Belém que, compreendendo a importância desta obra, deseja implantá-la de imediato, aproveitando a realização das obras de recuperação da BL-01 e o período de estiagem que se estende até dezembro". Um resumo do conteúdo do relatório é apresentado a seguir.

\section{RESUMO DO CONTEÚDO}

\begin{tabular}{|c|c|c|}
\hline & Capítulo & Conteúdo \\
\hline A. & $\begin{array}{l}\text { Considerações } \\
\text { Iniciais }\end{array}$ & $\begin{array}{l}\text { Neste capítulo trata-se da justificativa da antecipação da publicação do projeto, } \\
\text { conforme descrito acima, e da caracterização da necessidade da construção de uma } \\
\text { ciclovia nessa região que liga ao distrito de Icoaraci, região que abriga várias } \\
\text { indústrias. Estas se localizam ao longo da rodovia municipal BL-01. }\end{array}$ \\
\hline \multirow[t]{2}{*}{ B. } & Diagnóstico & $\begin{array}{l}\text { Além do levantamento das informações sobre a ocupação do solo local por indústrias, } \\
\text { foram realizadas entrevistas com os operários dessas empresas e contagens do } \\
\text { número de bicicletas circulando ao longo da rodovia. }\end{array}$ \\
\hline & & $\begin{array}{l}\text { Foram levantadas as origens e destinos das viagens realizadas por bicicleta, os } \\
\text { problemas enfrentados pelos usuários e as razões para escolha desse modo de } \\
\text { transporte. Verificou-se também a quantidade de pessoas que possuíam bicicleta, mas } \\
\text { não a utilizavam por falta de uma infraestrutura mais adequada. }\end{array}$ \\
\hline C. & $\begin{array}{l}\text { Proposição da } \\
\text { Ciclovia da BL- } \\
01\end{array}$ & $\begin{array}{l}\text { A proposição ficou no nível de anteprojeto e tratou dos seguintes aspectos: } \\
\text { - } \quad \text { Geométrico; } \\
\text { - } \quad \text { Sinalização; } \\
\text { - } \quad \text { Pavimentação; } \\
\text { - } \quad \text { Abrigos; } \\
\text { - Paisagismo. } \\
\text { São apresentadas as plantas da ciclovia, contendo os elementos de sinalização e } \\
\text { paisagismo, além de detalhes construtivos dos abrigos. }\end{array}$ \\
\hline D. & Conclusão & $\begin{array}{l}\text { A conclusão destaca, principalmente, o pioneirismo desse tipo de projeto no Brasil, } \\
\text { mesmo considerando-se que foi publicado ainda incompleto, deixando alguns aspectos } \\
\text { para serem resolvidos quando da implantação. }\end{array}$ \\
\hline E. & Custos & O estudo apresenta um orçamento para implantação da ciclovia. \\
\hline
\end{tabular}

\section{COMENTÁRIOS}

Este é apenas um estudo parcial. Adiantaram-se alguns resultados do TRANSCOL (GEIPOT, 1980) para atender a uma necessidade da administração local. Esta proposta de implantação de ciclovia, provavelmente um dos primeiros projetos desse tipo feito para uma grande cidade brasileira, representou um avanço no sentido de valorizar o transporte não motorizado. No entanto, como será visto nas próximas seções, não foi suficiente para criar uma rotina de melhoria da infraestrutura para o modo cicloviário. 


\section{Propostas para o transporte não motorizado}

Este é um plano específico para o transporte não motorizado. Deve-se destacar que no plano anterior, e que faz parte da série, o transporte por bicicleta nem foi citado. Isso pode ter ocorrido porque esta área não era as mais problemáticas do sistema de transportes de Belém. Pode ter surgido da ideia de algum técnico que encontrou apoio no prefeito da época.

\section{Propostas para o transporte público}

O plano não trata do sistema de transporte público.

\section{Propostas para o transporte individual}

O plano não trata do transporte individual motorizado.

\section{Propostas para o sistema viário}

A proposta do plano trata do sistema viário com a utilização de uma rodovia que estava em recuperação/ampliação, melhorando-a com a adição da ciclovia que possibilita a separação dos fluxos das bicicletas dos veículos motorizados. 


\title{
C.3. ESTUDO DE TRANSPORTES URBANOS DA REGIÃO METROPOLITANA DE BELÉM I ESTUDO DE TRANSPORTES COLETIVOS - TRANSCOL (GEIPOT, 1980)
}

\begin{abstract}
Este estudo constitui a segunda etapa do Estudo de Transportes da RMB. Segundo a apresentação do relatório, "Com alcance de médio prazo, as proposições aqui apresentadas destinam-se à solução dos angustiantes problemas enfrentados pela população de Belém nos seus deslocamentos realizados por transporte coletivo". O objetivo geral é a reorganização / otimização do sistema de transporte público por ônibus, incluindo medidas de prioridade no sistema viário e adequação do serviço à demanda do crescente número de viagens ligando a área central e os bairros periféricos dos dois municípios componentes da RMB. Aqui já foram utilizados os dados da pesquisa domiciliar, realizada em 1978, que atingiu 13000 habitações.
\end{abstract}

\section{RESUMO DO CONTEÚDO}

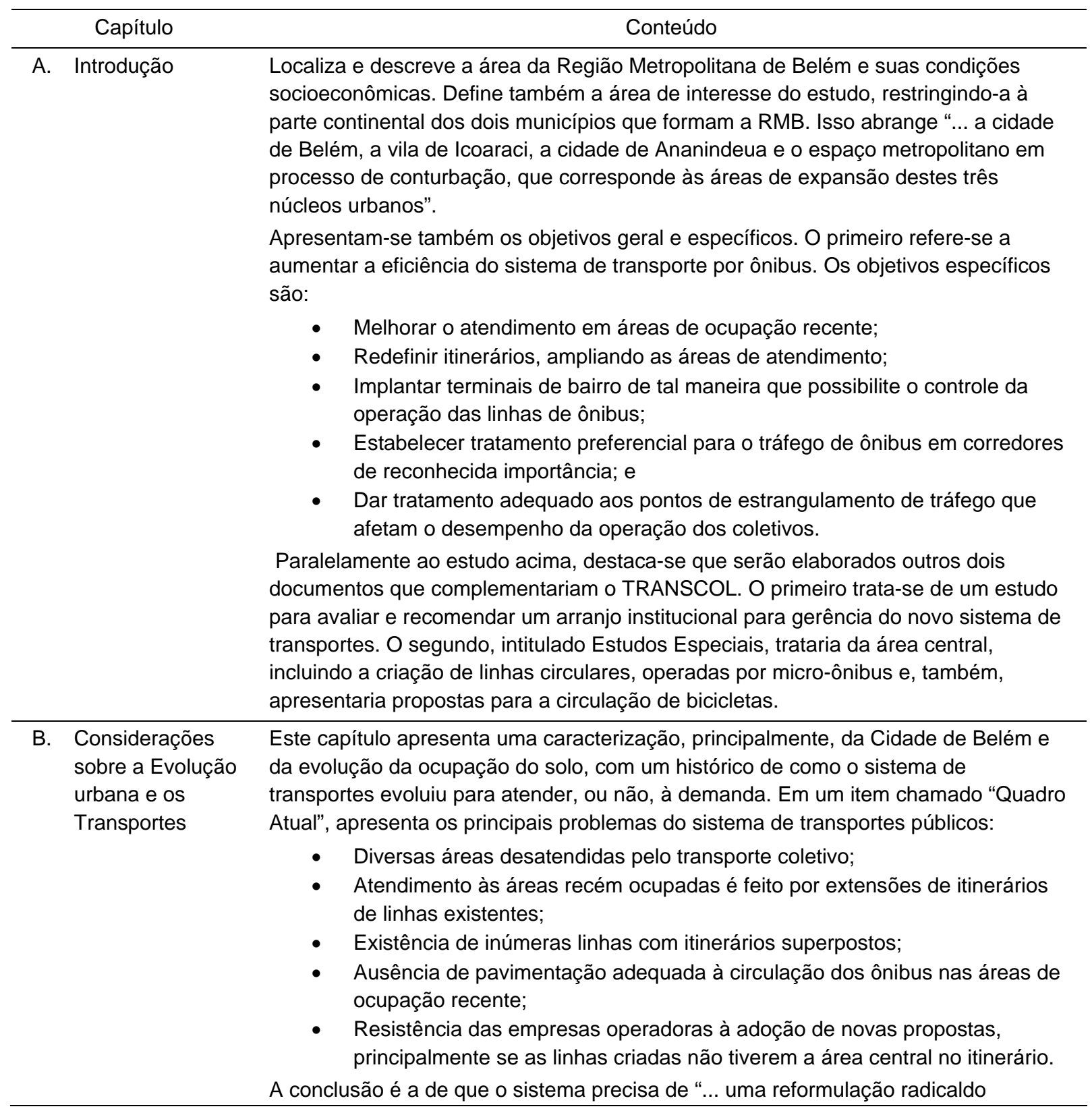




\begin{tabular}{|c|c|c|}
\hline \multirow{2}{*}{\multicolumn{2}{|c|}{ Capítulo }} & Conteúdo \\
\hline & & atendimento em todos os seus aspectos". \\
\hline C. & $\begin{array}{l}\text { Levantamentos } \\
\text { Básicos para o } \\
\text { Processo de } \\
\text { Análise }\end{array}$ & 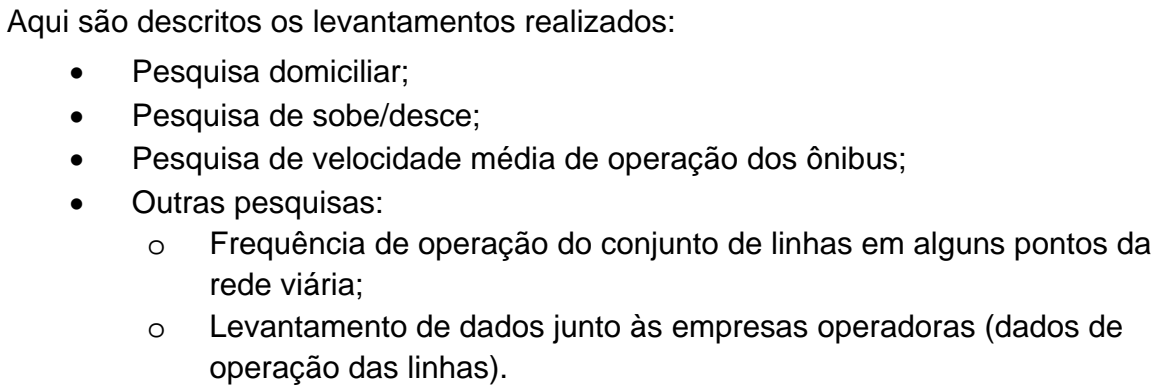 \\
\hline
\end{tabular}

D. Dados da Oferta Aqui são apresentados dados das 36 linhas de ônibus da RMB, sendo que apenas uma é metropolitana. Foi feito um levantamento completo de itinerários e localização de pontos de parada. Também se descreve as características da frota, na qual se pode destacar uma idade média de 2,9 anos, que é um valor abaixo da média normalmente considerada como adequada.

\begin{tabular}{ll}
\hline E. Dados da & Aqui se apresentam os resultados da pesquisa domiciliar, nos aspectos referentes ao \\
Demanda & transporte por ônibus. A demanda é caracterizada por matrizes de origem-destino, \\
& gráficos de variação ao longo do dia e mapas de linhas de desejo. A repartição modal \\
& é apresentada como:
\end{tabular}

- Ônibus - 67,4\%

- $\quad$ Automóveis - $25 \%$

- Táxis - 7,6\%

Deve-se destacar que, neste caso, o transporte não motorizado é, simplesmente, ignorado.

Apresentam-se também alguns dados socioeconômicos, estratificados pelas zonas de tráfego.

$\begin{array}{ll}\text { F. Análise do } & \text { Esta análise esta dividida em: } \\ \text { Sistema Atual } & \text { - Aspectos da infraestrutura: } \\ & \text { - Características dos itinerários } \\ & \text { - } \text { Características da demanda } \\ & \text { - Repartição modal } \\ & \text { - } \text { Variação temporal das viagens }\end{array}$

Aqui são mais detalhados, na maioria, aspectos já destacados nos capítulos sobre a oferta e a demanda.

A característica radioconcêntrica da rede de linhas de ônibus urbanos dificulta a mobilidade das pessoas no caso daquelas viagens que não se destinam à área central. Não existia uma padronização do layout interno dos ônibus e até mesmo a integração física entre as linhas era dificultada pela não possibilidade de veículos de empresas diferentes operarem no mesmo terminal.

G. Diretrizes Gerais Foi realizada reunião com dirigentes e técnicos de tos os órgãos envolvidos “... no para o Sistema planejamento, na execução de obras físicas e na operação do sistema de transportes da RMB..." aos quais foram apresentadas três opções de diretrizes para elaboração das propostas.

- $\quad$ Alternativa 1 - racionalização do sistema de transportes coletivos atual;

- $\quad$ Alternativa 2 - implantação de uma nova rede de transportes coletivos, sem "maiores compromissos" com a configuração anterior, atendendo de maneira mais próxima às linhas de desejo de viagens. Inclui também a ideia de implantação de corredores prioritários para o transporte público.

- Alternativa 3 - Abandono total do sistema anterior e a criação de um único corredor estrutural operando em um esquema tronco-alimentador.

Foi escolhida a primeira alternativa, mas “... propuseram, também, que a equipe fizesse o possível para adequá-la, em termos de proposições físicas, às 


\begin{tabular}{|c|c|c|}
\hline \multirow{2}{*}{\multicolumn{2}{|c|}{ Capítulo }} & Conteúdo \\
\hline & & $\begin{array}{l}\text { recomendações da segunda alternativa, a fim de preparar a nova rede de ônibus, a } \\
\text { médio prazo, para o atendimento das mudanças do comportamento da população, } \\
\text { em face das intenções de reorganização futura do uso do solo urbano". }\end{array}$ \\
\hline \multirow[t]{5}{*}{$\mathrm{H}$. } & Rede Básica & Esta rede era constituída de quatro componentes principais: \\
\hline & Proposta & $\begin{array}{l}\text { - Corredores de transporte coletivo } \\
\text { - Vias complementares de transporte coletivo } \\
\text { - Anel viário da área central e vias de ligação dos corredores ao anel } \\
\text { - Terminais de bairros }\end{array}$ \\
\hline & & $\begin{array}{l}\text { Conforme visto no capítulo anterior, o sistema será racionalizado. Algumas linhas } \\
\text { terão o itinerário alterado, buscando distribuir o carregamento por outras vias e, com } \\
\text { isso, aumentar a velocidade de operação. }\end{array}$ \\
\hline & & $\begin{array}{l}\text { A construção dos terminais de bairro é saudada como uma maneira de “... iniciar o } \\
\text { processo de controle da operação dos coletivos". }\end{array}$ \\
\hline & & $\begin{array}{l}\text { Segue-se a essa introdução um total de } 283 \text { páginas com plantas de cada trecho do } \\
\text { projeto, incluindo geometria da via e sinalização, além de quadros de orçamento. }\end{array}$ \\
\hline \multirow[t]{3}{*}{ I. } & $\begin{array}{l}\text { Processo } \\
\text { Operacional } \\
\text { Proposto }\end{array}$ & $\begin{array}{l}\text { Dividiu-se a operação em três tipos de serviço: principal, expresso e circular. O que } \\
\text { se chama de principal é o serviço normal das linhas existentes, ligando os bairros às } \\
\text { áreas centrais. Uma linha na área central de Belém e duas na área central de } \\
\text { Icoaraci serão do tipo circular, ligando estas áreas aos bairros vizinhos. Para as } \\
\text { ligações mais longas, propôs-se a oferta de viagens do tipo expresso, com menor } \\
\text { número de paradas intermediárias. }\end{array}$ \\
\hline & & $\begin{array}{l}\text { Apresenta-se todo o conjunto de linhas, com a descrição dos itinerários e a nova } \\
\text { numeração, que considera o terminal do bairro de origem, e um conjunto de } \\
\text { parâmetros operacionais. }\end{array}$ \\
\hline & & $\begin{array}{l}\text { Também se recomenda a padronização da frota de veículos, para os quais são } \\
\text { detalhadas condições de conforto e segurança. Propões ainda um modelo de } \\
\text { sinalização informativa para os pontos de parada e terminais. }\end{array}$ \\
\hline $\mathrm{J}$. & $\begin{array}{l}\text { Custos do } \\
\text { Sistema Básico } \\
\text { Proposto }\end{array}$ & $\begin{array}{l}\text { Aqui se apresentam os custos totais de execução do projeto, incluindo despesas com } \\
\text { desapropriações, obras viárias, sinalização, edificações, elaboração de projetos, } \\
\text { medidas complementares e divulgação e publicidade. }\end{array}$ \\
\hline \multirow[t]{4}{*}{ L. } & $\begin{array}{l}\text { Avaliação do } \\
\text { Sistema Proposto }\end{array}$ & $\begin{array}{l}\text { A avaliação seguiu o método de se calcular a relação benefício/custo econômico para } \\
\text { a área do projeto. Destacam-se a existência de benefícios quantificados e não } \\
\text { quantificados. Estes últimos são apenas relacionados e incluem o aumento da } \\
\text { acessibilidade, maior conforto e conveniência, maior segurança para os pedestres e } \\
\text { fluidez para o tráfego em geral. Destaca também a melhoria da qualidade ambiental } \\
\text { da Área Central com o aumento das áreas exclusivas para pedestres e a organização } \\
\text { do tráfego de veículos motorizados. }\end{array}$ \\
\hline & & Os custos e benefícios quantificados foram: \\
\hline & & $\begin{array}{l}\text { - Benefícios da rede de transportes coletivos (redução de tempo de viagem); } \\
\text { - } \text { Benefícios do sistema expresso (idem); } \\
\text { - } \text { quilomento do custo operacional do sistema de transporte coletivo (maior } \\
\text { - Custos de implantação do sistema. }\end{array}$ \\
\hline & & $\begin{array}{l}\text { A relação B/c resultou em } 1,26 \text {, para uma taxa de desconto de } 11 \% \text { a.a., } \\
\text { proporcionando uma taxa interna de retorno de } 20,9 \% \text {. }\end{array}$ \\
\hline \multirow[t]{2}{*}{ M. } & $\begin{array}{l}\text { Medidas } \\
\text { Complementares }\end{array}$ & $\begin{array}{l}\text { A principal medida complementar, de acordo com o relatório, seria a organização } \\
\text { institucional, isto é, seria preciso criar um órgão de gerência com competência } \\
\text { técnica e legal para o novo sistema. }\end{array}$ \\
\hline & & $\begin{array}{l}\text { Existem também recomendações quanto aos equipamentos necessários à operação } \\
\text { do sistema viário durante a realização das obras; quanto à área de comunicação, } \\
\text { para informar o usuário sobre a operação do novo sistema e de como ele pode tirar } \\
\text { melhor proveito do mesmo; e a preparação do pessoal de fiscalização e operação do } \\
\text { sistema. }\end{array}$ \\
\hline
\end{tabular}




\section{COMENTÁRIOS}

Este estudo já tem um escopo bem maior do que o RII-RMB (GEIPOT, 1978) e já contou com uma melhor base de dados, proveniente da pesquisa domiciliar. O objetivo principal foi a melhoria do sistema de transporte coletivo por ônibus, mas a escolha da opção para operação do novo sistema foi bastante modesta, provavelmente em virtude da pressão conservadora das empresas operadoras.

Considerando os recursos empregados na realização das pesquisas de campo, poderia ter sido feita uma proposta que buscasse atender as necessidades da população, sem a preocupação de preservar a estrutura do sistema atual.

\section{Propostas para o transporte não motorizado}

A preocupação com o transporte não motorizado aparece quando o estudo trata das áreas de pedestre, do centro da cidade, que serão melhoradas e ampliadas. Existe certa preocupação com o acesso ao sistema de transporte público, mas ela não se estende muito além dos terminais e pontos de parada. O transporte por bicicleta aparece apenas nas plantas, já que parte da área atendida por este projeto contempla aquela do estudo preliminar da ciclovia de Icoaraci (GEIPOT, 1979). Quando trata da divisão modal, o estudo cita apenas os modos motorizados (ver item E da tabela de conteúdo). A solução envolvendo "uma nova rede de ônibus" foi deixada para o "médio prazo".

\section{Propostas para o transporte público}

As propostas para o transporte público compreendem a reformulação das linhas existentes, incluindo mudanças de itinerário e redimensionamento da oferta, implantação de faixas exclusivas ou prioritárias para o tráfego dos ônibus, construção de terminais de bairro e melhoria das condições dos pontos de parada. É uma proposta que poderia ter melhorado muito a qualidade do transporte por ônibus na RMB, mas poderia ser mais arrojado, propondo uma solução de maior eficácia, com integração não apenas física e no centro da cidade, mas atendendo as demais importantes linhas de desejo.

\section{Propostas para o transporte individual}

O transporte individual é bastante beneficiado na medida em que grande parte dos recursos destinase a melhorias do sistema viário. Além disso, neste caso, as faixas para ônibus seriam utilizadas por várias linhas de ônibus, diferente do que seria em um sistema tronco-alimentado. Assim, a implantação de uma faixa exclusiva para ônibus, nesses corredores, pode ser vista como a implantação de duas faixas exclusivas para os automóveis e os demais veículos.

\section{Propostas para o sistema viário}

A maior parte dos recursos propostos se referiu a obras no sistema viário, com $65,3 \%$ do total orçado. Adicionando os custos de desapropriação e de sinalização, essa fatia sobe para 78,5\%. A parcela referente aos custos dos corredores de transportes, aquelas vias com faixas exclusivas ou preferenciais para os ônibus, foi de 34,5\%. 


\section{C.4. ESTUDO DE RACIONALIZAÇÃO DO TRANSPORTE COLETIVO DA REGIÃO METROPOLITANA DE BELÉM - ERTC-RMB (GEIPOT, 1986)}

Dentro da lógica da série de estudos do GEIPOT, o estudo seguinte deveria ser o Plano Diretor de Transportes Urbanos. Este estudo de racionalização apresenta-se como uma atualização do TRANSCOL. A razão deve ser o fato de que muito poucas das propostas anteriores foram implantadas. Trata-se, como será visto a seguir de mais um plano pouco ambicioso, que praticamente mantém o modo corrente de operação.

Deve-se destacar a participação, neste projeto, de duas novas instituições. A Empresa Metropolitana de Transportes Urbanos de Belém, criada em 1982 ${ }^{12}$, e a Empresa Brasileira dos Transportes Urbanos, criada em $1975^{13}$. Nesta época o GEIPOT mantinha a mesma sigla, mas já se denominava Empresa Brasileira de Planejamento de Transportes. A criação da EMTU denotava o atendimento de uma das recomendações do TRANSCOL, a organização institucional, que é fundamental para uma boa gerência do sistema de transportes de uma região metropolitana.

$\mathrm{Na}$ apresentação se destaca que:

Assim, o objetivo principal deste estudo é propor medidas para racionalizar o transporte coletivo na RMB, por meio da análise dos desejos de viagens da população e da operação atual do sistema.

Para atingir esse objetivo é necessário alcançar algumas metas específicas: suprimir ou retificar trechos de itinerário de linhas, criar itinerários racionais, adequar oferta à demanda.

A EMTU aparece como a instituição que tem, "por delegação das prefeituras, mediante convênio, competência para administrar e gerenciar os serviços de transporte público de passageiros". O estudo faz somente "a avaliação operacional do sistema proposto, quantitativa e quantitativamente". Traz ainda recomendações para a continuidade ao processo de planejamento de transportes. O conteúdo é sintetizado a seguir.

\section{RESUMO DO CONTEÚDO}

\begin{tabular}{|c|c|}
\hline Capítulo & Conteúdo \\
\hline \multirow[t]{4}{*}{ 1. Introdução } & $\begin{array}{l}\text { Neste curto capítulo são apresentadas algumas informações preliminares sobre o } \\
\text { enquadramento do estudo como parte de um processo de planejamento do sistema de } \\
\text { transportes da RMB, descreve-se a área de estudo e os objetivos do mesmo. }\end{array}$ \\
\hline & $\begin{array}{l}\text { Criticando a "forma simplista" de procurar atender a novas demandas do sistema, } \\
\text { apresenta-se o objetivo principal do estudo que é "encontrar medidas e soluções para } \\
\text { racionalizar o transporte coletivo por ônibus da RMB, por um período máximo de cinco } \\
\text { anos, através do conhecimento dos desejos de viagens da população e da operação } \\
\text { das concessionárias do sistema". }\end{array}$ \\
\hline & Segue uma relação de metas específicas: \\
\hline & $\begin{array}{l}\text { - Promover a eficiência do transporte público por ônibus em áreas de ocupação } \\
\text { recente; } \\
\text { - Retificar itinerários de linhas, para suprimir trechos desnecessários ao }\end{array}$ \\
\hline
\end{tabular}

\footnotetext{
${ }^{12}$ A EMTU foi extinta em 1990.

${ }^{13}$ A EBTU foi extinta em 1991
} 


\begin{tabular}{ll}
\hline Capítulo & \multicolumn{1}{c}{ Conteúdo } \\
\hline - & Crendimento da demanda; \\
desejos de viagens da população; & \\
- & Reduzir tempos de viagens, distribuindo melhor os pontos de parada ao longo \\
dos itinerários; & Redimensionar a oferta de lugares, adequando-a à flutuação da demanda; \\
- & Redefinir a localização dos terminais de bairro; \\
- & Reduzir as transferências, efetuando melhorias nas que permanecerem.
\end{tabular}

2. Urbanização e Neste capítulo traça-se um rápido perfil da RMB, principalmente da cidade de Belém, e Estrutura Viária da maneira como ocorreu e está ocorrendo a sua ocupação. Destaca o processo de desocupação desordenada da região periférica, além dos limites da chamada "Primeira Légua", o núcleo tradicional de urbanização de Belém. O centro da cidade continua a ser o principal polo de atração de viagens.

Sobre a estrutura viária, o relatório apenas destaca que ela pouco mudou desde o último estudo (TRANSCOL).

3. Situação Atual O capítulo tem início com os aspectos institucionais, apresentando as instituições do Transporte Coletivo envolvidas no transporte público de passageiros da RMB:

- Empresa Brasileira dos Transportes Urbanos - EBTU

- Empresa Brasileira de Planejamento de Transportes - GEIPOT

- Departamento Nacional de Estradas de Rodagem - DNER

- Departamento de Estradas de Rodagem do Estado do Pará - DER-PA

- Departamento de Trânsito do Estado do Pará - DETRAN-PA

- Empresa Metropolitana de Transportes Urbanos de Belém - EMTU/Belém

- $\quad$ Secretaria Municipal de Obras - SEMOB

- Departamento Municipal de Estradas de Rodagem - DMER

Nos aspectos organizacionais merece destaque o parágrafo que afirma que a atuação da EMTU/Belém "... no cumprimento de suas atribuições não tem alcançado total êxito, por diversos motivos, entre os quais o da não-regulamentação (grifo do autor) dos serviços de transportes públicos".

Nos aspectos tarifários apresenta-se a diferença que existe desde 1985, que é a tarifa única para a RMB. Anteriormente, três linhas apresentavam uma tarifa mais alta.

Os dados operacionais e outras características das linhas de ônibus são apresentados nos aspectos da oferta, que é composta por 18 empresas concessionárias (grifo do autor), que exploram 51 linhas, com uma frota de 813 ônibus, com idade média de 3,4 anos.

Por fim, são apresentados os aspectos da demanda. Em virtude de alterações feitas pelo IBGE nos limites dos setores censitários, ficou inviável, segundo o relatório, a utilização dos dados da pesquisa domiciliar dos estudos anteriores. Foi feita uma nova divisão de zonas de tráfego e a demanda de viagens foi calculada a partir de dados da pesquisa de embarque/desembarque, realizada pela EMTU em 1984/85, e se fez uma pesquisa de origem/destino por entrevistas nos ônibus que cobriu apenas a chamada Área de Expansão, isto é, excluída a área da $1^{\mathrm{a}}$. Légua.

Assim, tem-se o conhecimento das origens e destinos apenas das viagens geradas na Área de Expansão. Para o restante, os dados permitem calcular o carregamento das linhas e vias pelas quais passam os ônibus, além de identificar a flutuação da demanda ao longo do dia. Vale destacar que a demanda diária total de viagens por ônibus não é apresentada.

4. Princípios básicos do Estudo
É um capítulo que consta de dois tópicos com três parágrafos cada um. Nas "Considerações Gerais" está escrito que os princípios básicos foram definidos pelo estudo "na ausência de diretrizes estabelecidas para o transporte público de passageiros na RMB - de competência da EMTU/Belém".

A definição levou em conta a reduzida capacidade de investimento no sistema viário, o quadro institucional vigente e a perspectiva de se adotarem tecnologia de alta capacidade em um futuro próximo (grifo do autor). Espera-se que os princípios 


\begin{tabular}{|c|c|c|}
\hline \multicolumn{2}{|r|}{ Capítulo } & Conteúdo \\
\hline & & $\begin{array}{l}\text { adotados levem "à melhoria na utilização da malha viária existente, à racionalização da } \\
\text { operação e a um melhor atendimento da demanda, principalmente da população da } \\
\text { área da faixa de influência dos corredores". }\end{array}$ \\
\hline & & $\begin{array}{l}\text { No tópico que trata do "Modelo Físico-Operacional" destaca-se que o conjunto de } \\
\text { linhas da RMB continua com uma configuração predominantemente radial e que o } \\
\text { estudo não identificou necessidade de linhas transversais. O estudo procurou ainda } \\
\text { "imprimir uma visão de eixos troncais para transporte coletivo". }\end{array}$ \\
\hline \multirow[t]{3}{*}{5.} & $\begin{array}{l}\text { Rede Básica } \\
\text { Proposta }\end{array}$ & $\begin{array}{l}\text { O capítulo inicia por uma "Descrição Geral da Rede" na qual, mais uma vez, são } \\
\text { descritos os principais problemas do transporte público e se apresenta a concepção } \\
\text { geral: }\end{array}$ \\
\hline & & $\begin{array}{l}\text { - Criação de duas novas linhas denominadas de "linhas de corredor", criando } \\
\text { - } \quad \text { uma espécie de "embrião" de um futuro sistema de maior capacidade; } \\
\text { estrutura urbana"; } \\
\text { - As intervenções proposta contemplaram a supressão de trechos de itinerários; } \\
\text { redução do número de pontos de parada; redução do número de conversões } \\
\text { à esquerda; extinção e criação de linhas; e adequação da oferta; e melhoria } \\
\text { do atendimento de deslocamentos dos usuários. }\end{array}$ \\
\hline & & $\begin{array}{l}\text { A proposta visou, “... basicamente, a proporcionar ganho de tempo de percurso e maior } \\
\text { confiabilidade, a reduzir o número de transferências e a dar maior conforto e segurança } \\
\text { ao usuário de ônibus na RMB". }\end{array}$ \\
\hline \multirow[t]{4}{*}{6.} & $\begin{array}{l}\text { Avaliação } \\
\text { Operacional do }\end{array}$ & $\begin{array}{l}\text { Segundo o relatório, "O sistema proposto foi avaliado segundo sua eficiência } \\
\text { operacional, a nível quantitativo e qualitativo". }\end{array}$ \\
\hline & $\begin{array}{l}\text { Sistema } \\
\text { Proposto }\end{array}$ & $\begin{array}{l}\text { Em termos quantitativos, comparou-se a quilometragem diária percorrida nas situações } \\
\text { com e sem projeto. Assim, se obtém uma redução de } 3.679 \mathrm{~km} \text {, que equivale a uma } \\
\text { economia de } 3.973 \text { litros de combustível. Esta economia ocorreria não apenas pela } \\
\text { redução da quilometragem percorrida, mas também do aumento da velocidade, } \\
\text { estimado entre } 3 \text { e } 5 \% \text {. }\end{array}$ \\
\hline & & $\begin{array}{l}\text { Em termos qualitativos, são apresentados benefícios “... que são de difícil } \\
\text { mensuração": }\end{array}$ \\
\hline & & $\begin{array}{l}\text { - Maior confiabilidade no sistema; } \\
\text { - Maior conforto e segurança; } \\
\text { - Menores caminhadas a pé para acesso ao sistema; } \\
\text { - Menor tempo de espera nos pontos de parada; } \\
\text { - Menor despesa para os usuários. }\end{array}$ \\
\hline \multirow[t]{2}{*}{7.} & $\begin{array}{l}\text { Considerações } \\
\text { Finais }\end{array}$ & $\begin{array}{l}\text { Aqui se destaca que as medidas recomendadas pelo estudo não serão suficientes para } \\
\text { "... eliminar o quadro de inércia em que se encontra o setor de transporte coletivo na } \\
\text { Área de Interesse. É necessário complementá-las com outras medidas saneadoras, } \\
\text { como: estabelecer novas regras para o quadro institucional, adotar um plano e } \\
\text { controlar a utilização do solo e fortalecer os órgãos atuantes no setor". }\end{array}$ \\
\hline & & $\begin{array}{l}\text { Reforçam-se, ainda, recomendações do TRANSCOL (GEIPOT, 1980) e a necessidade } \\
\text { da continuidade dos estudos que levem a um Plano Diretor de Transportes Urbanos - } \\
\text { PDTU. }\end{array}$ \\
\hline
\end{tabular}

\section{COMENTÁRIOS}

Esta é mais uma tentativa de se organizar o sistema de transporte coletivo por ônibus da Região Metropolitana de Belém, mas parece que as dificuldades são grandes. Boa parte do material produzido nos estudos anteriores, principalmente os dados da pesquisa origem-destino, já deixou de 
ser considerada, por já estar defasada e pelo novo arranjo dos setores censitários utilizados pelo IBGE no Censo de 2000.

\section{Propostas para o transporte não motorizado}

Trata-se de um plano que tratou exclusivamente das questões do transporte coletivo por ônibus.

\section{Propostas para o transporte público}

Conforme descrito acima, todas as propostas deste estudo visam à racionalização do transporte coletivo da RMB, com intervenções como:

- Supressão de trechos de itinerários;

- Redução do número de pontos de parada;

- Redução do número de conversões à esquerda;

- Extinção e criação de linhas;

- Adequação da oferta;

- Melhoria do atendimento de deslocamentos dos usuários.

\section{Propostas para o transporte individual}

Trata-se de um plano que tratou exclusivamente das questões do transporte coletivo por ônibus.

\section{Propostas para o sistema viário}

Trata-se de um plano que tratou exclusivamente das questões do transporte coletivo por ônibus. Foram feita recomendações, gerais, de melhorias das condições do pavimento das vias pelas quais circulam os ônibus. 


\section{C.5. PLANO DIRETOR DE TRANSPORTES URBANOS - REGIÃO METROPOLITANA DE BELÉM - REPÚBLICA FEDERATIVA DO BRASIL - PDTU-RMB-91 (JICA, 1991)}

Depois de três anos de publicação do último estudo, o ERTC-RMB (GEIPOT, 1986), e seguindo uma de suas recomendações, foram iniciados os trabalhos deste Plano Diretor de Transportes Urbanos. Este novo estudo já não conta com a participação da EBTU ou GEIPOT, cujos processos de extinção começaram pouco depois. Também o órgão metropolitano, a EMTU, foi extinto no ano de conclusão deste projeto. Não eram boas notícias para um setor no qual a carência de organização institucional era um dos principais problemas.

A nova instituição participante e executora do estudo foi a JICA - Agência de Cooperação Internacional do Japão. O estudo foi realizado mediante convênio desta agência com o Governo do Estado do Pará, com a interveniência dos governos brasileiro e japonês.

Foram feitos os levantamentos de dados e adotados os procedimentos padrão do processo usual de planejamento de transportes. A seguir, se apresenta um resumo do que constitui o relatório final deste plano.

\section{RESUMO DO CONTEÚDO}

\begin{tabular}{|c|c|}
\hline Capítulo & Conteúdo \\
\hline \multirow[t]{3}{*}{ 1. Introdução } & $\begin{array}{l}\text { Aqui se apresenta uma visão geral do estudo, incluindo uma primeira caracterização } \\
\text { dos problemas de trânsito e transportes da RMB, como base para a justificativa de } \\
\text { realização do mesmo. O objetivo é definido: }\end{array}$ \\
\hline & $\begin{array}{l}\text { “... formular um plano diretor abrangendo políticas de transporte e plano de } \\
\text { desenvolvimento e programa de longo e médio prazos, incluindo planejamento do uso } \\
\text { do solo futuro da Área de Estudo, que efetivamente atenderá as demandas presente e } \\
\text { futura e contribuirá para o desenvolvimento urbano na Região Metropolitana de Belém." }\end{array}$ \\
\hline & $\begin{array}{l}\text { Define-se a área de estudo e são apresentadas as etapas do trabalho, começando por } \\
\text { extenso trabalho de coleta de dados. Segue a análise dos dados e da situação atual, } \\
\text { identificando-se os problemas e a demanda do sistema (atual e prevista). A partir daí } \\
\text { são propostas soluções em termos de planos para os sistemas viário, de transporte } \\
\text { público e gerência de tráfego. }\end{array}$ \\
\hline
\end{tabular}

2. Tendência da Aqui são apresentados dados sobre a população e sua tendência de crescimento. São Socioeconomia dados sociais e econômicos, tais como idade, sexo, renda, emprego, PIB e propriedade de veículos. Os dados são agregados por "zonas integradas", divisão administrativa utilizada pelo poder público local.

3. Uso do solo Aqui se apresenta um histórico de formação da cidade de Belém e da RM. Além da atual forma como ocorreu a ocupação do solo, são descritas as características físicas e ambientais, incluindo as limitações impostas pela legislação de uso e ocupação do solo vigente.

Para a cidade de Belém existia legislação para regular o uso do solo e planejar a futura ocupação. O mesmo não ocorria com Ananindeua, o que fazia prever uma expansão maior da urbanização dessa cidade.

Os principais problemas apontados foram:

- Concentração excessiva das atividades na área central de Belém;

- Segregação das áreas residenciais por nível de renda;

- Existência de área institucional ao redor da área central, dificultando a travessia com ampliação da rede de transportes. 


\begin{tabular}{|c|c|}
\hline Capítulo & Conteúdo \\
\hline $\begin{array}{l}\text { 4. Condições } \\
\text { atuais das vias }\end{array}$ & $\begin{array}{l}\text { No início, são relacionadas as instituições responsáveis pelo sistema viário, nos níveis } \\
\text { federal, estadual e municipal. O conjunto de vias da área de estudo é descrito em } \\
\text { termos de sua classificação funcional, condições do pavimento, largura e existência de } \\
\text { estruturas como pontes e viadutos. }\end{array}$ \\
\hline $\begin{array}{l}\text { 5. Condições } \\
\text { atuais de } \\
\text { tráfego }\end{array}$ & $\begin{array}{l}\text { São caracterizadas as condições atuais do tráfego, dividindo-se em: } \\
\text { - Volume de tráfego } \\
\text { - } \quad \text { Tempo de viagem } \\
\text { - } \quad \text { Controle de tráfego } \\
\text { - Estacionamento } \\
\text { São apresentados, para cada um desses itens, relatórios de levantamento de dados } \\
\text { bem abrangente. }\end{array}$ \\
\hline $\begin{array}{l}\text { 6. Pesquisa de } \\
\text { transporte } \\
\text { público }\end{array}$ & $\begin{array}{l}\text { Os sistemas de transporte público por ônibus e por táxis são apresentados, com dados } \\
\text { de oferta e demanda. Os dados são provenientes da pesquisa domiciliar e de outras, } \\
\text { específicas, realizadas em cada um desses serviços. Também é descrita a } \\
\text { organização para a operação e o controle destes. }\end{array}$ \\
\hline $\begin{array}{l}\text { 7. Características } \\
\text { atuais de } \\
\text { viagens de } \\
\text { residentes }\end{array}$ & $\begin{array}{l}\text { Na introdução se descreve rapidamente a pesquisa domiciliar e o tipo de dados } \\
\text { levantados. A seguir, é apresentado, de maneira mais detalhada, o método utilizado na } \\
\text { pesquisa domiciliar e complementares e apresenta-se uma caracterização da } \\
\text { demanda, dividida nas seguintes categorias: } \\
\text { - Número total de viagens } \\
\text { - Índice de produção de viagem } \\
\text { - Geração e atração de viagem } \\
\text { - Distribuição de viagem } \\
\text { - Produção e distribuição de viagem por modo } \\
\text { - Características das viagens de famílias }\end{array}$ \\
\hline
\end{tabular}

8. Estrutura socioeconômica e plano do uso do solo
Aqui se analisa a situação existente e a prevista na legislação vigente para o uso do solo. A esta análise se somam as informações socioeconômicas o que permite a elaboração de modelos que permitam prever a situação futura da região, incluindo variáveis que podem explicar a geração de viagens, como números de empregos, vagas escolares, posse de automóvel e outras.

9. Futura demanda No capítulo se explica como foi feita a estimativa da demanda de tráfego futura. de tráfego Descreve-se inicialmente o método de modelagem. Trata-se do "Modelo de Quatro Etapas". Os domicílios foram divididos em dois tipos:

- Motorizados: Proprietário de carro;

- Não motorizados: proprietário de motocicleta ou bicicleta.

Os motivos de viagem foram divididos em trabalho, estudo, negócios, assuntos particulares / compras e residência. Os modos foram:

- A pé e motocicleta: a pé, motocicleta e bicicleta;

- Modo privado: carro, táxi e caminhão;

- $\quad$ Modo público: ônibus.

Foram desenvolvidos dois modelos de geração de viagem, separando as viagens produzidas pelos dois tipos de domicílio. As demais etapas também consideram esse tipo de divisão. Para a distribuição de viagens foram ajustados modelos do tipo gravitacional e para a repartição modal se utilizou o método da escolha binária. $A$ alocação de viagens foi modelada em duas etapas, a primeira para os veículos privados e a segunda para os ônibus. No caso da alocação dos passageiros dos ônibus, se experimentou com um modelo considerando a frequência de viagens e outro na extensão das rotas.

O próximo passo foi a estimativa do número de domicílios motorizados e não motorizados no horizonte futuro (2010), apresentando-se taxas de crescimento, deste número, de 2,1\% e 1,6\% a.a., respectivamente, para um crescimento anual estimado em $1,71 \%$ para a população. O número de viagens cresceria a uma taxa de 1,78\% a.a. Para o período 1990-2010, o modelo de atração e geração de viagens estimou 


\begin{tabular}{|c|c|}
\hline Capítulo & Conteúdo \\
\hline & $\begin{array}{l}\text { crescimento pequeno para as áreas central e aquelas próximas a essa ( } 1,2 \text { a 1,8 } \\
\text { vezes) e um crescimento bem maior para as "áreas de expansão" ( } 2 \text { a } 5 \text { vezes). }\end{array}$ \\
\hline & $\begin{array}{l}\text { O modelo de distribuição de viagens confirma a forte polarização da área central, mas } \\
\text { estima-se se previu a queda dessa concentração de uma média de } 26 \text { para 19\%, das } \\
\text { viagens das demais zonas que têm ligação com a área central. }\end{array}$ \\
\hline & $\begin{array}{l}\text { Na repartição modal, estimou-se um crescimento de } 1,23 \% \text { a.a. para o modo "a pé", } \\
2,05 \% \text { para o modo público e } 1,86 \text { para o modo privado. }\end{array}$ \\
\hline & $\begin{array}{l}\text { Apresentam-se também duas análises considerando diferentes cenários. A primeira } \\
\text { prevê uma política de intervenção no tipo de uso do solo. A segunda especula com um } \\
\text { aumento de } 50 \% \text { na posse de automóvel. }\end{array}$ \\
\hline \multirow[t]{3}{*}{$\begin{array}{l}\text { 10. Políticas de } \\
\text { transportes }\end{array}$} & $\begin{array}{l}\text { Aqui se apresentam as ideias que, provavelmente, nortearam a geração das propostas } \\
\text { para o sistema de transportes. Embora no capítulo } 1 \text { deste relatório se apresente o } \\
\text { excessivo volume de tráfego como um problema, aqui se argumenta que "...a posse de } \\
\text { veículos ainda está a um nível baixo ..." e que" ...embora o fluxo de tráfego futuro,..., } \\
\text { mostre congestionamento de tráfego em várias vias principais, tais vias situam-se } \\
\text { principalmente na área de expansão, onde o sistema viário precisa ser ampliado ....". }\end{array}$ \\
\hline & $\begin{array}{l}\text { Outra afirmação interessante é a de que "Portanto, pode-se concluir que não há razão } \\
\text { para se restringir a posse de veículos particulares em Belém tanto agora como no } \\
\text { futuro e, de se introduzir o sistema de transporte de massa no futuro próximo com o } \\
\text { objetivo de diminuir o tráfego de veículos particulares no sistema viário". Deve-se } \\
\text { ressaltar que o transporte de massa aqui parece ter sido entendido como uma solução } \\
\text { de modo ferroviário. }\end{array}$ \\
\hline & $\begin{array}{l}\text { São apresentadas medidas que precisam ser tomadas nas áreas de } \\
\text { - Uso do solo e planejamento urbano; } \\
\text { - Planejamento da rede viária; } \\
\text { - Rede de transporte público; } \\
\text { - Gerenciamento e controle de tráfego. }\end{array}$ \\
\hline
\end{tabular}

11. Planejamento da rede viária transporte público
Apresenta-se a proposta para o planejamento da rede viária, mas tem mais características de uma proposta de melhoria / ampliação. É listado um conjunto de intervenções em vias, para o qual foram feitas estimativas de custos, avaliação econômica, definindo um plano de implantação considerando diferentes cenários.

Foram analisadas a seguintes alternativas:

- Alternativa 1: Sistema atual (convencional) na rede viária atual (nada a fazer);

- Alternativa 2: Sistema atual (convencional) na rede viária proposta neste plano;

- Alternativa 3: Sistema tronco alimentado com seis rotas troncais rodoviárias, usando rede viária atual;

- Alternativa 4: Sistema tronco alimentado com oito rotas troncais rodoviárias, usando rede viária do plano diretor;

- $\quad$ Alternativa 5: Sistema no qual as rotas troncais do corredor BR-316 / Av. Almirante Barroso são substituídas pelo modo ferroviário.

Para a situação atual e o horizonte de 10 anos, foram simuladas apenas as alternativas 1 e 3 . O conjunto de cinco alternativas só foi simulado para o horizonte de 20 anos (2010). A alternativa 3 se apresentou como a mais adequada, mesmo que sejam feitas ressalvas quanto à capacidade de atendimento da demanda em 2010, que exigiria um modo de maior capacidade.

Também são apresentadas propostas para o sistema de táxi e de micro-ônibus. Deve destacar a seguinte frase do relatório: "O táxi e o micro-ônibus são classificados como meios de transporte público de boa qualidade". Será que o sistema de ônibus é um sistema de má qualidade?

13. Plano de gerenciamento de tráfego
Com este plano pretendia-se separar os fluxos de tráfego:

- Tráfego público e privado

- Tráfego interzonal e intrazonal 


\begin{tabular}{ll}
\hline Capítulo & \multicolumn{1}{c}{ Conteúdo } \\
\hline & $\begin{array}{l}\text { A atividade principal consistiria em adequar as vias e sua sinalização a um fluxo } \\
\text { adequado e seguro, utilizando desde melhorias na geometria da via até um sistema de } \\
\text { sincronização semafórica e de controle automatizado do tráfego. }\end{array}$ \\
\hline $\begin{array}{ll}\text { 14. Programa de } \\
\text { implemento }\end{array}$ & $\begin{array}{l}\text { No sumário do relatório se encontra o título "Programa de Implemento". No próprio } \\
\text { capítulo 14 o título é "Programa de Investimento". Na primeira parte se define o que } \\
\text { seriam projetos e a sua classificação em viários, de transporte público e de } \\
\text { gerenciamento de tráfego. A seguir, são definidos os momentos de execução de cada } \\
\text { projeto, no período de 20 anos. Também são analisadas as fontes de recursos } \\
\text { financeiros para essa implantação. }\end{array}$ \\
\hline $\begin{array}{l}\text { 15. Avaliação do } \\
\text { plano diretor de } \\
\text { transporte }\end{array}$ & $\begin{array}{l}\text { Aqui se apresenta uma avaliação econômica, uma financeira e são listados impactos } \\
\text { socioeconômicos provenientes das medidas propostas no plano. }\end{array}$ \\
\hline
\end{tabular}

\section{COMENTÁRIOS}

Este foi um estudo mais abrangente do que os realizados anteriormente. Foram feitas pesquisas abrangentes sobre a situação existente, inclusive uma pesquisa domiciliar, que permitiu estimar os desejos de viagem da população da RMB. O estudo se enquadra dentro da metodologia tradicional de planejamento de transportes. Por mais que o centro da cidade seja o grande polo de atração, são tímidas as propostas para reverter a situação. Pelo contrário, as medidas propostas tendem a reforçar esse aspecto, mesmo que se preveja uma diminuição da concentração de atividades nessa área.

\section{Propostas para o transporte não motorizado}

Pode-se dizer que não existem propostas para os modos não motorizados. Existe, é claro, a preocupação com a segurança dos pedestres, quando se fala na gerência do tráfego, mas não se fala nas condições de acesso ao sistema de transportes proposto.

A pouca importância pode ser percebida quando se classifica como modo "a pé e por motocicleta" o conjunto de viagens feitas a pé e utilizando motocicletas ou bicicletas.

\section{Propostas para o transporte público}

Desta vez destaca-se a necessidade de um sistema integrado para atender às necessidades da população, mesmo que seja deixado para um horizonte de cinco anos, considerando o tempo para implantação. É uma previsão bastante conservadora, pois um sistema desse tipo pode ser implantado em um período bem mais curto.

A proposta, se implantada, traria uma melhoria muito grande para o sistema de transporte público, tanto em qualidade quanto em redução de custos operacionais. Além do sistema principal, o plano também apresenta propostas para os sistemas de táxi e de transporte seletivo, de maior conforto, que teria o objetivo de atrair usuários dos automóveis.

Uma das alternativas estudadas, mas apenas como "referência superior", segundo o próprio relatório, envolve o uso do modo ferroviário em um dos corredores. Apesar de ser apresentada como a única alternativa para atender a demanda do ano horizonte, ela é considerada de implantação muito difícil, em virtude do alto custo. 


\section{Propostas para o transporte individual}

A organização do sistema como um todo, incluindo a hierarquização das vias e a separação dos fluxos de diferentes tipos de transportes, certamente beneficia o transporte individual. Em um trecho do relatório afirma-se que não existe qualquer necessidade de se restringir esse modo de transporte.

As principais medidas dizem respeito à melhoria e ampliação do sistema viário, a adequada sinalização horizontal e vertical e um sistema sofisticado de controle de tráfego. Propostas que não devem agradar a todos, envolvem o controle das áreas de estacionamento.

\section{Propostas para o sistema viário}

A maior parte dos recursos financeiros (341 milhões de dólares contra 42 milhões para o sistema de transporte público), necessários à materialização deste plano, se refere a obras de melhoria e ampliação do sistema viário. No total foram 11 projetos de construção de novas vias (125,7 km - 74\% dos recursos para o sistema viário) e 11 projetos de melhorias em vias existentes (39,7 km - 26\% dos recursos). 


\section{C.6. PLANO DIRETOR DE TRANSPORTE URBANO DA REGIÃO METROPOLITANA DE BELÉM - PDTU-RMB-01 (JICA, 2001)}

Depois de 10 anos do primeiro PDTU-RMB (JICA, 1991) e, praticamente, sem nenhuma das propostas implantadas, prepara-se mais um Plano Diretor de Transportes Urbanos, também em conjunto com a JICA. Já não existia mais a EMTU, órgão metropolitano de transportes, e as instituições responsáveis pelo estudo foram, além da JICA, a COHAB/PA ${ }^{14}$ e a SEDURB ${ }^{15}$.

Aqui aparecem, com maior destaque, preocupações com o transporte não motorizado e os impactos ambientais. Destaca-se que é um trabalho de atualização do PDTU de 1991 e, para tanto, muitas das pesquisas foram feitas novamente, já que se passaram muito anos e as características de ocupação do território e da demanda dos transportes mudaram bastante.

A RMB aumentou de tamanho. Desde 1996 juntaram-se a Belém e Ananindeua, os municípios de Marituba, Benevides e Santa Bárbara do Pará. O número de linhas de ônibus dobrou e foi implantado um serviço de linhas especiais, mais confortáveis, mas a operação continua no modo convencional, sem qualquer tipo de integração organizada. A seguir, se apresenta uma síntese do conteúdo do relatório final do plano.

\section{RESUMO DO CONTEÚDO}

\begin{tabular}{ll}
\hline \multicolumn{1}{c}{ Capítulo } & \multicolumn{1}{c}{ Conteúdo } \\
\hline Síntese do Plano & O volume do relatório final apresenta, logo no início, uma síntese do plano. \\
\hline Introdução & O início do capítulo de introdução trata dos antecedentes do processo de planejamento \\
e gestão do sistema de transportes da RMB. Apresenta-se um breve histórico e uma \\
justificativa para a não implantação das medidas previstas no plano anterior (JICA, \\
1991). Entre as principais razões cita-se o desmonte da estrutura federal voltada para \\
os transportes urbanos, com a extinção da EBTU, e um fato semelhante ocorrido no \\
nível estadual, com a extinção da EMTU. Embora o município de Belém tenha criado \\
uma empresa para gerir o sistema, a CTBel ${ }^{16}$, segundo o relatório, esta não incorporou \\
o PDTU como "norteador de suas ações". \\
O objetivo geral deste plano foi o de "Reavaliar as diretrizes propostas no PDTU/1991 \\
no que tange a sistema viário, circulação e, principalmente ao transporte público [grifo \\
do autor], considerando as alterações territoriais ocorridas na RMB, os projetos de \\
impacto implantados ou em implantação nesse território na última década, bem como \\
as novas tecnologias de transporte coletivo disponíveis". \\
São também apresentados objetivos específicos: \\
a) Apresentar o diagnóstico da atual situação dos sistemas de transporte, de \\
circulação e viário da RMB; \\
b) Gerar dados que possibilitem, em curto prazo, a racionalização operacional do \\
cistema de transporte coletivo metropolitano; \\
c) Levantar indicadores ambientais referentes à emissão de poluentes nos \\
principais corredores metropolitanos; \\
d) Prever a demanda futura dos sistemas de transporte e de circulação na RMB; \\
e) Recomendar intervenções de curto prazo nos sistemas de circulação e viário da \\
f) Apontar projetos a serem detalhados com vistas à realização de estudos de
\end{tabular}

\footnotetext{
${ }^{14}$ Companhia de Habitação do Estado do Pará

${ }^{15}$ Secretaria de Estado de Desenvolvimento Urbano e Regional

${ }^{16}$ Companhia de Transportes do Município de Belém
} 


\begin{tabular}{|c|c|}
\hline Capítulo & Conteúdo \\
\hline & $\begin{array}{l}\text { viabilidade econômica; } \\
\text { g) Apontar tecnologias de sistemas compatíveis com as condições locais, } \\
\text { considerando a demanda e as características físicas dos principais corredores } \\
\text { de transporte da RMB; e } \\
\text { h) Capacitar e instrumentalizar a equipe de contrapartida local, através do } \\
\text { acompanhamento de todas as atividades desenvolvidas no projeto, além da } \\
\text { doação de equipamentos e programas utilizados na elaboração do mesmo. }\end{array}$ \\
\hline $\begin{array}{l}\text { 1. Pesquisas de } \\
\text { Campo }\end{array}$ & 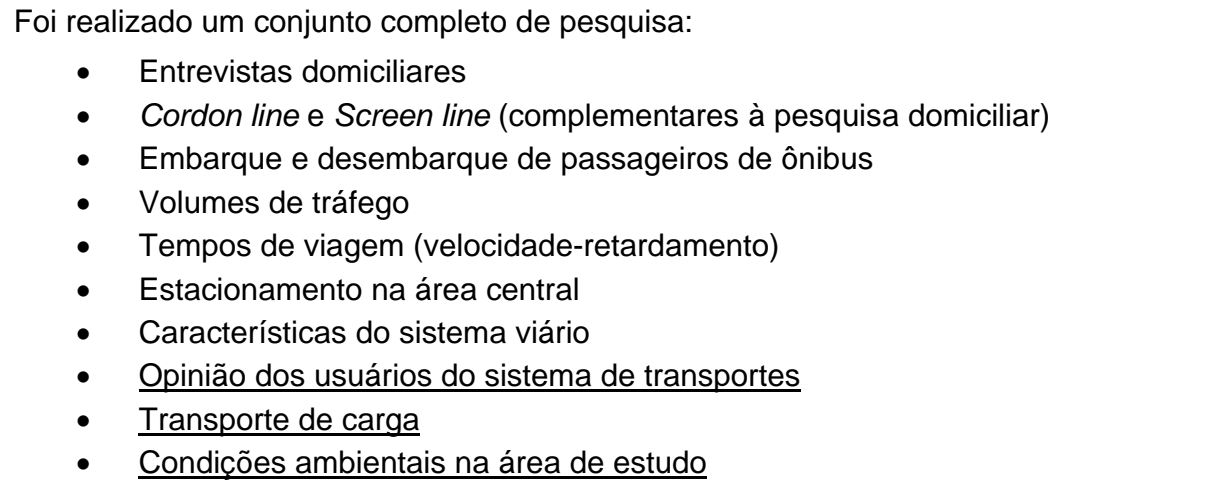 \\
\hline
\end{tabular}

As três últimas (grifadas pelo autor) são novidades, quando se consideram os trabalhos desenvolvidos nos planos anteriores.

Os resultados dessas pesquisas são apresentados no formato de tabelas, gráficos e mapas temáticos, constituindo uma boa caracterização do sistema de transportes de Belém, em termos de oferta e demanda.

\begin{tabular}{l}
\hline 2. Estrutura Sócio- \\
Econômica e \\
Tendências de \\
Desenvolvimento \\
da Região \\
Metropolitana
\end{tabular}

3. Diagnóstico e Prognóstico
A partir de estudos de tendência de desenvolvimento para a região amazônica, o estado do Pará e a região "ampliada" da RMB, existem cenários previstos para o futuro. Foi promovido um seminário que se reuniu técnicos e dirigentes de instituições governamentais e representantes da sociedade civil, para discutir as "tendências espacializadas de desenvolvimento econômico, de ocupação e alocação de usos". De acordo com o relatório, esta reunião supriu a falta de uma estrutura de planejamento e gestão urbanística na RMB.

A "Identificação dos grandes problemas de transportes da Região Metropolitana de Belém" foi preparada no "Seminário de Diagnóstico e Formulação de Diretrizes para o Sistema de Transportes da RMB", realizado em novembro de 2000, do qual participaram representantes de 61 instituições governamentais e não governamentais. Foram discutidos os problemas e apresentadas propostas, divididas nos sistemas viário, de transporte público e de circulação.

A seguir, foram formuladas as alternativas para a "rede viária" e para a "rede de transporte coletivo". A primeira compreendia um conjunto de sete grupos de vias, cada um composto por um eixo principal e uma rede de vias secundárias. A rede de transporte público previa um sistema integrado composto de linhas troncais, alimentadoras e convencionais.

A "Previsão da demanda de transportes na região metropolitana" foi obtida através da modelagem utilizando o método de quatro etapas, através do software Transcad (CALIPER, 2007). Para o período de projeto, previu-se um aumento na quilometragem percorrida pelo tráfego geral de 191.592 veic. X km, em 2000 com a rede atual, para 556.976 veic. $\mathrm{Km}$, em 2020 com a rede futura, ou seja, crescimento de 191\%. No caso das viagens por transporte coletivo, o aumento previsto é de $110 \%$, de 580.341 para 1.223.640 pass. $X \mathrm{~km}$, para o mesmo período e configurações de rede. Vale ressaltar o surgimento do transporte hidroviário na rede futura, com um total de 60.434 pass. x km. Fora esse valor, não se apresenta qualquer outro detalhe, mas é uma evolução em relação aos planos passados.

A "Avaliação e programa de implantação das proposições" foi feita através do método de cálculo das relações benefício-custo, comparando custos de implantação com as alterações nos custos operacionais e de tempo de viagem. 


\begin{tabular}{|c|c|}
\hline Capítulo & Conteúdo \\
\hline $\begin{array}{l}\text { 4. Diretrizes e } \\
\text { Recomendações }\end{array}$ & 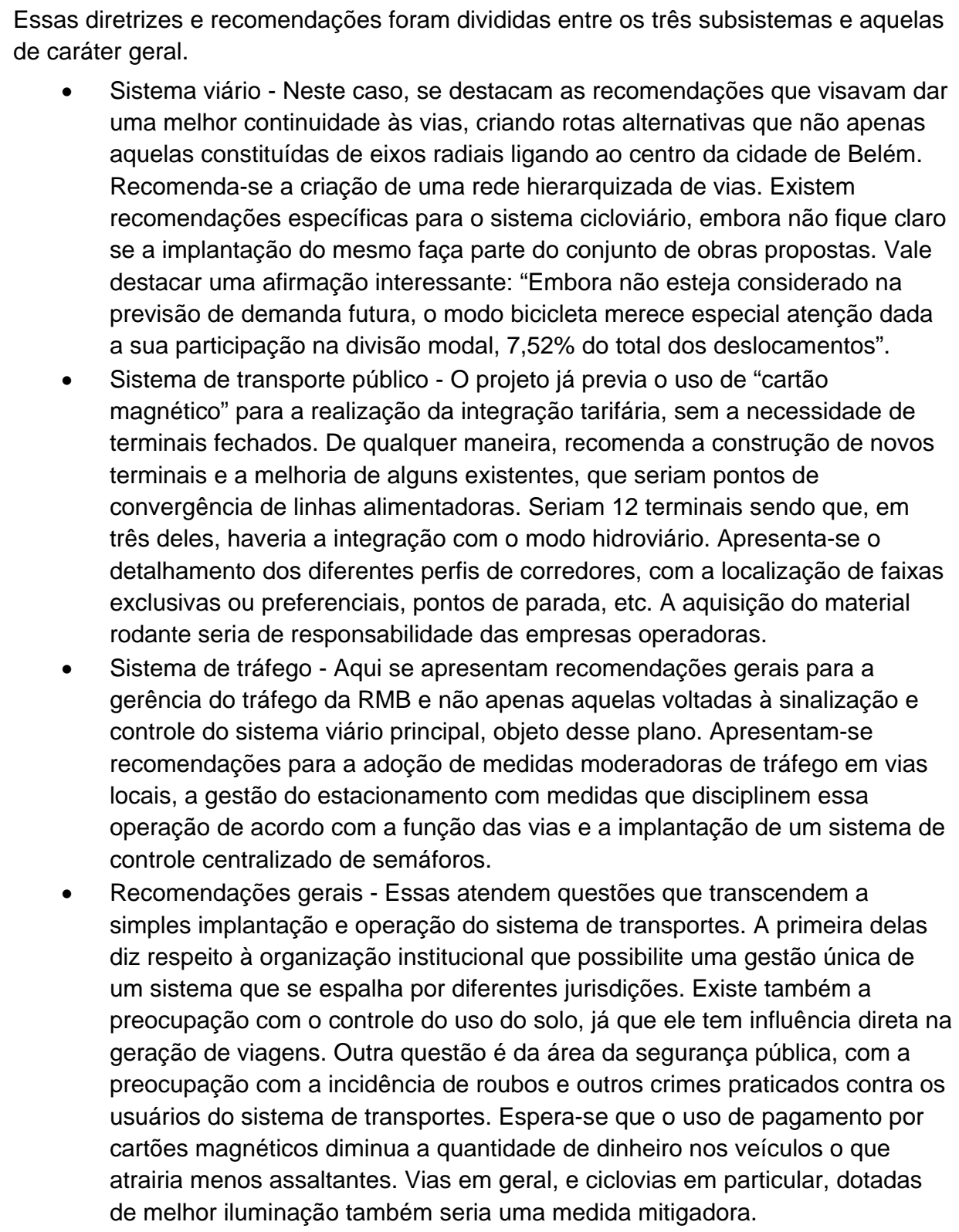 \\
\hline Anexos & $\begin{array}{l}\text { A. Matrizes de Origem e Destino de Viagens entre Macrozonas } \\
\text { B. Dados Operacionais do Sistema de Transporte Coletivo da RMB } \\
\text { C. Síntese das Contagens Volumétricas Classificadas em Interseções de Vias } \\
\text { D. Síntese das Contagens Volumétricas Classificadas em Seções de Vias } \\
\text { E. Síntese da Pesquisa de Tempos de Viagem (Velocidade-Retardamento) } \\
\text { F. Síntese da Pesquisa de Estacionamento } \\
\text { G. Síntese do Cadastramento Viário } \\
\text { H. Tabela de Dados Sócio-Econômicos por ZT - 2000/2010/2020 }\end{array}$ \\
\hline
\end{tabular}

\section{COMENTÁRIOS}

Embora mantenha a característica de apresentar soluções de tendência conservadora, este plano representa um grande avanço, pois conclui pela necessidade de um sistema que dê prioridade ao transporte público, incluindo faixas exclusivas e a implantação de integração física e tarifária. Nos planos anteriores isto era sempre deixado para o futuro. Parece que o futuro chegou. 
Dentre os levantamentos feitos, apareceram três pesquisas "novas". A pesquisa de opinião com os usuários dos principais modos é importante para identificar possíveis prioridades do ponto de vista da população. A caracterização da movimentação da carga urbana também é importante, pois tem interferência nos fluxos de pessoas e veículos de passageiros e, quase sempre, é esquecida ou, no mínimo, não é quantificada. Os levantamentos dos impactos ambientais, nos aspectos de poluição sonora e atmosférica, foram bem restritos, mas servem para indicar que providências precisam ser tomadas para mitigar esses problemas.

Outra novidade são as propostas para uma integração com o transporte hidroviário, algo que parece evidente considerando-se a facilidade de navegação e que parte do território da RMB é constituída por ilhas. No entanto, não são apresentados detalhes ou anteprojetos específicos para esse modo.

Deve-se destacar, ainda, que os municípios de Marituba, Benevides e Santa Bárbara do Pará, passaram a fazer parte da Região Metropolitana de Belém.

\section{Propostas para o transporte não motorizado}

O plano trás, de uma maneira um pouco mais forte, a preocupação com o deslocamento de pedestres e ciclistas. Naquelas vias previstas nas intervenções do plano, existem recomendações de calçadas adequadas e, em alguma delas, a implantação de ciclovias. No entanto, não fica claro se a implantação do "sistema cicloviário" faz parte do orçamento considerado no estudo de viabilidade. Embora na apresentação em mapas apareçam traçados de ciclovias coincidindo com o traçado dos corredores por onde passariam as linhas troncais, nos detalhes dessas vias não aparecem as faixas para a circulação das bicicletas.

Outro aspecto interessante é o "desaparecimento" da fatia da divisão modal referentes ao modo cicloviário. São 7,52\% das viagens em 2000, e esse tipo de viagem não aparece em 2020.

\section{Propostas para o transporte público}

Diferentemente do PDTU-1991, este plano deixa claro que o sistema integrado é a solução para o transporte público da RMB. Não se trata mais de uma questão de implantar um sistema viário que começaria a estruturar um futuro sistema com terminais, linhas troncais e alimentadoras. Também deve se destacar a previsão do uso de cartões magnéticos, o que seriam atualmente os smartcards, possibilitando a integração em qualquer ponto da rede. Não se fala especificamente de uma integração temporal, mas com esse tipo de instrumento ela seria possível.

O transporte hidroviário aparece como "novidade" já que geralmente foi esquecido nos planos anteriores. No entanto ele é citado rapidamente e não existem projetos para a sua implantação. Parte da população de Belém mora em grandes ilhas que não possuem ligação rodoviária com o continente, para onde precisa se deslocar para utilizar alguns serviços públicos.

\section{Propostas para o transporte individual}

Existem propostas que favorecem o uso desse modo e outras que restringem. As primeiras são maioria. A construção de novas vias e adequação da geometria de vias existentes, acompanhada de 
uma correta sinalização, inclusive com um sistema de controle de tráfego em área, tende a melhorar a fluidez e a segurança.

Por outro lado, o plano recomenda um controle mais rigoroso do estacionamento na via, criação de espaços exclusivos para o transporte público e/ou para o transporte não motorizado e medidas moderadoras de tráfego em vias locais. São medidas que enfrentam a resistência de parte dos usuários do transporte individual.

\section{Propostas para o sistema viário}

O gasto com o sistema viário, incluindo obras de arte, foi orçado em 80,0 milhões de dólares, correspondendo a $50 \%$ dos recursos previstos, para um total de $62 \mathrm{~km}$ de vias. A outra metade iria para a construção dos terminais de transporte público. 


\section{C.7. ESTUDO DE VIABILIDADE ECONÔMICA DE PROJETOS PARA O MELHORAMENTO DO SISTEMA DE TRANSPORTE NA REGIÃO METROPOLITANA DE BELÉM NA REPÚBLICA FEDERATIVA DO BRASIL - EVE-MST-RMB (JICA, 2003)}

Este é um estudo que atualiza algumas informações do PDTU-2001 (JICA, 2001) e prepara um melhor detalhamento das propostas e uma melhor análise das questões relativas a impactos ambientais e à viabilidade econômica dos projetos. Percebe-se, também, nesse detalhamento uma melhoria da qualidade das propostas como, por exemplo, a infraestrutura para o transporte por bicicleta. A seguir, se apresenta um resumo do conteúdo do relatório final.

\section{RESUMO DO CONTEÚDO}

\begin{tabular}{|c|c|}
\hline Capítulo & Conteúdo \\
\hline \multirow[t]{4}{*}{ 1. Introdução } & $\begin{array}{l}\text { Apresenta um breve histórico dos últimos planos (JICA, 1991, 2001) e os objetivos } \\
\text { deste estudo: }\end{array}$ \\
\hline & $\begin{array}{l}\text { - Assegurar no estudo de viabilidade econômica o melhoramento de projetos } \\
\text { para o sistema de transporte que contenha os projetos viários e o projeto do } \\
\text { sistema de ônibus, necessários para mitigar a ineficiência do atual sistema de } \\
\text { transporte na Região Metropolitana de Belém, e; }\end{array}$ \\
\hline & $\begin{array}{l}\text { - Procurar transferir tecnologia para a equipe de contrapartida brasileira no } \\
\text { decorrer da realização do Estudo. }\end{array}$ \\
\hline & $\begin{array}{l}\text { Também se descreve o conjunto de etapas em que se dividiu o estudo, o andamento } \\
\text { do mesmo, já que se trata de um relatório final, e a equipe responsável pela execução. }\end{array}$ \\
\hline PARTE A & CONDIÇÕES ATUAIS DA ÁREA DE ESTUDO \\
\hline $\begin{array}{l}\text { 2. Condições Atuais } \\
\text { da Área de } \\
\text { Estudo }\end{array}$ & $\begin{array}{l}\text { Apresenta os vários aspectos físicos da área de estudo divididos em condições } \\
\text { socioeconômicas, geográficas, geológicas e topográficas. }\end{array}$ \\
\hline $\begin{array}{l}\text { 3. Planos de } \\
\text { Desenvolvimento } \\
\text { Existente na Área } \\
\text { de Estudo }\end{array}$ & $\begin{array}{l}\text { Inicia pela listagem dos "Planos de Desenvolvimento Existentes": } \\
\text { - } \quad \text { Projeto de Macrodrenagem da Bacia do Una, } \\
\text { - } \quad \text { Melhoramento do sistema viário e terminal de ônibus no Entroncamento, } \\
\text { Continua pelos projetos em andamento: } \\
\text { - Avenida Independência; } \\
\text { - Avenida Primeiro de Dezembro; } \\
\text { - Alça Viária; } \\
\text { - Projeto de Macrodrenagem da Bacia do Una. } \\
\text { Termina com uma análise geral das infraestruturas da RMB, passando por } \\
\text { abastecimento d'água, esgotamento sanitário, eletricidade e outros, mas fazendo } \\
\text { detalhamento maior na análise da infraestrutura viária. }\end{array}$ \\
\hline
\end{tabular}

4. Condições Atuais
de Tráfego e
Transporte

Aqui são descritos os levantamentos feitos e os seus resultados. Para ajustar os volumes de tráfego e de passageiros das pesquisas do PDTU-2001, foram feitas levantamentos de volume de tráfego em screen line, nas principais vias e interseções. A seguir, na seção "Características de viagens" se apresentam os resultados da atualização das matrizes de viagem para o ano de 2002. Na seção seguinte, esse mesmo procedimento é adotado, mas considerando apenas as viagens na hora de pico.

5. Condições de Gerenciamento de Tráfego
Descreve-se o sistema viário da RMB, em termos de condições de circulação e a estrutura institucional referente à gerência do trânsito da área de estudo. A seguir são apresentadas estatísticas de acidentes de trânsito para esta área, incluindo a análise das possíveis causas e a proposta de soluções para os problemas descritos. No final do capítulo, na seção "Medidas de Segurança para Passageiros do Sistema de 


\begin{tabular}{|c|c|}
\hline Capítulo & Conteúdo \\
\hline & $\begin{array}{l}\text { Ônibus de Curitiba", apresenta-se o relato de uma visita a Curitiba e entrevista com } \\
\text { alguns técnicos desta cidade, no qual aparecem os problemas de segurança de } \\
\text { trânsito enfrentados pela cidade paranaense e as soluções utilizadas. }\end{array}$ \\
\hline & $\begin{array}{l}\text { É interessante destacar uma figura na qual se destacam o mapa do sistema de } \\
\text { transportes de Curitiba e algumas fotos descritas como "cenas de trânsito em Curitiba". } \\
\text { São fotos, claramente, de períodos fora de pico e pode-se questionar a utilidade para } \\
\text { ilustrar uma situação "real". }\end{array}$ \\
\hline $\begin{array}{l}\text { 6. Levantamento } \\
\text { Preliminar de } \\
\text { Impacto } \\
\text { Ambiental }\end{array}$ & $\begin{array}{l}\text { Aqui se apresentam o início da coleta de dados e montagem dos estudos ambientais, } \\
\text { caracterizado no Levantamento Preliminar de Impacto Ambiental (IAP). Isso envolveu a } \\
\text { descrição do meio ambiente e da estrutura jurídica e administrativa responsável pelo } \\
\text { controle do processo, além do conjunto de pesquisas para coletar dados ambientais. } \\
\text { Foram levantados dados de qualidade do ar, ruído na via, vibração e qualidade da } \\
\text { água. No final do capítulo são descritos, em caráter preliminar, os impactos previstos } \\
\text { para cada uma das intervenções propostas para o sistema de transportes. }\end{array}$ \\
\hline PARTE B & PLANEJAMENTO DO SISTEMA TRONCAL DE ÔNIBUS \\
\hline $\begin{array}{l}\text { 7. Características } \\
\text { Atuais do } \\
\text { Transporte } \\
\text { Público }\end{array}$ & $\begin{array}{l}\text { Neste capítulo, bastante extenso, se faz uma análise do sistema de transportes em } \\
\text { operação na época. Inicia-se por uma caracterização da demanda, temporal e } \\
\text { espacialmente, montada a partir de dados existentes e de pesquisas realizadas para o } \\
\text { estudo. Também se analisa detalhadamente a situação institucional, que é um } \\
\text { problema citado desde os primeiros estudos e, até então, não solucionado a contento. } \\
\text { No final, se apresenta uma tabela com um conjunto de problemas verificados no } \\
\text { sistema de transporte público. }\end{array}$ \\
\hline
\end{tabular}

8. Plano Conceitual Na seção "Estratégia e Política de Planejamento Básico" são discutidos, novamente e para o Sistema Troncal de rapidamente, os principais problemas do sistema de transportes da RMB e se Ônibus apresenta uma organização para propor e escolher soluções para esses problemas. Depois de todos os planos e projetos já realizados, apesar de se descrever um processo de geração de soluções, aparentemente elas já existem a priori.

A segunda parte do capítulo é a denominada "Planejamento Conceitual para o Sistema Troncal". Aqui se apresenta a configuração proposta para o novo sistema de transporte por ônibus, dividido em um conjunto de linhas troncais e suas linhas alimentadoras, além de um grupo de linhas, denominadas convencionais, que não continuariam operando como o sistema atual. Estas últimas continuariam a operar em tráfego misto, isto é, sem utilizar as caneletas ou faixas exclusivas ou as faixas prioritárias.

O sistema também seria dividido em duas áreas de operação, não havendo integração entre elas. Cada uma dessas áreas seria atendida por linhas troncais, em um corredor principal, e um conjunto de linhas alimentadoras.

Nesta mesma seção fala-se do sistema de micro-ônibus, com serviço mais caro, que estava operando apenas com cinco linhas de um total inicial de 25 linhas há cinco anos. A tarifa desse sistema é o dobro daquela do sistema convencional, o que estaria afastando os usuários. As empresas estariam planejando acabar com o serviço em virtude da demanda muito baixa.

9. Previsão da Neste capítulo se apresenta a metodologia de atualização dos dados do PDTU-2001 Demanda Futura de Transportes (JICA, 2001). Os modelos utilizados foram praticamente os mesmos daquele estudo, para os quais foram recalculados os parâmetros. Adotou-se, como anteriormente, um processo do tipo "Quatro Etapas", alterando-se um ou outro modelo conforme, provavelmente, a preferência dos técnicos do estudo atual.

10. Análise Técnica Este capítulo trata de uma modelagem para previsão das condições de operação do do Sistema Troncal de sistema proposto, incluindo desempenho e custos de operação, volumes de passageiros, tempos de viagem e impactos nos fluxos dos demais veículos. PretendiaÔnibus se assim analisar a eficácia do esquema operacional proposto e fornecer elementos para ajustes no projeto e a avaliação das viabilidades técnica e econômica.

11. Plano Operacional do Apresenta-se o plano detalhado de operação das linhas de ônibus e uma avaliação Sistema Troncal operacional feita com o uso de software de microssimulação de tráfego. Também são descritas as tecnologias a serem utilizadas para os veículos e as vias. Para o sistema 


\begin{tabular}{|c|c|}
\hline Capítulo & Conteúdo \\
\hline de Ônibus & $\begin{array}{l}\text { de sinalização foi previsto o uso de equipamentos de sensoriamento para possibilitar a } \\
\text { adaptação dos tempos dos semáforos para priorizar o fluxo dos ônibus. }\end{array}$ \\
\hline PARTE C & PLANEJAMENTO DOS PROJETOS VIÁRIOS \\
\hline $\begin{array}{l}\text { 12. Condições das } \\
\text { Vias Existentes }\end{array}$ & $\begin{array}{l}\text { Aqui se apresenta uma caracterização do sistema viário atual e seus problemas. } \\
\text { Apesar do título do capítulo, são também apresentadas possíveis soluções para os } \\
\text { problemas. }\end{array}$ \\
\hline \multirow[t]{2}{*}{$\begin{array}{l}\text { 13. Planejamento dos } \\
\text { Projetos Viários }\end{array}$} & $\begin{array}{l}\text { Aqui se propõe uma estrutura para classificação e hierarquização das vias e a } \\
\text { concepção de um sistema viário principal, com vias principais, secundárias e coletoras. } \\
\text { Também existem propostas para as principais interseções. }\end{array}$ \\
\hline & $\begin{array}{l}\text { Quanto às ciclovias, altera-se a proposta anterior, deslocando-as para o lado direito da } \\
\text { pista, quando antes ficavam junto ao canteiro central. A justificativa é preservar o } \\
\text { ciclista da realização de travessias perigosas. O projeto de ciclovias no centro da via } \\
\text { também considera como fator principal a segurança, pois se reduz o número de pontos } \\
\text { de conflito com o transporte motorizado. A necessidade de travessia de vias sempre } \\
\text { existirá. }\end{array}$ \\
\hline PARTE D & $\begin{array}{l}\text { DESENHO PRELIMINAR DE ENGENHARIA DAS VIAS EXCLUSIVAS PARA ÔNIBUS } \\
\text { E DOS PROJETOS VIÁRIOS }\end{array}$ \\
\hline $\begin{array}{l}\text { 14. Desenho } \\
\text { Preliminar de } \\
\text { Infra-Estrutura de } \\
\text { Vias Exclusivas } \\
\text { para Ônibus }\end{array}$ & $\begin{array}{l}\text { Aqui se apresentam detalhes da geometria das vias que compõem o sistema de vias } \\
\text { exclusivas e também do esquema de circulação do tráfego do projeto dos terminais de } \\
\text { integração e pontos de parada. São feitas recomendações de segurança e } \\
\text { acessibilidade de pedestres, mas sem maiores detalhes. }\end{array}$ \\
\hline $\begin{array}{l}\text { 15. Desenhos } \\
\text { Preliminares dos } \\
\text { Projetos viários }\end{array}$ & $\begin{array}{l}\text { Aqui se tratam dos detalhes para orientar os projetos das vias. São descritas seções } \\
\text { transversais tipo, estruturas especiais e sistemas de drenagem. Além disso, estima-se } \\
\text { o volume total de trabalho, isto é, quantificam-se os elementos construtivos a serem } \\
\text { executados (quilômetros de via, por exemplo). }\end{array}$ \\
\hline $\begin{array}{l}\text { 16. Plano de } \\
\text { Construção e } \\
\text { Estimativa de } \\
\text { Custo }\end{array}$ & $\begin{array}{l}\text { Aqui se detalham os processos construtivos a serem utilizados e preparam-se os } \\
\text { orçamentos de cada uma das intervenções. }\end{array}$ \\
\hline PARTE E & AVALIAÇÃO DO PROJETO E CONCLUSÕES \\
\hline $\begin{array}{l}\text { 17. Avaliação do } \\
\text { Impacto } \\
\text { Ambiental }\end{array}$ & $\begin{array}{l}\text { Aqui se apresentam as atividades de preparação do Estudo de Impactos Ambientais - } \\
\text { EIA e os seus principais resultados e medidas mitigadoras estabelecidas. }\end{array}$ \\
\hline \multirow[t]{5}{*}{$\begin{array}{l}\text { 18. Plano de } \\
\text { Implementação }\end{array}$} & $\begin{array}{l}\text { Aqui se apresenta o cronograma de implantação do projeto para um período de dez } \\
\text { anos. Ele se divide em duas etapas: }\end{array}$ \\
\hline & Etapa 1: Identificação de projetos prioritários através de análise custo-benefício. \\
\hline & $\begin{array}{l}\text { Etapa 2: Preparação dos cronogramas de implementação e de investimento. } \\
\text { Na segunda etapa são consideradas as seguintes condições }\end{array}$ \\
\hline & $\begin{array}{l}\text { a. O ajuste de construção, por ano, dos projetos viários e de infraestrutura de } \\
\text { transporte público serão baseados na demanda de viagens; } \\
\text { b) O equilíbrio do custo do investimento anual. }\end{array}$ \\
\hline & $\begin{array}{l}\text { Parte das intervenções que fariam parte do novo sistema de transportes já estavam em } \\
\text { processo de licitação ou construção. Este plano visa adequar o grande conjunto de } \\
\text { obras a uma capacidade de investimento e de execução. Considerando a demanda de } \\
\text { viagens para priorizar a implantação, pode proporcionar maiores benefícios logo no } \\
\text { início da operação. }\end{array}$ \\
\hline $\begin{array}{l}\text { 19. Organização do } \\
\text { Sistema Troncal } \\
\text { de Ônibus }\end{array}$ & $\begin{array}{l}\text { Aqui se discute, principalmente, o problema institucional da gerência do sistema de } \\
\text { transporte público, tratando-se da operação das linhas e dos terminais de integração, } \\
\text { além da manutenção dessa infraestrutura. Relata-se a experiência de outras regiões } \\
\text { metropolitanas brasileiras, com seus sucessos e reveses. Tecnicamente, é um } \\
\text { problema relativamente simples de se resolver. Politicamente, é muito complicado. }\end{array}$ \\
\hline
\end{tabular}




\begin{tabular}{|c|c|}
\hline Capítulo & Conteúdo \\
\hline & $\begin{array}{l}\text { Outro problema tratado é o dos operadores do novo sistema. A primeira alternativa } \\
\text { previa a licitação de todas as linhas, trazendo uma maior organização, com novos } \\
\text { contratos e um número menor de operadores. Nas outras opções se previa a } \\
\text { continuidade das empresas atuais na operação do sistema, individualmente ou em } \\
\text { consórcio. } \\
\text { Esse é outro problema que não é exclusivo de Belém. A continuidade da operação } \\
\text { pelas empresas atuais, sem passarem por uma licitação, é ilegal. Na época desse } \\
\text { estudo já estava se esgotando o prazo dado pela Constituição (BRASIL, 1988) para } \\
\text { que se regularizassem os contratos de serviços de transportes públicos. }\end{array}$ \\
\hline $\begin{array}{l}\text { 20. Avaliação } \\
\text { Econômica e } \\
\text { Financeira }\end{array}$ & $\begin{array}{l}\text { Compara-se o custo econômico total dos projetos com os benefícios decorrentes da } \\
\text { redução do custo operacional dos veículos e da redução do custo de tempo de viagem } \\
\text { das pessoas, utilizando-se combinações de demanda atual e futura alocadas às redes } \\
\text { atual e futura. } \\
\text { O objetivo da análise financeira foi examinar a lucratividade de operações comerciais } \\
\text { de partes do sistema proposto. Ela ficou restrita às "operações de transportes de } \\
\text { ônibus troncal, operações de linhas de ônibus alimentadoras e operações de terminais } \\
\text { diretamente relacionados com as operações do sistema troncal". }\end{array}$ \\
\hline $\begin{array}{l}\text { 21. Gerenciamento } \\
\text { de Demanda de } \\
\text { Transporte }\end{array}$ & $\begin{array}{l}\text { Aqui se faz um rápido exercício para estimar a transferência de usuários do modo } \\
\text { automóvel para o sistema de transporte público. São propostas possíveis medidas de } \\
\text { restrição ao uso do automóvel, incluindo aumento do preço dos veículos, aumento de } \\
\text { impostos, implantação de rodízios e pedágios. São propostas que entram em hora } \\
\text { errada no estudo, praticamente sem conexão com intervenções concretas propostas no } \\
\text { estudo. }\end{array}$ \\
\hline $\begin{array}{l}\text { Conclusão e } \\
\text { Recomendações }\end{array}$ & $\begin{array}{l}\text { Aqui se apresenta um resumo das propostas do estudo e recomenda-se que elas } \\
\text { sejam implantadas e que sejam contratados novos serviços de consultoria para apoio a } \\
\text { essas atividades. } \\
\text { Segundo o relatório, "A atividade referente à análise da demanda futura de tráfego, no } \\
\text { Brasil, ainda se encontra no estágio inicial necessitando, portanto, de tempo, } \\
\text { experiência e recursos humanos para o desenvolvimento de trabalhos futuros". }\end{array}$ \\
\hline ANEXOS & $\begin{array}{l}\text { Conteúdo: } \\
\begin{array}{l}\text { - Pesquisa inicial de meio ambiente } \\
\text { - Plano operacional do sistema troncal de ônibus } \\
\text { - Plano de construção e estimativa de custos } \\
\text { - Avaliação do impacto ambiental } \\
\text { - } \quad \text { Avaliação econômica e financeira }\end{array}\end{array}$ \\
\hline
\end{tabular}

\section{COMENTÁRIOS}

Este estudo consiste de uma atualização e aperfeiçoamento daqueles relativos ao PDTU-2001 (JICA, 2001). As intervenções no sistema viário e as propostas para o novo sistema de transporte público são detalhadas e avaliadas dos pontos de vista técnico, econômico e financeiro. Também foi feita um estudo de impactos ambientais, de acordo com o que determina a legislação federal e local.

O estudo de demanda, como é de se esperar desse tipo de análise, aponta para um crescimento ao longo do período de projeto. Todas as propostas são preparadas com base nesse crescimento. No último capítulo do relatório são apresentadas, sem nenhum detalhe, propostas de gerência da demanda. 


\section{Propostas para o transporte não motorizado}

Este é um estudo abrangente para o sistema de transportes e trás propostas para melhorar a situação do transporte não motorizado. As vias a serem reformadas ou construídas, apresentam calçadas razoavelmente largas, a maioria com 3,5 m. Não existem, no entanto, recomendações para garantir a acessibilidade de pessoas com deficiências, por exemplo. Vale destacar que não se utilizou muito o recurso da passarela para a travessia de pedestres.

A demanda do modo cicloviário apareceu nos levantamentos dos fluxos de veículos, mas não aparece na matriz de viagens. Talvez seja limitação dos modelos utilizados. Em alguns trechos do relatório se diz que a demanda por esse modo é significativa. Mesmo não aparecendo nas matrizes futuras, existem propostas para uma extensa rede de ciclovias e ciclofaixas o que, de algum modo, corrige essa deficiência da modelagem.

Lendo o relatório, nos trechos que tratam do transporte por bicicleta, tem-se a impressão de que ele é visto mais como um problema do que uma das soluções para melhorar o sistema de transportes da RMB. A ideia é sempre de segregar os ciclistas em vias ou faixas apropriadas.

\section{Propostas para o transporte público}

Esta é uma proposta "completa" para o transporte público, prevendo espaço exclusivo de circulação, terminais, integração física e tarifária, prioridade semafórica, etc. A maior pendência fica sempre por conta do arranjo institucional. Implanta-se um sistema melhor, mas bem mais complexo, e é preciso uma gestão muito mais abrangente e eficaz.

\section{Propostas para o transporte individual}

O transporte individual é beneficiado pela extensa reforma do sistema viário como um todo, criando novas ligações e implantando novos esquemas de circulação que inclui nova sinalização semafórica com controle centralizado.

\section{Propostas para o sistema viário}

O sistema viário, de uso geral e exclusivo para transporte público, é onde a maior parte dos recursos é aplicada. Estão também incluídos, nessas obras de recuperação e construção de vias, vários trechos de ciclovias e ciclofaixas. 


\section{C.8. DIRETRIZES DE ORDENAMENTO TERRITORIAL PARA A REGIÃO METROPOLITANA DE BELÉM - DOT-RMB (PARÁ, 2006)}

Este é um estudo que sintetiza uma série de análises sobre a RMB e o seu território. Algumas das análises envolvem também outros municípios vizinhos. São estudados aspectos do uso e ocupação do solo e as infraestruturas de transportes e de saneamento básico. O estudo foi desenvolvido em três etapas:

- Definição da metodologia do estudo e escolha dos temas a serem enfocados;

- Elaboração de diagnóstico, baseado nos temas definidos na etapa anterior;

- Elaboração das diretrizes de ordenamento territorial.

A seguir, se apresenta um resumo do conteúdo do relatório, tratando apenas das questões que envolvem direta ou indiretamente o sistema de transportes urbanos.

\section{RESUMO DO CONTEÚDO}

\begin{tabular}{|c|c|}
\hline Capítulo & Conteúdo \\
\hline $\begin{array}{l}\text { 1. Caracterização } \\
\text { da RMB }\end{array}$ & Aqui se apresenta uma caracterização física e histórica do território da RMB. \\
\hline \multirow[t]{2}{*}{$\begin{array}{l}\text { 2. Uso e Ocupação } \\
\text { do Solo }\end{array}$} & $\begin{array}{l}\text { Mais específico do que a caracterização do capítulo anterior, aqui se parte para um } \\
\text { diagnóstico do uso e ocupação do solo, destacando-se os principais problemas e as } \\
\text { propostas de planos mais antigos ou em desenvolvimento na época do estudo. O } \\
\text { sistema de transportes tem papel destacado pelos autores do estudo, que destacam o } \\
\text { seu papel de agente que facilita a ocupação do território e também das dificuldades } \\
\text { deste sistema para atender a sempre crescente demanda de viagens. }\end{array}$ \\
\hline & $\begin{array}{l}\text { São feitas propostas para criar novas "centralidades", que seriam polos de comércio, } \\
\text { serviços, empregos e outras atividades que se encontram muito concentradas na área } \\
\text { central de Belém. }\end{array}$ \\
\hline $\begin{array}{l}\text { 3. Portos, } \\
\text { Aeroportos, } \\
\text { Transporte e } \\
\text { Sistema Viário } \\
\text { Urbano }\end{array}$ & $\begin{array}{l}\text { Aqui se faz uma caracterização e diagnóstico de todos os modos de transportes. Em } \\
\text { termos de transporte urbano, se repetem as análises e recomendações dos estudos } \\
\text { mais recentes nesta área (JICA, 2001, 2003). }\end{array}$ \\
\hline $\begin{array}{l}\text { 4. Saneamento } \\
\text { Básico }\end{array}$ & $\begin{array}{l}\text { Aqui se apresenta uma caracterização, um diagnóstico e recomendações para a } \\
\text { melhoria da infraestrutura de saneamento básico. }\end{array}$ \\
\hline $\begin{array}{l}\text { 5. Diretrizes de } \\
\text { Ordenamento } \\
\text { Territorial }\end{array}$ & $\begin{array}{l}\text { Para efeito do presente trabalho, este é o capítulo mais interessante, pois compila } \\
\text { diretrizes que irão guiar o desenvolvimento da RMB, incluindo aquelas referentes aos } \\
\text { transportes urbanos e o uso do solo. Na primeira parte, podem-se destacar problemas } \\
\text { levantados na fase de diagnóstico que afetam direta ou indiretamente o sistema de } \\
\text { transportes: } \\
\text { - Grande concentração de atividades terciárias no Núcleo Expandido (centro da } \\
\text { cidade de Belém); } \\
\text { - Expansão espraiada e de baixíssima densidade das áreas urbanas } \\
\text { - } \quad \text { Exiséricas; } \\
\text { - Posicioncia de grandes terrenos vazios de porte significativo; } \\
\text { (destinado a aviões de pequeno porte); } \\
\text { Concepção operacional obsoleta do sistema de transporte coletivo } \\
\text { metropolitano; } \\
\text { Predominância de eixos estruturais radiais, convergindo para o } \\
\text { Entroncamento e daí para o centro da cidade. }\end{array}$ \\
\hline
\end{tabular}




\begin{tabular}{|c|c|}
\hline Capítulo & Conteúdo \\
\hline & 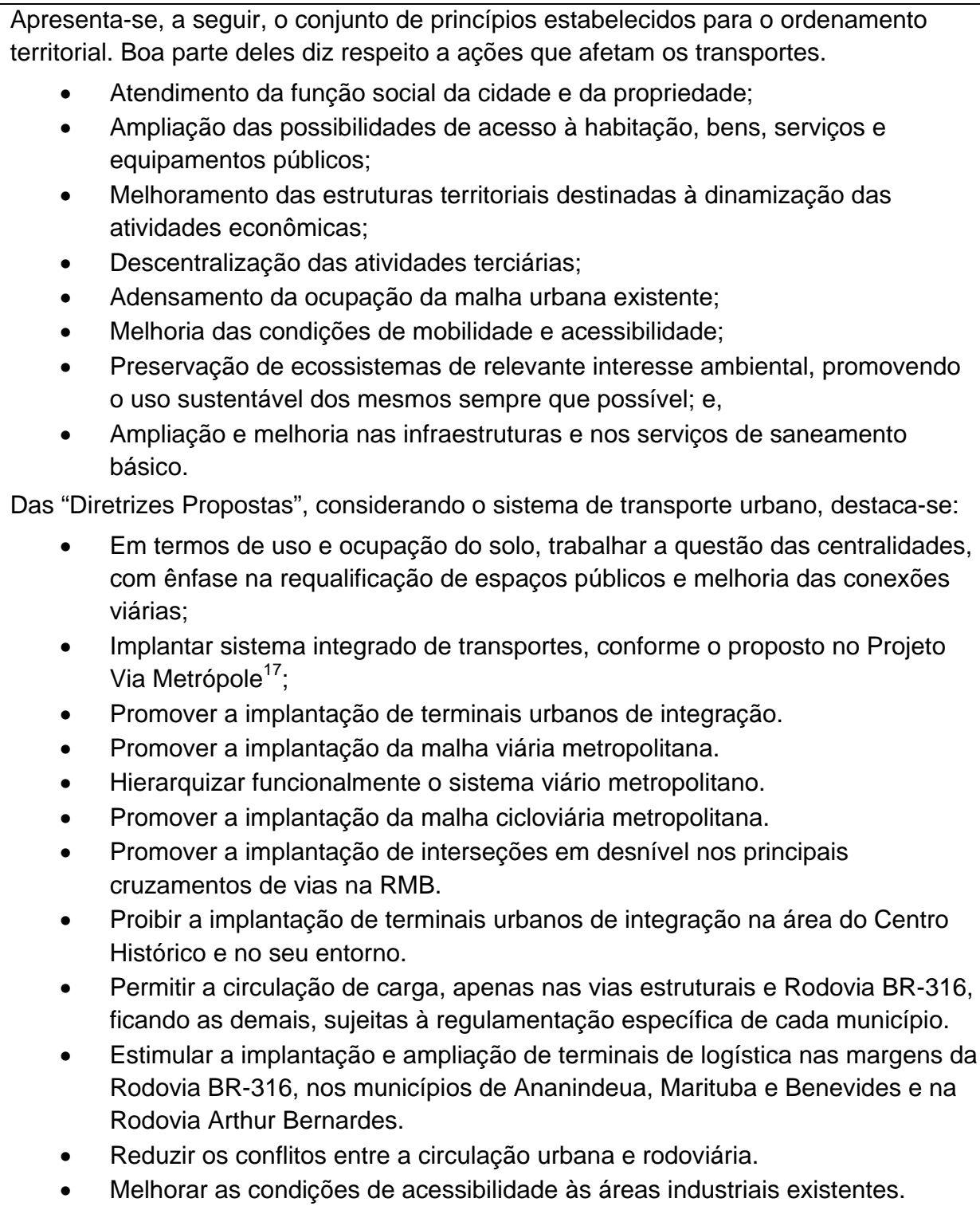 \\
\hline
\end{tabular}

\section{COMENTÁRIOS}

O Governo Federal, através de leis como o Estatuto das Cidades (BRASIL, 2001) e de ações do próprio Ministério das Cidades, obrigou os municípios a prepararem seus Planos Diretores. A ideia dessas "Diretrizes de Ordenamento Territorial" é a de harmonizar as propostas desses planos para os municípios da RMB. Isso é muito interessante, pois grande parte de determinadas infraestruturas são compartilhas por esses vizinhos.

Em termos de transportes urbanos, é interessante que ele seja tratado dentro de um mesmo "pacote" onde estão uso e ocupação do solo, localização de polos geradores de viagens, sistemas de drenagem, localização de habitações e áreas industriais. Tudo tem influência na demanda e na qualidade do serviço de transportes.

\footnotetext{
${ }^{17}$ Este é o nome de fantasia do projeto proposto pelos estudos feitos com a JICA (JICA, 1991, 2001, 2003). Na capa do relatório de 2003 aparece um logotipo e a denominação "Via Metrópole".
} 


\section{Propostas para o transporte não motorizado}

A hierarquização proposta para o sistema viário beneficia, de algum modo, o transporte não motorizado, pois tende a concentrar o maior volume de tráfego em um conjunto menor de vias. Retirase o tráfego mais intenso das vias locais.

Em termos de transporte por bicicleta existe uma diretriz específica recomendando a implantação da "malha cicloviária metropolitana".

\section{Propostas para o transporte público}

A proposta básica é a implantação do plano "Via Metrópole" que contempla uma proposta de reestruturação do sistema de transporte público.

Na diretriz de "Proibir a implantação de terminais urbanos de integração na área do Centro Histórico e no seu entorno" precisa ser bem analisada, para que se ofereçam outras opções de integração para os usuários. Um terminal de integração é inadequado para aquela área, mas a necessidade de integração pode existir.

\section{Propostas para o transporte individual}

As propostas seguem o recomendado pela JICA (2003) e beneficiam esse modo com uma melhoria geral da malha viária principal da RMB.

\section{Propostas para o sistema viário}

As propostas são as mesmas de planos anteriores, com a construção de novas vias, incluindo vias e faixas exclusivas para ônibus e para bicicletas.

As diretrizes também trazem "novidades", em relação ao Via Metrópole, como o incentivo à implantação de terminais logísticos, melhoria de acesso às áreas industriais e regulamentação da circulação de veículos de carga na malha urbana. 


\section{C.9. ESTUDO PREPARATÓRIO PARA O PROJETO DE SISTEMA DE TRANSPORTE DE ÔNIBUS DA REGIÃO METROPOLITANA DE BELÉM NA REPÚBLICA FEDERATIVA DO BRASIL - EP-STO-RMB (JICA, 2010)}

Mais uma vez as propostas de melhoria para o sistema de transportes da RMB deixaram de ser implantadas (JICA, 2003). Os dados produzidos para os estudos anteriores ficaram desatualizados. Mesmo a infraestrutura foi alterada e, assim, fez-se este novo trabalho como uma nova tentativa de introduzir um sistema de transporte público mais eficaz.

O conjunto de intervenções precisou ser reduzido, em virtude dos custos, pois a capacidade de endividamento do governo local não possibilita o financiamento de todas elas. Algumas obras foram realizadas em desacordo com os projetos do PDTU-2001 (JICA, 2001) e levaram a alterações de alguns deles. Este foi o caso de ciclovias construídas junto ao canteiro central de um corredor. No PDTU elas estavam previstas para as laterais externas das pistas.

Algumas novidades aparecem na modelagem da demanda e na definição dos recursos a serem utilizados para o financiamento dos projetos. A seguir, apresenta-se um breve resumo do conteúdo do relatório final deste estudo. O conjunto de propostas agora recebe o nome de "Ação Metrópole".

\section{RESUMO DO CONTEÚDO}

\begin{tabular}{|c|c|}
\hline Capítulo & Conteúdo \\
\hline 1. Antecedentes & $\begin{array}{l}\text { Aqui se faz um rápido histórico dos últimos estudos e se destaca a necessidade de } \\
\text { atualizarem as propostas, considerando que se passaram cinco anos deste a última } \\
\text { (JICA, 2003). Os objetivos seriam "Atualizar o EV/2003, coletar informações necessárias } \\
\text { à análise do empréstimo em iene, analisar de forma adequada o conteúdo do } \\
\text { empreendimento e demais dados necessários à cooperação financeira elaborando } \\
\text { documentos para sua análise como projeto". Em termos de prazo, foi estabelecido como } \\
\text { horizonte o ano de "... 2018, sendo o de curto prazo o ano } 2013 \text { e o de longo prazo o } \\
\text { ano } 2025 \text { ". }\end{array}$ \\
\hline & $\begin{array}{l}\text { Apresenta-se também a definição do escopo do estudo, já que parte das intervenções } \\
\text { foi excluída por restrições orçamentárias. A seguir, descreve-se a metodologia do } \\
\text { estudo. }\end{array}$ \\
\hline
\end{tabular}

2. Visão Geral da Área de Estudo

Apresenta-se uma visão geral da área de estudos, com dados atualizados, incluindo aqueles referentes aos novos levantamentos de dados no sistema de transportes. Entre os estudos de 2003 e este de 2010, a população cresceu 14\% e a frota de veículos aumentou $60 \%$. A nova divisão modal, das viagens motorizadas, foi estimada em $62,3 \%$ para o transporte público e $37,7 \%$ para automóveis, contra $66 \%$ e $34 \%$, respectivamente, da estimativa do estudo anterior.

3. Plano de Empreendimento Selecionado e Situação de Apoio Financeiro

Aqui se apresenta um conjunto de projetos bem mais amplo, que fazem parte de um plano denominado "Ação Metrópole". São 39 projetos listados como componentes desse grande plano. A execução se divide entre o Governo do Estado e a Prefeitura de Belém. O estágio desses projetos variava de "em fase de planejamento", a maioria, até "obra em andamento" ou "trabalhos concluídos".

O presente estudo (JICA, 2010) faz a análise mais detalhada de um subconjunto de 19 intervenções dentre as 39 citadas acima. Dizem respeito, basicamente, à maior parte das obras viárias compostas por vias ou faixas exclusivas/prioritárias para ônibus.

\footnotetext{
4. Projeção de Os dados de crescimento populacional e da renda média foram revistos, alterando-se as Demanda de previsões do estudo anterior (JICA, 2003). Essa revisão aponta um menor aumento da Passageiros população e estima maior crescimento da renda média. Na nova rodada de modelagem da demanda, ocorreu alteração no conjunto de modelos
} 


\begin{tabular}{|c|c|}
\hline \multirow[t]{5}{*}{ Capítulo } & Conteúdo \\
\hline & $\begin{array}{l}\text { utilizados. Segundo o relatório, "O motivo da substituição foi fazer refletir precisamente a } \\
\text { mudança socioeconômica na divisão modal entre o transporte público e o privado". Para } \\
\text { a preparação do modelo de divisão modal foi utilizado um método de "preferência } \\
\text { declarada". Completando o conjunto de "Quatro Etapas", utilizou-se análise de } \\
\text { regressão para a geração de viagens, um modelo do tipo gravitacional para a } \\
\text { distribuição e considerou-se a restrição de capacidade para a alocação do tráfego. }\end{array}$ \\
\hline & $\begin{array}{l}\text { São preocupantes as previsões de divisão modal entre o transporte público e o privado } \\
\text { que seriam de } 62 \text { x } 38 \text { em } 2009,57 \text { x } 43 \text { em } 2018 \text { e } 53 \text { x } 47 \text { em } 2025 \text {. }\end{array}$ \\
\hline & $\begin{array}{l}\text { Ou fato a ser destacado é o de que o "sistema troncal" deverá operar em paralelo ao } \\
\text { sistema convencional, com uma redução gradual das linhas deste último. O relatório cita } \\
\text { informações de outras cidades que não levam a se ter uma confiança muito grande } \\
\text { nesse tipo de processo. }\end{array}$ \\
\hline & $\begin{array}{l}\text { A proposta de política tarifária prevê integração das tarifas apenas no novo sistema, } \\
\text { deixando de fora o sistema convencional. }\end{array}$ \\
\hline \multirow[t]{5}{*}{$\begin{array}{l}\text { 5. Plano Básico do } \\
\text { Empreendimento }\end{array}$} & $\begin{array}{l}\text { O capítulo inicia pela discussão da capacidade de arranjos de veículos do tipo rodoviário } \\
\text { ou ferroviário. Para o corredor da Av. Almirante Barroso, em 2009, estima-se uma } \\
\text { demanda de } 39.000 \text { passageiros/hora/sentido. Isso elimina muitas das opções, restando } \\
\text { apenas o sistema troncal de ônibus em canaletas exclusivas ou um sistema ferroviário } \\
\text { pesado (metroviário). }\end{array}$ \\
\hline & $\begin{array}{l}\text { Para a escolha da modalidade rodoviária, o estudo enumera algumas razões como a } \\
\text { flexibilidade geral do sistema, sistema mais simples de administração / manutenção, } \\
\text { custo de construção, espaço físico e mesmo a experiência local com a operação desse } \\
\text { tipo de veículo. Mesmo que ambientalmente o modo ferroviário pudesse trazer maiores } \\
\text { benefícios, o argumento é que o novo sistema reduzirá o número de ônibus em } \\
\text { circulação, o que também implicará em ganho ambiental. }\end{array}$ \\
\hline & $\begin{array}{l}\text { Continuando, descreve-se o modelo de operação dos três subsistemas rodoviários, } \\
\text { quais sejam, o troncal, o alimentador e o convencional, e as suas relações com o } \\
\text { sistema viário, os terminais e os pontos de parada. Trata-se também da localização e do } \\
\text { projeto de garagens para os veículos do novo sistema. Estas seriam localizadas } \\
\text { próximas aos principais terminais de integração. }\end{array}$ \\
\hline & $\begin{array}{l}\text { Na discussão do tipo de veículo a ser utilizado, apresenta-se as características básicas } \\
\text { e se discute a possibilidade de uso de outros tipos de propulsão como a elétrica, com } \\
\text { ônibus de tecnologia híbrida, ou utilizando gás natural comprimido. Embora tragam } \\
\text { ganho em termos de poluição ambiental, os custos de aquisição e manutenção dos } \\
\text { veículos tornam inviáveis essas opções. }\end{array}$ \\
\hline & $\begin{array}{l}\text { Apresenta-se um dimensionamento de todo o sistema, incluindo a frota por tipo de } \\
\text { veículo, o número de plataformas em terminais e estações de integração, incluindo o } \\
\text { projeto básico dos mesmos. }\end{array}$ \\
\hline
\end{tabular}

6. Estabelecimento Aqui se apresentam os orçamentos das várias intervenções e um cronograma de do Projeto de execução e de desembolso dos recursos.

Execução do Empreendimento

7. Estrutura de Aqui se faz uma análise da estrutura institucional local tanto para a implantação do Implementação e sistema quanto para a gerência da sua operação. Apresenta-se, inclusive, uma proposta Manutenção inicial de um "Consórcio Público" que seria a entidade responsável por essa gerência. Trata-se de uma proposta bem detalhada. Modelos para esse tipo de operação até existem. O maior problema sempre é a aprovação pelas administrações municipais que compõem a região metropolitana. No mesmo capítulo discute-esse também a relação desta entidade e os operadores privados e se prepara uma estimativa do custo de operação, não apenas dos veículos mas da estrutura de terminais, pontos de paradas e vias exclusivas.

8. Consideração Este capítulo apresenta o conjunto de estudos ambientais preparados para este plano, Sócio-Ambiental considerando o que exige a legislação. Lista também as medidas mitigadoras, necessárias tanto para o período de implantação quanto de operação do novo sistema. 


\begin{tabular}{ll}
\hline \multicolumn{1}{c}{ Capítulo } & \multicolumn{1}{c}{ Conteúdo } \\
\hline 9. Efeito do Projeto & $\begin{array}{l}\text { Aqui se trata da apropriação de custos e benefícios, econômicos e financeiros, das } \\
\text { intervenções previstas neste plano, incluindo aqueles ocorridos durante a implantação } \\
\text { do sistema. Trata-se de uma avaliação um pouco mais sofisticada do que aquelas de } \\
\text { planos anteriores, pois introduz um detalhamento e uma variedade maior de custos, } \\
\text { principalmente, e benefícios. }\end{array}$ \\
\hline $\begin{array}{l}\text { 10. Análise para o } \\
\text { Projeto CDM }\end{array}$ & $\begin{array}{l}\text { Apresenta-se aqui, de uma maneira bastante complexa, um estudo/proposta de } \\
\text { enquadramento do presente plano dentro de um esquema de CDM - Clean } \\
\text { Development Mechanism (Mecanismo de Desenvolvimento Limpo - MDL). Não fica claro } \\
\text { qual seria o benefício para o sistema, o que isso implicaria em termos de redução dos } \\
\text { custos de operação. }\end{array}$ \\
\hline Apêndice & $\begin{array}{l}\text { Aqui se apresenta o estudo de implantação de duas novas vias, a Avenida João Paulo II } \\
\text { e a Estrada da Pedreirinha. }\end{array}$ \\
\hline
\end{tabular}

\section{COMENTÁRIOS}

Esta é mais uma atualização de uma proposta de implantação de um sistema de transportes de maior capacidade na Região Metropolitana de Belém. Ocorre que com o passar do tempo, o cenário muda, por exemplo, com a implantação de novas infraestruturas. A atuação da Prefeitura de Belém e de órgãos do Governo do Estado, no que se refere ao sistema viário, procura seguir as recomendações dos planos de transportes. Assim, mesmo alterado o cenário, a maioria das propostas precisa de pequenos ajustes.

Pelo menos no que diz respeito à parte que seria financiada pelo governo japonês, analisada neste estudo, ocorreram cortes nas metas físicas, por problemas de limitação orçamentária do governo estadual.

Aspectos interessantes dizem respeito à previsão de divisão modal, que aponta percentuais quase iguais para os modos público e privado no horizonte de 2025, e a questão da continuidade de operação do sistema convencional, que seria reduzido ao longo do tempo, mas não teria integração com o sistema troncal.

\section{Propostas para o transporte não motorizado}

Este estudo mantém o que existia de acessos para pedestres e ciclistas aos terminais. Continuam projetadas as ciclovias já previstas anteriormente e os bicicletários dos terminais.

\section{Propostas para o transporte público}

O sistema a ser implantado prevê a divisão nos subsistemas troncal, alimentador e convencional. Os dois primeiros contam com a nova estrutura de vias, pontos de parada, estações e terminais de integração. Também existirá integração tarifária para aqueles transbordos que ocorrerem nos terminais ou estações. O subsistema convencional usará o mesmo sistema viário, compartilhado com automóveis e outros veículos, e não terá integração tarifária com os outros dois. A integração física ocorrerá quando houve a proximidade de seus pontos de parada com os pontos de embarque/desembarque do serviço trono-alimentado. 
Esta não integração total dos serviços é um retrocesso e perde-se a oportunidade de prestar um melhor serviço à população. Entende-se que isso ocorra como uma fuga ao enfrentamento dos interesses dos operadores atuais. É um problema político complicado, mas o poder público tem a legislação para Ihe dar apoio nessa tarefa. É provável que os operadores atuais constituam o grupo mais preparado para a operação do novo sistema "total", não havendo porque temerem um processo de licitação.

\section{Propostas para o transporte individual}

Considerando apenas o pacote deste plano, as propostas se resumiriam à melhoria geral das vias no processo de implantação das faixas para os ônibus e a construção de duas novas vias, que melhorariam as opções de acesso e desafogariam alguns trechos viários. No pacote maior do projeto "Ação Metrópole" existem outros trechos de vias a serem reformados ou implantados.

O novo sistema, trás também melhor sinalização para facilitar a circulação do transporte motorizado. Não fica muito claro nos estudos de previsão de demanda, se o sistema viário suportaria a alta taxa de motorização prevista para 2025.

\section{Propostas para o sistema viário}

Excetuando-se a construção de terminais e garagens para os ônibus, o presente plano é basicamente de melhoria do sistema viário. Contemplam-se o tráfego geral, incluindo ônibus convencionais, com a melhoria e a ampliação do sistema viário e, com a introdução de vias e/ou faixas exclusivas, o transporte por ônibus e por bicicletas. 



\section{ANEXO D. RESUMO DOS INDICADORES CALCULADOS PARA O IMUS - RMB}

Apresenta-se na tabela a seguir a lista dos Domínios, Temas e Indicadores do IMUS com a indicação do que foi possível calcular para cada um dos cenários. Destaca-se nas cores verde e vermelha, respectivamente, aqueles indicadores com dados para todos ou nenhum dos cenários. No total foram 36 indicadores para os quais foi possível calcular os escores de todos os cenários e 15 sem informação para quaisquer deles.

\begin{tabular}{|c|c|c|c|c|c|c|}
\hline \multirow{2}{*}{ Domínio } & \multirow{2}{*}{ Tema } & \multirow{2}{*}{ Indicador } & \multicolumn{4}{|c|}{ Cenário } \\
\hline & & & 1980 & 1991 & 2001 & 2011 \\
\hline \multirow{10}{*}{ 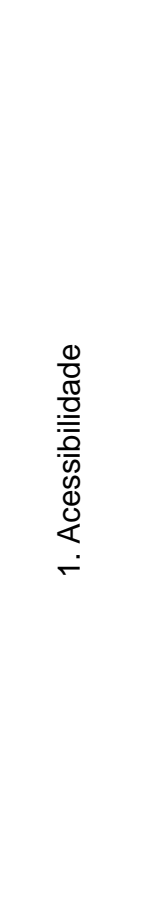 } & \multirow{3}{*}{$\begin{array}{l}\text { 1.1. Acessibilidade aos } \\
\text { sistemas de transporte }\end{array}$} & $\begin{array}{l}\text { 1.1.1. Acessibilidade ao transporte } \\
\text { público }\end{array}$ & $x$ & $\mathbf{x}$ & $\checkmark$ & $x$ \\
\hline & & $\begin{array}{l}\text { 1.1.2. Transporte público para } \\
\text { pessoas com necessidades } \\
\text { especiais }\end{array}$ & $\checkmark$ & $\checkmark$ & $\checkmark$ & $\checkmark$ \\
\hline & & 1.1.3. Despesas com transportes & $x$ & $x$ & $\checkmark$ & $\checkmark$ \\
\hline & \multirow{5}{*}{ 1.2. Acessibilidade universal } & $\begin{array}{l}\text { 1.2.1. Travessias adaptadas para } \\
\text { pessoas com necessidades } \\
\text { especiais }\end{array}$ & $\checkmark$ & $\checkmark$ & $\checkmark$ & $\checkmark$ \\
\hline & & $\begin{array}{l}\text { 1.2.2. Acessibilidade aos espaços } \\
\text { abertos }\end{array}$ & $x$ & $\mathbf{x}$ & $\checkmark$ & $\checkmark$ \\
\hline & & $\begin{array}{l}\text { 1.2.3. Vagas de estacionamento } \\
\text { para pessoas com necessidades } \\
\text { especiais }\end{array}$ & $x$ & $\mathbf{x}$ & $x$ & $\checkmark$ \\
\hline & & $\begin{array}{l}\text { 1.2.4. Acessibilidade a edifícios } \\
\text { públicos }\end{array}$ & $x$ & $x$ & $x$ & $x$ \\
\hline & & $\begin{array}{l}\text { 1.2.5. Acessibilidade aos serviços } \\
\text { essenciais }\end{array}$ & $x$ & $x$ & $x$ & $\checkmark$ \\
\hline & 1.3. Barreiras físicas & 1.3.1. Fragmentação urbana & $\checkmark$ & $\checkmark$ & $\checkmark$ & $\checkmark$ \\
\hline & $\begin{array}{l}\text { 1.4. Legislação para pessoas } \\
\text { com necessidades especiais }\end{array}$ & $\begin{array}{l}\text { 1.4.1. Ações para acessibilidade } \\
\text { universal }\end{array}$ & $\checkmark$ & $\checkmark$ & $\checkmark$ & $\checkmark$ \\
\hline \multirow{6}{*}{ 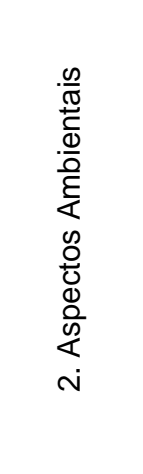 } & \multirow{4}{*}{$\begin{array}{l}\text { 2.1. Controle dos impactos no } \\
\text { meio ambiente }\end{array}$} & 2.1.1. Emissões de CO & $x$ & $x$ & $x$ & $x$ \\
\hline & & 2.1.2. Emissões de $\mathrm{CO} 2$ & $x$ & $x$ & $x$ & $x$ \\
\hline & & $\begin{array}{l}\text { 2.1.3. População exposta ao ruído } \\
\text { de tráfego }\end{array}$ & $x$ & $x$ & $\checkmark$ & $\checkmark$ \\
\hline & & $\begin{array}{l}\text { 2.1.4. Estudos de Impacto } \\
\text { Ambiental }\end{array}$ & $\checkmark$ & $\checkmark$ & $\checkmark$ & $\checkmark$ \\
\hline & \multirow{2}{*}{ 2.2. Recursos naturais } & 2.2.1. Consumo de combustível & $x$ & $\checkmark$ & $\checkmark$ & $\checkmark$ \\
\hline & & $\begin{array}{l}\text { 2.2.2. Uso de energia limpa e } \\
\text { combustíveis alternativos }\end{array}$ & $\checkmark$ & $\checkmark$ & $\checkmark$ & $\checkmark$ \\
\hline \multirow{5}{*}{$\begin{array}{l}\frac{n}{\pi} \\
\frac{\pi}{0} \\
0 \\
0 \\
0 \\
\frac{0}{0} \\
\frac{0}{0} \\
\frac{0}{4} \\
\infty \\
n\end{array}$} & 3.1. Apoio ao cidadão & $\begin{array}{l}\text { 3.1.1. Informação disponível ao } \\
\text { cidadão }\end{array}$ & $\checkmark$ & $\checkmark$ & $\checkmark$ & $\checkmark$ \\
\hline & 3.2. Inclusão social & 3.2.1. Eqüidade vertical (renda) & $x$ & $\checkmark$ & $\checkmark$ & $\checkmark$ \\
\hline & 3.3. Educação e cidadania & $\begin{array}{l}\text { 3.3.1. Educação para o } \\
\text { desenvolvimento sustentável }\end{array}$ & $x$ & $x$ & $\checkmark$ & $\checkmark$ \\
\hline & 3.4. Participação popular & $\begin{array}{l}\text { 3.4.1. Participação na tomada de } \\
\text { decisão }\end{array}$ & $\checkmark$ & $\checkmark$ & $\checkmark$ & $\checkmark$ \\
\hline & 3.5. Qualidade de vida & 3.5.1. Qualidade de vida & $x$ & $x$ & $x$ & $\checkmark$ \\
\hline
\end{tabular}




\begin{tabular}{|c|c|c|c|c|c|c|}
\hline \multirow{2}{*}{ Domínio } & \multirow{2}{*}{ Tema } & \multirow{2}{*}{ Indicador } & \multicolumn{4}{|c|}{ Cenário } \\
\hline & & & 1980 & 1991 & 2001 & 2011 \\
\hline \multirow{7}{*}{$\begin{array}{l}0 \\
0 \\
.0 \\
: 0 \\
0 \\
0 \\
0 \\
0 \\
0 \\
0 \\
0 \\
0 \\
0 \\
0 \\
\dot{0} \\
\dot{+}\end{array}$} & \multirow{2}{*}{$\begin{array}{l}\text { 4.1. Integração de ações } \\
\text { políticas }\end{array}$} & $\begin{array}{l}\text { 4.1.1. Integração entre níveis de } \\
\text { governo }\end{array}$ & $\checkmark$ & $\checkmark$ & $\checkmark$ & $\checkmark$ \\
\hline & & 4.1.2. Parcerias público-privadas & $\checkmark$ & $\checkmark$ & $\checkmark$ & $\checkmark$ \\
\hline & \multirow{4}{*}{$\begin{array}{l}\text { 4.2. Captação e } \\
\text { gerenciamento de recursos }\end{array}$} & 4.2.1. Captação de recursos & $x$ & $x$ & $x$ & $x$ \\
\hline & & $\begin{array}{l}\text { 4.2.2. Investimentos em sistemas } \\
\text { de transporte }\end{array}$ & $x$ & $x$ & $x$ & $x$ \\
\hline & & $\begin{array}{l}\text { 4.2.3. Distribuição dos recursos } \\
\text { (coletivo x privado) }\end{array}$ & $x$ & $x$ & $x$ & $x$ \\
\hline & & $\begin{array}{l}\text { 4.2.4. Distribuição dos recursos } \\
\text { (motorizados x não-motorizados) }\end{array}$ & $x$ & $\checkmark$ & $\checkmark$ & $\checkmark$ \\
\hline & $\begin{array}{l}\text { 4.3. Política de mobilidade } \\
\text { urbana }\end{array}$ & $\begin{array}{l}\text { 4.3.1. Política de mobilidade } \\
\text { urbana }\end{array}$ & $\checkmark$ & $\checkmark$ & $\checkmark$ & $\checkmark$ \\
\hline \multirow{5}{*}{ 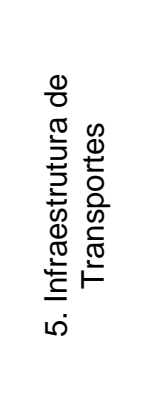 } & \multirow{4}{*}{$\begin{array}{l}\text { 5.1. Provisão e manutenção } \\
\text { da infraestrutura de } \\
\text { transportes }\end{array}$} & $\begin{array}{l}\text { 5.1.1. Densidade e conectividade } \\
\text { da rede viária }\end{array}$ & $x$ & $x$ & $x$ & $x$ \\
\hline & & 5.1.2. Vias pavimentadas & $x$ & $\checkmark$ & $\checkmark$ & $\checkmark$ \\
\hline & & $\begin{array}{l}\text { 5.1.3. Despesas com manutenção } \\
\text { da infraestrutura }\end{array}$ & $x$ & $x$ & $x$ & $x$ \\
\hline & & 5.1.4. Sinalização viária & $x$ & $x$ & $x$ & $\checkmark$ \\
\hline & $\begin{array}{l}\text { 5.2. Distribuição da } \\
\text { infraestrutura de transporte }\end{array}$ & 5.2.1. Vias para transporte coletivo & $\checkmark$ & $\checkmark$ & $\checkmark$ & $\checkmark$ \\
\hline \multirow{9}{*}{ 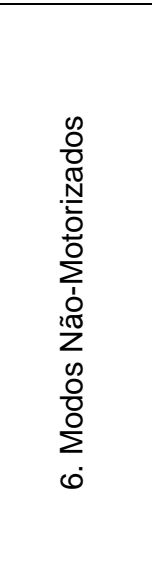 } & \multirow{3}{*}{ 6.1. Transporte cicloviário } & $\begin{array}{l}\text { 6.1.1. Extensão e conectividade de } \\
\text { ciclovias }\end{array}$ & $\checkmark$ & $\checkmark$ & $\checkmark$ & $\checkmark$ \\
\hline & & 6.1.2. Frotas de bicicletas & $x$ & $x$ & $\checkmark$ & $x$ \\
\hline & & $\begin{array}{l}\text { 6.1.3. Estacionamento de } \\
\text { bicicletas }\end{array}$ & $\checkmark$ & $\checkmark$ & $\checkmark$ & $\checkmark$ \\
\hline & \multirow{2}{*}{ 6.2. Deslocamentos a pé } & 6.2.1. Vias para pedestres & $\checkmark$ & $\checkmark$ & $\checkmark$ & $\checkmark$ \\
\hline & & 6.2.2. Vias com calçadas & $x$ & $x$ & $\checkmark$ & $\checkmark$ \\
\hline & \multirow{4}{*}{ 6.3. Redução de viagens } & 6.3.1. Distância de viagem & $x$ & $\checkmark$ & $x$ & $x$ \\
\hline & & 6.3.2. Tempo de viagem & $x$ & $\checkmark$ & $x$ & $x$ \\
\hline & & 6.3.3. Número de viagens & $\checkmark$ & $\checkmark$ & $\checkmark$ & $x$ \\
\hline & & $\begin{array}{l}\text { 6.3.4. Ações para redução do } \\
\text { tráfego motorizado }\end{array}$ & $\checkmark$ & $\checkmark$ & $\checkmark$ & $\checkmark$ \\
\hline
\end{tabular}




\begin{tabular}{|c|c|c|c|c|c|c|}
\hline \multirow{2}{*}{ Domínio } & \multirow{2}{*}{ Tema } & \multirow{2}{*}{ Indicador } & \multicolumn{4}{|c|}{ Cenário } \\
\hline & & & 1980 & 1991 & 2001 & 2011 \\
\hline \multirow{18}{*}{ 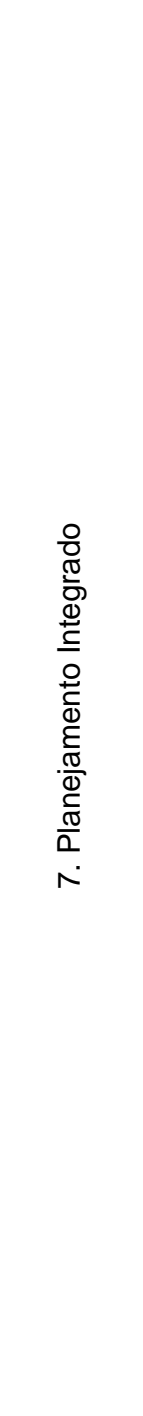 } & \multirow{2}{*}{ 7.1. Capacitação de gestores } & $\begin{array}{l}\text { 7.1.1. Nível de formação de } \\
\text { técnicos e gestores }\end{array}$ & $x$ & $x$ & $x$ & $x$ \\
\hline & & $\begin{array}{l}\text { 7.1.2. Capacitação de técnicos e } \\
\text { gestores }\end{array}$ & $\checkmark$ & $x$ & $x$ & $x$ \\
\hline & $\begin{array}{l}\text { 7.2. Áreas centrais e de } \\
\text { interesse histórico }\end{array}$ & 7.2.1. Vitalidade do centro & $x$ & $x$ & $x$ & $x$ \\
\hline & 7.3. Integração regional & 7.3.1. Consórcios intermunicipais & $\checkmark$ & $\checkmark$ & $\checkmark$ & $\checkmark$ \\
\hline & $\begin{array}{l}\text { 7.4. Transparência do } \\
\text { processo de planejamento }\end{array}$ & $\begin{array}{l}\text { 7.4.1. Transparência e } \\
\text { responsabilidade }\end{array}$ & $x$ & $x$ & $x$ & $\checkmark$ \\
\hline & \multirow{5}{*}{$\begin{array}{l}\text { 7.5. Planejamento e controle } \\
\text { do uso e ocupação do solo }\end{array}$} & 7.5.1. Vazios urbanos & $x$ & $x$ & $x$ & $x$ \\
\hline & & 7.5.2. Crescimento urbano & $x$ & $x$ & $x$ & $x$ \\
\hline & & $\begin{array}{l}\text { 7.5.3. Densidade populacional } \\
\text { urbana }\end{array}$ & $\checkmark$ & $\checkmark$ & $\checkmark$ & $\checkmark$ \\
\hline & & 7.5.4. Índice de uso misto & $x$ & $x$ & $\checkmark$ & $\checkmark$ \\
\hline & & 7.5.5. Ocupações irregulares & $x$ & $x$ & $x$ & $\checkmark$ \\
\hline & \multirow{2}{*}{$\begin{array}{l}\text { 7.6. Planejamento estratégico } \\
\text { e integrado }\end{array}$} & $\begin{array}{l}\text { 7.6.1. Planejamento urbano, } \\
\text { ambiental e de transporte } \\
\text { integrado }\end{array}$ & $\checkmark$ & $\checkmark$ & $\checkmark$ & $\checkmark$ \\
\hline & & $\begin{array}{l}\text { 7.6.2. Efetivação e continuidade } \\
\text { das ações }\end{array}$ & $\checkmark$ & $\checkmark$ & $\checkmark$ & $\checkmark$ \\
\hline & \multirow{3}{*}{$\begin{array}{l}\text { 7.7. Planejamento da } \\
\text { infraestrutura urbana e } \\
\text { equipamentos urbanos }\end{array}$} & 7.7.1. Parques e áreas verdes & $x$ & $x$ & $x$ & $x$ \\
\hline & & $\begin{array}{l}\text { 7.7.2. Equipamentos urbanos } \\
\text { (escolas) }\end{array}$ & $x$ & $x$ & $\checkmark$ & $\checkmark$ \\
\hline & & $\begin{array}{l}\text { 7.7.3. Equipamentos urbanos } \\
\text { (postos de saúde) }\end{array}$ & $\checkmark$ & $\checkmark$ & $\checkmark$ & $\checkmark$ \\
\hline & \multirow{3}{*}{$\begin{array}{l}\text { 7.8. Plano diretor e legislação } \\
\text { urbanística }\end{array}$} & 7.8.1. Plano diretor & $\checkmark$ & $\checkmark$ & $\checkmark$ & $\checkmark$ \\
\hline & & 7.8.2. Legislação urbanística & $\checkmark$ & $\checkmark$ & $\checkmark$ & $\checkmark$ \\
\hline & & $\begin{array}{l}\text { 7.8.3. Cumprimento da legislação } \\
\text { urbanística }\end{array}$ & $x$ & $x$ & $x$ & $x$ \\
\hline \multirow{9}{*}{ 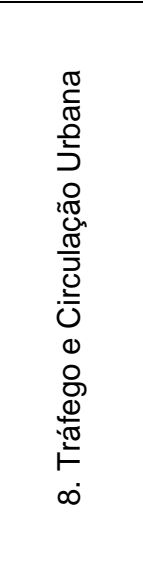 } & \multirow{3}{*}{ 8.1. Acidentes de trânsito } & 8.1.1. Acidentes de trânsito & $x$ & $x$ & $\checkmark$ & $\checkmark$ \\
\hline & & $\begin{array}{l}\text { 8.1.2. Acidentes com pedestres e } \\
\text { ciclistas }\end{array}$ & $x$ & $x$ & $\checkmark$ & $\checkmark$ \\
\hline & & 8.1.3. Prevenção de acidentes & $x$ & $x$ & $x$ & $\checkmark$ \\
\hline & 8.2. Educação para o trânsito & 8.2.1. Educação para o trânsito & $x$ & $x$ & $x$ & $\checkmark$ \\
\hline & \multirow{2}{*}{ 8.3. Fluidez e circulação } & 8.3.1. Congestionamento & $x$ & $x$ & $x$ & $\checkmark$ \\
\hline & & 8.3.2. Velocidade média do tráfego & $\checkmark$ & $\checkmark$ & $\checkmark$ & $\checkmark$ \\
\hline & $\begin{array}{l}\text { 8.4. Operação e fiscalização } \\
\text { de trânsito }\end{array}$ & 8.4.1. Violação das leis de trânsito & $x$ & $x$ & $x$ & $\checkmark$ \\
\hline & \multirow[b]{2}{*}{ 8.5. Transporte individual } & 8.5.1. Índice de motorização & $\checkmark$ & $\checkmark$ & $\checkmark$ & $\checkmark$ \\
\hline & & $\begin{array}{l}\text { 8.5.2. Taxa de ocupação de } \\
\text { veículos }\end{array}$ & $x$ & $x$ & $\checkmark$ & $\checkmark$ \\
\hline
\end{tabular}




\begin{tabular}{|c|c|c|c|c|c|c|}
\hline \multirow{2}{*}{ Domínio } & \multirow{2}{*}{ Tema } & \multirow{2}{*}{ Indicador } & \multicolumn{4}{|c|}{ Cenário } \\
\hline & & & 1980 & 1991 & 2001 & 2011 \\
\hline \multirow{18}{*}{ 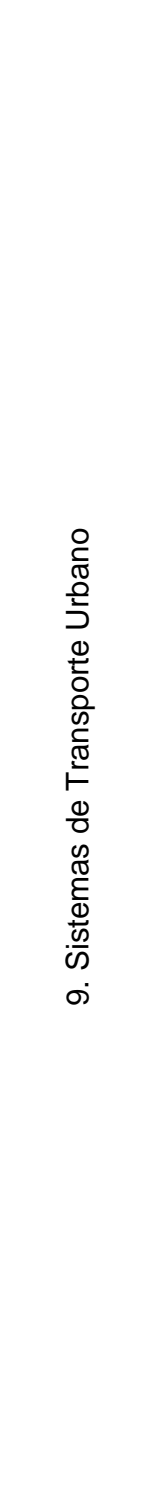 } & \multirow{8}{*}{$\begin{array}{l}\text { 9.1. Disponibilidade e } \\
\text { qualidade do transporte } \\
\text { público }\end{array}$} & $\begin{array}{l}\text { 9.1.1. Extensão da rede transporte } \\
\text { público }\end{array}$ & $x$ & $x$ & $\checkmark$ & $x$ \\
\hline & & $\begin{array}{l}\text { 9.1.2. Frequência de atendimento } \\
\text { do transporte público }\end{array}$ & $\checkmark$ & $\checkmark$ & $\checkmark$ & $\checkmark$ \\
\hline & & 9.1.3. Pontualidade & $x$ & $x$ & $x$ & $x$ \\
\hline & & $\begin{array}{l}\text { 9.1.4. Velocidade média do } \\
\text { transporte público }\end{array}$ & $\checkmark$ & $\checkmark$ & $\checkmark$ & $\checkmark$ \\
\hline & & $\begin{array}{l}\text { 9.1.5. Idade média da frota de } \\
\text { transporte público }\end{array}$ & $\checkmark$ & $\checkmark$ & $\checkmark$ & $\checkmark$ \\
\hline & & $\begin{array}{l}\text { 9.1.6. Índice de passageiros por } \\
\text { quilômetro }\end{array}$ & $\checkmark$ & $\checkmark$ & $\checkmark$ & $\checkmark$ \\
\hline & & $\begin{array}{l}\text { 9.1.7. Passageiros transportados } \\
\text { anualmente }\end{array}$ & $\checkmark$ & $\checkmark$ & $\checkmark$ & $\checkmark$ \\
\hline & & $\begin{array}{l}\text { 9.1.8. Satisfação do usuário com o } \\
\text { serviço de transporte público }\end{array}$ & $x$ & $x$ & $\checkmark$ & $\checkmark$ \\
\hline & \multirow{3}{*}{ 9.2. Diversificação modal } & $\begin{array}{l}\text { 9.2.1. Diversidade de modos de } \\
\text { transporte }\end{array}$ & $\checkmark$ & $\checkmark$ & $\checkmark$ & $\checkmark$ \\
\hline & & $\begin{array}{l}\text { 9.2.2. Transporte coletivo } x \\
\text { transporte individual }\end{array}$ & $\checkmark$ & $\checkmark$ & $\checkmark$ & $\checkmark$ \\
\hline & & $\begin{array}{l}\text { 9.2.3. Modos não-motorizados x } \\
\text { modos motorizados }\end{array}$ & $\checkmark$ & $\checkmark$ & $\checkmark$ & $x$ \\
\hline & \multirow{2}{*}{$\begin{array}{l}\text { 9.3. Regulação e fiscalização } \\
\text { do transporte público }\end{array}$} & 9.3.1. Contratos e licitações & $\checkmark$ & $\checkmark$ & $\checkmark$ & $\checkmark$ \\
\hline & & 9.3.2. Transporte clandestino & $x$ & $x$ & $x$ & $\checkmark$ \\
\hline & \multirow{2}{*}{$\begin{array}{l}\text { 9.4. Integração do transporte } \\
\text { público }\end{array}$} & 9.4.1. Terminais intermodais & $\checkmark$ & $\checkmark$ & $\checkmark$ & $\checkmark$ \\
\hline & & $\begin{array}{l}\text { 9.4.2. Integração do transporte } \\
\text { público }\end{array}$ & $\checkmark$ & $\checkmark$ & $\checkmark$ & $\checkmark$ \\
\hline & \multirow{3}{*}{ 9.5. Política tarifária } & 9.5.1. Descontos e gratuidades & $x$ & $x$ & $\checkmark$ & $\checkmark$ \\
\hline & & 9.5.2. Tarifas de transporte & $x$ & $x$ & $\checkmark$ & $\checkmark$ \\
\hline & & 9.5.3. Subsídios públicos & $\checkmark$ & $\checkmark$ & $\checkmark$ & $\checkmark$ \\
\hline \multicolumn{3}{|c|}{ Total de inidicadores calculados } & 39 & 44 & 58 & 64 \\
\hline
\end{tabular}




\section{ANEXO E. MEMÓRIA DE CÁLCULO DO IMUS - RMB}

Observação: Alguns dos indicadores para o cenário 2011, aqui apresentados, tiveram seus cálculos refeitos ou complementados após a conclusão das correções da tese. Estes novos resultados não foram incorporados às análises pois não alteram significativamente o valor do IMUS.

1. ACESSIBILIDADE 147

1.1. Acessibilidade aos sistemas de transportes. 147

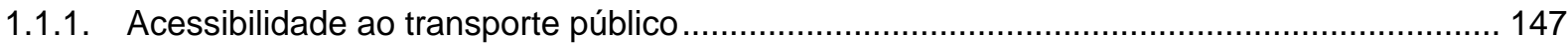

1.1.2. Transporte público para pessoas com necessidades especiais .......................................... 147

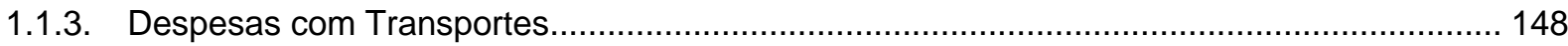

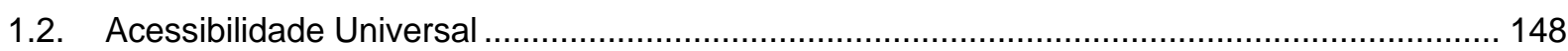

1.2.1. Travessias adaptadas para pessoas com necessidades especiais .................................... 148

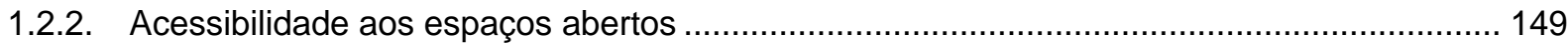

1.2.3. Vagas de estacionamento para pessoas com necessidades especiais .............................. 149

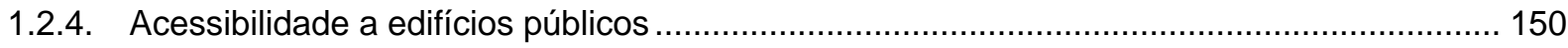

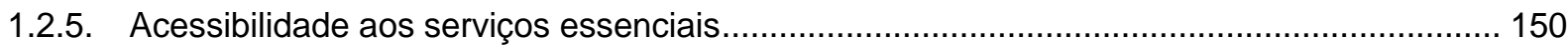

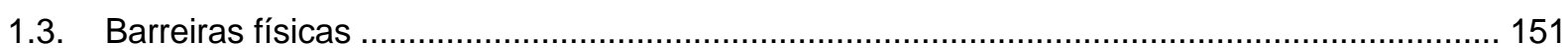

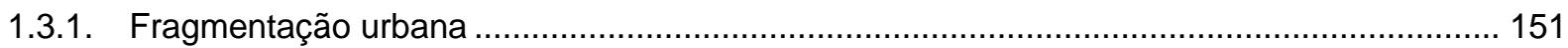

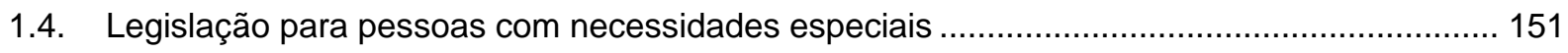

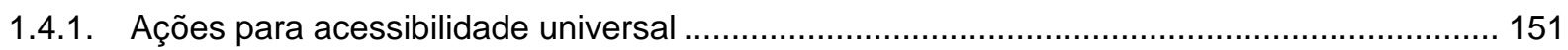

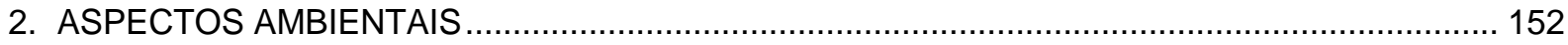

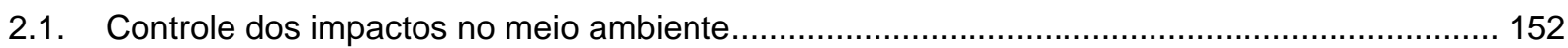

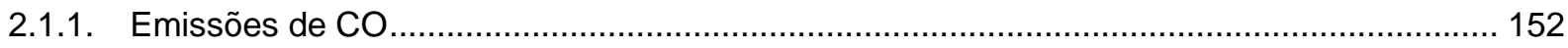

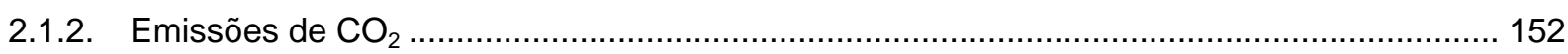

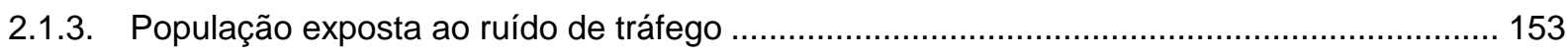

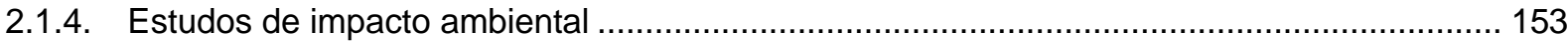

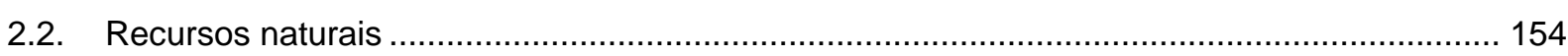

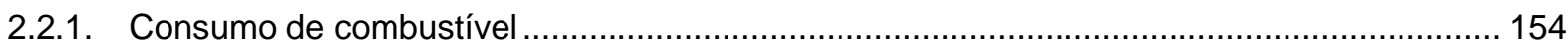

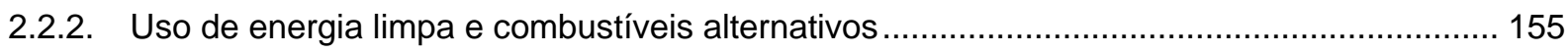

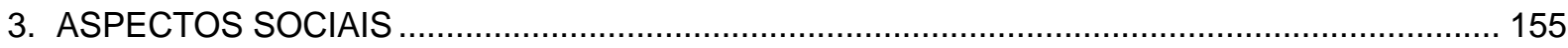

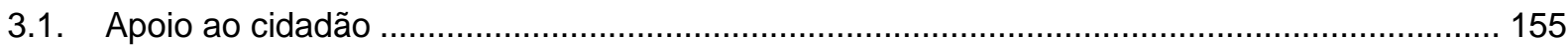

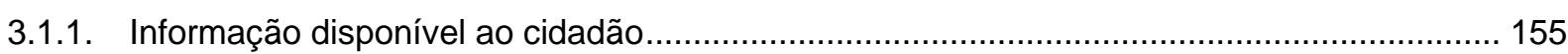

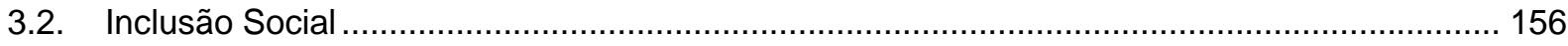

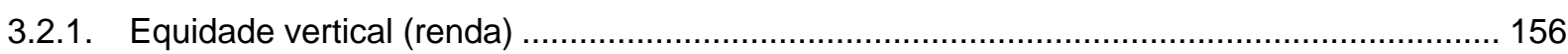

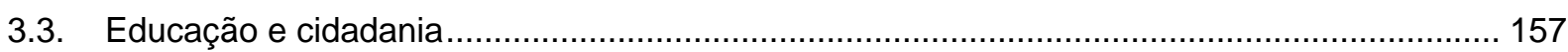

3.3.1. Educação para o desenvolvimento sustentável ............................................................. 157 


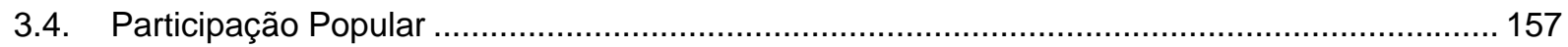

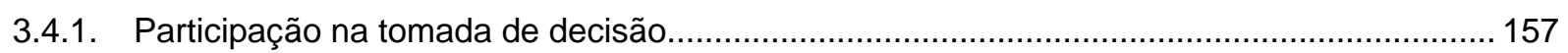

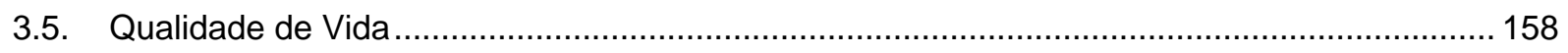

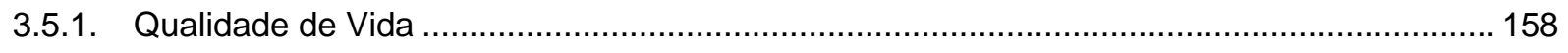

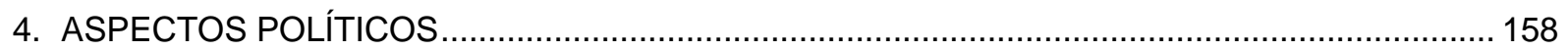

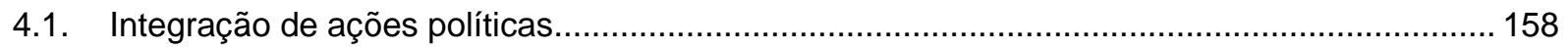

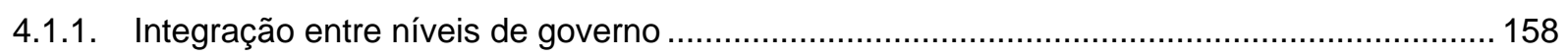

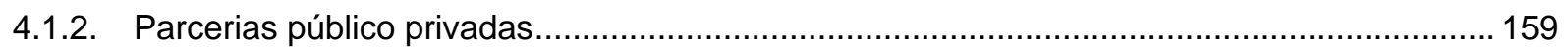

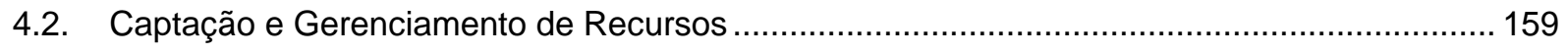

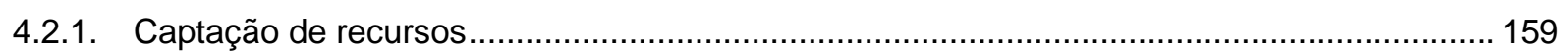

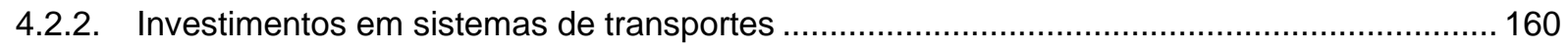

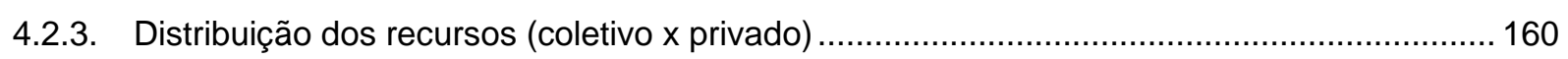

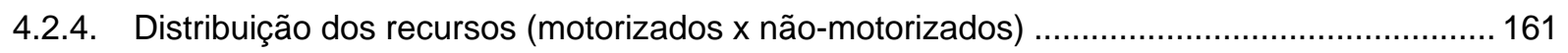

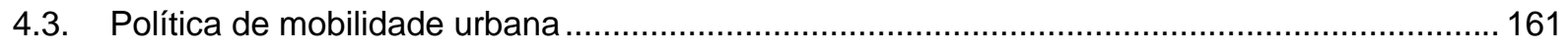

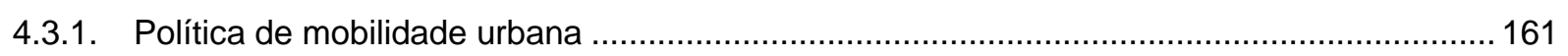

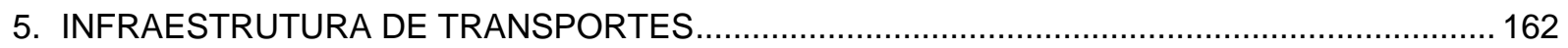

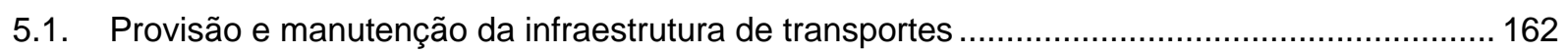

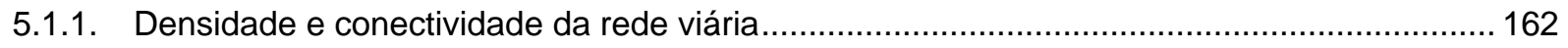

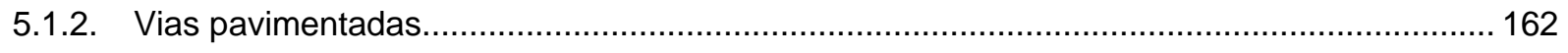

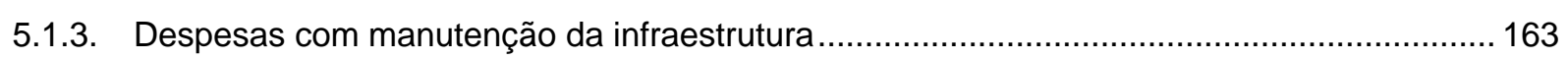

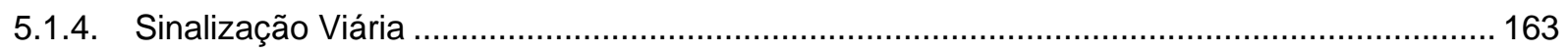

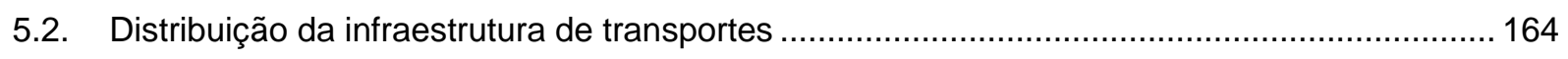

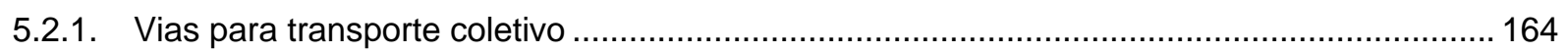

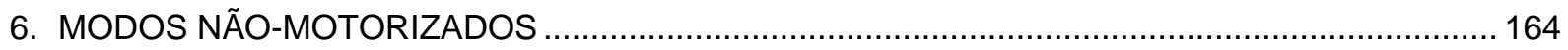

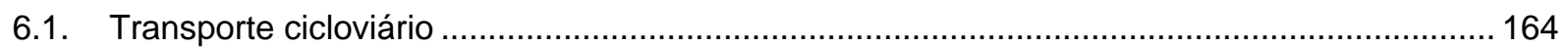

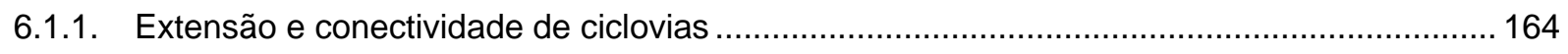

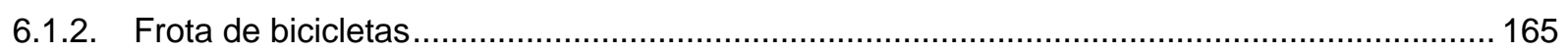

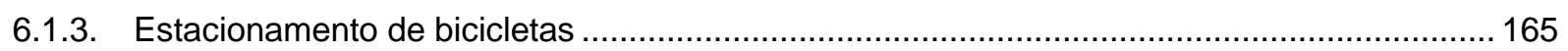

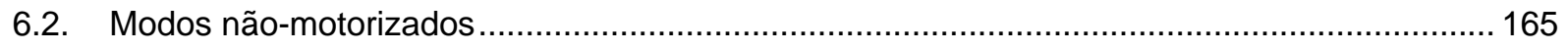

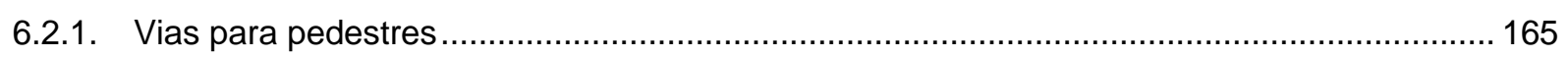

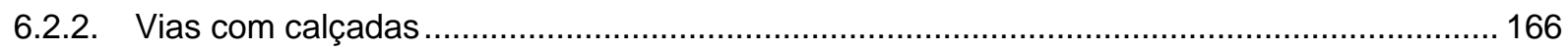

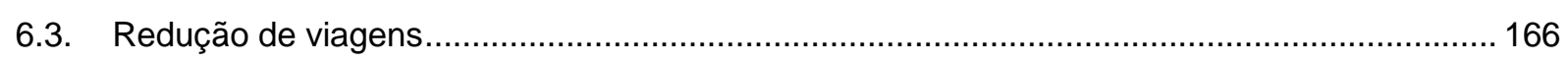

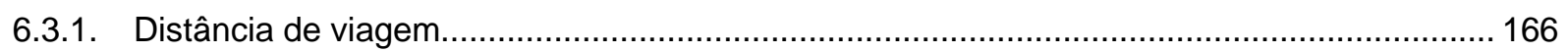

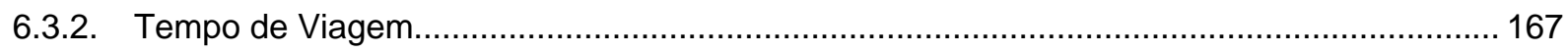

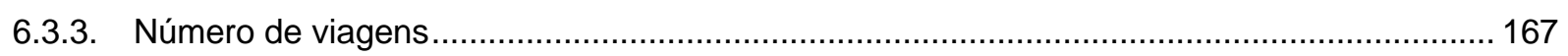

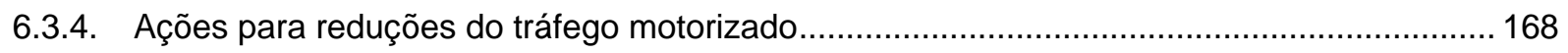

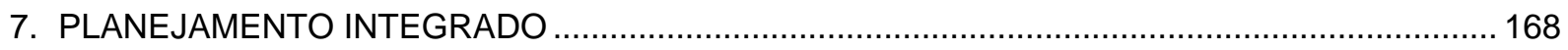

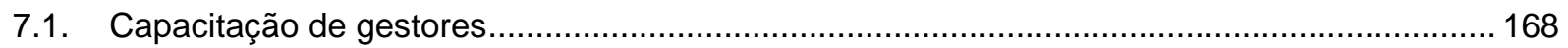




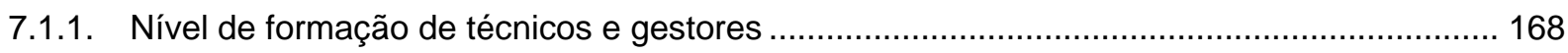

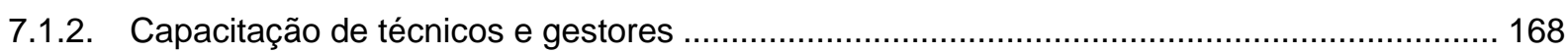

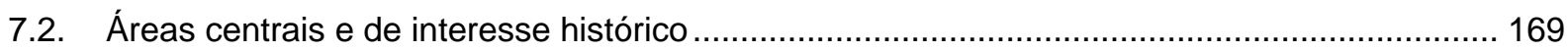

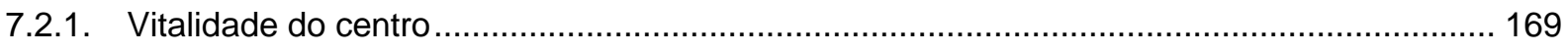

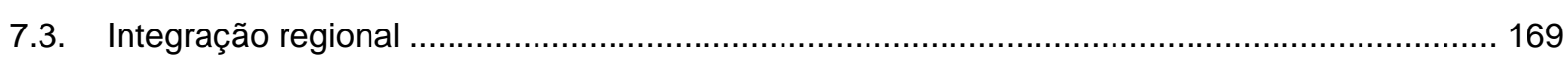

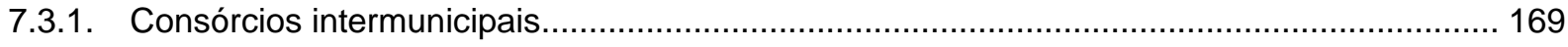

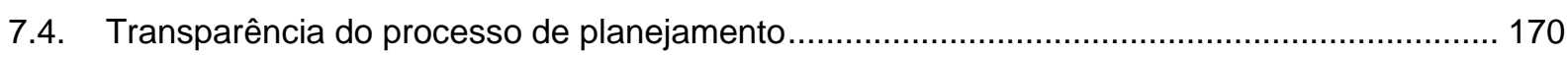

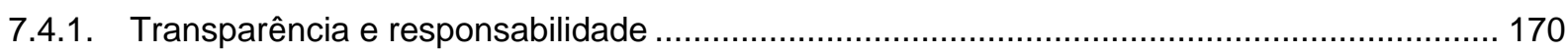

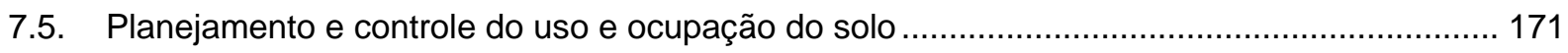

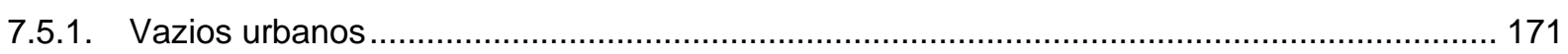

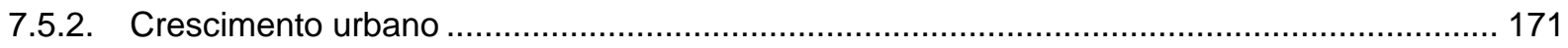

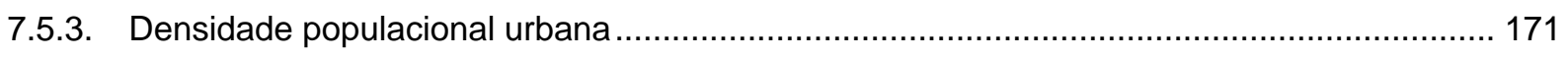

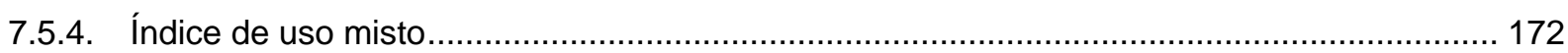

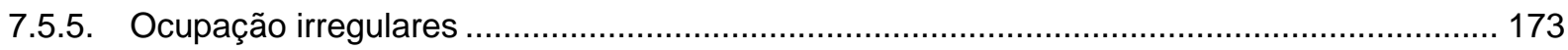

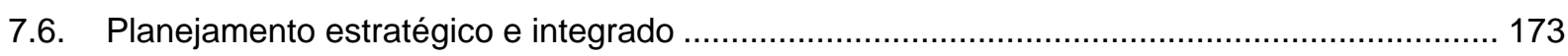

7.6.1. Planejamento urbano, ambiental e de transportes integrado ............................................. 173

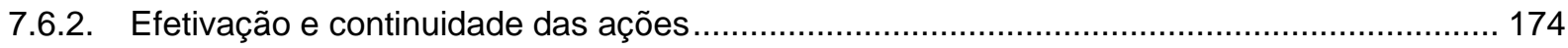

7.7. Planejamento da infraestrutura urbana e equipamentos urbanos.......................................... 174

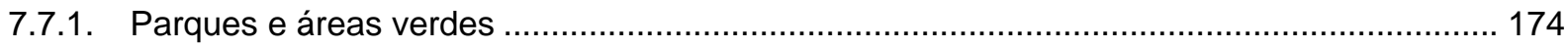

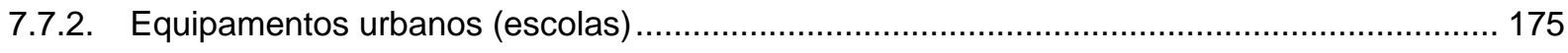

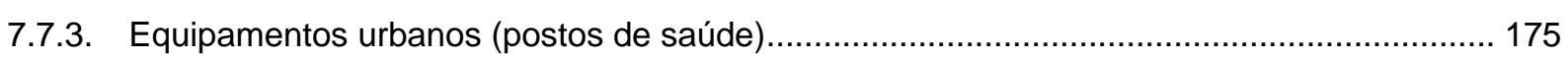

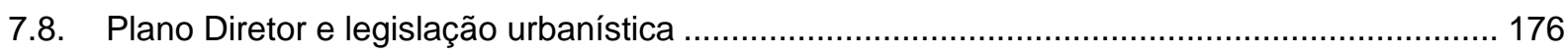

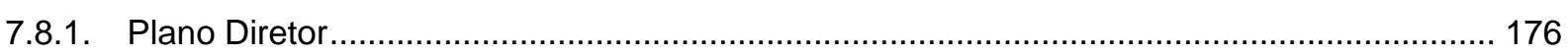

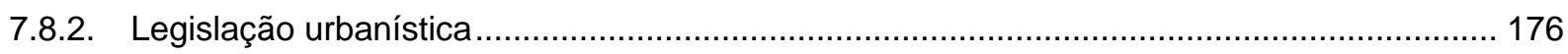

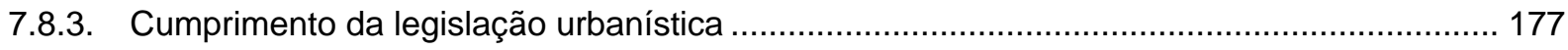

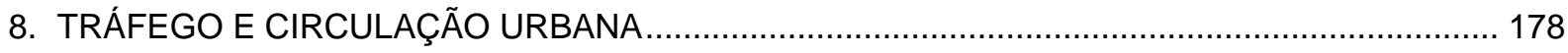

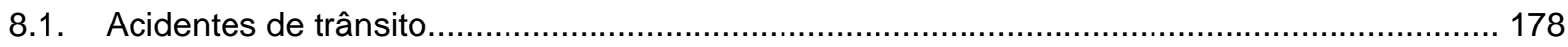

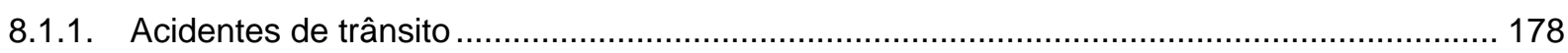

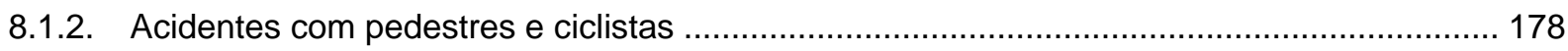

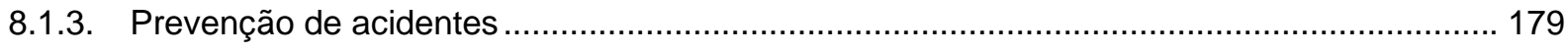

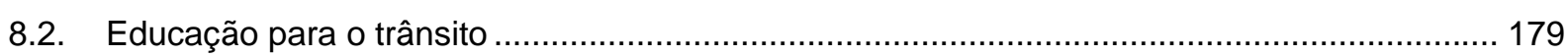

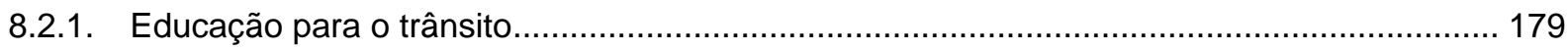

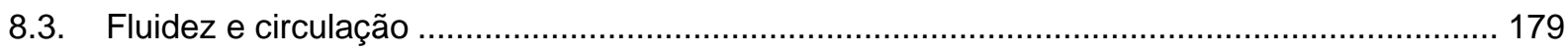

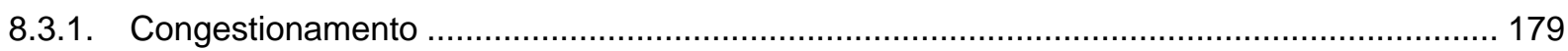

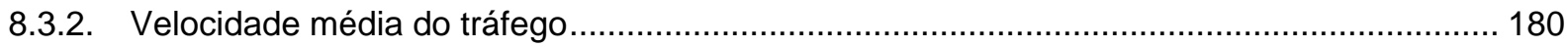

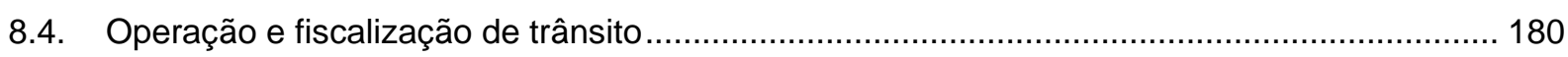

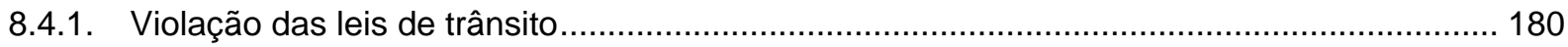

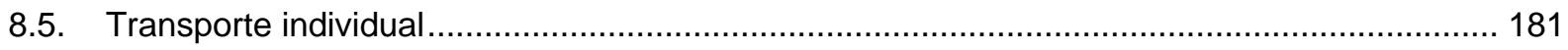

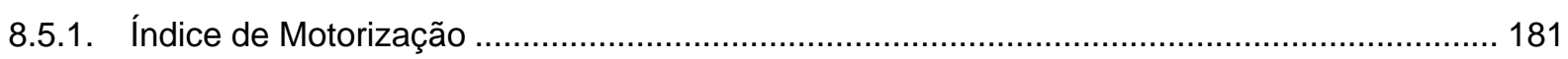

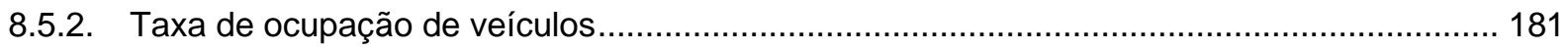




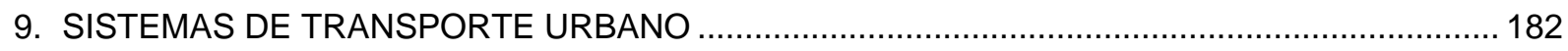

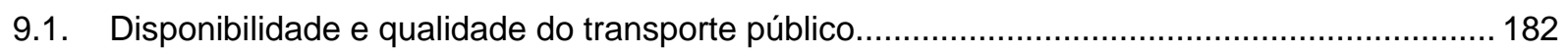

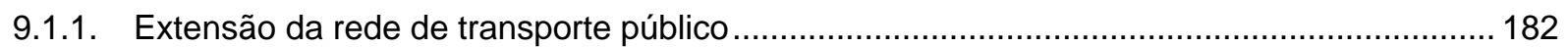

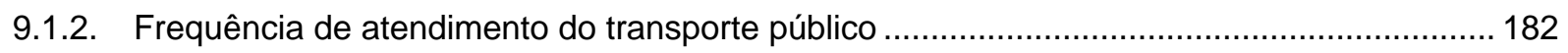

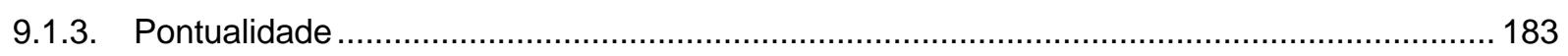

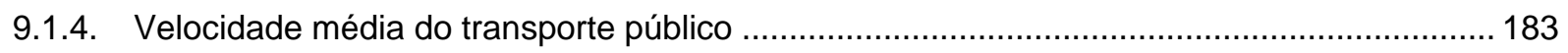

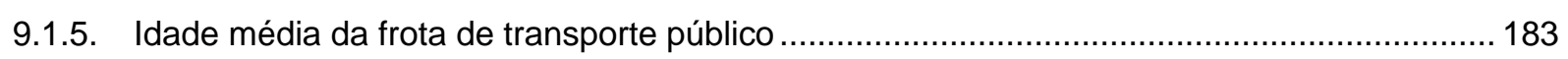

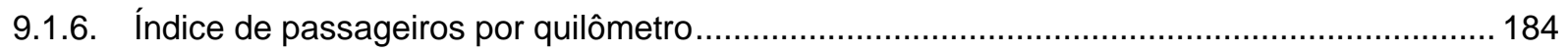

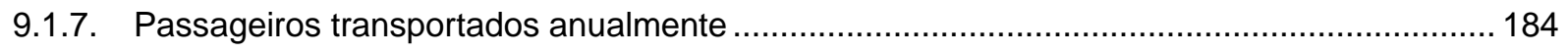

9.1.8. Satisfação do usuário com o serviço de transporte público ................................................ 185

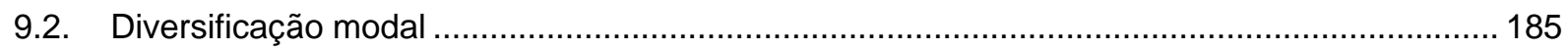

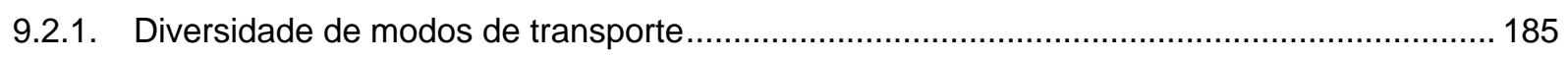

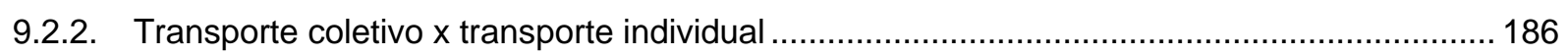

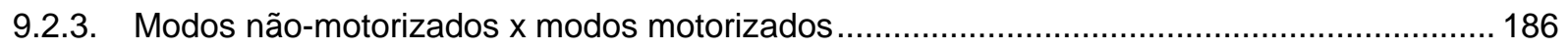

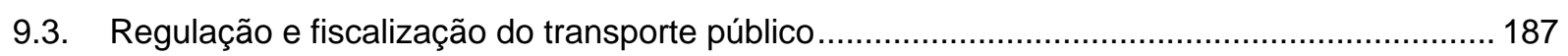

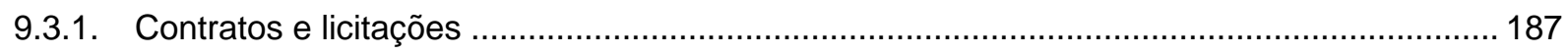

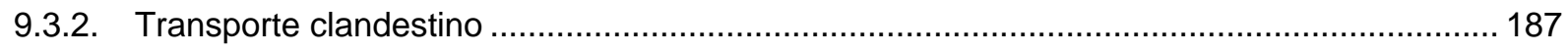

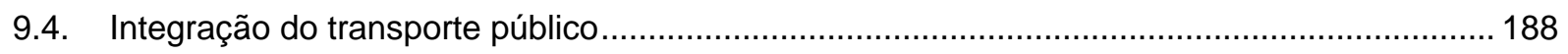

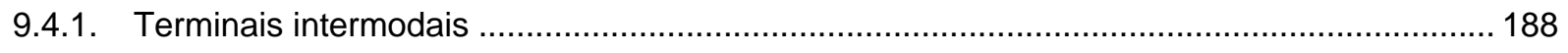

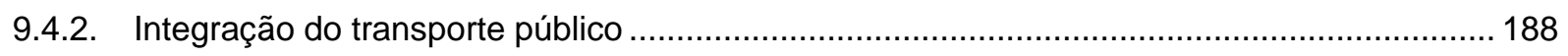

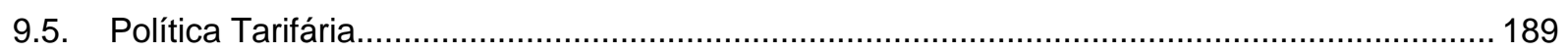

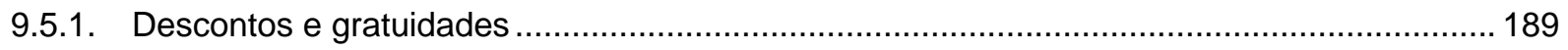

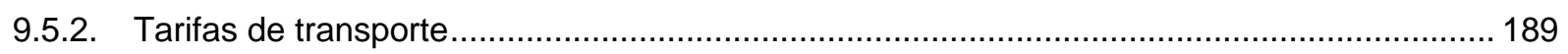

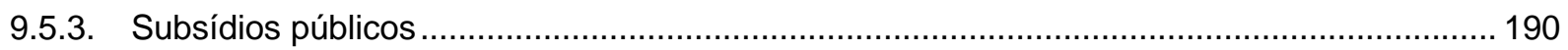




\begin{tabular}{ll}
\hline Domínio & 1. Acessibilidade \\
\hline Tema & $\begin{array}{l}\text { 1.1. Acessibilidade aos sistemas de } \\
\text { transportes }\end{array}$ \\
\hline Indicador & 1.1.1. Acessibilidade ao transporte público \\
\hline Definição & $\begin{array}{l}\text { Porcentagem da população urbana residente } \\
\text { na área de cobertura de um ponto de acesso } \\
\text { aos serviços de transporte público, } \\
\text { considerando todos os modos disponíveis. }\end{array}$ \\
\hline
\end{tabular}

a) Fontes de Dados

\begin{tabular}{ll}
\hline 1980 & $\begin{array}{l}\text { Não foram obtidas informações para este } \\
\text { cálculo. }\end{array}$ \\
\hline 1991 & $\begin{array}{l}\text { Não foram encontradas informações para este } \\
\text { cálculo. }\end{array}$ \\
\hline & $\begin{array}{l}\text { Existe um mapa de cobertura espacial na } \\
\text { página 153 do Plano de 2003 (JICA, 2003), } \\
\text { mas não são apresentados números. }\end{array}$ \\
& $\begin{array}{l}\text { - Arquivo "RDVIA_TC.dbd" do CD 1 do PDTU- } \\
\text { RMR (JICA, 2001), que contém as vias } \\
\text { utilizadas pelo sistema de transporte público. }\end{array}$ \\
& $\begin{array}{l}\text { Base de dados do IBGE, Censo 2000 (IBGE, } \\
\text { 2001). }\end{array}$ \\
\hline $2011 \quad \begin{array}{l}\text { Não foram obtidas informações para este } \\
\text { cálculo. }\end{array}$ \\
\hline
\end{tabular}

b) Método de Cálculo

\begin{tabular}{ll}
\hline 1980 & n/a \\
\hline 1991 & n/a \\
\hline & - Ferramentas auxiliares: Calculadora e \\
& Sistema de Informações Geográficas; \\
& - Utilização do arquivo geográfico com as vias \\
& percorridas pelo sistema de transporte \\
& coletivo por ônibus; \\
& - Adição da base de setores censitários do \\
& IBGE; \\
& - Criação de um buffer ao redor das vias, com \\
& largurao de 300 m, considerando junção das \\
& áreas sobrepostas; \\
& - Cálculo da população na área total coberta \\
& pelo buffer: 879.735 habitantes; \\
& - População urbana do município segundo o \\
& Censo 2000 (IBGE, 2001) - 1.244.505 \\
& habitantes; \\
& - O Escore é obtido pela razão entre população \\
& total da camada de buffer e a população total \\
& do município.
\end{tabular}

c) Escore

\begin{tabular}{ccc}
\hline Cenário & Escore & Escore Normalizado \\
\hline 1980 & $\mathrm{n} / \mathrm{a}$ & $\mathrm{n} / \mathrm{a}$ \\
\hline 1991 & $\mathrm{n} / \mathrm{a}$ & $\mathrm{n} / \mathrm{a}$ \\
\hline 2001 & $70,69 \%$ & 0,67 \\
\hline 2011 & $\mathrm{n} / \mathrm{a}$ & $\mathrm{n} / \mathrm{a}$ \\
\hline
\end{tabular}

\begin{tabular}{|c|c|}
\hline & Valores de Referência \\
\hline Escore & $\begin{array}{l}\text { Porcentagem da população urbana residente na } \\
\text { área de cobertura de pontos de acesso ao } \\
\text { transporte público }\end{array}$ \\
\hline 1,00 & $100 \%$ \\
\hline 0,75 & $77,5 \%$ \\
\hline 0,50 & $55 \%$ \\
\hline 0,25 & $32,5 \%$ \\
\hline 0,00 & Até $10 \%$ \\
\hline Domínio & Acessibilidade \\
\hline Tema & Acessibilidade aos sistemas de transportes \\
\hline Indicador & $\begin{array}{l}\text { 1.1.2. Transporte público para pessoas com } \\
\text { necessidades especiais }\end{array}$ \\
\hline Definição & $\begin{array}{l}\text { Porcentagem dos veículos da frota municipal } \\
\text { de transporte público por ônibus adaptada } \\
\text { para pessoas com necessidades especiais e } \\
\text { restrições de mobilidade. }\end{array}$ \\
\hline
\end{tabular}

\section{a) Fontes de Dados}

\begin{tabular}{cl}
\hline \multirow{2}{*}{1980} & $\begin{array}{l}\text { No relatório final do TRANSCOL (GEIPOT, } \\
\text { estes nãosenta-se o tipo de veículo utilizado e } \\
\text { deficiência. Mesmo os novos veículos, do tipo } \\
\text { PADRON, propostos para substituírem os } \\
\text { primeiros, não apresentavam essas } \\
\text { características. }\end{array}$ \\
\hline 1991 & $\begin{array}{l}\text { No relatório do PDTU (JICA, 1991) não existe } \\
\text { qualquer menção a este tipo de serviço. }\end{array}$ \\
\hline 2001 & $\begin{array}{l}\text { Informação não encontrada no relatório. } \\
\text { Estimou-se um valor baseando-se em algumas } \\
\text { informações locais e na experiência de outras } \\
\text { cidades brasileiras. }\end{array}$ \\
\hline 2011 & $\begin{array}{l}\text { Sindicato das Empresas de Transportes de } \\
\text { Passageiros de Belém. }\end{array}$ \\
\hline
\end{tabular}

\section{b) Método de Cálculo}

\begin{tabular}{ll}
\hline 1980 & $\begin{array}{l}\text { Considerou-se que não existiam veículos } \\
\text { adaptados. }\end{array}$ \\
\hline 1991 & $\begin{array}{l}\text { Considerou-se que o percentual da frota } \\
\text { adaptada era insignificante. }\end{array}$ \\
\hline 2001 & $\begin{array}{l}\text { Considerando o percentual de } 42 \% \text { da frota do } \\
\text { cenário } 2011, \text { foi estabelecido um valor } \\
\text { "pessimista" de 10\% da frota. }\end{array}$ \\
\hline 2011 & $\begin{array}{l}\text { - Frota total = 1695 } \\
\text { - Frota adaptada }=716\end{array}$ \\
\hline
\end{tabular}

c) Escore e Normalização

\begin{tabular}{ccc}
\hline Cenário & Escore & $\begin{array}{c}\text { Escore } \\
\text { Normalizado }\end{array}$ \\
\hline 1980 & $0 \%$ & 0,00 \\
\hline 1991 & $0 \%$ & 0,00 \\
\hline 2001 & $10 \%$ & 0,10 \\
\hline 2011 & $42 \%$ & 0,42 \\
\hline
\end{tabular}




\begin{tabular}{cl}
\hline Escore & $\begin{array}{l}\text { Valores de Referência } \\
\text { Porcentagem da frota municipal de ônibus } \\
\text { urbano adaptada para pessoas com } \\
\text { necessidades especiais ou restrições de } \\
\text { mobilidade }\end{array}$ \\
\hline 1,00 & $\begin{array}{l}\text { Mais de 75\% (ou há serviços especiais para } \\
\text { transporte de pessoas com necessidades } \\
\text { especiais) }\end{array}$ \\
\hline 0,75 & $75 \%$ \\
\hline 0,50 & $50 \%$ \\
\hline 0,25 & $25 \%$ \\
\hline 0,00 & $\begin{array}{l}0 \text { (ou não há serviços especiais para transporte } \\
\text { de pessoas com necessidades especiais) }\end{array}$ \\
\hline \multicolumn{1}{|c|}{\begin{tabular}{l} 
Acessibilidade \\
\hline Domínio
\end{tabular}} & Acessibilidade aos sistemas de transportes \\
\hline Tema & 1.1.3. Despesas com Transportes \\
\hline Indicador & $\begin{array}{l}\text { Porcentagem da renda mensal pessoal (ou do } \\
\text { domicilio) gasta com transporte público. }\end{array}$ \\
\hline Definição
\end{tabular}

\section{a. Fontes de Dados}

\begin{tabular}{ll}
\hline 1980 & Informações não disponíveis. \\
\hline 1991 & Informações não disponíveis. \\
\hline & $\begin{array}{l}\text { Planilhas “PD - DADOS DO DOMICÍLIO.xIs", "PD } \\
2001\end{array}$ \\
$\begin{array}{l}\text { - DESLOCAMENTOS 1.xIs" e “PD - } \\
\text { DESLOCAMENTOS 2.xIs" que constam do CD 2 } \\
\text { do PDTU-RMB (JICA, 2001) e relatório sobre } \\
\text { evolução das tarifas do Ministério das Cidades } \\
\text { (MCIDADES, 2004). }\end{array}$ \\
\hline 2011 & Dados do Censo 2010 (IBGE, 2011a) e CTBel. \\
\hline
\end{tabular}

\section{b. Método de Cálculo}

\begin{tabular}{|c|c|}
\hline 1980 & $\mathrm{n} / \mathrm{a}$ \\
\hline 1991 & $\mathrm{n} / \mathrm{a}$ \\
\hline 2001 & $\begin{array}{l}\text { - Este indicador é calculado a partir de } \\
\text { informações sobre o gasto mensal médio das } \\
\text { pessoas (ou do domicílio) com transporte } \\
\text { público. } \\
\text { - A partir dos dados da primeira planilha } \\
\text { calculou-se uma renda média de } \mathrm{R} \$ 848,36 \text {. } \\
\text { Da mesma planilha verifica-se o número de } \\
\text { famílias: } 7452 \text {. Das outras duas planilhas } \\
\text { pode-se obter o número de deslocamentos } \\
\text { diários por transporte público: } 26896 \text {. Isso } \\
\text { leva a um número médio de } 3,6 \text { viagens/dia. } \\
\text { - Multiplicando esse número de viagens pelo } \\
\text { valor da tarifa (R\$ 0,85) e por } 22 \text { dias úteis } \\
\text { tem-se uma despesa mensal total de } \mathrm{R} \$ \\
67,50 \text {. Isso corresponde a } 7,95 \% \text { da renda } \\
\text { média. }\end{array}$ \\
\hline 2011 & $\begin{array}{l}\text { Tarifa }=\mathrm{R} \$ 1,85 \\
\text { Renda média per capita mensal = R } \$ 697,00 \\
\text { Neste caso, considerando as informações } \\
\text { disponíveis, foi utilizada a renda média pessoal } \\
\text { comparada com o custo de duas viagens diárias. } \\
\text { Custos }=2 \times 22 \times 1,85=\mathrm{R} \$ 81,40 \\
\text { Gasto percentual }=81,40 / 697,00=11,7 \%\end{array}$ \\
\hline
\end{tabular}

\section{c. Escore e Normalização}

\begin{tabular}{ccc}
\hline Cenário & Escore & Escore Normalizado \\
\hline 1980 & $\mathrm{n} / \mathrm{a}$ & $\mathrm{n} / \mathrm{a}$ \\
\hline 1991 & $\mathrm{n} / \mathrm{a}$ & $\mathrm{n} / \mathrm{a}$ \\
\hline 2001 & $7,95 \%$ & 0,85 \\
\hline 2011 & $11,7 \%$ & 0,67 \\
\hline
\end{tabular}

\begin{tabular}{ll}
\hline Escore & $\begin{array}{l}\text { Valores de Referência } \\
\text { Porcentagem da renda mensal pessoal (ou } \\
\text { domiciliar) relativa a despesas com transporte } \\
\text { público }\end{array}$ \\
\hline 1,00 & Até $5 \%$ \\
\hline 0,75 & $10 \%$ \\
\hline 0,50 & $15 \%$ \\
\hline 0,25 & $20 \%$ \\
\hline 0,00 & Mais de 20\% \\
\hline Domínio & Acessibilidade \\
\hline Tema & 1.2. Acessibilidade Universal \\
\hline Indicador & $\begin{array}{l}\text { 1.2.1. Travessias adaptadas para pessoas } \\
\text { com necessidades especiais }\end{array}$ \\
\hline & $\begin{array}{l}\text { Porcentagem das travessias de pedestres da } \\
\text { rede viária principal adaptadas e atendendo } \\
\text { aos padrões de conforto e segurança para } \\
\text { pessoas com necessidades especiais e } \\
\text { restrições de mobilidade. }\end{array}$ \\
\hline
\end{tabular}

\section{a. Fontes de Dados}

\begin{tabular}{cl}
\hline 1980 & $\begin{array}{l}\text { Não existem informações a esse respeito nos } \\
\text { relatórios (GEIPOT, 1978, 1979, 1980). }\end{array}$ \\
\hline 1991 & $\begin{array}{l}\text { Não existem informações a esse respeito no } \\
\text { relatório (JICA, 1991) }\end{array}$ \\
\hline 2001 & $\begin{array}{l}\text { Informação não encontrada no relatório. O } \\
\text { percentual deve ser muito baixo para o ano de } \\
\text { 2001, pois mesmo a situação atual não parece } \\
\text { muito favorável. }\end{array}$ \\
\hline 2011 & $\begin{array}{l}\text { Levantamento de campo feito, em uma amostra } \\
\text { das vias do sistema viário principal, pela equipe } \\
\text { do ITEP/UFPA }\end{array}$ \\
\hline
\end{tabular}

\section{b. Método de Cálculo}

\begin{tabular}{cl}
\hline 1980 & Considerou-se um percentual igual a zero. \\
\hline 1991 & Considerou-se um percentual igual a zero. \\
\hline 2001 & $\begin{array}{l}\text { Baseado na situação atual, estimo que um } \\
\text { percentual muito pequeno das travessias } \\
\text { estavam adaptadas em 2001. }\end{array}$ \\
\hline 2011 & $\begin{array}{l}\text { Verificou-se que 15\% dos cruzamentos atendiam } \\
\text { aos padrões }\end{array}$ \\
\hline
\end{tabular}

\section{c. Escore e Normalização}

\begin{tabular}{ccc}
\hline Cenário & Escore & Escore Normalizado \\
\hline 1980 & $0 \%$ & 0,00 \\
\hline 1991 & $0 \%$ & 0,00 \\
\hline 2001 & $5 \%$ & 0,05 \\
\hline 2011 & $15 \%$ & 0,15 \\
\hline
\end{tabular}




\begin{tabular}{|c|c|}
\hline Escore & $\begin{array}{l}\text { Valores de Referência } \\
\text { Porcentagem das travessias da rede viária } \\
\text { principal adaptada a pessoas com } \\
\text { necessidades especiais e restrições de } \\
\text { mobilidade }\end{array}$ \\
\hline 1,00 & $100 \%$ \\
\hline 0,75 & $75 \%$ \\
\hline 0,50 & $50 \%$ \\
\hline 0,25 & $25 \%$ \\
\hline 0,00 & 0 \\
\hline Domínio & Acessibilidade \\
\hline Tema & Acessibilidade universal \\
\hline Indicador & 1.2.2. Acessibilidade aos espaços abertos \\
\hline Definição & $\begin{array}{l}\text { Porcentagem da população urbana residente } \\
\text { próxima a áreas abertas (áreas verdes ou de } \\
\text { lazer), considerando os seguintes parâmetros: } \\
\text { - Até } 500 \text { metros de praças, playgrounds e } \\
\text { outras áreas de recreação de pequeno e } \\
\text { médio porte; } \\
\text { - Até } 1000 \text { metros de parques urbanos. }\end{array}$ \\
\hline
\end{tabular}

\section{a. Fontes de Dados}

\begin{tabular}{ll}
\hline 1980 & Informações não encontradas. \\
\hline 1991 & Informações não encontradas. \\
\hline 2001 & $\begin{array}{l}\text { Mapa preparado pela Equipe da UFPA e Censo } \\
2000 \text { (IBGE, 2001) }\end{array}$ \\
\hline 2011 & $\begin{array}{l}\text { Mapa preparado pela Equipe da UFPA e Censo } \\
2010 \text { (IBGE, 2011a) }\end{array}$ \\
\hline
\end{tabular}

\section{b. Método de Cálculo}

\begin{tabular}{ll}
\hline 1980 & n/a \\
\hline 1991 & n/a \\
\hline & • \\
& Foi utilizado o mesmo conjunto de praças e \\
& para a situação de 2011, o que não deve \\
& representar grande erro. A partir da \\
& localização das praças e parques foi utilizado \\
& o software TransCAD (CALIPER, 2007) para \\
& traçar bandas de 500 m de largura no entorno \\
& das praças e 1000m no entorno dos parques. \\
& A seguir, foi sobreposta uma camada com os \\
& setores censitários urbanos do Censo 2000 e \\
& estimou-se a população residente que estaria \\
& coberta por essas bandas. Considerou-se, de \\
& maneira simplificada, a distribuição uniforme \\
& da população na área de cada setor \\
& censitário. \\
& População urbana de Belém: 1.244 .505 hab. \\
& População coberta pelas bandas de 500 e \\
& 1000 m: 496.227 hab. (39,9\%) \\
\hline & A partir da localização das praças e parques \\
& foi utilizado o software TransCAD (CALIPER, \\
& 2007) para traçar bandas de 500 m de largura \\
& no entorno das praças e 1000m no entorno \\
& dos parques. A seguir, foi sobreposta uma \\
& camada com os setores censitários urbanos \\
& do Censo 2010 e estimou-se a população \\
& residente que estaria coberta por essas \\
& bandas. Considerou-se, de maneira \\
& simplificada, a distribuição uniforme da \\
& população na área de cada setor censitário. \\
\hline &
\end{tabular}

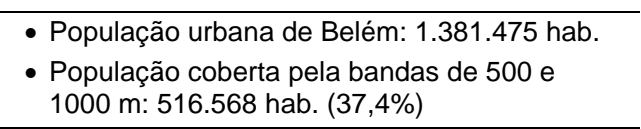

\section{c. Escore e Normalização}

\begin{tabular}{ccc}
\hline Cenário & Escore & Escore Normalizado \\
\hline 1980 & $\mathrm{n} / \mathrm{a}$ & $\mathrm{n} / \mathrm{a}$ \\
\hline 1991 & $\mathrm{n} / \mathrm{a}$ & $\mathrm{n} / \mathrm{a}$ \\
\hline 2001 & 39,9 & 0,40 \\
\hline 2011 & 37,4 & 0,37 \\
\hline
\end{tabular}

\begin{tabular}{ll}
\hline Escore & $\begin{array}{l}\text { Valores de Referência } \\
\text { Porcentagem da população urbana que reside } \\
\text { na área de influência de espaços verdes e de } \\
\text { recreação }\end{array}$ \\
\hline 1,00 & $100 \%$ \\
\hline 0,75 & $75 \%$ \\
\hline 0,50 & $50 \%$ \\
\hline 0,25 & $25 \%$ \\
\hline 0,00 & 0 \\
\hline
\end{tabular}

\begin{tabular}{ll}
\hline Domínio & Acessibilidade \\
\hline Tema & Acessibilidade universal \\
\hline Indicador & $\begin{array}{r}\text { 1.2.3. Vagas de estacionamento para } \\
\text { pessoas com necessidades especiais }\end{array}$ \\
\hline Definição & $\begin{array}{l}\text { Porcentagem de vagas em estacionamentos } \\
\text { públicos para pessoas com necessidades } \\
\text { especiais. }\end{array}$ \\
\hline
\end{tabular}

\section{a. Fontes de Dados}

\begin{tabular}{cl}
\hline 1980 & Informação não encontrada no relatório. \\
\hline 1991 & Informação não encontrada no relatório. \\
\hline 2001 & Informação não encontrada no relatório. \\
\hline 2011 & $\begin{array}{l}\text { Levantamento de campo feito, em uma } \\
\text { amostra das vias do sistema viário principal, } \\
\text { pela equipe do ITEP/UFPA }\end{array}$ \\
\hline
\end{tabular}

\section{b. Método de Cálculo}

\begin{tabular}{ll}
\hline 1980 & Não calculado \\
\hline 1991 & Não calculado \\
\hline 2001 & Não calculado \\
\hline 2011 & $\begin{array}{l}\text { Há disponibilidade de vagas para pessoas } \\
\text { comecessidades especiais em número } \\
\text { inferior aos valores estabelecidos por lei } \\
\text { específica (ou indicados na NBR 9050) }\end{array}$ \\
\hline
\end{tabular}

\section{c. Escore e Normalização}

\begin{tabular}{ccc}
\hline Cenário & Escore & Escore Normalizado \\
\hline 1980 & $\mathrm{n} / \mathrm{a}$ & $\mathrm{n} / \mathrm{a}$ \\
\hline 1991 & $\mathrm{n} / \mathrm{a}$ & $\mathrm{n} / \mathrm{a}$ \\
\hline 2001 & $\mathrm{n} / \mathrm{a}$ & $\mathrm{n} / \mathrm{a}$ \\
\hline 2011 & 0,20 & 0,20 \\
\hline
\end{tabular}




\begin{tabular}{|c|c|}
\hline Escore & Valores de Referência \\
\hline 1,00 & $\begin{array}{l}\text { Há disponibilidade de vagas para pessoas com } \\
\text { necessidades especiais em número superior } \\
\text { aos valores estabelecidos por lei específica (ou } \\
\text { indicados na NBR 9050) e estas se encontram } \\
\text { devidamente sinalizadas e dimensionadas }\end{array}$ \\
\hline 0,80 & $\begin{array}{l}\text { Há disponibilidade de vagas para pessoas com } \\
\text { necessidades especiais em número superior } \\
\text { aos valores estabelecidos por lei específica (ou } \\
\text { indicados na NBR 9050), porém as vagas estão } \\
\text { mal sinalizadas ou não apresentam as } \\
\text { dimensões adequadas }\end{array}$ \\
\hline 0,60 & $\begin{array}{l}\text { Há disponibilidade de vagas para pessoas com } \\
\text { necessidades especiais em número igual aos } \\
\text { valores estabelecidos por lei específica (ou } \\
\text { indicados na NBR 9050) e estas se encontram } \\
\text { devidamente sinalizadas e dimensionadas }\end{array}$ \\
\hline 0,40 & $\begin{array}{l}\text { Há disponibilidade de vagas para pessoas com } \\
\text { necessidades especiais em número igual aos } \\
\text { valores estabelecidos por lei específica (ou } \\
\text { indicados na NBR 9050), porém as vagas estão } \\
\text { mal sinalizadas ou não apresentam as } \\
\text { dimensões adequadas }\end{array}$ \\
\hline 0,20 & $\begin{array}{l}\text { Há disponibilidade de vagas para pessoas com } \\
\text { necessidades especiais em número inferior aos } \\
\text { valores estabelecidos por lei específica (ou } \\
\text { indicados na NBR 9050) }\end{array}$ \\
\hline 0,00 & $\begin{array}{l}\text { Não há disponibilidade de vagas para pessoas } \\
\text { com necessidades especiais em } \\
\text { estacionamentos públicos }\end{array}$ \\
\hline Domínio & Acessibilidade \\
\hline Tema & Acessibilidade universal \\
\hline Indicador & 1.2.4. Acessibilidade a edifícios públicos \\
\hline Definição & $\begin{array}{l}\text { Porcentagem de edifícios públicos adaptados } \\
\text { para acesso e utilização de pessoas com } \\
\text { necessidades especiais ou restrições de } \\
\text { mobilidade. }\end{array}$ \\
\hline
\end{tabular}

a) Fontes de Dados

\begin{tabular}{ll}
\hline 1980 & Informação não encontrada no relatório. \\
\hline 1991 & Informação não encontrada no relatório. \\
\hline 2001 & Informação não encontrada no relatório. \\
\hline 2011 & Informações não encontradas. \\
\hline
\end{tabular}

b) Método de Cálculo

\begin{tabular}{ll}
\hline 1980 & $\mathrm{n} / \mathrm{a}$ \\
\hline 1991 & $\mathrm{n} / \mathrm{a}$ \\
\hline 2001 & $\mathrm{n} / \mathrm{a}$ \\
\hline 2011 & $\mathrm{n} / \mathrm{a}$ \\
\hline
\end{tabular}

\section{c) Escore e Normalização}

\begin{tabular}{ccc}
\hline Cenário & Escore & Escore Normalizado \\
\hline 1980 & $\mathrm{n} / \mathrm{a}$ & $\mathrm{n} / \mathrm{a}$ \\
\hline 1991 & $\mathrm{n} / \mathrm{a}$ & $\mathrm{n} / \mathrm{a}$ \\
\hline 2001 & $\mathrm{n} / \mathrm{a}$ & $\mathrm{n} / \mathrm{a}$ \\
\hline 2011 & $\mathrm{n} / \mathrm{a}$ & $\mathrm{n} / \mathrm{a}$ \\
\hline
\end{tabular}

\begin{tabular}{ll}
\hline Domínio & Acessibilidade \\
\hline Tema & Acessibilidade universal \\
\hline Indicador & $\begin{array}{l}\text { 1.2.5. Acessibilidade aos serviços } \\
\text { essenciais }\end{array}$ \\
\hline Definição & $\begin{array}{l}\text { Porcentagem da população urbana } \\
\text { residente até 500 metros de distância de } \\
\text { serviços essenciais, entendidos aqui como } \\
\text { equipamentos de saúde de atendimento } \\
\text { primário e equipamentos de educação } \\
\text { infantil e ensino fundamental, públicas e } \\
\text { particulares. }\end{array}$ \\
\hline
\end{tabular}

a) Fontes de Dados

\begin{tabular}{ll}
\hline 1980 & Informação não disponível. \\
\hline 1991 & Informação não disponível. \\
\hline 2001 & Informação não disponível. \\
\hline 2011 & $\begin{array}{l}\text { Mapa preparado pela Equipe da UFPA e Censo } \\
2010 \text { (IBGE, 2011a) }\end{array}$ \\
\hline
\end{tabular}

\section{b) Método de Cálculo}

\begin{tabular}{ll}
\hline 1980 & n/a \\
\hline 1991 & n/a \\
\hline 2001 & n/a \\
\hline
\end{tabular}

- A partir da localização das escolas e unidades de saúde foi utilizado o software TransCAD (CALIPER, 2007) para traçar bandas de 500 $m$ de largura no entorno dessas unidades. A seguir, foi sobreposta uma camada com os setores censitários urbanos do Censo 2010 e estimou-se a população residente que estaria

2011 coberta por essas bandas. Considerou-se, de maneira simplificada, a distribuição uniforme da população na área de cada setor censitário.

- População urbana de Belém: 1.381.475 habitantes.

- População coberta pela banda: $1.041,118$ habitantes $(75 \%)$

\section{c) Escore e Normalização}

\begin{tabular}{ccc}
\hline Cenário & Escore & Escore Normalizado \\
\hline 1980 & $\mathrm{n} / \mathrm{a}$ & $\mathrm{n} / \mathrm{a}$ \\
\hline 1991 & $\mathrm{n} / \mathrm{a}$ & $\mathrm{n} / \mathrm{a}$ \\
\hline 2001 & $\mathrm{n} / \mathrm{a}$ & $\mathrm{n} / \mathrm{a}$ \\
\hline 2011 & $75 \%$ & 0,72 \\
\hline
\end{tabular}

\begin{tabular}{ll}
\hline Escore & $\begin{array}{l}\text { Valores de Referência } \\
\text { Porcentagem da população urbana residente } \\
\text { até } 500 \text { metros de um equipamento de saúde } \\
\text { e/ou educação }\end{array}$ \\
\hline 1,00 & $100 \%$ \\
\hline 0,75 & $77,5 \%$ \\
\hline 0,50 & $55 \%$ \\
\hline 0,25 & $32,5 \%$ \\
\hline 0,00 & Até $10 \%$ \\
\hline
\end{tabular}




\begin{tabular}{ll}
\hline Domínio & Acessibilidade \\
\hline Tema & 1.3. Barreiras físicas \\
\hline Indicador & 1.3.1. Fragmentação urbana \\
\hline & $\begin{array}{l}\text { Proporção de terra urbanizada contínua do } \\
\text { total da área urbanizada do município, ou } \\
\text { seja, não cortada por infraestrutura de } \\
\text { transporte principal como vias de trânsito } \\
\text { rápido (rodovias, vias expressas e vias } \\
\text { arteriais), corredores de transporte coletivo, } \\
\text { vias para transporte ferroviário ou metroviário } \\
\text { de superfície, terminais de transporte de } \\
\text { grande porte, ou qualquer outra barreira } \\
\text { física, natural ou construída, que acarrete em } \\
\text { descontinuidade do tecido urbano. }\end{array}$ \\
\hline
\end{tabular}

\section{a) Fontes de Dados}

\begin{tabular}{cl}
\hline 1980 & $\begin{array}{l}\text { Informação não encontrada no relatório. Os } \\
\text { valores foram calculados com base no mesmo } \\
\text { procedimento utilizado para o PDTU-2001. }\end{array}$ \\
\hline 1991 & $\begin{array}{l}\text { Informação não encontrada no relatório. Os } \\
\text { valores foram calculados com base no mesmo } \\
\text { procedimento utilizado para o PDTU-2001. }\end{array}$ \\
\hline 2001 & $\begin{array}{l}\text { Inspeção visual no Google Earth, para a situação } \\
\text { atual, considerando que seria a mesma em 2001. }\end{array}$ \\
\hline 2011 & $\begin{array}{l}\text { Informação não encontrada no relatório. Os } \\
\text { valores foram calculados com base no mesmo } \\
\text { procedimento utilizado para o PDTU-2001. }\end{array}$ \\
\hline
\end{tabular}

\section{b) Método de Cálculo}

\begin{tabular}{ll}
\hline 1980 & Delimitação de áreas no Google Earth. \\
\hline 1991 & Delimitação de áreas no Google Earth. \\
\hline 2001 & Delimitação de áreas no Google Earth. \\
\hline 2011 & Delimitação de áreas no Google Earth. \\
\hline
\end{tabular}

\section{c) Escore e Normalização}

\begin{tabular}{ccc}
\hline Cenário & Escore & Escore Normalizado \\
\hline 1980 & 12 & 0,40 \\
\hline 1991 & 12 & 0,40 \\
\hline 2001 & 12 & 0,40 \\
\hline 2011 & 12 & 0,40 \\
\hline
\end{tabular}

\begin{tabular}{ll}
\hline Escore & $\begin{array}{l}\text { Valores de Referência } \\
\text { Número de subdivisões (parcelas) da área } \\
\text { urbanizada do município em função da } \\
\text { infraestrutura de transportes }\end{array}$ \\
\hline 1,00 & 0 (100\% da área urbanizada é contínua $)$ \\
\hline 0,75 & 5 \\
\hline 0,50 & 10 \\
\hline 0,25 & 15 \\
\hline 0,00 & 20 ou mais \\
\hline
\end{tabular}

\begin{tabular}{ll}
\hline Domínio & Acessibilidade \\
\hline Tema & $\begin{array}{l}\text { 1.4. Legislação para pessoas com } \\
\text { necessidades especiais }\end{array}$ \\
\hline Indicador & 1.4.1. Ações para acessibilidade universal \\
\hline & $\begin{array}{l}\text { Existência e tipos de ações, medidas, } \\
\text { programas ou instrumentos, incluindo } \\
\text { Definiçãonanhas, projetos, legislação e normas } \\
\text { técnicas destinadas à promoção de } \\
\text { acessibilidade universal. }\end{array}$ \\
\hline
\end{tabular}

\section{a) Fontes de Dados}

\begin{tabular}{cl}
\hline 1980 & $\begin{array}{l}\text { Analisando a legislação urbanística do município } \\
\text { de Belém, disponível na Internet, não foi } \\
\text { encontrado esse tipo de instrumento. }\end{array}$ \\
\hline 1991 & $\begin{array}{l}\text { Analisando a legislação urbanística do município } \\
\text { de Belém, disponível na Internet, não foi } \\
\text { encontrado esse tipo de instrumento. }\end{array}$ \\
\hline 2001 & Página de legislação da PMB (PMB, 2006b) \\
\hline 2011 & Página de legislação da PMB (PMB, 2006b) \\
\hline
\end{tabular}

\section{b) Método de Cálculo}

\begin{tabular}{cl}
\hline 1980 & $\begin{array}{l}\text { O município não dispunha de qualquer ação ou } \\
\text { instrumento para acessibilidade universal }\end{array}$ \\
\hline 1991 & $\begin{array}{l}\text { O município não dispunha de qualquer ação ou } \\
\text { instrumento para acessibilidade universal }\end{array}$ \\
\hline 2001 & $\begin{array}{l}\text { O município dispõe de legislação específica, } \\
\text { normas técnicas e recomendações para } \\
\text { acessibilidade universal. }\end{array}$ \\
\hline 2011 & $\begin{array}{l}\text { O município dispõe de legislação específica, } \\
\text { normas técnicas, recomendações e ações ou } \\
\text { programas de iniciativa pública para } \\
\text { acessibilidade universal. Considerando aqui } \\
\text { também a realização do "Ill Fórum Municipal dos } \\
\text { Direitos da Pessoa com Deficiência"18 }\end{array}$ \\
\hline
\end{tabular}

\section{c) Escore e Normalização}

\begin{tabular}{ccc}
\hline Cenário & Escore & Escore Normalizado \\
\hline 1980 & 0,00 & 0,00 \\
\hline 1991 & 0,00 & 0,00 \\
\hline 2001 & 0,50 & 0,50 \\
\hline 2011 & 0,75 & 0,75 \\
\hline
\end{tabular}

\footnotetext{
${ }^{18}$ Prefeitura promove III Fórum Municipal dos Direitos da Pessoa com Deficiência

(http://ww3.belem.pa.gov.br/?pg=txt\&id=1020\&tit=Prefeitura \%20promove\%20III\%20F\%C3\%B3rum\%20Municipal\%20dos\%20 direitos\%20da\%20pessoa\%20com\%20defici\%C3\%AAncia).
} 


\begin{tabular}{cl}
\hline Escore & Valores de Referência \\
\hline 1,00 & $\begin{array}{l}\text { O município dispõe de legislação específica, } \\
\text { normas técnicas, recomendações, programas } \\
\text { de iniciativa pública e campanhas de educação } \\
\text { e sensibilização para acessibilidade universal }\end{array}$ \\
\hline 0,75 & $\begin{array}{l}\text { O município dispõe de legislação específica, } \\
\text { normas técnicas, recomendações e ações ou } \\
\text { programas de iniciativa pública para } \\
\text { acessibilidade universal }\end{array}$ \\
\hline 0,50 & $\begin{array}{l}\text { O município dispõe de legislação específica, } \\
\text { normas técnicas e recomendações para } \\
\text { acessibilidade universal }\end{array}$ \\
\hline 0,25 & $\begin{array}{l}\text { O município dispõe de legislação específica } \\
\text { sobre acessibilidade universal }\end{array}$ \\
\hline 0,00 & $\begin{array}{l}\text { O município não dispõe de qualquer ação ou } \\
\text { instrumento para acessibilidade universal }\end{array}$ \\
\hline Domínio & 2. Aspectos Ambientais \\
\hline Tema & 2.1. Controle dos impactos no meio ambiente \\
\hline Indicador & 2.1.1. Emissões de Co \\
\hline Definição & $\begin{array}{l}\text { Emissões anuais de monóxido de carbono } \\
\text { (CO) por veículos automotores. }\end{array}$ \\
\hline
\end{tabular}

a) Fontes de Dados

\begin{tabular}{ll}
\hline 1980 & Dados não disponíveis. \\
\hline 1991 & Dados não disponíveis. \\
\hline 2001 & Dados não disponíveis. \\
\hline 2011 & Dados não disponíveis. \\
\hline
\end{tabular}

b) Método de Cálculo

\begin{tabular}{ll}
\hline 1980 & $\mathrm{n} / \mathrm{a}$ \\
\hline 1991 & $\mathrm{n} / \mathrm{a}$ \\
\hline 2001 & $\mathrm{n} / \mathrm{a}$ \\
\hline 2011 & $\mathrm{n} / \mathrm{a}$ \\
\hline
\end{tabular}

c) Escore e Normalização

\begin{tabular}{ccc}
\hline Cenário & Escore & Escore Normalizado \\
\hline 1980 & $\mathrm{n} / \mathrm{a}$ & $\mathrm{n} / \mathrm{a}$ \\
\hline 1991 & $\mathrm{n} / \mathrm{a}$ & $\mathrm{n} / \mathrm{a}$ \\
\hline 2001 & $\mathrm{n} / \mathrm{a}$ & $\mathrm{n} / \mathrm{a}$ \\
\hline 2011 & $\mathrm{n} / \mathrm{a}$ & $\mathrm{n} / \mathrm{a}$ \\
\hline
\end{tabular}

\begin{tabular}{|c|c|}
\hline Escore & $\begin{array}{l}\text { Valores de Referência } \\
\text { Parâmetro de controle: Quilometragem anual } \\
\text { percorrida pela frota municipal de veículos leves } \\
\text { em área urbana vezes o limite para níveis de } \\
\text { emissão de CO para veículos leves novos ( } 2,0 \\
\text { g/km) + quilometragem anual percorrida pela } \\
\text { frota municipal de veículos ciclomotores em } \\
\text { área urbana vezes o limite para níveis de } \\
\text { emissão de CO para ciclomotores novos (5,5 } \\
\text { g/km, respectivamente) }\end{array}$ \\
\hline 1,00 & $\begin{array}{l}\text { A emissão de CO anual por veículos } \\
\text { automotores é igual ou inferior ao parâmetro de } \\
\text { controle }\end{array}$ \\
\hline 0,75 & $\begin{array}{l}\text { A emissão de CO anual por veículos } \\
\text { automotores é } 25 \% \text { maior que o parâmetro de } \\
\text { controle }\end{array}$ \\
\hline 0,50 & $\begin{array}{l}\text { A emissão de CO anual por veículos } \\
\text { automotores é } 50 \% \text { maior que o parâmetro de } \\
\text { controle }\end{array}$ \\
\hline 0,25 & $\begin{array}{l}\text { A emissão de } \mathrm{CO} \text { anual por veículos } \\
\text { automotores é } 75 \% \text { maior que o parâmetro de } \\
\text { controle }\end{array}$ \\
\hline 0,00 & $\begin{array}{l}\text { A emissão de CO anual por veículos } \\
\text { automotores é } 100 \% \text { maior que parâmetro de } \\
\text { controle }\end{array}$ \\
\hline Domínio & Aspectos Ambientais \\
\hline Tema & Controle dos impactos no meio ambiente \\
\hline Indicador & 2.1.2. Emissões de $\mathrm{CO}_{2}$ \\
\hline Definição & $\begin{array}{l}\text { Emissões anuais de dióxido de carbono }\left(\mathrm{CO}_{2}\right) \\
\text { por veículos automotores. }\end{array}$ \\
\hline
\end{tabular}

\section{a) Fontes de Dados}

\begin{tabular}{ll}
\hline 1980 & Dados não disponíveis. \\
\hline 1991 & Dados não disponíveis. \\
\hline 2001 & Dados não disponíveis. \\
\hline 2011 & Dados não disponíveis. \\
\hline
\end{tabular}

\section{b) Método de Cálculo}

\begin{tabular}{ll}
\hline 1980 & n/a \\
\hline 1991 & n/a \\
\hline 2001 & n/a \\
\hline 2011 & n/a \\
\hline
\end{tabular}

\section{c) Escore e Normalização}

\begin{tabular}{ccc}
\hline Cenário & Escore & Escore Normalizado \\
\hline 1980 & $\mathrm{n} / \mathrm{a}$ & $\mathrm{n} / \mathrm{a}$ \\
\hline 1991 & $\mathrm{n} / \mathrm{a}$ & $\mathrm{n} / \mathrm{a}$ \\
\hline 2001 & $\mathrm{n} / \mathrm{a}$ & $\mathrm{n} / \mathrm{a}$ \\
\hline 2011 & $\mathrm{n} / \mathrm{a}$ & $\mathrm{n} / \mathrm{a}$ \\
\hline
\end{tabular}




\begin{tabular}{cl}
\hline Escore & Valores de Referência \\
\hline 1,00 & $\begin{array}{l}\text { A emissão de } \mathrm{CO}_{2} \text { anual por veículos } \\
\text { automotores é igual ou inferior ao parâmetro de } \\
\text { controle }\end{array}$ \\
\hline 0,75 & $\begin{array}{l}\text { A emissão de } \mathrm{CO}_{2} \text { anual por veículos } \\
\text { automotores é } 25 \% \text { maior que o parâmetro de } \\
\text { controle }\end{array}$ \\
\hline 0,50 & $\begin{array}{l}\text { A emissão de } \mathrm{CO}_{2} \text { anual por veículos } \\
\text { automotores é } 50 \% \text { maior que o parâmetro de } \\
\text { controle }\end{array}$ \\
\hline 0,25 & $\begin{array}{l}\text { A emissão de } \mathrm{CO}_{2} \text { anual por veículos } \\
\text { automotores é } 75 \% \text { maior que o parâmetro de } \\
\text { controle }\end{array}$ \\
\hline 0,00 & $\begin{array}{l}\text { A emissão de } \mathrm{CO}_{2} \text { anual por veículos } \\
\text { automotores é } 100 \% \text { maior que parâmetro de } \\
\text { controle }\end{array}$ \\
\hline Domínio & Aspectos Ambientais \\
\hline Tema & \begin{tabular}{l} 
Controle dos impactos no meio ambiente \\
\hline Indicador
\end{tabular} \\
\hline 2.1.3. População exposta ao ruído de tráfego \\
\hline Definição
\end{tabular}

a) Fontes de Dados

\begin{tabular}{cc}
\hline 1980 & Informação não encontrada no relatório \\
\hline 1991 & Informação não encontrada no relatório \\
\hline & $\begin{array}{l}\text { - Foram feitos levantamentos em } 9 \text { pontos } \\
\text { (JICA, 2001), página 77; } \\
\text { - Base de dados do IBGE - Censo de 2000 } \\
\text { (IBGE, 2001). }\end{array}$ \\
\hline 2001 & (MORAES et al., 2003) e (PMB, 2011a) \\
\hline
\end{tabular}

\section{b) Método de Cálculo}

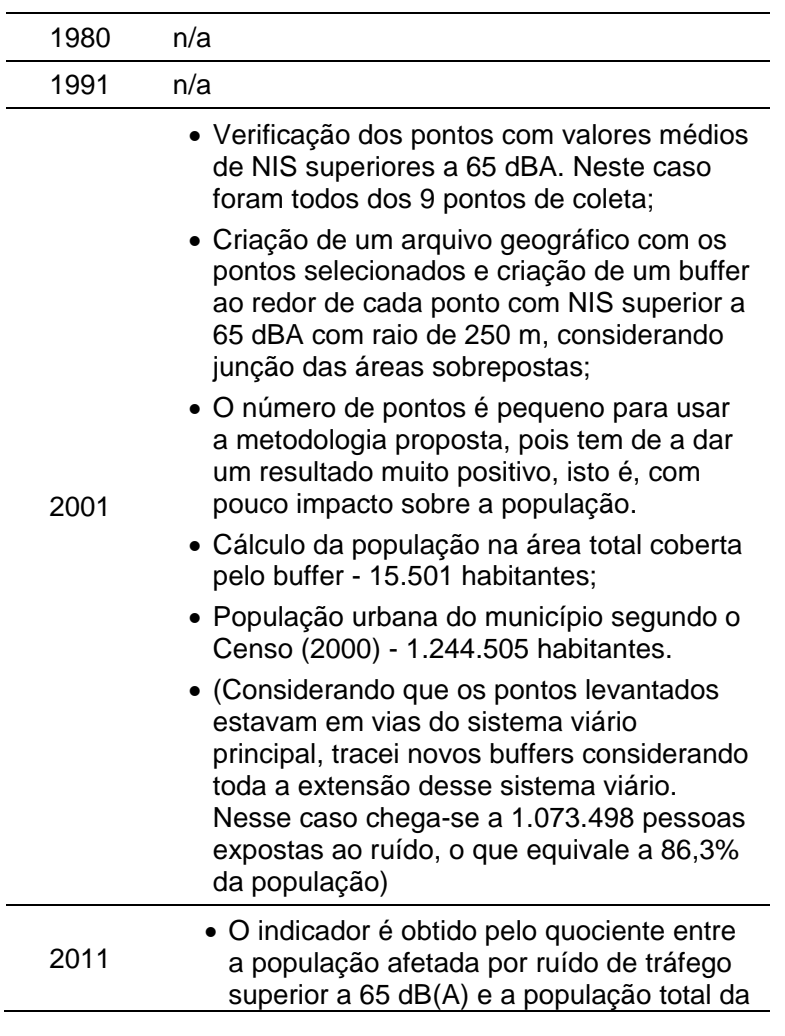

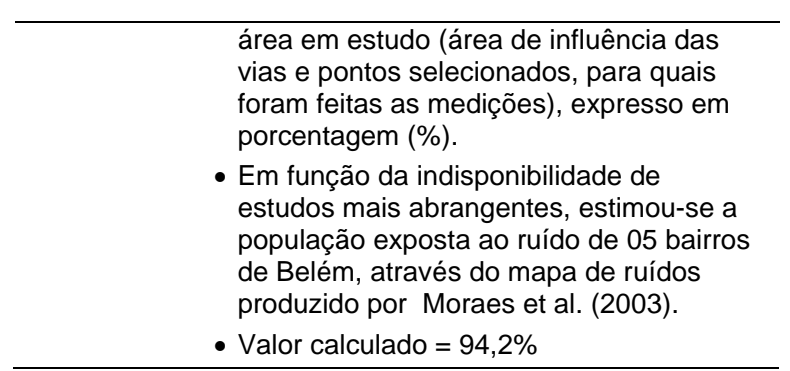

\section{c) Escore e Normalização}

\begin{tabular}{ccc}
\hline Cenário & Escore & Escore Normalizado \\
\hline 1980 & $\mathrm{n} / \mathrm{a}$ & $\mathrm{n} / \mathrm{a}$ \\
\hline 1991 & $\mathrm{n} / \mathrm{a}$ & $\mathrm{n} / \mathrm{a}$ \\
\hline 2001 & 86,3 & 0,86 \\
\hline 2011 & 94,2 & 0,06 \\
\hline
\end{tabular}

\begin{tabular}{|c|c|}
\hline Escore & $\begin{array}{l}\text { Valores de Referência } \\
\text { Porcentagem da população urbana (ou da área } \\
\text { em estudo) exposta a ruído de tráfego superior } \\
\text { a } 65 \mathrm{~dB}(\mathrm{~A})\end{array}$ \\
\hline 1,00 & 0 \\
\hline 0,75 & $25 \%$ \\
\hline 0,50 & $50 \%$ \\
\hline 0,25 & $75 \%$ \\
\hline 0,00 & $100 \%$ \\
\hline Domínio & Aspectos Ambientais \\
\hline Tema & Controle dos impactos no meio ambiente \\
\hline Indicador & 2.1.4. Estudos de impacto ambiental \\
\hline Definição & $\begin{array}{l}\text { Exigência por parte do município de estudos } \\
\text { de impacto ambiental, impactos urbanos e de } \\
\text { vizinhança para projetos de transportes e } \\
\text { mobilidade, incluindo: projetos de } \\
\text { infraestrutura viária, terminais de transporte, } \\
\text { corredores de transporte público, introdução } \\
\text { de novas tecnologias, sistemas de média e } \\
\text { alta capacidade, entre outros. }\end{array}$ \\
\hline
\end{tabular}

\section{a) Fontes de Dados}

\begin{tabular}{|c|c|}
\hline 1980 & $\begin{array}{l}\text { Informação não disponível nos documentos } \\
\text { analisados. Como essas exigências não existiam } \\
\text { em 1980, pode-se pressupor que também } \\
\text { inexistiam em um período anterior. }\end{array}$ \\
\hline 1991 & $\begin{array}{l}\text { Informação não disponível nos documentos } \\
\text { analisados. Como essas exigências não existiam } \\
\text { em 1991, pode-se pressupor que também } \\
\text { inexistiam em um período anterior. }\end{array}$ \\
\hline 2001 & $\begin{array}{l}\text { - Informação não disponível nos documentos } \\
\text { analisados. } \\
\text { - Analisando a legislação urbanística de Belém } \\
\text { (PMB, 2011b), não se encontrou qualquer } \\
\text { exigência de estudos específicos (EIV }{ }^{19} \text {, por } \\
\text { exemplo) referentes a impactos ambientais } \\
\text { dos transportes. }\end{array}$ \\
\hline 2011 & Prefeitura de Belém \\
\hline
\end{tabular}

${ }^{19}$ Estudo de Impacto de Vizinhança 
b) Método de Cálculo

\begin{tabular}{cl}
\hline 1980 & $\begin{array}{l}\text { O município não exigia qualquer estudo ou } \\
\text { medida mitigadora sobre impactos dos sistemas } \\
\text { de transportes e mobilidade urbana }\end{array}$ \\
\hline 1991 & $\begin{array}{l}\text { O município não exigia qualquer estudo ou } \\
\text { medida mitigadora sobre impactos dos sistemas } \\
\text { de transportes e mobilidade urbana }\end{array}$ \\
\hline 2001 & $\begin{array}{l}\text { O município não exigia qualquer estudo ou } \\
\text { medida mitigadora sobre impactos dos sistemas } \\
\text { de transportes e mobilidade urbana }\end{array}$ \\
\hline \multirow{2}{*}{2011} & $\begin{array}{l}\text { Estudo de impacto ambiental e estudo de } \\
\text { impacto de vizinhança para projetos de } \\
\text { transportes e mobilidade urbana, mas não define } \\
\text { medidas compensatórias ou mitigadoras }\end{array}$ \\
\hline
\end{tabular}

c) Escore e Normalização

\begin{tabular}{|c|c|c|}
\hline Cenário & Escore & Escore Normalizado \\
\hline 1980 & 0,00 & 0,00 \\
\hline 1991 & 0,00 & 0,00 \\
\hline 2001 & 0,00 & 0,00 \\
\hline 2011 & 0,50 & 0,50 \\
\hline Escore & \multicolumn{2}{|c|}{$\begin{array}{l}\text { Valores de Referência } \\
\text { O município exige: }\end{array}$} \\
\hline 1,00 & \multicolumn{2}{|c|}{$\begin{array}{l}\text { Estudo de impacto ambiental e estudo de } \\
\text { impacto de vizinhança para projetos de } \\
\text { transportes e mobilidade urbana, e define } \\
\text { medidas compensatórias ou mitigadoras }\end{array}$} \\
\hline 0,75 & \multicolumn{2}{|c|}{$\begin{array}{l}\text { Estudo de impacto ambiental para projetos de } \\
\text { transportes e mobilidade urbana e define } \\
\text { medidas compensatórias ou mitigadoras }\end{array}$} \\
\hline 0,50 & \multicolumn{2}{|c|}{$\begin{array}{l}\text { Estudo de impacto ambiental e estudo de } \\
\text { impacto de vizinhança para projetos de } \\
\text { transportes e mobilidade urbana, mas não } \\
\text { define medidas compensatórias ou mitigadoras }\end{array}$} \\
\hline 0,25 & \multicolumn{2}{|c|}{$\begin{array}{l}\text { Estudo de impacto ambiental para projetos de } \\
\text { transportes e mobilidade urbana, mas não } \\
\text { define medidas compensatórias ou mitigadoras }\end{array}$} \\
\hline 0,00 & \multicolumn{2}{|c|}{$\begin{array}{l}\text { O município não exige qualquer estudo ou } \\
\text { medida mitigadora sobre impactos dos sistemas } \\
\text { de transportes e mobilidade urbana }\end{array}$} \\
\hline Domínio & \multicolumn{2}{|c|}{ Aspectos Ambientais } \\
\hline Tema & \multicolumn{2}{|c|}{ 2.2. Recursos naturais } \\
\hline Indicador & \multicolumn{2}{|c|}{ 2.2.1. Consumo de combustível } \\
\hline Definição & \multicolumn{2}{|c|}{$\begin{array}{l}\text { Número de litros de gasolina consumido } \\
\text { anualmente por pessoa utilizando veículo } \\
\text { motorizado individual na área urbana. }\end{array}$} \\
\hline
\end{tabular}

\section{a) Fontes de Dados}

\begin{tabular}{cl}
\hline 1980 & Informações não disponíveis. \\
\hline 1991 & $\begin{array}{l}\text { Não foi possível obter informações sobre o } \\
\text { consumo de combustíveis para a cidade de } \\
\text { Belém ou a sua região metropolitana, mas } \\
\text { existem estatísticas de vendas estimadas para o } \\
\text { Estado do Pará (ANP, 2001, 2011). Os dados de } \\
\text { população são provenientes da página de séries } \\
\text { históricas do IBGE (2012). }\end{array}$ \\
\hline
\end{tabular}

b) Método de Cálculo

\begin{tabular}{|c|c|}
\hline 1980 & n/a \\
\hline 1991 & $\begin{array}{l}\text { - População urbana do estado: } 2.609 .777 \text { hab. } \\
\text { - População rural do estado: } 2.571 .793 \text { hab. } \\
\text { - População total do estado: } 5.181 .570 \text { hab. } \\
\text { - Vendas estimadas de gasolina para o estado: } \\
148.633 \mathrm{~m}^{3} \\
\text { - Vendas estimadas de etanol para o estado: } \\
130.680 \mathrm{~m}^{3} \\
\text { - Total de vendas (gasolina + etanol) para o } \\
\text { estado: } 279.317 \mathrm{~m}^{3} \\
\text { - Consumo per capita considerando a } \\
\text { população total: } 53,9 \text { l/hab. } \\
\text { - Consumo per capita considerando apenas a } \\
\text { população urbana: } 107,0 \text { l/hab. } \\
\text { - Será utilizado como escore esta segunda } \\
\text { média, que caracteriza uma pior situação. }\end{array}$ \\
\hline 2001 & $\begin{array}{l}\text { - População urbana do estado: } 4.116 .378 \text { hab. } \\
\text { - População rural do estado: } 2.073 .172 \text { hab. } \\
\text { - População total do estado: } 6.189 .550 \text { hab. } \\
\text { - Vendas estimadas de gasolina para o estado: } \\
357.685 \mathrm{~m}^{3} \\
\text { - Vendas estimadas de etanol para o estado: } \\
28.122 \mathrm{~m}^{3} \\
\text { - Total de vendas (gasolina + etanol) para o } \\
\text { estado: } 385.807 \mathrm{~m}^{3} \\
\text { - Consumo per capita considerando a } \\
\text { população total: } 62,3 \mathrm{l} / \mathrm{hab} \text {. } \\
\text { - Consumo per capita considerando apenas a } \\
\text { população urbana: } 93,7 \text { l/hab. } \\
\text { - Será utilizado como escore esta segunda } \\
\text { média, que caracteriza uma pior situação. }\end{array}$ \\
\hline 2011 & $\begin{array}{l}\text { - Usando dados de } 2010 \\
\text { - População urbana do estado: } 5.191 .559 \text { hab. } \\
\text { - População rural do estado: } 2.389 .492 \text { hab. } \\
\text { - População total do estado: } 7.581 .051 \text { hab. } \\
\text { - Vendas estimadas de gasolina para o estado: } \\
674.941 \mathrm{~m}^{3} \\
\text { - Vendas estimadas de etanol para o estado: } \\
46.967 \mathrm{~m}^{3} \\
\text { - Total de vendas (gasolina + etanol) para o } \\
\text { estado: } 721.908 \mathrm{~m}^{3} \\
\text { - Consumo per capita considerando a } \\
\text { população total: } 95,2 \text { l/hab. } \\
\text { - Consumo per capita considerando apenas a } \\
\text { população urbana: } 139,1 \text { l/hab. } \\
\text { - Será utilizado como escore esta segunda } \\
\text { média, que caracteriza uma pior situação. }\end{array}$ \\
\hline
\end{tabular}

c) Escore e Normalização

\begin{tabular}{ccc}
\hline Cenário & Escore & Escore Normalizado \\
\hline 1980 & $\mathrm{n} / \mathrm{a}$ & $\mathrm{n} / \mathrm{a}$ \\
\hline 1991 & 107,0 & 1,00 \\
\hline 2001 & 93,7 & 1,00 \\
\hline 2011 & 139,1 & 1,00 \\
\hline
\end{tabular}




\begin{tabular}{|c|c|}
\hline & Valores de Referência \\
\hline Escore & $\begin{array}{l}\text { Consumo anual per capita de gasolina em } \\
\text { veículo motorizado individual }\end{array}$ \\
\hline 1,00 & Inferior a 150 I/habitante \\
\hline 0,75 & 300 I/habitante \\
\hline 0,50 & 450 I/habitante \\
\hline 0,25 & 600 I/habitante \\
\hline 0,00 & 750 ou mais I/habitante \\
\hline Domínio & Aspectos Ambientais \\
\hline Tema & Recursos naturais \\
\hline Indicador & $\begin{array}{l}\text { 2.2.2. Uso de energia limpa e combustíveis } \\
\text { alternativos }\end{array}$ \\
\hline Definição & $\begin{array}{l}\text { Porcentagem de veículos da frota municipal } \\
\text { de transporte público (ônibus, microônibus, } \\
\text { vans) e semi-público (táxis e serviços } \\
\text { especiais) utilizando combustíveis menos } \\
\text { poluentes ou fontes de energia alternativa } \\
\text { como: gás natural, gás natural líquido, } \\
\text { propano, eletricidade, biodiesel, gasolina } \\
\text { híbrida ou hidrogênio. }\end{array}$ \\
\hline
\end{tabular}

\section{a) Fontes de Dados}

\begin{tabular}{ll}
\hline 1980 & $\begin{array}{l}\text { Em 1980 ainda não existia o programa de } \\
\text { biodiesel. O estado do Pará ainda não é } \\
\text { abastecido de gás natural, e não existe qualquer } \\
\text { registro de uso de outros combustíveis além do } \\
\text { óleo diesel. }\end{array}$ \\
\hline 1991 & $\begin{array}{l}\text { Em } 1991 \text { ainda não existia o programa de } \\
\text { biodiesel. O estado do Pará ainda não é } \\
\text { abastecido de gás natural, e não existe qualquer } \\
\text { registro de uso de outros combustíveis além do } \\
\text { óleo diesel. }\end{array}$ \\
\hline 2001 & $\begin{array}{l}\text { Em } 2001 \text { ainda não existia o programa de } \\
\text { biodiesel. O estado do Pará ainda não é } \\
\text { abastecido de gás natural, e não existe qualquer } \\
\text { registro de uso de outros combustíveis além do } \\
\text { óleo diesel. }\end{array}$ \\
\hline 2011 & $\begin{array}{l}\text { O estado do Pará ainda não é abastecido de gás } \\
\text { natural, e não existe qualquer registro de uso de } \\
\text { outros combustíveis além do óleo diesel. }\end{array}$ \\
\hline
\end{tabular}

\section{b) Método de Cálculo}

\begin{tabular}{ll}
\hline 1980 & n/a \\
\hline 1991 & n/a \\
\hline 2001 & n/a \\
\hline 2011 & n/a \\
\hline
\end{tabular}

\section{c) Escore e Normalização}

\begin{tabular}{ccc}
\hline Cenário & Escore & Escore Normalizado \\
\hline 1980 & 0 & 0,00 \\
\hline 1991 & 0 & 0,00 \\
\hline 2001 & 0 & 0,00 \\
\hline 2011 & 0 & 0,00 \\
\hline
\end{tabular}

\begin{tabular}{|c|c|}
\hline Escore & $\begin{array}{l}\text { Valores de Referência } \\
\text { Porcentagem da frota municipal de veículos de } \\
\text { transporte público e semi-público que utiliza } \\
\text { combustíveis "limpos" ou alternativos }\end{array}$ \\
\hline 1,00 & $100 \%$ \\
\hline 0,75 & $75 \%$ \\
\hline 0,50 & $50 \%$ \\
\hline 0,25 & $25 \%$ \\
\hline 0,00 & 0 \\
\hline Domínio & 3. Aspectos Sociais \\
\hline Tema & 3.1. Apoio ao cidadão \\
\hline Indicador & 3.1.1. Informação disponível ao cidadão \\
\hline Definição & $\begin{array}{l}\text { Existência e diversidade de informação sobre } \\
\text { mobilidade e transportes urbanos } \\
\text { disponibilizados ao cidadão, incluindo: } \\
\text { informações sobre os sistemas de transportes } \\
\text { em todas as suas modalidades, serviços de } \\
\text { auxílio ao usuário, canais de comunicação } \\
\text { para reclamações e denúncias, atendimento } \\
\text { on-line, informações sobre condições de } \\
\text { tráfego e circulação, entre outros. }\end{array}$ \\
\hline
\end{tabular}

\section{a) Fontes de Dados}

Não existem informações nos relatórios (GEIPOT, 1978, 1979, 1980), mas assume-se,

1980 considerando o porte da cidade, e o próprio fato desses estudos terem sido feitos, que havia uma estrutura mínima de informação aos usuários.

Não existem informações específicas sobre este assunto, mas os documentos do PDTU-1991 (JICA, 1991) apresentam um sistema de

1991 transporte público com razoável organização. Pode-se deduzir que exista alguma estrutura mínima de informação ao usuário, incluindo canal para reclamações.

Não existem informações específicas sobre este assunto, mas os documentos do PDTU-RMB (JICA, 2001) apresentam um sistema de

2001 transporte público com boa organização. Podese deduzir que exista alguma estrutura mínima de informação ao usuário, incluindo canal para reclamações.

2011 Sítio na Internet da Prefeitura de Belém

b) Método de Cálculo

\begin{tabular}{cl}
\hline 1980 & $\begin{array}{l}\text { Assume-se que existia em Belém pelo menos } \\
\text { "Informação sobre serviços de transporte } \\
\text { público". }\end{array}$ \\
\hline 1991 & $\begin{array}{l}\text { Assume-se que existia em Belém pelo menos } \\
\text { "Informação sobre serviços de transporte público } \\
\text { e canais de comunicação para denúncias e } \\
\text { reclamações". }\end{array}$ \\
\hline 2001 & $\begin{array}{l}\text { Assume-se que existia em Belém pelo menos } \\
\text { "Informação sobre serviços de transporte público } \\
\text { e canais de comunicação para denúncias e } \\
\text { reclamações". }\end{array}$ \\
\hline 2011 & $\begin{array}{l}\text { Informação sobre serviços de transporte público } \\
\text { e canais de comunicação para denúncias e } \\
\text { reclamações }\end{array}$ \\
\hline
\end{tabular}


c) Escore e Normalização

\begin{tabular}{ccc}
\hline Cenário & Escore & Escore Normalizado \\
\hline 1980 & 0,25 & 0,25 \\
\hline 1991 & 0,50 & 0,50 \\
\hline 2001 & 0,50 & 0,50 \\
\hline 2011 & 0,50 & 0,50 \\
\hline
\end{tabular}

\begin{tabular}{cl}
\hline Escore & $\begin{array}{l}\text { Valores de Referência } \\
\text { Há disponibilidade de: }\end{array}$ \\
\hline 1,00 & $\begin{array}{l}\text { Informação sobre serviços de transporte } \\
\text { público, canais de comunicação para denúncias } \\
\text { e reclamações, informações sobre condições } \\
\text { de trânsito e circulação e informações sobre } \\
\text { planos e projetos de transporte e mobilidade } \\
\text { urbana }\end{array}$ \\
\hline $0,75 \quad \begin{array}{l}\text { Informação sobre serviços de transporte } \\
\text { público, canais de comunicação para denúncias } \\
\text { e reclamações e informações sobre condições } \\
\text { de trânsito e circulação }\end{array}$ \\
\hline $0,50 \quad \begin{array}{l}\text { Informação sobre serviços de transporte público } \\
\text { e canais de comunicação para denúncias e } \\
\text { reclamações }\end{array}$ \\
\hline 0,25 & Informação sobre serviços de transporte público \\
\hline 0,00 & $\begin{array}{l}\text { Não há disponibilidade de qualquer tipo de } \\
\text { informação sobre transportes e mobilidade para } \\
\text { os cidadãos }\end{array}$ \\
\hline
\end{tabular}

\begin{tabular}{ll}
\hline Domínio & Aspectos Sociais \\
\hline Tema & 3.2. Inclusão Social \\
\hline Indicador & 3.2.1. Equidade vertical (renda) \\
\hline & $\begin{array}{l}\text { Razão entre o número médio de viagens } \\
\text { diárias dos moradores de domicílios mais } \\
\text { pobres, entendidos como os domicílios com } \\
\text { Definição até } 3 \text { salários mínimos, e dos } \\
\text { rendadores dos domicílios mais ricos, } \\
\text { montendidos como os domicílios com renda } \\
\text { superior a 20 salários mínimos. }\end{array}$ \\
\hline
\end{tabular}

a) Fontes de Dados

\begin{tabular}{|c|c|}
\hline 1980 & Informação não disponível. \\
\hline 1991 & Relatório do Plano Diretor (JICA, 1991). \\
\hline \multirow[t]{2}{*}{2001} & $\begin{array}{l}\text { Relatório e CDs do PDTU-RMB (JICA, 2001) } \\
\text { Planilhas: "PD - DESLOCAMENTOS 1.xIs", "PD - } \\
\text { DESLOCAMENTOS 2.xIs" e "PD - DADOS DO } \\
\text { DOMICILIO.xIs". }\end{array}$ \\
\hline & $\begin{array}{l}\text { Documento com os valores dos salários mínimos } \\
\text { (MTE, 2011). }\end{array}$ \\
\hline 2011 & $\begin{array}{l}\text { Relatório do Estudo Preparatório para o Projeto } \\
\text { de Sistema de Transporte de Ônibus da RMB } \\
\text { (JICA, 2010). }\end{array}$ \\
\hline
\end{tabular}

\section{b) Método de Cálculo}

\begin{tabular}{|c|c|}
\hline 1980 & $\mathrm{n} / \mathrm{a}$ \\
\hline 1991 & $\begin{array}{l}\text { - Da Figura 7.2-5, pag. 138, pode-se estimar: } \\
\text { - Número médio de viagens para domicílios } \\
\text { com renda até } 3 \text { S.M. = } 2,1 \\
\text { - Número médio de viagens para domicílios } \\
\text { com renda maior que } 20 \text { S.M. = 3,5 } \\
\text { - Escore }=2,1 / 3,5=0,6\end{array}$ \\
\hline
\end{tabular}

- Número de domicílios com renda menor ou igual a 3 SM: 3.809 domicílios com 17.400 moradores;

- Número de domicílios com renda maior ou igual a 20 SM: 177 domicílios com 900 moradores;

- Número de viagens realizadas por membros de domicílios com renda menor ou igual a 3 SM: 33.372 viagens, com média de 1,92 viagens/pessoa;

- Número de viagens realizadas por membros de domicílios com renda maior ou igual a 20 SM: 2.166 viagens, com média de 2,41 viagens/pessoa;

- O Escore é obtido através da razão entre a média de viagens para o grupo dos domicílios mais pobres pela média do grupo dos domicílios mais ricos.

- O estudo analisado (JICA, 2010) não trás informações sobre faixas de renda, mas pode-se estimar essa razão com as quantidades de viagens por pessoa dos

2011 domicílios motorizados e dos não motorizados.

- Pessoas não motorizadas: 1,72 viagens/dia

- Pessoas motorizadas: 2,03 viagens/dia

\section{c) Escore e Normalização}

\begin{tabular}{ccc}
\hline Cenário & Escore & Escore Normalizado \\
\hline 1980 & $\mathrm{n} / \mathrm{a}$ & $\mathrm{n} / \mathrm{a}$ \\
\hline 1991 & 0,60 & 0,60 \\
\hline 2001 & 0,80 & 0,80 \\
\hline 2011 & 0,85 & 0,85 \\
\hline
\end{tabular}

\begin{tabular}{ll}
\hline Escore & $\begin{array}{l}\text { Valores de Referência } \\
\text { Razão entre o número médio de viagens diárias } \\
\text { dos moradores de domicílios mais pobres e o } \\
\text { número médio de viagens diárias dos } \\
\text { moradores de domicílios mais ricos }\end{array}$ \\
\hline 1,00 & 1,00 ou mais \\
\hline 0,75 & 0,75 \\
\hline 0,50 & 0,50 \\
\hline 0,25 & 0,25 \\
\hline 0,00 & 0 \\
\hline
\end{tabular}




\begin{tabular}{ll}
\hline Domínio & Aspectos Sociais \\
\hline Tema & 3.3. Educação e cidadania \\
\hline Indicador & $\begin{array}{l}\text { 3.3.1. Educação para o desenvolvimento } \\
\text { sustentável }\end{array}$ \\
\hline Definição & $\begin{array}{l}\text { Existência de ações continuadas de } \\
\text { formação e sensibilização, equipamentos } \\
\text { públicos específicos, programas e projetos } \\
\text { desenvolvidos pelo município em matéria de } \\
\text { educação para o desenvolvimento } \\
\text { sustentável. }\end{array}$ \\
\hline
\end{tabular}

a) Fontes de Dados

\begin{tabular}{ll}
\hline 1980 & Informação não disponível. \\
\hline 1991 & Informação não disponível. \\
\hline 2001 & $\begin{array}{l}\text { Relatório do PDTU (JICA, 2001) e páginas de } \\
\text { legislação da Prefeitura de Belém (PMB, 2006b, } \\
\text { a, 2011b) }\end{array}$ \\
\hline 2011 & Prefeitura Municipal de Belém \\
\hline
\end{tabular}

b) Método de Cálculo

\begin{tabular}{ll}
\hline 1980 & n/a \\
\hline 1991 & n/a \\
\hline & $\begin{array}{l}\text { No relatório do PDTU não existem } \\
\text { informações sobre as ações, mas pode-se } \\
\text { constatar que existe legislação prevendo } \\
\text { atividades de educação ambiental, inclusive } \\
\text { com a criação de centro de referência (PMB, } \\
\text { 1995). Não se tem informação sobre a } \\
\text { continuidade e a abrangência da formação e } \\
\text { das ações e, portanto, optou-se por um } \\
\text { escore pessimista. }\end{array}$ \\
\hline 2011 & $\begin{array}{l}\text { Promove campanhas de sensibilização para o } \\
\text { desenvolvimento sustentável }\end{array}$ \\
\hline
\end{tabular}

c) Escore e Normalização

\begin{tabular}{ccc}
\hline Cenário & Escore & Escore Normalizado \\
\hline 1980 & $\mathrm{n} / \mathrm{a}$ & $\mathrm{n} / \mathrm{a}$ \\
\hline 1991 & $\mathrm{n} / \mathrm{a}$ & $\mathrm{n} / \mathrm{a}$ \\
\hline 2001 & 0,25 & 0,25 \\
\hline 2011 & 0,25 & 0,25 \\
\hline Escore & $\begin{array}{l}\text { Valores de Referência } \\
\text { O município dispõe de: }\end{array}$ \\
\hline 1,00 & $\begin{array}{l}\text { Equipamentos específicos, ações de formação } \\
\text { continuada para crianças, jovens e adultos e } \\
\text { promove campanhas de sensibilização para o } \\
\text { desenvolvimento sustentável }\end{array}$ \\
\hline 0,75 & $\begin{array}{l}\text { Ações de formação continuada para crianças, } \\
\text { jovens e adultos e promove campanhas de } \\
\text { sensibilização para o desenvolvimento } \\
\text { sustentável }\end{array}$ \\
\hline 0,50 & $\begin{array}{l}\text { Ações de formação continuada somente para } \\
\text { crianças e promove campanhas de } \\
\text { sensibilização para o desenvolvimento } \\
\text { sustentável }\end{array}$ \\
\hline 0,25 & $\begin{array}{l}\text { Promove campanhas de sensibilização para o } \\
\text { desenvolvimento sustentável }\end{array}$ \\
\hline 0,00 & $\begin{array}{l}\text { O município não dispõe de nenhuma ação em } \\
\text { matéria de educação para o desenvolvimento } \\
\text { sustentável }\end{array}$ \\
\hline
\end{tabular}

\begin{tabular}{ll}
\hline Domínio & Aspectos Sociais \\
\hline Tema & 3.4. Participação Popular \\
\hline Indicador & 3.4.1. Participação na tomada de decisão \\
\hline & $\begin{array}{l}\text { Incentivo e viabilização por parte da } \\
\text { administração municipal para a participação } \\
\text { popular nos processos de elaboração, } \\
\text { implementação e monitoramento das } \\
\text { políticas, ações e projetos de transporte e } \\
\text { mobilidade urbana. }\end{array}$ \\
\hline
\end{tabular}

\section{a) Fontes de Dados}

\begin{tabular}{ll}
\hline 1980 & $\begin{array}{l}\text { Relatórios dos estudos e projetos (GEIPOT, } \\
1978,1979,1980,1986) .\end{array}$ \\
\hline 1991 & Relatório do PDTU (JICA, 1991). \\
\hline 2001 & Relatório do PDTU (JICA, 2001). \\
\hline 2011 & $\begin{array}{l}\text { Consultas feitas junto à Prefeitura de Belém pelo } \\
\text { pessoal do ITEP/UFPA. }\end{array}$ \\
\hline
\end{tabular}

\section{b) Método de Cálculo}

\begin{tabular}{ll}
\hline \multirow{2}{*}{1980} & $\begin{array}{l}\text { A julgar pelos relatórios, não houve qualquer tipo } \\
\text { de participação da comunidade na análise dos } \\
\text { problemas e proposta de soluções. }\end{array}$ \\
\hline 1991 & $\begin{array}{l}\text { A julgar pelos relatórios, não houve qualquer tipo } \\
\text { de participação da comunidade na análise dos } \\
\text { problemas e proposta de soluções. }\end{array}$ \\
\hline & $\begin{array}{l}\text { Nesta seção do relatório descreve-se as } \\
\text { atividades do “Seminário de Diagnóstico e } \\
\text { Formulação de Diretrizes para o Sistema de } \\
\text { Transportes da RMB", com a participação de } \\
\text { "cerca de 61 instituições governamentais e não } \\
\text { governamentais, assim como especialistas e } \\
\text { estudiosos envolvidos com transporte e } \\
\text { desenvolvimento urbano na RMB". } \\
\text { Consideramos que isso configura a participação } \\
\text { da comunidade, pelo menos, na fase de } \\
\text { planejamento. }\end{array}$ \\
\hline $\begin{array}{l}\text { Incentivou e viabilizou a participação popular no } \\
\text { desenvolvimento de políticas, ações e projetos } \\
\text { de transportes, mobilidade e desenvolvimento } \\
\text { urbano, somente em uma de suas etapas } \\
\text { (elaboração, implementação ou monitoramento) }\end{array}$ \\
\hline 2011
\end{tabular}

\section{c) Escore e Normalização}

\begin{tabular}{ccc}
\hline Cenário & Escore & Escore Normalizado \\
\hline 1980 & 0,00 & 0,00 \\
\hline 1991 & 0,00 & 0,00 \\
\hline 2001 & 0,33 & 0,33 \\
\hline 2011 & 0,33 & 0,33 \\
\hline
\end{tabular}




\begin{tabular}{cl}
\hline Escore & $\begin{array}{l}\text { Valores de Referência } \\
\text { A administração municipal: }\end{array}$ \\
\hline 1,00 & $\begin{array}{l}\text { Incentivou e viabilizou a participação popular no } \\
\text { desenvolvimento de políticas, ações e projetos } \\
\text { de transportes, mobilidade e desenvolvimento } \\
\text { urbano, em todas as suas etapas (elaboração, } \\
\text { implementação e monitoramento) }\end{array}$ \\
\hline 0,66 & $\begin{array}{l}\text { Incentivou e viabilizou a participação popular no } \\
\text { desenvolvimento de políticas, ações e projetos } \\
\text { de transportes, mobilidade e desenvolvimento } \\
\text { urbano, em duas de suas etapas (elaboração, } \\
\text { implementação ou monitoramento) }\end{array}$ \\
\hline 0,33 & $\begin{array}{l}\text { Incentivou e viabilizou a participação popular no } \\
\text { desenvolvimento de políticas, açoses e projetos } \\
\text { de transportes, mobilidade e desenvolvimento } \\
\text { urbano, somente em uma de suas etapas } \\
\text { (elaboração, implementação ou monitoramento) }\end{array}$ \\
\hline 0,00 & $\begin{array}{l}\text { Não incentivou nem viabilizou a participação } \\
\text { popular no desenvolvimento de quaisquer } \\
\text { políticas, ações e projetos de transportes, } \\
\text { mobilidade e desenvolvimento urbano }\end{array}$ \\
\hline Definição & $\begin{array}{l}\text { Porcentagem da população satisfeita com a } \\
\text { cidade como local para viver. }\end{array}$ \\
\hline Indicador & Aspectos Sociais \\
\hline 3.5. Qualidade de Vida
\end{tabular}

a) Fontes de Dados

\begin{tabular}{ll}
\hline 1980 & Informação não disponível. \\
\hline 1991 & Informação não disponível. \\
\hline 2001 & Informação não disponível. \\
\hline 2011 & Estimativa feita pela equipe do ITEP/UFPA. \\
\hline
\end{tabular}

b) Método de Cálculo

\begin{tabular}{ll}
\hline 1980 & n/a \\
\hline 1991 & n/a \\
\hline 2001 & n/a \\
\hline 2011 & $\begin{array}{l}\text { Baseada no valor do IDH da RMB, a equipe do } \\
\text { ITEP/UFPA estimou o valor de 0,80. }\end{array}$ \\
\hline
\end{tabular}

c) Escore e Normalização

\begin{tabular}{|c|c|c|}
\hline Cenário & Escore & Escore Normalizado \\
\hline 1980 & $\mathrm{n} / \mathrm{a}$ & $\mathrm{n} / \mathrm{a}$ \\
\hline 1991 & $\mathrm{n} / \mathrm{a}$ & $\mathrm{n} / \mathrm{a}$ \\
\hline 2001 & $\mathrm{n} / \mathrm{a}$ & $\mathrm{n} / \mathrm{a}$ \\
\hline \multirow[t]{2}{*}{2011} & $80 \%$ & 0,80 \\
\hline & \multicolumn{2}{|c|}{ Valores de Referência } \\
\hline Escore & \multicolumn{2}{|c|}{$\begin{array}{l}\text { Porcentagem da população (ou dos } \\
\text { entrevistados) considera a cidade como um } \\
\text { lugar "bom" e "excelente" para se viver }\end{array}$} \\
\hline 1,00 & \multicolumn{2}{|l|}{$100 \%$} \\
\hline 0,75 & \multicolumn{2}{|l|}{$75 \%$} \\
\hline 0,50 & \multicolumn{2}{|l|}{$50 \%$} \\
\hline 0,25 & \multicolumn{2}{|l|}{$25 \%$} \\
\hline 0,00 & \multicolumn{2}{|l|}{0} \\
\hline
\end{tabular}

\begin{tabular}{ll}
\hline Domínio & 4. Aspectos Políticos \\
\hline Tema & 4.1. Integração de ações políticas \\
\hline Indicador & 4.1.1. Integração entre níveis de governo \\
\hline Definição & $\begin{array}{l}\text { Frequência e grau de integração de ações, } \\
\text { programas e projetos de transportes, } \\
\text { mobilidade e desenvolvimento urbano } \\
\text { desenvolvidos pelo município, em conjunto } \\
\text { com o governo estadual e/ou federal. }\end{array}$ \\
\hline
\end{tabular}

\section{a) Fontes de Dados}

\begin{tabular}{ll}
\hline 1980 & $\begin{array}{l}\text { Relatórios dos planos e estudos (GEIPOT, } \\
1978,1980,1986)\end{array}$ \\
\hline 1991 & Relatório do PDTU-1991 (JICA, 1991) \\
\hline 2001 & Relatório do PDTU-2001 (JICA, 2001). \\
\hline 2011 & $\begin{array}{l}\text { Relatórios de planos e estudos da RMB } \\
\text { (JICA, 2003; PARÁ, 2006; JICA, 2010) }\end{array}$ \\
\hline
\end{tabular}

\section{b) Método de Cálculo}

\begin{tabular}{ll}
\hline 1980 & $\begin{array}{l}\text { A própria organização para execução dos } \\
\text { planos e estudos demonstra uma integração } \\
\text { de ações dos três níveis de governo. }\end{array}$ \\
\hline \multirow{3}{*}{$\begin{array}{l}\text { A própria organização para execução dos } \\
\text { planos e estudos demonstra uma integração } \\
\text { de ações dos três níveis de governo. }\end{array}$} \\
- Pela leitura do relatório do PDTU-RMB \\
percebe-se que existe uma colaboração \\
entre os municípios da região \\
metropolitana e o Governo do Estado; \\
• A configuração de uma região \\
metropolitana, envolvendo um número \\
significativo de deslocamentos \\
intermunicipais, leva, obrigatoriamente, a \\
algum tipo de acerto institucional; \\
• Parte de um dos principais corredores da \\
RMB é constituído por uma rodovia federal; \\
- A relação do Governo do Pará com a JICA, \\
que financia a realização deste plano, \\
ocorre com a interveniência do Governo \\
Federal; \\
• Pode-se, então, deduzir que ocorrem \\
ações integradas entre os três níveis de \\
poder.
\end{tabular}

\section{c) Escore e Normalização}

\begin{tabular}{ccc}
\hline Cenário & Escore & Escore Normalizado \\
\hline 1980 & 0,50 & 0,50 \\
\hline 1991 & 0,50 & 0,50 \\
\hline 2001 & 0,75 & 0,75 \\
\hline 2011 & 0,75 & 0,75 \\
\hline
\end{tabular}




\begin{tabular}{|c|c|}
\hline Escore & $\begin{array}{l}\text { Valores de Referência } \\
\text { As ações integradas são: }\end{array}$ \\
\hline 1,00 & $\begin{array}{l}\text { Muito frequentes, envolvendo os governos } \\
\text { municipal, estadual e federal }\end{array}$ \\
\hline 0,75 & $\begin{array}{l}\text { Frequentes, envolvendo os governos municipal, } \\
\text { estadual e federal }\end{array}$ \\
\hline 0,50 & $\begin{array}{l}\text { Pouco frequentes, envolvendo os governos } \\
\text { municipal, estadual e federal }\end{array}$ \\
\hline 0,25 & $\begin{array}{l}\text { Pouco frequentes, envolvendo somente os } \\
\text { governos municipal e estadual }\end{array}$ \\
\hline 0,00 & $\begin{array}{l}\text { As ações integradas entre os governos } \\
\text { municipal, estadual e federal são raras no } \\
\text { município }\end{array}$ \\
\hline Domínio & Aspectos Políticos \\
\hline Tema & Integração de Ações Políticas \\
\hline Indicador & 4.1.2. Parcerias público privadas \\
\hline Definição & $\begin{array}{l}\text { Ações, projetos, serviços ou infraestrutura de } \\
\text { transporte urbano viabilizados por meio de } \\
\text { parcerias entre o governo municipal e } \\
\text { entidades privadas. }\end{array}$ \\
\hline
\end{tabular}

a) Fontes de Dados

\begin{tabular}{ll}
\hline 1980 & $\begin{array}{l}\text { Relatórios dos planos e estudos (GEIPOT, } \\
1978,1980,1986)\end{array}$ \\
\hline 1991 & Relatório do PDTU-1991 (JICA, 1991) \\
\hline 2001 & Relatório do PDTU-RMB (JICA, 2001) \\
\hline 2011 & $\begin{array}{l}\text { Relatórios de planos e estudos da RMB } \\
\text { (JICA, 2003; PARÁ, 2006; JICA, 2010) }\end{array}$ \\
\hline
\end{tabular}

b) Método de Cálculo

\begin{tabular}{ll}
\hline 1980 & $\begin{array}{l}\text { A leitura dos relatórios não leva à } \\
\text { identificação de qualquer iniciativa nesse } \\
\text { sentido. }\end{array}$ \\
\hline 1991 & $\begin{array}{l}\text { A leitura do relatório não leva à identificação } \\
\text { de qualquer iniciativa nesse sentido. }\end{array}$ \\
\hline 2001 & $\begin{array}{l}\text { A leitura do relatório não leva à identificação } \\
\text { de qualquer iniciativa nesse sentido. }\end{array}$ \\
\hline 2011 & $\begin{array}{l}\text { A leitura do relatório não leva à identificação } \\
\text { de qualquer iniciativa nesse sentido. }\end{array}$ \\
\hline
\end{tabular}

c) Escore e Normalização

\begin{tabular}{ccc}
\hline Cenário & Escore & Escore Normalizado \\
\hline 1980 & 0,00 & 0,00 \\
\hline 1991 & 0,00 & 0,00 \\
\hline 2001 & 0,00 & 0,00 \\
\hline 2011 & 0,00 & 0,00 \\
\hline
\end{tabular}

\begin{tabular}{cl}
\hline \multirow{2}{*}{ Escore } & $\begin{array}{l}\text { Valores de Referência } \\
\text { Projetos de transportes e mobilidade urbana por } \\
\text { meio de parcerias público-privadas: }\end{array}$ \\
\hline 1,00 & Já foram implementados no município \\
\hline 0,50 & Encontram-se em preparação no município \\
\hline 0,00 & $\begin{array}{l}\text { Não estão previstos nem foram implementados } \\
\text { no município }\end{array}$ \\
\hline
\end{tabular}

\begin{tabular}{ll}
\hline Domínio & Aspectos Políticos \\
\hline Tema & 4.2. Captação e Gerenciamento de Recursos \\
\hline Indicador & 4.2.1. Captação de recursos \\
\hline & $\begin{array}{l}\text { Porcentagem dos recursos municipais para } \\
\text { financiamento de projetos de transportes e } \\
\text { mobilidade oriundos de taxações aos } \\
\text { veículos/usuários, multas ou pedágios } \\
\text { urbanos. }\end{array}$ \\
\hline
\end{tabular}

\section{a) Fontes de Dados}

\begin{tabular}{ll}
\hline 1980 & $\begin{array}{l}\text { Informação não disponível nos documentos } \\
\text { consultados. }\end{array}$ \\
\hline 1991 & $\begin{array}{l}\text { Informação não disponível nos documentos } \\
\text { consultados. }\end{array}$ \\
\hline 2001 & $\begin{array}{l}\text { Informação não disponível nos documentos } \\
\text { consultados. }\end{array}$ \\
\hline 2011 & Informação não obtida. \\
\hline
\end{tabular}

\section{b) Método de Cálculo}

\begin{tabular}{ll}
\hline 1980 & n/a \\
\hline 1991 & n/a \\
\hline 2001 & n/a \\
\hline 2011 & n/a \\
\hline
\end{tabular}

c) Escore e Normalização

\begin{tabular}{ccc}
\hline Cenário & Escore & Escore Normalizado \\
\hline 1980 & $\mathrm{n} / \mathrm{a}$ & $\mathrm{n} / \mathrm{a}$ \\
\hline 1991 & $\mathrm{n} / \mathrm{a}$ & $\mathrm{n} / \mathrm{a}$ \\
\hline 2001 & $\mathrm{n} / \mathrm{a}$ & $\mathrm{n} / \mathrm{a}$ \\
\hline 2011 & $\mathrm{n} / \mathrm{a}$ & $\mathrm{n} / \mathrm{a}$ \\
\hline
\end{tabular}

\begin{tabular}{ll}
\hline Escore & $\begin{array}{l}\text { Valores de Referência } \\
\text { Porcentagem dos recursos municipais para } \\
\text { transportes e mobilidade obtidos por meio de } \\
\text { taxações, multa ou pedágios urbanos }\end{array}$ \\
\hline 1,00 & $20 \%$ ou mais \\
\hline 0,75 & $15 \%$ \\
\hline 0,50 & $10 \%$ \\
\hline 0,25 & $5 \%$ \\
\hline 0,00 & 0 \\
\hline
\end{tabular}




\begin{tabular}{ll}
\hline Domínio & Aspectos Políticos \\
\hline Tema & Captação e Gerenciamento de recursos \\
\hline Indicador & $\begin{array}{l}\text { 4.2.2. Investimentos em sistemas de } \\
\text { transportes }\end{array}$ \\
\hline Definição & $\begin{array}{l}\text { Investimentos em sistemas de transportes e } \\
\text { mobilidade urbana feitos pelo município no } \\
\text { ano de referência. }\end{array}$ \\
\hline
\end{tabular}

\section{a) Fontes de Dados}

\begin{tabular}{cl}
\hline 1980 & $\begin{array}{l}\text { Informação não disponível nos documentos } \\
\text { consultados. }\end{array}$ \\
\hline 1991 & $\begin{array}{l}\text { Informação não disponível nos documentos } \\
\text { consultados. }\end{array}$ \\
\hline 2001 & $\begin{array}{l}\text { Informação não disponível nos documentos } \\
\text { consultados. }\end{array}$ \\
\hline 2011 & Informação não obtida \\
\hline
\end{tabular}

b) Método de Cálculo

\begin{tabular}{ll}
\hline 1980 & $\mathrm{n} / \mathrm{a}$ \\
\hline 1991 & $\mathrm{n} / \mathrm{a}$ \\
\hline 2001 & $\mathrm{n} / \mathrm{a}$ \\
\hline 2011 & $\mathrm{n} / \mathrm{a}$ \\
\hline
\end{tabular}

c) Escore e Normalização

\begin{tabular}{clc}
\hline Cenário & Escore & Escore Normalizado \\
\hline 1980 & n/a & n/a \\
\hline 1991 & n/a & n/a \\
\hline 2001 & n/a & n/a \\
\hline 2011 & n/a & n/a \\
\hline Escore & $\begin{array}{l}\text { Valores de Referência } \\
\text { Houve investimentos no ano de referência no } \\
\text { município em: }\end{array}$ \\
\hline 1,00 & $\begin{array}{l}\text { Obras de infraestrutura, investimentos na } \\
\text { provisão e melhoria de serviços de transporte } \\
\text { coletivo, projetos para os modos não- } \\
\text { motorizados de transporte e ampliação da } \\
\text { mobilidade de pessoas com necessidades } \\
\text { especiais, além de planos de mobilidade urbana }\end{array}$ \\
\hline 0,75 & $\begin{array}{l}\text { Obras de infraestrutura, investimentos na } \\
\text { provisão e melhoria de serviços de transporte } \\
\text { coletivo, modos não-motorizados de transporte } \\
\text { ou ampliação da mobilidade de pessoas com } \\
\text { necessidades especiais }\end{array}$ \\
\hline 0,50 & $\begin{array}{l}\text { Obras de infraestrutura e investimentos na } \\
\text { provisão e melhoria de serviços de transporte } \\
\text { coletivo }\end{array}$ \\
\hline 0,25 & $\begin{array}{l}\text { Somente em obras emergenciais, corretivas e } \\
\text { preventivas de infraestrutura de transportes }\end{array}$ \\
\hline 0,00 & $\begin{array}{l}\text { Não houve investimentos em infraestrutura, } \\
\text { sistemas de transportes e mobilidade }\end{array}$ \\
\hline &
\end{tabular}

\begin{tabular}{ll}
\hline Domínio & Aspectos Políticos \\
\hline Tema & Captação e Gerenciamento de Recursos \\
\hline Indicador & $\begin{array}{l}\text { 4.2.3. Distribuição dos recursos (coletivo x } \\
\text { privado) }\end{array}$ \\
\hline Definição & $\begin{array}{l}\text { Razão entre os investimentos públicos com } \\
\text { infraestrutura para o transporte coletivo e } \\
\text { infraestrutura para o transporte privado. }\end{array}$ \\
\hline
\end{tabular}

\section{a) Fontes de Dados}

\begin{tabular}{ll}
\hline 1980 & Informação não disponível \\
\hline 1991 & Informação não disponível \\
\hline 2001 & Informação não disponível \\
\hline 2011 & Informação não obtida \\
\hline
\end{tabular}

\section{b) Método de Cálculo}

\begin{tabular}{ll}
\hline 1980 & n/a \\
\hline 1991 & n/a \\
\hline 2001 & n/a \\
\hline 2011 & n/a \\
\hline
\end{tabular}

\section{c) Escore e Normalização}

\begin{tabular}{ccc}
\hline Cenário & Escore & Escore Normalizado \\
\hline 1980 & $\mathrm{n} / \mathrm{a}$ & $\mathrm{n} / \mathrm{a}$ \\
\hline 1991 & $\mathrm{n} / \mathrm{a}$ & $\mathrm{n} / \mathrm{a}$ \\
\hline 2001 & $\mathrm{n} / \mathrm{a}$ & $\mathrm{n} / \mathrm{a}$ \\
\hline 2011 & $\mathrm{n} / \mathrm{a}$ & $\mathrm{n} / \mathrm{a}$ \\
\hline
\end{tabular}

\begin{tabular}{cl}
\hline Escore & Valores de Referência \\
\hline 1,00 & $\begin{array}{l}\text { I }>1 \text { Os investimentos em infraestrutura para } \\
\text { transporte coletivo no município no ano de } \\
\text { referência foram superiores aos investimentos } \\
\text { em infraestrutura para o transporte privado }\end{array}$ \\
\hline $\begin{array}{l}\text { I =1 Os investimentos em infraestrutura para } \\
\text { transporte coletivo no município no ano de } \\
\text { referência foram equivalentes aos } \\
\text { investimentos em infraestrutura para o } \\
\text { transporte privado }\end{array}$ \\
\hline
\end{tabular}

$0,5<1<1$ Houve investimentos em infraestrutura para transporte coletivo no município no ano de

0,50 referência, porém, estes foram um pouco inferiores aos investimentos em infraestrutura para o transporte privado

$0<\mathrm{I} \leq 0,5$ Houve investimentos em infraestrutura para transporte coletivo no

0,25 município no ano de referência, porém, estes foram bastante inferiores aos investimentos em infraestrutura para o transporte privado

I=0 Não houve investimentos em infraestrutura para transporte coletivo no município no ano de

0,00 referência. Os recursos foram destinados à provisão, ampliação e manutenção de vias de uso predominante de automóveis 


\begin{tabular}{ll}
\hline Domínio & Aspectos Políticos \\
\hline Tema & Captação e Gerenciamento de Recursos \\
\hline Indicador & $\begin{array}{l}\text { 4.2.4. Distribuição dos recursos (motorizados } \\
\text { x não-motorizados) }\end{array}$ \\
\hline Definição & $\begin{array}{l}\text { Razão entre os gastos públicos com } \\
\text { infraestrutura para os modos não-motorizados } \\
\text { e infraestrutura para os modos motorizados } \\
\text { de transporte. }\end{array}$ \\
\hline
\end{tabular}

a) Fontes de Dados

\begin{tabular}{ll}
\hline 1980 & $\begin{array}{l}\text { Relatórios dos planos e estudos (GEIPOT, } \\
1978,1979,1980,1986)\end{array}$ \\
\hline 1991 & Relatório do PDTU-1991 (JICA, 1991) \\
\hline 2001 & Relatório do PDTU-RMB (JICA, 2001) \\
\hline 2011 & $\begin{array}{l}\text { Relatórios de planos e estudos da RMB } \\
\text { (JICA, 2003; PARÁ, 2006; JICA, 2010) e } \\
\text { visitas aos locais. }\end{array}$ \\
\hline
\end{tabular}

b) Método de Cálculo

\begin{tabular}{ll}
\hline 1980 & n/a \\
\hline 1991 & $\begin{array}{l}\text { Deduz-se, da leitura do relatório, que } \\
\text { praticamente inexistiu investimento em infra- } \\
\text { estrutura para os modos não motorizados. Foi } \\
\text { atribuído escore 0. }\end{array}$ \\
\hline 2001 & $\begin{array}{l}\text { Deduz-se, da leitura do relatório, que } \\
\text { praticamente inexistiu investimento em infra- } \\
\text { estrutura para os modos não motorizados. Foi } \\
\text { atribuído escore 0. }\end{array}$ \\
\hline 2011 & $\begin{array}{l}\text { Houve investimento em infraestrutura para } \\
\text { modos não-motorizados de transporte no } \\
\text { município no ano de referência, porém, estes } \\
\text { foram bastante inferiores aos investimentos } \\
\text { em infraestrutura para os modos motorizados. }\end{array}$ \\
\hline
\end{tabular}

c) Escore e Normalização

\begin{tabular}{lll}
\hline Cenário & Escore & \multicolumn{2}{c}{ Escore Normalizado } \\
\hline 1980 & n/a & n/a \\
\hline 1991 & 0,00 & 0,00 \\
\hline 2001 & 0,00 & 0,00 \\
\hline 2011 & 0,25 & 0,25 \\
\hline Escore & Valores de Referência \\
\hline 1,00 & $\begin{array}{l}\text { I }>1 \text { Os investimentos em infraestrutura para } \\
\text { modos não-motorizados de transporte no } \\
\text { município no ano de referência foram } \\
\text { superiores aos investimentos em infraestrutura } \\
\text { para os modos motorizados }\end{array}$ \\
\hline 0,75 & $\begin{array}{l}\text { I }=1 \text { Os investimentos em infraestrutura para } \\
\text { modos não-motorizados de transporte no } \\
\text { município no ano de referência foram } \\
\text { equivalentes aos investimentos em } \\
\text { infraestrutura para os modos motorizados }\end{array}$ \\
\hline 0,50 & $\begin{array}{l}0,5<1<1 \text { Houve investimentos em } \\
\text { infraestrutura para modos não-motorizados de } \\
\text { transporte no município no ano de referência, } \\
\text { porém, estes foram um pouco inferiores aos } \\
\text { investimentos em infraestrutura para os modos } \\
\text { motorizados }\end{array}$ \\
\hline 0,25 & $\begin{array}{l}0<\text { I } \leq \text { 0,5 Houve investimentos em } \\
\text { infraestrutura para modos não-motorizados de } \\
\text { transporte no município no ano de referência, }\end{array}$ \\
\hline &
\end{tabular}

\begin{tabular}{|c|c|}
\hline & $\begin{array}{l}\text { porém, estes foram bastante inferiores aos } \\
\text { investimentos em infraestrutura para os modos } \\
\text { motorizados }\end{array}$ \\
\hline 0,00 & $\begin{array}{l}\text { I = } 0 \text { Não houve investimentos em infraestrutura } \\
\text { para modos não motorizados de transporte no } \\
\text { município no ano de referência. Os recursos } \\
\text { foram destinados a provisão, ampliação e } \\
\text { manutenção de vias de uso de veículos }\end{array}$ \\
\hline Domínio & Aspectos Políticos \\
\hline Tema & 4.3. Política de mobilidade urbana \\
\hline Indicador & 4.3.1. Política de mobilidade urbana \\
\hline Definição & $\begin{array}{l}\text { Existência ou desenvolvimento de política de } \\
\text { transportes e mobilidade em nível local, } \\
\text { especialmente no que diz respeito à } \\
\text { elaboração do Plano Diretor de Transporte e } \\
\text { da Mobilidade. }\end{array}$ \\
\hline
\end{tabular}

a) Fontes de Dados

\begin{tabular}{ll}
\hline 1980 & $\begin{array}{l}\text { Estudos e planos do GEIPOT (1978, 1979, } \\
\text { 1980, 1986). }\end{array}$ \\
\hline 1991 & Relatório do PDTU (JICA, 1991). \\
\hline 2001 & Relatório do PDTU (JICA, 2001). \\
\hline 2011 & $\begin{array}{l}\text { Relatório do Estudo Preparatório para o } \\
\text { Projeto do Sistema de Transporte de Ônibus } \\
\text { da RMB (JICA, 2010) }\end{array}$ \\
\hline
\end{tabular}

\section{b) Método de Cálculo}

\begin{tabular}{ll}
\hline \multirow{2}{*}{1980} & $\begin{array}{l}\text { Fase de desenvolvimento de estudos e } \\
\text { projetos relacionados à elaboração do Plano } \\
\text { Diretor de Transporte e da Mobilidade ou } \\
\text { outro instrumento referente à política de } \\
\text { mobilidade urbana }\end{array}$ \\
\hline \multirow{2}{*}{$\begin{array}{l}\text { Fase de desenvolvimento de estudos e } \\
\text { projetos relacionados à elaboração do Plano } \\
\text { Diretor de Transporte e da Mobilidade ou } \\
\text { outro instrumento referente à política de } \\
\text { mobilidade urbana }\end{array}$} \\
\hline \multirow{2001}{}{$\begin{array}{l}\text { Fase de desenvolvimento de estudos e } \\
\text { projetos relacionados à elaboração do Plano } \\
\text { Diretor de Transporte e da Mobilidade ou } \\
\text { outro instrumento referente à política de } \\
\text { mobilidade urbana }\end{array}$} \\
\hline $\begin{array}{l}\text { Fase de desenvolvimento de estudos e } \\
\text { projetos relacionados à elaboração do Plano } \\
\text { Diretor de Transporte e da Mobilidade ou } \\
\text { outro instrumento referente à política de } \\
\text { mobilidade urbana }\end{array}$ \\
\hline
\end{tabular}

\section{c) Escore e Normalização}

\begin{tabular}{ccc}
\hline Cenário & Escore & Escore Normalizado \\
\hline 1980 & 0,50 & 0,50 \\
\hline 1991 & 0,50 & 0,50 \\
\hline 2001 & 0,50 & 0,50 \\
\hline 2011 & 0,50 & 0,50 \\
\hline
\end{tabular}




\begin{tabular}{|c|c|}
\hline Escore & $\begin{array}{l}\text { Valores de Referência } \\
\text { O município encontra-se no seguinte estágio } \\
\text { no ano de referência: }\end{array}$ \\
\hline 1,00 & $\begin{array}{l}\text { Fase de implantação e efetivação do Plano } \\
\text { Diretor de Transporte e da Mobilidade ou outro } \\
\text { instrumento referente à política de mobilidade } \\
\text { urbana }\end{array}$ \\
\hline 0,75 & $\begin{array}{l}\text { Fase de institucionalização do Plano Diretor de } \\
\text { Transporte e da Mobilidade ou outro } \\
\text { instrumento referente à política de mobilidade } \\
\text { urbana }\end{array}$ \\
\hline 0,50 & $\begin{array}{l}\text { Fase de desenvolvimento de estudos e } \\
\text { projetos relacionados à elaboração do Plano } \\
\text { Diretor de Transporte e da Mobilidade ou outro } \\
\text { instrumento referente à política de mobilidade } \\
\text { urbana }\end{array}$ \\
\hline 0,25 & $\begin{array}{l}\text { Fase de mobilização ou contratação de } \\
\text { consultoria especializada para elaboração do } \\
\text { Plano Diretor de Transporte e da Mobilidade } \\
\text { ou outro instrumento referente à política de } \\
\text { mobilidade urbana }\end{array}$ \\
\hline 0,00 & $\begin{array}{l}\text { O município não possui qualquer política ou } \\
\text { plano de mobilidade urbana em implantação } \\
\text { ou em desenvolvimento }\end{array}$ \\
\hline Domínio & 5. Infraestrutura de Transportes \\
\hline Tema & $\begin{array}{l}\text { 5.1. Provisão e manutenção da infraestrutura } \\
\text { de transportes }\end{array}$ \\
\hline Indicador & $\begin{array}{l}\text { 5.1.1. Densidade e conectividade da rede } \\
\text { viária }\end{array}$ \\
\hline Definição & $\begin{array}{l}\text { Densidade e conectividade da rede viária } \\
\text { urbana. }\end{array}$ \\
\hline
\end{tabular}

\section{a) Fontes de Dados}

\begin{tabular}{ll}
\hline 1980 & Informação não disponível. \\
\hline 1991 & Informação não disponível. \\
\hline 2001 & Informação não disponível. \\
\hline 2011 & Informação não disponível. \\
\hline
\end{tabular}

\section{b) Método de Cálculo}

\begin{tabular}{ll}
\hline 1980 & n/a \\
\hline 1991 & n/a \\
\hline 2001 & n/a \\
\hline 2011 & n/a \\
\hline
\end{tabular}

\section{c) Escore e Normalização}

\begin{tabular}{ccc}
\hline Cenário & Escore & Escore Normalizado \\
\hline 1980 & $\mathrm{n} / \mathrm{a}$ & $\mathrm{n} / \mathrm{a}$ \\
\hline 1991 & $\mathrm{n} / \mathrm{a}$ & $\mathrm{n} / \mathrm{a}$ \\
\hline 2001 & $\mathrm{n} / \mathrm{a}$ & $\mathrm{n} / \mathrm{a}$ \\
\hline 2011 & $\mathrm{n} / \mathrm{a}$ & $\mathrm{n} / \mathrm{a}$ \\
\hline
\end{tabular}

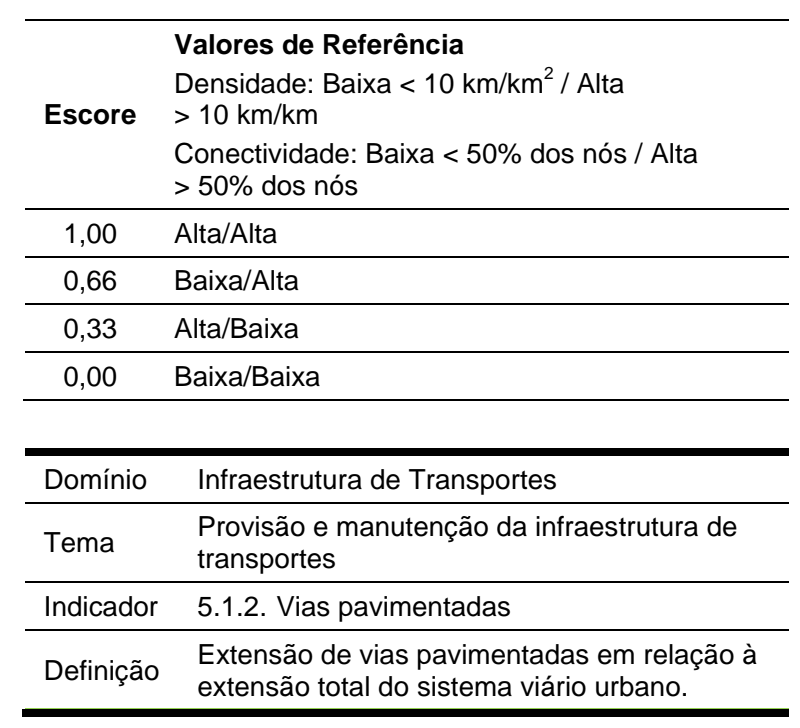

\section{a) Fontes de Dados}

\begin{tabular}{ll}
\hline 1980 & Informação não encontrada. \\
\hline 1991 & Relatório do PDTU (JICA, 1991). \\
\hline 2001 & Informações obtidas junto a técnicos locais \\
\hline 2011 & Informações obtidas junto a técnicos locais \\
\hline
\end{tabular}

\section{b) Método de Cálculo}

\begin{tabular}{cl}
\hline 1980 & n/a \\
\hline 1991 & $\begin{array}{l}\text { A informação que consta da página 55 do } \\
\text { relatório é de que } 200 \mathrm{~km}, \text { de um total de } 443 \\
\text { km de vias urbanas, estão pavimentadas. }\end{array}$ \\
\hline 2001 & $\begin{array}{l}\text { Foi considerado o mesmo percentual do cenário } \\
2011\end{array}$ \\
\hline 2011 & $\begin{array}{l}\text { A informação obtida junto aos órgãos locais } \\
\text { indica um valor de 68\% de vias pavimentadas }\end{array}$ \\
\hline
\end{tabular}

\section{c) Escore e Normalização}

\begin{tabular}{ccc}
\hline Cenário & Escore & Escore Normalizado \\
\hline 1980 & $\mathrm{n} / \mathrm{a}$ & $\mathrm{n} / \mathrm{a}$ \\
\hline 1991 & 45 & 0,39 \\
\hline 2001 & 68 & 0,64 \\
\hline 2011 & 68 & 0,64 \\
\hline
\end{tabular}

\begin{tabular}{ll}
\hline Escore & $\begin{array}{l}\text { Valores de Referência } \\
\text { Porcentagem do sistema viário urbano } \\
\text { pavimentado. }\end{array}$ \\
\hline 1,00 & $100 \%$ \\
\hline 0,75 & $77,5 \%$ \\
\hline 0,50 & $55 \%$ \\
\hline 0,25 & $32,5 \%$ \\
\hline 0,00 & Até $10 \%$ \\
\hline
\end{tabular}




\begin{tabular}{ll}
\hline Domínio & Infraestrutura de Transportes \\
\hline Tema & $\begin{array}{l}\text { Provisão e manutenção da infraestrutura de } \\
\text { transportes }\end{array}$ \\
\hline Indicador & $\begin{array}{l}\text { 5.1.3. Despesas com manutenção da } \\
\text { infraestrutura }\end{array}$ \\
\hline Definição & $\begin{array}{l}\text { Forma de aplicação dos recursos públicos na } \\
\text { manutenção e conservação da infraestrutura } \\
\text { para todos os modos de transportes. }\end{array}$ \\
\hline
\end{tabular}

a) Fontes de Dados

\begin{tabular}{ll}
\hline 1980 & $\begin{array}{l}\text { Relatórios dos estudos e planos (GEIPOT, } \\
1978,1979,1980,1986)\end{array}$ \\
\hline 1991 & Relatório do PDTU (JICA, 1991) \\
\hline 2001 & Relatório do PDTU (JICA, 2001) \\
\hline 2011 & Informação não disponível \\
\hline
\end{tabular}

\section{b) Método de Cálculo}

\begin{tabular}{ll}
\hline 1980 & $\begin{array}{l}\text { Informação não disponível nos documentos } \\
\text { consultados. }\end{array}$ \\
\hline 1991 & $\begin{array}{l}\text { Informação não disponível nos documentos } \\
\text { consultados. }\end{array}$ \\
\hline 2001 & $\begin{array}{l}\text { Informação não disponível nos documentos } \\
\text { consultados. }\end{array}$ \\
\hline 2011 & n/a \\
\hline
\end{tabular}

\section{c) Escore e Normalização}

\begin{tabular}{ccc}
\hline Cenário & Escore & Escore Normalizado \\
\hline 1980 & $\mathrm{n} / \mathrm{a}$ & $\mathrm{n} / \mathrm{a}$ \\
\hline 1991 & $\mathrm{n} / \mathrm{a}$ & $\mathrm{n} / \mathrm{a}$ \\
\hline 2001 & $\mathrm{n} / \mathrm{a}$ & $\mathrm{n} / \mathrm{a}$ \\
\hline 2011 & $\mathrm{n} / \mathrm{a}$ & $\mathrm{n} / \mathrm{a}$ \\
\hline
\end{tabular}

\section{Escore Valores de Referência}

As despesas com manutenção e conservação de infraestrutura de transportes contemplaram intervenções de caráter emergencial,

1,00 manutenção corretiva e preventiva das infraestruturas existentes, representando mais de $50 \%$ do total de recursos municipais investidos em sistemas de transportes e mobilidade no ano de referência

As despesas com manutenção e conservação de infraestrutura de transportes contemplaram intervenções de caráter emergencial,

0,75 manutenção corretiva e preventiva das infraestruturas existentes, representando aproximadamente $50 \%$ do total de recursos municipais investidos em sistemas de transportes e mobilidade no ano de referência

As despesas com manutenção e conservação de infraestrutura de transportes contemplaram intervenções de caráter emergencial,

0,50 manutenção corretiva e preventiva das infraestruturas existentes, porém, estas despesas representaram menos de $50 \%$ do total de recursos municipais investidos em sistemas de transportes e mobilidade no ano de referência As despesas com manutenção e conservação de

0,25 infraestrutura de transportes se limitaram a intervenções de caráter emergencial, representando menos de $50 \%$ do total de

\begin{tabular}{|c|c|}
\hline & $\begin{array}{l}\text { recursos municipais investidos em sistemas de } \\
\text { transportes e mobilidade no ano de referência }\end{array}$ \\
\hline 0,00 & $\begin{array}{l}\text { Não houve qualquer despesa com manutenção e } \\
\text { conservação da infraestrutura de transportes no } \\
\text { ano de referência no município }\end{array}$ \\
\hline Domínio & Infraestrutura de Transportes \\
\hline Tema & $\begin{array}{l}\text { Provisão e manutenção da infraestrutura de } \\
\text { transportes }\end{array}$ \\
\hline Indicador & 5.1.4. Sinalização Viária \\
\hline Definição & $\begin{array}{l}\text { Avaliação por parte da população sobre a } \\
\text { qualidade da sinalização viária implantada na } \\
\text { área urbana do município. }\end{array}$ \\
\hline
\end{tabular}

a) Fontes de Dados

\begin{tabular}{ll}
\hline 1980 & Informação não disponível. \\
\hline 1991 & Informação não disponível. \\
\hline 2001 & Informação não disponível. \\
\hline 2011 & Pesquisa feita pela equipe do ITEP/UFPA \\
\hline
\end{tabular}

b) Método de Cálculo

\begin{tabular}{ll}
\hline 1980 & n/a \\
\hline 1991 & n/a \\
\hline 2001 & n/a \\
\hline 2011 & $\begin{array}{l}\text { "Ruim" para os modos motorizados e não- } \\
\text { motorizados de transporte }\end{array}$ \\
\hline
\end{tabular}

c) Escore e Normalização

\begin{tabular}{clc}
\hline Cenário & Escore & Escore Normalizado \\
\hline 1980 & $\mathrm{n} / \mathrm{a}$ & $\mathrm{n} / \mathrm{a}$ \\
\hline 1991 & $\mathrm{n} / \mathrm{a}$ & $\mathrm{n} / \mathrm{a}$ \\
\hline 2001 & $\mathrm{n} / \mathrm{a}$ & $\mathrm{n} / \mathrm{a}$ \\
\hline 2011 & 0,00 & 0,00 \\
\hline & Valores de Referência \\
\hline Escore & $\begin{array}{l}\text { A maioria da população (ou dos entrevistados) } \\
\text { classifica a sinalização viária como: }\end{array}$ \\
\hline 1,00 & $\begin{array}{l}\text { "Excelente" para os modos motorizados e não- } \\
\text { motorizados de transporte }\end{array}$ \\
\hline 0,80 & $\begin{array}{l}\text { "Excelente" somente para os modos } \\
\text { motorizados de transporte }\end{array}$ \\
\hline 0,60 & $\begin{array}{l}\text { "Boa" para os modos motorizados e não- } \\
\text { motorizados de transporte }\end{array}$ \\
\hline 0,40 & $\begin{array}{l}\text { "Boa" somente para os modos motorizados de } \\
\text { transporte }\end{array}$ \\
\hline 0,20 & $\begin{array}{l}\text { "Ruim" somente para os modos motorizados de } \\
\text { transporte }\end{array}$ \\
\hline 0,00 & $\begin{array}{l}\text { "Ruim" para os modos motorizados e não- } \\
\text { motorizados de transporte }\end{array}$ \\
\hline
\end{tabular}




\begin{tabular}{|c|c|}
\hline Domínio & Infraestrutura de Transportes \\
\hline Tema & $\begin{array}{l}\text { 5.2. Distribuição da infraestrutura de } \\
\text { transportes }\end{array}$ \\
\hline Indicador & 5.2.1. Vias para transporte coletivo \\
\hline Definição & $\begin{array}{l}\text { Porcentagem da área urbana da cidade } \\
\text { atendida por vias exclusivas ou preferenciais } \\
\text { para transporte coletivo por ônibus. }\end{array}$ \\
\hline
\end{tabular}

\section{a) Fontes de Dados}

\begin{tabular}{ll}
\hline 1980 & $\begin{array}{l}\text { Relatórios dos estudos e planos (GEIPOT, 1978, } \\
1979,1980,1986)\end{array}$ \\
\hline 1991 & Relatório do PDTU (JICA, 1991) \\
\hline 2001 & Relatório Final do PDTU-RMB (JICA, 2001). \\
\hline 2011 & Consulta a técnicos locais \\
\hline
\end{tabular}

\section{b) Método de Cálculo}

\begin{tabular}{cl}
\hline 1980 & $\begin{array}{l}\text { Pela leitura dos relatórios, verifica-se que não } \\
\text { existiam vias exclusivas ou preferenciais para } \\
\text { ônibus. }\end{array}$ \\
\hline 1991 & $\begin{array}{l}\text { Pela leitura do relatório, verifica-se que não } \\
\text { existiam vias exclusivas ou preferenciais para } \\
\text { ônibus. }\end{array}$ \\
\hline 2001 & $\begin{array}{l}\text { Pela leitura do relatório, verifica-se que não } \\
\text { existiam vias exclusivas ou preferenciais para } \\
\text { ônibus. }\end{array}$ \\
\hline 2011 & $\begin{array}{l}\text { Belém ainda não conta com esse tipo de } \\
\text { infraestrutura }\end{array}$ \\
\hline
\end{tabular}

c) Escore e Normalização

\begin{tabular}{|c|c|c|}
\hline Cenário & Escore & Escore Normalizado \\
\hline 1980 & 0,00 & 0,00 \\
\hline 1991 & 0,00 & 0,00 \\
\hline 2001 & 0,00 & 0,00 \\
\hline 2011 & 0,00 & 0,00 \\
\hline Escore & \multicolumn{2}{|c|}{$\begin{array}{l}\text { Valores de Referência } \\
\text { Porcentagem da área urbana do município é } \\
\text { atendida por vias exclusivas ou preferenciais } \\
\text { para transporte coletivo por ônibus e linhas } \\
\text { alimentadoras integradas }\end{array}$} \\
\hline 1,00 & \multicolumn{2}{|l|}{$100 \%$} \\
\hline 0,75 & \multicolumn{2}{|l|}{$75 \%$} \\
\hline 0,50 & \multicolumn{2}{|l|}{$50 \%$} \\
\hline 0,25 & \multicolumn{2}{|l|}{$25 \%$} \\
\hline 0,00 & \multicolumn{2}{|l|}{0} \\
\hline Domínio & \multicolumn{2}{|c|}{ 6. Modos Não-motorizados } \\
\hline Tema & \multicolumn{2}{|c|}{ 6.1. Transporte cicloviário } \\
\hline Indicador & \multicolumn{2}{|c|}{ 6.1.1. Extensão e conectividade de ciclovias } \\
\hline Definição & \multicolumn{2}{|c|}{$\begin{array}{l}\text { Cobertura e conectividade da rede de vias } \\
\text { para bicicleta. }\end{array}$} \\
\hline
\end{tabular}

a) Fontes de Dados

\begin{tabular}{cl}
\hline 1980 & $\begin{array}{l}\text { Relatório do TRANSCOL-Ciclovia (GEIPOT, } \\
\text { 1979) }\end{array}$ \\
\hline 1991 & Relatório do PDTU (JICA, 1991) \\
\hline 2001 & $\begin{array}{l}\text { Mapa da rede cicloviária atual, disponível na } \\
\text { página 172 do Relatório Final do PDTU (JICA, } \\
\text { 2001) e arquivos geográficos do sistema viário } \\
\text { de Belém, presente no CD 1 do mesmo plano. }\end{array}$ \\
\hline 2011 & Levantamento feito pela equipe do ITEP/UFPA \\
\hline
\end{tabular}

\section{b) Método de Cálculo}

\begin{tabular}{ll}
\hline \multirow{2}{*}{1980} & $\begin{array}{l}\text { O relatório do projeto o coloca como pioneiro e } \\
\text { não faz referência a qualquer outra ciclovia } \\
\text { existente em Belém. Deduz-se que não havia } \\
\text { nenhum trecho de ciclovia. }\end{array}$ \\
O relatório do PDTU apresenta uma extensão \\
total de 443 km para o sistema viário e não trata \\
de ciclovias. Considerou-se que haveria uma \\
extensão pouco maior do que a ciclovia da BL- \\
01 (GEIPOT, 1979) com seus 6 km. Assim, \\
existia pelo menos uma ciclovia mas o \\
percentual era abaixo de 25\% da malha viária.
\end{tabular}

\section{c) Escore e Normalização}

\begin{tabular}{lcc}
\hline Cenário & Escore & Escore Normalizado \\
\hline 1980 & 0,00 & 0,00 \\
\hline 1991 & 0,25 & 0,25 \\
\hline 2001 & 0,25 & 0,25 \\
\hline 2011 & 0,25 & 0,25 \\
\hline
\end{tabular}

\begin{tabular}{cl}
\hline Escore & Valores de Referência \\
\hline 1,00 & $\begin{array}{l}\text { Mais de 25\% do sistema viário urbano } \\
\text { apresenta ciclovia ou ciclofaixas e a rede } \\
\text { apresenta alta conectividade }\end{array}$ \\
\hline 0,75 & $\begin{array}{l}\text { Mais de 25\% do sistema viário urbano } \\
\text { apresenta ciclovia ou ciclofaixas, porém, a rede } \\
\text { apresenta baixa conectividade }\end{array}$ \\
\hline 0,50 & $\begin{array}{l}\text { Até 25\% do sistema viário urbano apresenta } \\
\text { ciclovia ou ciclofaixas e a rede apresenta alta } \\
\text { conectividade }\end{array}$ \\
\hline 0,25 & $\begin{array}{l}\text { Até 25\% do sistema viário urbano apresenta } \\
\text { ciclovia ou ciclofaixas, porém, a rede apresenta } \\
\text { baixa conectividade }\end{array}$ \\
\hline 0,00 & $\begin{array}{l}\text { Não há no município nenhum trecho de ciclovia } \\
\text { ou ciclofaixa }\end{array}$ \\
\hline
\end{tabular}




\begin{tabular}{ll}
\hline Domínio & Modos Não-motorizados \\
\hline Tema & Transporte cicloviário \\
\hline Indicador & 6.1.2. Frota de bicicletas \\
\hline Definição & $\begin{array}{l}\text { Número de bicicletas por } 100 \text { habitantes no } \\
\text { município. }\end{array}$ \\
\hline
\end{tabular}

\section{a) Fontes de Dados}

\begin{tabular}{ll}
\hline 1980 & Informação não encontrada. \\
\hline 1991 & Informação não encontrada. \\
\hline 2001 & $\begin{array}{l}\text { Dados não disponíveis relatório do PDTU (JICA, } \\
\text { 2001). Alguma informação encontrada no } \\
\text { trabalho de Tobias e Peixeira (2005). }\end{array}$ \\
\hline 2011 & Informação não encontrada. \\
\hline
\end{tabular}

\section{b) Método de Cálculo}

\begin{tabular}{ll}
\hline 1980 & n/a \\
\hline 1991 & n/a \\
\hline \multirow{2}{2001}{} & $\begin{array}{l}\text { Segundo estimativa de Tobias e Peixeira (2005), } \\
\text { a frota de bicicletas de Belém era de 249.307, } \\
\text { em 2000, o que resulta em uma taxa de 20 } \\
\text { bicicletas por 100 habitantes. }\end{array}$ \\
\hline 2011 & n/a \\
\hline
\end{tabular}

c) Escore e Normalização

\begin{tabular}{ccc}
\hline Cenário & Escore & Escore Normalizado \\
\hline 1980 & $\mathrm{n} / \mathrm{a}$ & $\mathrm{n} / \mathrm{a}$ \\
\hline 1991 & $\mathrm{n} / \mathrm{a}$ & $\mathrm{n} / \mathrm{a}$ \\
\hline 2001 & 20 & 0,25 \\
\hline 2011 & $\mathrm{n} / \mathrm{a}$ & $\mathrm{n} / \mathrm{a}$ \\
\hline
\end{tabular}

\begin{tabular}{|c|c|}
\hline Escore & $\begin{array}{l}\text { Valores de Referência } \\
\text { Número de bicicletas por } 100 \text { habitantes do } \\
\text { município }\end{array}$ \\
\hline 1,00 & 35 ou mais \\
\hline 0,75 & 30 \\
\hline 0,50 & 25 \\
\hline 0,25 & 20 \\
\hline 0,00 & Até 15 \\
\hline Domínio & Modos Não-motorizados \\
\hline Tema & Transporte cicloviário \\
\hline Indicador & 6.1.3. Estacionamento de bicicletas \\
\hline Definição & $\begin{array}{l}\text { Porcentagem dos terminais de transporte } \\
\text { público urbano que possuem estacionamento } \\
\text { para bicicletas. }\end{array}$ \\
\hline
\end{tabular}

\section{a) Fontes de Dados}

\begin{tabular}{ll}
\hline 1980 & $\begin{array}{l}\text { Relatórios dos estudos e planos (GEIPOT, 1978, } \\
1979,1980,1986) .\end{array}$ \\
\hline 1991 & Relatório do PDTU (JICA, 1991). \\
\hline 2001 & Relatório Final do PDTU (JICA, 2001). \\
\hline 2011 & Observação local. \\
\hline
\end{tabular}

b) Método de Cálculo

\begin{tabular}{cl}
\hline 1980 & $\begin{array}{l}\text { A cidade, praticamente, não dispunha de } \\
\text { terminais de transporte público e não se verificou } \\
\text { a existência de estacionamento para bicicletas. }\end{array}$ \\
\hline 1991 & $\begin{array}{l}\text { A cidade, praticamente, não dispunha de } \\
\text { terminais de transporte público e não se verificou } \\
\text { a existência de estacionamento para bicicletas. }\end{array}$ \\
\hline 2001 & $\begin{array}{l}\text { No capítulo que trata das recomendações para o } \\
\text { sistema cicloviário, destaca-se a quase total falta } \\
\text { de infraestrutura de apoio ao ciclista, incluindo } \\
\text { facilidades para estacionamento das bicicletas. } \\
\text { Deduziu-se daí que nenhum dos terminais } \\
\text { possui estacionamento. }\end{array}$ \\
\hline 2011 & Belém não possui terminais de integração \\
\hline
\end{tabular}

c) Escore e Normalização

\begin{tabular}{ccc}
\hline Cenário & Escore & Escore Normalizado \\
\hline 1980 & 0,00 & 0,00 \\
\hline 1991 & 0,00 & 0,00 \\
\hline 2001 & 0,00 & 0,00 \\
\hline 2011 & 0,00 & 0,00 \\
\hline
\end{tabular}

\begin{tabular}{ll}
\hline Escore & $\begin{array}{l}\text { Valores de Referência } \\
\text { Porcentagem dos terminais urbanos de } \\
\text { transporte público que apresentam área para } \\
\text { estacionamento de bicicletas }\end{array}$ \\
\hline 1,00 & $100 \%$ \\
\hline 0,75 & $75 \%$ \\
\hline 0,50 & $50 \%$ \\
\hline 0,25 & $25 \%$ \\
\hline 0,00 & 0 \\
\hline \multicolumn{2}{c}{} \\
\hline Domínio & Modos Não-motorizados \\
\hline Tema & 6.2. Modos não-motorizados \\
\hline Indicador & 6.2.1. Vias para pedestres \\
\hline Definição & $\begin{array}{l}\text { Cobertura e conectividade da rede de vias } \\
\text { para pedestres. }\end{array}$ \\
\hline
\end{tabular}

\section{a) Fontes de Dados}

\begin{tabular}{cl}
\hline 1980 & $\begin{array}{l}\text { Relatórios dos estudos e planos (GEIPOT, 1978, } \\
1979,1980,1986) .\end{array}$ \\
\hline 1991 & Relatório do PDTU (JICA, 1991). \\
\hline 2001 & Relatório do PDTU (JICA, 2001). \\
\hline 2011 & $\begin{array}{l}\text { Levantamentos de campo feito pelo pessoal do } \\
\text { ITEP/UFPA }\end{array}$ \\
\hline
\end{tabular}

\section{b) Método de Cálculo}

\begin{tabular}{|c|c|}
\hline 1980 & $\begin{array}{l}\text { O RII-RMB (GEIPOT, 1978) cita algumas áreas } \\
\text { reservadas, em alguns horários, para a } \\
\text { circulação exclusiva de pedestres e recomenda } \\
\text { que a dimensão desse tipo de uso seja } \\
\text { ampliada. Considera-se aqui que essas área } \\
\text { representavam um percentual muito baixo do } \\
\text { total do sistema viário e, portanto, foi } \\
\text { considerado escore } 0 .\end{array}$ \\
\hline 1991 & $\begin{array}{l}\text { No relatório do PDTU, pouco se trata do } \\
\text { transporte não motorizado e não aparecem } \\
\text { referências a áreas exclusivas para pedestres. }\end{array}$ \\
\hline
\end{tabular}




\begin{tabular}{ll}
\hline Considerou-se aqui que essas áreas \\
continuavam a representar muito pouco em \\
relação ao sistema viário total, atribuindo-se o \\
escore 0.
\end{tabular}

c) Escore e Normalização

\begin{tabular}{|c|c|c|}
\hline Cenário & Escore & Escore Normalizado \\
\hline 1980 & 0,00 & 0,00 \\
\hline 1991 & 0,00 & 0,00 \\
\hline 2001 & 0,00 & 0,00 \\
\hline 2011 & 0,00 & 0,00 \\
\hline Escore & \multicolumn{2}{|c|}{ Valores de Referência } \\
\hline 1,00 & \multicolumn{2}{|c|}{$\begin{array}{l}\text { Mais de } 25 \% \text { do sistema viário urbano é } \\
\text { composto por vias especiais ou preferenciais } \\
\text { para pedestres e a rede apresenta alta } \\
\text { conectividade }\end{array}$} \\
\hline 0,75 & \multicolumn{2}{|c|}{$\begin{array}{l}\text { Mais de } 25 \% \text { do sistema viário urbano é } \\
\text { composto por vias especiais ou preferenciais } \\
\text { para pedestres, porém, a rede apresenta baixa } \\
\text { conectividade }\end{array}$} \\
\hline 0,50 & \multicolumn{2}{|c|}{$\begin{array}{l}\text { Até } 25 \% \text { do sistema viário urbano é composto } \\
\text { por vias especiais ou preferenciais para } \\
\text { pedestres e a rede apresenta alta conectividade }\end{array}$} \\
\hline 0,25 & \multicolumn{2}{|c|}{$\begin{array}{l}\text { Até } 25 \% \text { do sistema viário urbano é composto } \\
\text { por vias especiais ou preferenciais para } \\
\text { pedestres, porém, a rede apresenta baixa } \\
\text { conectividade }\end{array}$} \\
\hline 0,00 & \multicolumn{2}{|c|}{$\begin{array}{l}\text { Não há no município vias especiais ou } \\
\text { preferenciais para pedestres }\end{array}$} \\
\hline Domínio & \multicolumn{2}{|c|}{ Modos Não-motorizados } \\
\hline Tema & \multicolumn{2}{|c|}{ Modos não-motorizados } \\
\hline Indicador & \multicolumn{2}{|c|}{ 6.2.2. Vias com calçadas } \\
\hline Definição & \multicolumn{2}{|c|}{$\begin{array}{l}\text { Extensão de vias com calçadas em ambos os } \\
\text { lados, com largura superior a 1,20 metros, em } \\
\text { relação à extensão total da rede viária } \\
\text { principal. }\end{array}$} \\
\hline
\end{tabular}

\section{a) Fontes de Dados}

\begin{tabular}{cl}
\hline 1980 & $\begin{array}{l}\text { Relatórios dos estudos e planos (GEIPOT, 1978, } \\
1979,1980,1986) .\end{array}$ \\
\hline 1991 & Relatório do PDTU (JICA, 1991). \\
\hline 2001 & Relatório do PDTU (JICA, 2001). \\
\hline 2011 & $\begin{array}{l}\text { Levantamentos de campo feitos pelo pessoal do } \\
\text { ITEP/UFPA em uma amostra das vias do } \\
\text { sistema viário principal. }\end{array}$ \\
\hline
\end{tabular}

\section{b) Método de Cálculo}

\begin{tabular}{ll}
\hline 1980 & $\begin{array}{l}\text { Informação não encontrada no relatório ou outra } \\
\text { fonte. }\end{array}$ \\
\hline 1991 & $\begin{array}{l}\text { Informação não encontrada no relatório ou outra } \\
\text { fonte. }\end{array}$ \\
\hline
\end{tabular}

\begin{tabular}{ll}
\hline 2001 & $\begin{array}{l}\text { Considerando os dados do Anexo G relatório } \\
\text { (JICA, 2001) pode-se estimar que mais de 70\% } \\
\text { das vias do sistema principal possuíam calçadas } \\
\text { com 1,2 m ou mais. }\end{array}$ \\
\hline $2011 \quad$ Levantou-se o valor de 68\%. \\
\hline
\end{tabular}

c) Escore e Normalização

\begin{tabular}{ccc}
\hline Cenário & Escore & Escore Normalizado \\
\hline 1980 & $\mathrm{n} / \mathrm{a}$ & $\mathrm{n} / \mathrm{a}$ \\
\hline 1991 & $\mathrm{n} / \mathrm{a}$ & $\mathrm{n} / \mathrm{a}$ \\
\hline 2001 & 70 & 0,67 \\
\hline 2011 & 68 & 0,65 \\
\hline
\end{tabular}

\begin{tabular}{cl}
\hline Escore & $\begin{array}{l}\text { Valores de Referência } \\
\text { Porcentagem da rede viária principal que } \\
\text { apresenta calçadas em ambos os lados e com } \\
\text { largura igual ou superior a 1,20 metros }\end{array}$ \\
\hline 1,00 & $100 \%$ \\
\hline 0,75 & $77,5 \%$ \\
\hline 0,50 & $55 \%$ \\
\hline 0,25 & $32,5 \%$ \\
\hline 0,00 & Até $10 \%$ \\
\hline
\end{tabular}

\begin{tabular}{ll}
\hline Domínio & Modos não-motorizados \\
\hline Tema & 6.3. Redução de viagens \\
\hline Indicador & 6.3.1. Distância de viagem \\
\hline Definição & $\begin{array}{l}\text { Distância média de viagens feitas na área } \\
\text { urbana ou metropolitana, para todos os } \\
\text { modos, em um único sentido, por motivo } \\
\text { trabalho ou estudo. }\end{array}$ \\
\hline
\end{tabular}

\section{a) Fontes de Dados}

\begin{tabular}{ll}
\hline 1980 & $\begin{array}{l}\text { Relatórios dos estudos e planos (GEIPOT, 1978, } \\
1979,1980,1986) .\end{array}$ \\
\hline 1991 & Relatório do PDTU (JICA, 1991) \\
\hline 2001 & Relatório do PDTU (JICA, 2001) \\
\hline 2011 & Informação não disponível \\
\hline
\end{tabular}

\section{b) Método de Cálculo}

\begin{tabular}{ll}
\hline 1980 & $\begin{array}{l}\text { Informação não encontrada nos documentos } \\
\text { consultados. }\end{array}$ \\
\hline 1991 & $\begin{array}{l}\text { No item } 9.5 .2, \text { página } 225, \text { do relatório, se } \\
\text { apresenta o valor médio de } 9,13 \mathrm{~km} .\end{array}$ \\
\hline 2001 & $\mathrm{n} / \mathrm{a}$ \\
\hline 2011 & $\mathrm{n} / \mathrm{a}$ \\
\hline
\end{tabular}

\section{c) Escore e Normalização}

\begin{tabular}{ccc}
\hline Cenário & Escore & Escore Normalizado \\
\hline 1980 & $\mathrm{n} / \mathrm{a}$ & $\mathrm{n} / \mathrm{a}$ \\
\hline 1991 & 9,13 & 0,11 \\
\hline 2001 & $\mathrm{n} / \mathrm{a}$ & $\mathrm{n} / \mathrm{a}$ \\
\hline 2011 & $\mathrm{n} / \mathrm{a}$ & $\mathrm{n} / \mathrm{a}$ \\
\hline
\end{tabular}




\begin{tabular}{cl}
\hline Escore & $\begin{array}{l}\text { Valores de Referência } \\
\text { Distância média das viagens urbanas e } \\
\text { metropolitanas, para todos os modos, em um } \\
\text { único sentido, por motivo trabalho ou estudo }\end{array}$ \\
\hline 1,00 & Igual ou inferior a $2 \mathrm{~km}$ \\
\hline 0,75 & $4 \mathrm{~km}$ \\
\hline 0,50 & $6 \mathrm{~km}$ \\
\hline 0,25 & $8 \mathrm{~km}$ \\
\hline 0,00 & Maior ou igual a 10 km \\
\hline Domínio & Modos Não-motorizados \\
\hline Tema & Redução de Viagem \\
\hline Indicador & 6.3.2. Tempo de Viagem \\
\hline & $\begin{array}{l}\text { Tempo médio de viagens feitas na área } \\
\text { urbana ou metropolitana, para todos os } \\
\text { modos, em um único sentido, por motivo } \\
\text { trabalho ou estudo }\end{array}$ \\
\hline
\end{tabular}

a) Fontes de Dados

\begin{tabular}{ll}
\hline 1980 & $\begin{array}{l}\text { Relatórios dos estudos e planos (GEIPOT, 1978, } \\
1979,1980,1986) .\end{array}$ \\
\hline 1991 & Relatório do PDTU (JICA, 1991). \\
\hline 2001 & Relatório do PDTU (JICA, 2001). \\
\hline 2011 & Informação não disponível \\
\hline
\end{tabular}

\section{b) Método de Cálculo}

\begin{tabular}{|c|c|}
\hline 1980 & $\begin{array}{l}\text { Essa informação não consta nos relatórios } \\
\text { consultados. }\end{array}$ \\
\hline \multirow{7}{*}{1991} & $\begin{array}{l}\text { - Tempo médio de viagem do modo automóvel: } \\
27 \text { min. (pag. 150) }\end{array}$ \\
\hline & $\begin{array}{l}\text { - Número de viagens por automóvel: 14\% (pag. } \\
\text { 136, veículo privado + táxi) }\end{array}$ \\
\hline & $\begin{array}{l}\text { - Tempo médio de viagem do modo ônibus: } 37 \\
\text { min. (pag. 150) }\end{array}$ \\
\hline & $\begin{array}{l}\text { - Percentual de viagens por ônibus: } 53,5 \% \\
\text { (pag. 136) }\end{array}$ \\
\hline & $\begin{array}{l}\text { - Tempo médio de viagem do modo a pé e } \\
\text { bicicleta: } 15 \text { min. (pag. 150) }\end{array}$ \\
\hline & $\begin{array}{l}\text { - Percentual de viagens a pé ou por bicicleta: } \\
29,3 \% \text { (pag. 136) }\end{array}$ \\
\hline & $\begin{array}{l}\text { - } \text { Tempo médio }=(27 \times 14+37 \times 53,5+ \\
\left.15^{\star} 29,3\right) /(14+53,5+29,3)=28,9 \text { minutos }\end{array}$ \\
\hline 2001 & $\begin{array}{l}\text { Essa informação não consta nos relatórios } \\
\text { consultados. }\end{array}$ \\
\hline 2011 & $\mathrm{n} / \mathrm{a}$ \\
\hline
\end{tabular}

c) Escore e Normalização

\begin{tabular}{ccc}
\hline Cenário & Escore & Escore Normalizado \\
\hline 1980 & $\mathrm{n} / \mathrm{a}$ & $\mathrm{n} / \mathrm{a}$ \\
\hline 1991 & 28,9 & 0,78 \\
\hline 2001 & $\mathrm{n} / \mathrm{a}$ & $\mathrm{n} / \mathrm{a}$ \\
\hline 2011 & $\mathrm{n} / \mathrm{a}$ & $\mathrm{n} / \mathrm{a}$ \\
\hline
\end{tabular}

\begin{tabular}{cl}
\hline Escore & $\begin{array}{l}\text { Valores de Referência } \\
\text { Tempo médio de viagem para deslocamentos } \\
\text { urbanos e metropolitanos, por motivo trabalho e } \\
\text { estudo, para todos os modos de transporte }\end{array}$ \\
\hline 1,00 & Igual ou inferior a 20 min \\
\hline 0,75 & 30 min \\
\hline 0,50 & 40 min \\
\hline 0,25 & 50 min \\
\hline 0,00 & 60 min ou mais \\
\hline Domínio & Modos Não-motorizados \\
\hline Tema & Redução de viagens \\
\hline Indicador & 6.3.3. Número de viagens \\
\hline Definição & $\begin{array}{l}\text { Número médio de viagens diárias por } \\
\text { habitante em área urbana ou metropolitana, } \\
\text { considerando todos os modos de transporte. }\end{array}$ \\
\hline
\end{tabular}

\section{a) Fontes de Dados}

\begin{tabular}{ll}
\hline 1980 & $\begin{array}{l}\text { Relatórios dos estudos e planos (GEIPOT, 1978, } \\
1979,1980,1986) .\end{array}$ \\
\hline 1991 & Relatório do PDTU (JICA, 1991). \\
\hline & $\begin{array}{l}\text { Resultado da pesquisa de Origem-Destino, } \\
\text { realizada para o PDTU-RMB (JICA, 2001), } \\
\text { arquivos "PD-DADOS DO DOMICILIO.xIs", "PD- } \\
\text { DESLOCAMENTOS 1.xIs" e "PD- } \\
\\
\text { DESLOCAMENTOS 2.xIs". }\end{array}$ \\
\hline 2011 & \\
\hline
\end{tabular}

\section{b) Método de Cálculo}

\begin{tabular}{|c|c|}
\hline 1980 & $\begin{array}{l}\text { No Quadro E.6-1, da página } 64 \text { do relatório do } \\
\text { TRANSCOL (GEIPOT, 1980) apresenta-se um } \\
\text { total de } 1.169 .790 \text { viagens por todos os modos, } \\
\text { para uma população de } 929.111 \text { habitantes. Isto } \\
\text { leva a uma média de } 1,26 \text { viagens por habitante. }\end{array}$ \\
\hline 1991 & $\begin{array}{l}\text { Na Tabela } 7.2-1 \text {, página } 137 \text {, do relatório } \\
\text { encontra-se o número médio de viagens } \\
\text { classificado pelas diferentes faixas etárias da } \\
\text { população. O valor médio é de } 2,25 \text { viagens por } \\
\text { habitante. }\end{array}$ \\
\hline 2001 & $\begin{array}{l}\text { - Levantamento do número total de viagens } \\
\text { pesquisadas para um dia útil: } 68424 \text {; } \\
\text { - Levantamento do número total de habitantes } \\
\text { pesquisados: } 33325 \text {. }\end{array}$ \\
\hline 2011 & $\mathrm{n} / \mathrm{a}$ \\
\hline
\end{tabular}

c) Escore e Normalização

\begin{tabular}{ccc}
\hline Cenário & Escore & Escore Normalizado \\
\hline 1980 & 1,26 & 0,63 \\
\hline 1991 & 2,25 & 1,00 \\
\hline 2001 & 2,05 & 1,00 \\
\hline 2011 & $\mathrm{n} / \mathrm{a}$ & $\mathrm{n} / \mathrm{a}$ \\
\hline
\end{tabular}




\begin{tabular}{|c|c|}
\hline Escore & $\begin{array}{l}\text { Valores de Referência } \\
\text { Número médio de viagens diárias por habitante }\end{array}$ \\
\hline 1,00 & 2 ou mais \\
\hline 0,75 & 1,5 \\
\hline 0,50 & 1,0 \\
\hline 0,25 & 0,5 \\
\hline 0,00 & Inferior a 0,5 \\
\hline Domínio & Modos Não-motorizados \\
\hline Tema & Redução de viagens \\
\hline Indicador & $\begin{array}{l}\text { 6.3.4. Ações para reduções do tráfego } \\
\text { motorizado }\end{array}$ \\
\hline Definição & $\begin{array}{l}\text { Políticas, estratégias ou ações empreendidas } \\
\text { pelo município com objetivo de reduzir o } \\
\text { tráfego motorizado. }\end{array}$ \\
\hline
\end{tabular}

a) Fontes de Dados

\begin{tabular}{ll}
\hline 1980 & $\begin{array}{l}\text { Relatórios dos estudos do GEIPOT (1978, 1979, } \\
1980,1986) .\end{array}$ \\
\hline 1991 & Relatório Final do PDTU (JICA, 1991). \\
\hline 2001 & Relatório Final do PDTU (JICA, 2001). \\
\hline 2011 & $\begin{array}{l}\text { Estudo Preparatório para o Projeto de Sistema } \\
\text { de Transporte de Ônibus da Região } \\
\text { Metropolitana de Belém (JICA, 2010). }\end{array}$ \\
\hline
\end{tabular}

b) Método de Cálculo

\begin{tabular}{cl}
\hline 1980 & $\begin{array}{l}\text { Não foi desenvolvido ou implantado nenhum } \\
\text { mecanismo visando a redução do tráfego } \\
\text { motorizado no município no ano de referência }\end{array}$ \\
\hline 1991 & $\begin{array}{l}\text { Não foi desenvolvido ou implantado nenhum } \\
\text { mecanismo visando a redução do tráfego } \\
\text { motorizado no município no ano de referência }\end{array}$ \\
\hline 2001 & $\begin{array}{l}\text { Não foi desenvolvido ou implantado nenhum } \\
\text { mecanismo visando a redução do tráfego } \\
\text { motorizado no município no ano de referência }\end{array}$ \\
\hline 2011 & $\begin{array}{l}\text { Não foi desenvolvido ou implantado nenhum } \\
\text { mecanismo visando a redução do tráfego } \\
\text { motorizado no município no ano de referência }\end{array}$ \\
\hline
\end{tabular}

\section{c) Escore e Normalização}

\begin{tabular}{ccc}
\hline Cenário & Escore & Escore Normalizado \\
\hline 1980 & 0,00 & 0,00 \\
\hline 1991 & 0,00 & 0,00 \\
\hline 2001 & 0,00 & 0,00 \\
\hline 2011 & 0,00 & 0,00 \\
\hline & \\
\hline Escore & $\begin{array}{l}\text { Valores de Referência } \\
\text { Foram implantados no município: }\end{array}$ \\
\hline 1,00 & $\begin{array}{l}\text { Campanha educativa, rodízio veicular, } \\
\text { delimitação de áreas com restrição para } \\
\text { circulação de veículos e pedágio urbano }\end{array}$ \\
\hline 0,75 & $\begin{array}{l}\text { Campanha educativa, rodízio veicular e } \\
\text { delimitação de áreas com restrição para } \\
\text { circulação de veículos }\end{array}$ \\
\hline 0,50 & Campanha educativa e rodízio veicular \\
\hline 0,25 & Apenas campanha educativa \\
\hline
\end{tabular}

\begin{tabular}{ll}
\hline 0,00 & $\begin{array}{l}\text { Não foi desenvolvido ou implantado nenhum } \\
\text { mecanismo visando a redução do tráfego } \\
\text { motorizado no município no ano de referência }\end{array}$ \\
\hline Domínio & 7. Planejamento Integrado \\
\hline Tema & 7.1. Capacitação de gestores \\
\hline Indicador & $\begin{array}{l}\text { 7.1.1. Nível de formação de técnicos e } \\
\text { gestores }\end{array}$ \\
\hline Definição & $\begin{array}{l}\text { Porcentagem de técnicos e gestores de } \\
\text { órgãos de planejamento urbano, transportes e } \\
\text { mobilidade com qualificação superior, do total } \\
\text { de trabalhadores destes órgãos no ano de } \\
\text { referência. }\end{array}$ \\
\hline
\end{tabular}

\section{a) Fontes de Dados}

\begin{tabular}{ll}
\hline 1980 & Informações não disponíveis \\
\hline 1991 & Informações não disponíveis \\
\hline 2001 & Informações não disponíveis \\
\hline 2011 & Informações não disponíveis \\
\hline
\end{tabular}

\section{b) Método de Cálculo}

\begin{tabular}{ll}
\hline 1980 & n/a \\
\hline 1991 & n/a \\
\hline 2001 & n/a \\
\hline 2011 & n/a \\
\hline
\end{tabular}

\section{c) Escore e Normalização}

\begin{tabular}{ccc}
\hline Cenário & Escore & Escore Normalizado \\
\hline 1980 & $\mathrm{n} / \mathrm{a}$ & $\mathrm{n} / \mathrm{a}$ \\
\hline 1991 & $\mathrm{n} / \mathrm{a}$ & $\mathrm{n} / \mathrm{a}$ \\
\hline 2001 & $\mathrm{n} / \mathrm{a}$ & $\mathrm{n} / \mathrm{a}$ \\
\hline 2011 & $\mathrm{n} / \mathrm{a}$ & $\mathrm{n} / \mathrm{a}$ \\
\hline
\end{tabular}

\begin{tabular}{cl}
\hline Escore & $\begin{array}{l}\text { Valores de Referência } \\
\text { Porcentagem dos técnicos e gestores de } \\
\text { órgãos de planejamento urbano, transportes } \\
\text { e mobilidade, no ano de referência, que } \\
\text { possuem qualificação superior }\end{array}$ \\
\hline 1,00 & $25 \%$ ou mais \\
\hline 0,75 & $20 \%$ \\
\hline 0,50 & $15 \%$ \\
\hline 0,25 & $10 \%$ \\
\hline 0,00 & Até 5\% \\
\hline Domínio & Planejamento Integrado \\
\hline Tema & Capacitação de gestores \\
\hline Indicador & \begin{tabular}{l} 
7.1.2. Capacitação de técnicos e gestores \\
\hline Número de horas de treinamento e \\
capacitação oferecidas por técnico e gestor \\
das áreas de planejamento urbano, \\
transportes e mobilidade durante o ano de \\
referência.
\end{tabular} \\
\hline
\end{tabular}


a) Fontes de Dados

\begin{tabular}{ll}
\hline \multirow{2}{*}{1980} & $\begin{array}{l}\text { Em 1979, o GEIPOT realizou em Belém um } \\
\text { "Curso de Especialização em Transportes } \\
\text { Urbanos" do qual participaram técnicos de } \\
\text { órgão municipais e estaduais ligados à área } \\
\text { de mobilidade. }\end{array}$ \\
\hline 1991 & Informações não disponíveis. \\
\hline 2001 & Informações não disponíveis. \\
\hline 2011 & Informações não disponíveis. \\
\hline
\end{tabular}

\section{b) Método de Cálculo}

\begin{tabular}{ll}
\hline 1980 & $\begin{array}{l}\text { Não se encontrou informação precisa sobre a } \\
\text { carga horária, mas esta foi, certamente, muito } \\
\text { superior a } 40 \text { horas. }\end{array}$ \\
\hline 1991 & $\mathrm{n} / \mathrm{a}$ \\
\hline 2001 & $\mathrm{n} / \mathrm{a}$ \\
\hline 2011 & $\mathrm{n} / \mathrm{a}$ \\
\hline
\end{tabular}

\section{c) Escore e Normalização}

\begin{tabular}{ccc}
\hline Cenário & Escore & Escore Normalizado \\
\hline 1980 & 240 & 1,00 \\
\hline 1991 & $\mathrm{n} / \mathrm{a}$ & $\mathrm{n} / \mathrm{a}$ \\
\hline 2001 & $\mathrm{n} / \mathrm{a}$ & $\mathrm{n} / \mathrm{a}$ \\
\hline 2011 & $\mathrm{n} / \mathrm{a}$ & $\mathrm{n} / \mathrm{a}$ \\
\hline
\end{tabular}

\begin{tabular}{|c|c|}
\hline & Valores de Referência \\
\hline Escore & $\begin{array}{l}\text { Horas/funcionário/ano de cursos e treinamentos } \\
\text { oferecidos a técnicos e gestores das áreas de } \\
\text { planejamento urbano, transportes e mobilidade } \\
\text { no ano de referência }\end{array}$ \\
\hline 1,00 & 40 horas ou mais \\
\hline 0,75 & 32 horas \\
\hline 0,50 & 24 horas \\
\hline 0,25 & 16 horas \\
\hline 0,00 & 8 horas ou menos \\
\hline Domínio & Planejamento Integrado \\
\hline Tema & 7.2. Áreas centrais e de interesse histórico \\
\hline Indicador & 7.2.1. Vitalidade do centro \\
\hline Definição & $\begin{array}{l}\text { Medida da vitalidade do centro da cidade em } \\
\text { dois momentos distintos, baseada no número } \\
\text { de residentes e no número de empregos nos } \\
\text { setores de comércio e serviços localizados na } \\
\text { área. }\end{array}$ \\
\hline
\end{tabular}

\section{a) Fontes de Dados}

\begin{tabular}{ll}
\hline 1980 & Informações não disponíveis. \\
\hline 1991 & Informações não disponíveis. \\
\hline 2001 & Informações não disponíveis. \\
\hline 2011 & Informações não disponíveis. \\
\hline
\end{tabular}

b) Método de Cálculo

\begin{tabular}{ll}
\hline 1980 & n/a \\
\hline 1991 & n/a \\
\hline 2001 & n/a \\
\hline 2011 & n/a \\
\hline
\end{tabular}

c) Escore e Normalização

\begin{tabular}{ccc}
\hline Cenário & Escore & Escore Normalizado \\
\hline 1980 & $\mathrm{n} / \mathrm{a}$ & $\mathrm{n} / \mathrm{a}$ \\
\hline 1991 & $\mathrm{n} / \mathrm{a}$ & $\mathrm{n} / \mathrm{a}$ \\
\hline 2001 & $\mathrm{n} / \mathrm{a}$ & $\mathrm{n} / \mathrm{a}$ \\
\hline 2011 & $\mathrm{n} / \mathrm{a}$ & $\mathrm{n} / \mathrm{a}$ \\
\hline
\end{tabular}

\section{Escore Valores de Referência}

\begin{tabular}{|c|c|}
\hline Escore & Valores de Referência \\
\hline 1,00 & $\begin{array}{l}\text { I > 1,50 O centro apresenta forte tendência de } \\
\text { crescimento do número de domicílios } \\
\text { particulares e empregos nos setores de } \\
\text { comércio e serviços, e forte equilíbrio entre as } \\
\text { atividades diurnas e noturnas }\end{array}$ \\
\hline 0,75 & $\begin{array}{l}\text { I = 1,50 O centro apresenta tendência de } \\
\text { crescimento do número de domicílios } \\
\text { particulares e empregos nos setores de } \\
\text { comércio e serviços, e equilíbrio entre as } \\
\text { atividades diurnas e noturnas }\end{array}$ \\
\hline 0,50 & $\begin{array}{l}\text { I = 1,00 O centro apresenta tendência de } \\
\text { estabilidade com manutenção do número de } \\
\text { domicílios particulares e empregos nos setores } \\
\text { de comércio e serviços, e equilíbrio entre as } \\
\text { atividades diurnas e noturnas }\end{array}$ \\
\hline 0,25 & $\begin{array}{l}\text { I = 0,50 O centro da cidade apresenta } \\
\text { tendência de esvaziamento, com declínio do } \\
\text { número de domicílios particulares e empregos } \\
\text { nos setores de comércio e serviços, e } \\
\text { desequilíbrio entre as atividades diurnas e } \\
\text { noturnas }\end{array}$ \\
\hline 0,00 & $\begin{array}{l}\text { I }<0,50 \text { O centro da cidade apresenta forte } \\
\text { tendência de esvaziamento, com declínio } \\
\text { acentuado do número de domicílios } \\
\text { particulares e empregos nos setores de } \\
\text { comércio e serviços, e forte desequilíbrio entre } \\
\text { as atividades diurnas e noturnas }\end{array}$ \\
\hline
\end{tabular}

\begin{tabular}{ll}
\hline Domínio & Planejamento Integrado \\
\hline Tema & 7.3. Integração regional \\
\hline Indicador & 7.3.1. Consórcios intermunicipais \\
\hline \multirow{2}{*}{ Definição } & $\begin{array}{l}\text { Existência de consórcios públicos } \\
\text { intermunicipais para provisão de infraestrutura } \\
\text { e serviços de transportes urbano e } \\
\text { metropolitano. }\end{array}$ \\
\hline
\end{tabular}

\section{a) Fontes de Dados}

\begin{tabular}{ll}
\hline 1980 & $\begin{array}{l}\text { Legislação disponível nos sítios da Prefeitura de } \\
\text { Belém na Internet. }\end{array}$ \\
\hline 1991 & $\begin{array}{l}\text { Legislação disponível nos sítios da Prefeitura de } \\
\text { Belém na Internet. }\end{array}$ \\
\hline 2001 & $\begin{array}{l}\text { Legislação disponível nos sítios da Prefeitura de } \\
\text { Belém na Internet. }\end{array}$ \\
\hline 2011 & $\begin{array}{l}\text { Legislação disponível nos sítios da Prefeitura de } \\
\text { Belém na Internet. }\end{array}$ \\
\hline
\end{tabular}




\section{b) Método de Cálculo}

\begin{tabular}{ll}
\hline 1980 & $\begin{array}{l}\text { Não foi firmado ou encontrava-se em vigor } \\
\text { nenhum consórcio intermunicipal para provisão } \\
\text { de infraestrutura e prestação de serviços de } \\
\text { transporte. }\end{array}$ \\
\hline 1991 & $\begin{array}{l}\text { Não foi firmado ou encontrava-se em vigor } \\
\text { nenhum consórcio intermunicipal para provisão } \\
\text { de infraestrutura e prestação de serviços de } \\
\text { transporte. }\end{array}$ \\
\hline $2001 \quad \begin{array}{l}\text { Não foi firmado ou encontrava-se em vigor } \\
\text { nenhum consórcio intermunicipal para provisão } \\
\text { de infraestrutura e prestação de serviços de } \\
\text { transporte. }\end{array}$ \\
\hline $2011 \quad \begin{array}{l}\text { Não foi firmado ou encontra-se em vigor nenhum } \\
\text { consórcio intermunicipal para provisão de } \\
\text { infraestrutura e prestação de serviços de } \\
\text { transporte. }\end{array}$ \\
\hline
\end{tabular}

c) Escore e Normalização

\begin{tabular}{ccc}
\hline Cenário & Escore & Escore Normalizado \\
\hline 1980 & 0,00 & 0,00 \\
\hline 1991 & 0,00 & 0,00 \\
\hline 2001 & 0,00 & 0,00 \\
\hline 2011 & 0,00 & 0,00 \\
\hline
\end{tabular}

\begin{tabular}{|c|c|}
\hline Escore & $\begin{array}{l}\text { Valores de Referência } \\
\text { Foi firmado ou encontra-se em vigor no ano de } \\
\text { referência consórcio intermunicipal para: }\end{array}$ \\
\hline 1,00 & $\begin{array}{l}\text { Aquisição de máquinas e equipamentos, } \\
\text { execução de obras de manutenção, } \\
\text { conservação e construção de infraestrutura e } \\
\text { prestação de serviços de transporte urbano e } \\
\text { metropolitano }\end{array}$ \\
\hline 0,75 & $\begin{array}{l}\text { Aquisição de máquinas e equipamentos e } \\
\text { execução de obras de manutenção, } \\
\text { conservação e construção de infraestrutura de } \\
\text { transportes }\end{array}$ \\
\hline 0,50 & $\begin{array}{l}\text { Aquisição de máquinas e equipamentos e } \\
\text { execução de obras de manutenção e } \\
\text { conservação de infraestrutura de transportes }\end{array}$ \\
\hline 0,25 & $\begin{array}{l}\text { Aquisição de máquinas e equipamentos para } \\
\text { provisão de infraestrutura de transportes }\end{array}$ \\
\hline 0,00 & $\begin{array}{l}\text { Não foi firmado ou encontra-se em vigor } \\
\text { nenhum consórcio intermunicipal para provisão } \\
\text { de infraestrutura e prestação de serviços de } \\
\text { transporte }\end{array}$ \\
\hline Domínio & Planejamento Integrado \\
\hline Tema & $\begin{array}{l}\text { 7.4. Transparência do processo de } \\
\text { planejamento }\end{array}$ \\
\hline Indicador & 7.4.1. Transparência e responsabilidade \\
\hline Definição & $\begin{array}{l}\text { Existência de publicação formal e periódica } \\
\text { por parte da administração municipal sobre } \\
\text { assuntos relacionados à infraestrutura, } \\
\text { serviços, planos e projetos de transportes e } \\
\text { mobilidade urbana. }\end{array}$ \\
\hline
\end{tabular}

a) Fontes de Dados

\begin{tabular}{ll}
\hline 1980 & Informação não disponível. \\
\hline 1991 & Informação não disponível. \\
\hline 2001 & Informação não disponível. \\
\hline 2011 & $\begin{array}{l}\text { Página as SEGEP (PMB, 2012d), Portal } \\
\text { Transparência Belém (PMB, 2012c) e Diário } \\
\text { Oficial do Município (PMB, 2012a) }\end{array}$ \\
\hline
\end{tabular}

b) Método de Cálculo

\begin{tabular}{|c|c|}
\hline 1980 & $\mathrm{n} / \mathrm{a}$ \\
\hline 1991 & $\mathrm{n} / \mathrm{a}$ \\
\hline 2001 & $\mathrm{n} / \mathrm{a}$ \\
\hline & $\begin{array}{l}\text { Nos sítios mantidos pela Prefeitura de Belém é } \\
\text { possível encontrar contratos, chamadas para } \\
\text { licitação e outros documentos oficiais que são } \\
\text { obrigatoriamente publicados no Diário Oficial do } \\
\text { Município. Na página da SEGEP pode-se ter } \\
\text { acesso a planos plurianuais, relatórios de gestão } \\
\text { financeira, de auditorias, de execução } \\
\text { orçamentária, gestão fiscal e outros. }\end{array}$ \\
\hline 2011 & $\begin{array}{l}\text { O "Portal da Transparência" serve para } \\
\text { organizar os links para esses documentos. } \\
\text { Enquadrou-se essa situação no escore } \\
\text { composto de "Contratos e licitações para } \\
\text { execução de obras de infraestrutura e prestação } \\
\text { de serviços de transporte público, estágio de } \\
\text { desenvolvimento de planos e projetos e } \\
\text { aplicação e fonte de recursos para planos e } \\
\text { projetos de transportes e mobilidade urbana". }\end{array}$ \\
\hline
\end{tabular}

c) Escore e Normalização

\begin{tabular}{ccc}
\hline Cenário & Escore & Escore Normalizado \\
\hline 1980 & $\mathrm{n} / \mathrm{a}$ & $\mathrm{n} / \mathrm{a}$ \\
\hline 1991 & $\mathrm{n} / \mathrm{a}$ & $\mathrm{n} / \mathrm{a}$ \\
\hline 2001 & $\mathrm{n} / \mathrm{a}$ & $\mathrm{n} / \mathrm{a}$ \\
\hline 2011 & 0,75 & 0,75 \\
\hline
\end{tabular}

Escore Existência de publicação formal e periódica sobre:

Contratos e licitações para execução de obras de infraestrutura e prestação de serviços de transporte público, estágio de desenvolvimento

1,00 de planos e projetos, aplicação e fonte de recursos, e impactos sociais, econômicos e ambientais de planos e projetos de transportes e mobilidade urbana

Contratos e licitações para execução de obras de infraestrutura e prestação de serviços de

0,75 transporte público, estágio de desenvolvimento de planos e projetos e aplicação e fonte de recursos para planos e projetos de transportes e mobilidade urbana

Contratos e licitações para execução de obras de infraestrutura e prestação de serviços de

0,50 transporte público, e estágio de desenvolvimento de planos e projetos de transportes e mobilidade urbana

Contratos e licitações para execução de obras

0,25 de infraestrutura e prestação de serviços de transporte públicos

0,00 Não há publicação formal e periódica sobre assuntos relacionados à infraestrutura, 


\begin{tabular}{|c|c|}
\hline & $\begin{array}{l}\text { serviços, planos e projetos de transportes e } \\
\text { mobilidade urbana }\end{array}$ \\
\hline Domínio & Planejamento Integrado \\
\hline Tema & $\begin{array}{l}\text { 7.5. Planejamento e controle do uso e } \\
\text { ocupação do solo }\end{array}$ \\
\hline Indicador & 7.5.1. Vazios urbanos \\
\hline Definição & $\begin{array}{l}\text { Porcentagem de áreas que se encontram } \\
\text { vazias ou desocupadas na área urbana do } \\
\text { município. }\end{array}$ \\
\hline
\end{tabular}

\section{a) Fontes de Dados}

\begin{tabular}{ll}
\hline 1980 & Informação não disponível. \\
\hline 1991 & Informação não disponível. \\
\hline 2001 & Informação não disponível. \\
\hline 2011 & Informação não disponível. \\
\hline
\end{tabular}

\section{b) Método de Cálculo}

\begin{tabular}{ll}
\hline 1980 & $\mathrm{n} / \mathrm{a}$ \\
\hline 1991 & $\mathrm{n} / \mathrm{a}$ \\
\hline 2001 & $\mathrm{n} / \mathrm{a}$ \\
\hline 2011 & $\mathrm{n} / \mathrm{a}$ \\
\hline
\end{tabular}

\section{c) Escore e Normalização}

\begin{tabular}{ccc}
\hline Cenário & Escore & Escore Normalizado \\
\hline 1980 & $\mathrm{n} / \mathrm{a}$ & $\mathrm{n} / \mathrm{a}$ \\
\hline 1991 & $\mathrm{n} / \mathrm{a}$ & $\mathrm{n} / \mathrm{a}$ \\
\hline 2001 & $\mathrm{n} / \mathrm{a}$ & $\mathrm{n} / \mathrm{a}$ \\
\hline 2011 & $\mathrm{n} / \mathrm{a}$ & $\mathrm{n} / \mathrm{a}$ \\
\hline
\end{tabular}

\begin{tabular}{|c|c|}
\hline Escore & $\begin{array}{l}\text { Valores de Referência } \\
\text { Porcentagem da área urbana do município } \\
\text { vazia ou desocupada. }\end{array}$ \\
\hline 1,00 & Até $10 \%$ \\
\hline 0,75 & $20 \%$ \\
\hline 0,50 & $30 \%$ \\
\hline 0,25 & $40 \%$ \\
\hline 0,00 & $50 \%$ ou mais \\
\hline Domínio & Planejamento Integrado \\
\hline Tema & $\begin{array}{l}\text { Planejamento e controle do uso e ocupação } \\
\text { do solo }\end{array}$ \\
\hline Indicador & 7.5.2. Crescimento urbano \\
\hline Definição & $\begin{array}{l}\text { Razão entre a área de novos projetos (para } \\
\text { diferentes usos) previstos ou em fase de } \\
\text { implantação em regiões dotadas de } \\
\text { infraestrutura e serviços de transportes, e a } \\
\text { área de novos projetos em regiões ainda não } \\
\text { desenvolvidas e sem infraestrutura de } \\
\text { transportes. }\end{array}$ \\
\hline
\end{tabular}

\section{a) Fontes de Dados}

\begin{tabular}{ll}
\hline 1980 & Informação não disponível. \\
\hline 1991 & Informação não disponível. \\
\hline 2001 & Informação não disponível. \\
\hline 2011 & Informação não disponível. \\
\hline
\end{tabular}

\section{b) Método de Cálculo}

\begin{tabular}{ll}
\hline 1980 & $\mathrm{n} / \mathrm{a}$ \\
\hline 1991 & $\mathrm{n} / \mathrm{a}$ \\
\hline 2001 & $\mathrm{n} / \mathrm{a}$ \\
\hline 2011 & $\mathrm{n} / \mathrm{a}$ \\
\hline
\end{tabular}

\section{c) Escore e Normalização}

\begin{tabular}{ccc}
\hline Cenário & Escore & Escore Normalizado \\
\hline 1980 & $\mathrm{n} / \mathrm{a}$ & $\mathrm{n} / \mathrm{a}$ \\
\hline 1991 & $\mathrm{n} / \mathrm{a}$ & $\mathrm{n} / \mathrm{a}$ \\
\hline 2001 & $\mathrm{n} / \mathrm{a}$ & $\mathrm{n} / \mathrm{a}$ \\
\hline 2011 & $\mathrm{n} / \mathrm{a}$ & $\mathrm{n} / \mathrm{a}$ \\
\hline
\end{tabular}

\begin{tabular}{|c|c|}
\hline & Valores de Referência \\
\hline Escore & $\begin{array}{l}\text { Razão entre a área total de novos projetos em } \\
\text { áreas dotadas de infraestrutura de transportes e } \\
\text { a área total de novos projetos em áreas sem } \\
\text { infraestrutura de transportes }\end{array}$ \\
\hline 1,00 & Igual ou maior que 2 \\
\hline 0,75 & 1,5 \\
\hline 0,50 & 1 \\
\hline 0,25 & 0,5 \\
\hline 0,00 & 0 \\
\hline Domínio & Planejamento Integrado \\
\hline Tema & $\begin{array}{l}\text { Planejamento e controle do uso e ocupação } \\
\text { do solo }\end{array}$ \\
\hline Indicador & 7.5.3. Densidade populacional urbana \\
\hline Definição & $\begin{array}{l}\text { Razão entre o número total de habitantes da } \\
\text { área urbana e a área total urbanizada do } \\
\text { município. }\end{array}$ \\
\hline
\end{tabular}

\section{a) Fontes de Dados}

\begin{tabular}{cl}
\hline \multirow{2}{*}{1980} & $\begin{array}{l}\text { Dados do IBGE (2012) e imagens do Google } \\
\text { Earth (GOOGLE, 2011). }\end{array}$ \\
\hline \multirow{2}{*}{2991} & $\begin{array}{l}\text { Dados do IBGE (2012) e imagens do Google } \\
\text { Earth (GOOGLE, 2011). }\end{array}$ \\
\hline 2001 & $\begin{array}{l}\text { Dados do Censo 2000 (IBGE, 2001) e imagens } \\
\text { do Google Earth (GOOGLE, 2011). }\end{array}$ \\
\hline 2011 & $\begin{array}{l}\text { Dados do Censo 2010 (IBGE, 2011a) e imagens } \\
\text { do Google Earth (GOOGLE, 2011). }\end{array}$ \\
\hline
\end{tabular}


b) Método de Cálculo

- Considerou-se a mesma área urbanizada do cenário 2011, de $149 \mathrm{~km}^{2}$.

1980 - População urbana de Belém: 902.067 habitantes. (estimada como $95 \%$ do total) ${ }^{20}$

- Densidade: 6054 hab/km².

- Considerou-se a mesma área urbanizada do cenário 2011, de $149 \mathrm{~km}^{2}$.

1991 • População urbana de Belém: 1.182.453 habitantes. (estimada como $95 \%$ do total) ${ }^{21}$

- Densidade: 7936 hab/km².

- Considerou-se a mesma área urbanizada do cenário 2011, de $149 \mathrm{~km}^{2}$.

2001 • População urbana de Belém: 1.244.505 habitantes;

- Densidade: $8.352 \mathrm{hab} / \mathrm{km}^{2}$

- Ferramenta auxiliar: software de sistema de informações geográficas (QGIS, 2011);

- Utilizando este software com uma camada da imagem de satélite do Google Earth, foi possível delimitar uma área urbanizada de aproximadamente $149 \mathrm{~km}^{2}$

2011

- Considerou-se a mesma área urbanizada do cenário 2001, de $149 \mathrm{~km}^{2}$.

- População urbana de Belém (2010): 1.381.475 habitantes

- Densidade: 9272 hab/km².

c) Escore e Normalização

\begin{tabular}{ccc}
\hline Cenário & Escore & Escore Normalizado \\
\hline 1980 & 6.054 & 0,03 \\
\hline 1991 & 7.936 & 0,07 \\
\hline 2001 & 8.352 & 0,08 \\
\hline 2011 & 9.272 & 0,11 \\
\hline
\end{tabular}

\begin{tabular}{|c|c|}
\hline Escore & $\begin{array}{l}\text { Valores de Referência } \\
\text { Densidade populacional urbana }\end{array}$ \\
\hline 1,00 & $45.000 \mathrm{hab} . / \mathrm{km}^{2}$ ou $450 \mathrm{hab} . / \mathrm{ha}$ \\
\hline 0,75 & 35.000 hab. $/ \mathrm{km}^{2}$ ou 350 hab./ha \\
\hline 0,50 & $25.000 \mathrm{hab} . / \mathrm{km}^{2}$ ou $250 \mathrm{hab} . / \mathrm{ha}$ \\
\hline 0,25 & 15.000 hab./km ${ }^{2}$ ou 150 hab./ha \\
\hline 0,00 & $\begin{array}{l}\text { Até } 5.000 \mathrm{hab} . / \mathrm{km}^{2} \text { ou } 50 \mathrm{hab} . / \mathrm{ha} \text { ou superior } \\
\text { a } 45.00 \mathrm{hab} . / \mathrm{km}^{2} \text { ou } 450 \mathrm{hab} . / \mathrm{ha}\end{array}$ \\
\hline Domínio & Planejamento Integrado \\
\hline Tema & $\begin{array}{l}\text { Planejamento e controle do uso e ocupação } \\
\text { do solo }\end{array}$ \\
\hline Indicador & 7.5.4. Índice de uso misto \\
\hline Definição & $\begin{array}{l}\text { Porcentagem da área urbana destinada ao } \\
\text { uso misto do solo, conforme definido em } \\
\text { legislação municipal. }\end{array}$ \\
\hline
\end{tabular}

\footnotetext{
${ }^{20}$ A população rural de Belém representava menos de $3 \%$ no Censo 2000 e menos de $1 \%$ no Censo 2010. Como não foram encontratos dados sobre as populações urbana e rural para o cenário de 1980, estimou-se a partir das população total.

${ }^{21}$ Idem para o cenário 1991.
}

\section{a) Fontes de Dados}

\begin{tabular}{ll}
\hline 1980 & Informação não disponível. \\
\hline 1991 & Informação não disponível. \\
\hline 2001 & $\begin{array}{l}\text { Lei Complementar de Controle Urbanístico - } \\
\text { LCCU (PMB, 1999) }\end{array}$ \\
\hline 2011 & $\begin{array}{l}\text { Plano Diretor do Município de Belém (PMB, } \\
\text { 2008) }\end{array}$ \\
\hline
\end{tabular}

\section{b) Método de Cálculo}

\begin{tabular}{ll}
\hline 1980 & n/a \\
\hline 1991 & n/a \\
\hline & A LCCU (PMB, 1999) divide o território em \\
& Zonas Habitacionais (ZH), Zonas de Uso Misto \\
& (ZUM, Zonas de Serviços (ZS), Zonas de \\
& Preservação Ambiental (ZPA) e Zonas \\
& Industriais (ZI). Existe ainda as Zonas de \\
& Interesse Urbano Especial (ZIUE), que não \\
& servem à ocupações urbanas habitacionais, \\
& comerciais, industriais ou de serviços. A partir do \\
& Mapa de Zoneamento, do Anexo 09 da LCCU \\
& (PMB, 2012b), pode-se estimar a dimensão \\
& dessas áreas. Tomando a área total e subtraindo \\
& as áreas referentes às ZPAs e ZIUEs tem-se \\
& área ocupável. Desta as ZUMs correspondem a \\
& aproximadamente 28\%.
\end{tabular}

O Plano Diretor do Município de Belém divide o território em duas macrozonas, a do Ambiente Natural (MZAN) e a do Ambiente Urbano (MZAU). O mapa de zoneamento corresponde ao Anexo V do Plano Diretor. A MZAN “... corresponde às áreas não urbanizadas das ilhas de Caratateua, Mosqueiro e Cotijuba, às demais ilhas do Município em sua totalidade, e a Área de Proteção Ambiental dos Mananciais de Abastecimento de Água de Belém (APA-Belém)" e a ocupação é bem limitada. A Macrozona do Ambiente Urbano (MZAU) "está dividida em sete Zonas de Ambiente Urbano (ZAU), em função das especificidades quanto aos padrões

2011 paisagísticos e urbanísticos de ocupação, dos problemas e potencialidades urbanos e objetivos específicos". Considerou-se aqui apenas a $M Z A U$, já que é a área que pode ser efetivamente ocupada. Dentro da MZAU, apenas a ZAU 7-III, que corresponde a uma parte da área portuária, tem diretriz de desincentivar 0 uso habitacional. No restante da MZAU o uso misto é liberado, regulamentando-se a dimensão das ocupações. $O$ uso industrial mais intenso fica restrito à ZAU 4, mas mesmo aí, existem outros tipos de uso permitidos. Considera-se assim que mais $75 \%$ da área urbana pode ter uso misto.

\section{c) Escore e Normalização}

\begin{tabular}{ccc}
\hline Cenário & Escore & Escore Normalizado \\
\hline 1980 & $\mathrm{n} / \mathrm{a}$ & $\mathrm{n} / \mathrm{a}$ \\
\hline 1991 & $\mathrm{n} / \mathrm{a}$ & $\mathrm{n} / \mathrm{a}$ \\
\hline 2001 & $28 \%$ & 0,28 \\
\hline 2011 & $>75 \%$ & 1,00 \\
\hline
\end{tabular}




\begin{tabular}{cl}
\hline Escore & $\begin{array}{l}\text { Valores de Referência } \\
\text { Porcentagem da área urbana do município } \\
\text { onde é permitido/incentivado o uso misto do } \\
\text { solo com atividades compatíveis entre si e com } \\
\text { o uso residencial }\end{array}$ \\
\hline 1,00 & Mais de 75\% \\
\hline 0,75 & $75 \%$ \\
\hline 0,50 & $50 \%$ \\
\hline 0,25 & $25 \%$ \\
\hline 0,00 & $\begin{array}{l}\text { A legislação urbanística municipal não permite } \\
\text { o uso misto do solo, determinando zonas de } \\
\text { uso exclusivamente residencial, comercial, } \\
\text { industrial ou institucional, resultando em intensa } \\
\text { setorização da área urbana }\end{array}$ \\
\hline
\end{tabular}

\begin{tabular}{ll}
\hline Domínio & Planejamento Integrado \\
\hline Tema & $\begin{array}{l}\text { Planejamento e controle do uso e ocupação } \\
\text { do solo }\end{array}$ \\
\hline Indicador & 7.5.5. Ocupação irregulares \\
\hline Definição & $\begin{array}{l}\text { Porcentagem da área urbana constituída por } \\
\text { assentamentos informais ou irregulares. }\end{array}$ \\
\hline
\end{tabular}

a) Fontes de Dados

\begin{tabular}{ll}
\hline 1980 & Informação não disponível. \\
\hline 1991 & Informação não disponível. \\
\hline 2001 & Informação não disponível. \\
\hline 2011 & $\begin{array}{l}\text { Informações do Censo } 2010 \text { (IBGE, 2011a) } \\
\text { sobre população residente em domicílios } \\
\text { localizados em aglomerados subnormais. }\end{array}$ \\
\hline
\end{tabular}

\section{b) Método de Cálculo}

\begin{tabular}{ll}
\hline 1980 & n/a \\
\hline 1991 & n/a \\
\hline 2001 & n/a \\
\hline & $\begin{array}{l}\text { Não existe a informação do percentual da área } \\
\text { urbana com ocupação irregular, mas aqui o } \\
\text { cálculo se baseou no percentual de domicílios } \\
\text { localizados nessas áreas. Segundo os dados do } \\
\text { Censo 2010, dos 369.177 domicílios de Belém, } \\
\text { 193.557 (52,4\%) se localizam nesse tipo de } \\
\text { área. }\end{array}$ \\
\hline
\end{tabular}

\section{c) Escore e Normalização}

\begin{tabular}{ccc}
\hline Cenário & Escore & Escore Normalizado \\
\hline 1980 & $\mathrm{n} / \mathrm{a}$ & $\mathrm{n} / \mathrm{a}$ \\
\hline 1991 & $\mathrm{n} / \mathrm{a}$ & $\mathrm{n} / \mathrm{a}$ \\
\hline 2001 & $\mathrm{n} / \mathrm{a}$ & $\mathrm{n} / \mathrm{a}$ \\
\hline 2011 & $52,4 \%$ & 0,00 \\
\hline
\end{tabular}

\begin{tabular}{|c|c|}
\hline Escore & $\begin{array}{l}\text { Valores de Referência } \\
\text { Porcentagem da área urbana constituída de } \\
\text { ocupações irregulares e assentamentos } \\
\text { informais }\end{array}$ \\
\hline 1,00 & Até $5 \%$ \\
\hline 0,75 & $10 \%$ \\
\hline 0,50 & $15 \%$ \\
\hline 0,25 & $20 \%$ \\
\hline 0,00 & Mais de $20 \%$ \\
\hline Domínio & Planejamento Integrado \\
\hline Tema & 7.6. Planejamento estratégico e integrado \\
\hline Indicador & $\begin{array}{l}\text { 7.6.1. Planejamento urbano, ambiental e de } \\
\text { transportes integrado }\end{array}$ \\
\hline Definição & $\begin{array}{l}\text { Existência de cooperação formalizada entre } \\
\text { os órgãos responsáveis pelo planejamento e } \\
\text { gestão de transportes, planejamento urbano e } \\
\text { meio ambiente no desenvolvimento de } \\
\text { estratégias integradas para a melhoria das } \\
\text { condições de mobilidade urbana. }\end{array}$ \\
\hline
\end{tabular}

a) Fontes de Dados

\begin{tabular}{ll}
\hline 1980 & Informações de técnicos locais \\
\hline 1991 & $\begin{array}{l}\text { Informações de técnicos locais e análise do } \\
\text { relatório do PDTU (JICA, 1991) }\end{array}$ \\
\hline 2001 & $\begin{array}{l}\text { Informações de técnicos locais e análise do } \\
\text { relatório do PDTU (JICA, 2001) }\end{array}$ \\
\hline 2011 & $\begin{array}{l}\text { Informações de técnicos locais e análise dos } \\
\text { relatórios de planos e estudos da RMB (JICA, } \\
\text { 2003; PARÁ, 2006; JICA, 2010) }\end{array}$ \\
\hline
\end{tabular}

\section{b) Método de Cálculo}

\begin{tabular}{cl}
\hline 1980 & $\begin{array}{l}\text { Órgãos gestores de transportes, meio ambiente } \\
\text { e planejamento urbano no desenvolvimento de } \\
\text { ações pontuais para melhoria das condições de } \\
\text { mobilidade urbana }\end{array}$ \\
\hline 1991 & $\begin{array}{l}\text { Órgãos gestores de transportes, meio ambiente } \\
\text { e planejamento urbano no desenvolvimento de } \\
\text { ações pontuais para melhoria das condições de } \\
\text { mobilidade urbana }\end{array}$ \\
\hline 2001 & $\begin{array}{l}\text { Órgãos gestores de transportes, meio ambiente } \\
\text { e planejamento urbano no desenvolvimento de } \\
\text { ações pontuais para melhoria das condições de } \\
\text { mobilidade urbana }\end{array}$ \\
\hline 2011 & $\begin{array}{l}\text { Órgãos gestores de transportes, meio ambiente } \\
\text { e planejamento urbano no desenvolvimento de } \\
\text { ações pontuais para melhoria das condições de } \\
\text { mobilidade urbana }\end{array}$ \\
\hline
\end{tabular}

\section{c) Escore e Normalização}

\begin{tabular}{ccc}
\hline Cenário & Escore & Escore Normalizado \\
\hline 1980 & 0,33 & 0,33 \\
\hline 1991 & 0,33 & 0,33 \\
\hline 2001 & 0,33 & 0,33 \\
\hline 2011 & 0,33 & 0,33 \\
\hline
\end{tabular}




\begin{tabular}{|c|c|}
\hline Escore & $\begin{array}{l}\text { Valores de Referência } \\
\text { Há cooperação formal entre: }\end{array}$ \\
\hline 1,00 & $\begin{array}{l}\text { Órgãos gestores de transportes, meio ambiente } \\
\text { e planejamento urbano no desenvolvimento de } \\
\text { planos e programas de abrangência municipal } \\
\text { para melhoria das condições de mobilidade } \\
\text { urbana, inclusive com a instituição de um órgão } \\
\text { intersecretarial permanente }\end{array}$ \\
\hline 0,66 & $\begin{array}{l}\text { Órgãos gestores de transportes, meio ambiente } \\
\text { e planejamento urbano no desenvolvimento de } \\
\text { planos e programas de abrangência municipal } \\
\text { para melhoria das condições de mobilidade } \\
\text { urbana }\end{array}$ \\
\hline 0,33 & $\begin{array}{l}\text { Órgãos gestores de transportes, meio ambiente } \\
\text { e planejamento urbano no desenvolvimento de } \\
\text { ações pontuais para melhoria das condições de } \\
\text { mobilidade urbana }\end{array}$ \\
\hline 0,00 & $\begin{array}{l}\text { Não há qualquer forma de cooperação entre os } \\
\text { órgãos gestores de transportes, meio ambiente } \\
\text { e planejamento urbano no desenvolvimento de } \\
\text { planos e ações para melhoria das condições de } \\
\text { mobilidade urbana }\end{array}$ \\
\hline Domínio & Planejamento Integrado \\
\hline Tema & Planejamento estratégico e integrado \\
\hline Indicador & 7.6.2. Efetivação e continuidade das ações \\
\hline Definição & $\begin{array}{l}\text { Programas e projetos de transportes e } \\
\text { mobilidade urbana efetivados pela } \\
\text { administração municipal no ano de referência } \\
\text { e continuidade das ações implementadas. }\end{array}$ \\
\hline
\end{tabular}

a) Fontes de Dados

\begin{tabular}{cl}
\hline 1980 & Informações de técnicos locais \\
\hline 1991 & Informações de técnicos locais \\
\hline 2001 & Informações de técnicos locais \\
\hline 2011 & Informações de técnicos locais \\
\hline
\end{tabular}

b) Método de Cálculo

\begin{tabular}{cl}
\hline 1980 & $\begin{array}{l}\text { Nenhuma ação para transportes e } \\
\text { mobilidade urbana prevista pela atual gestão } \\
\text { não foi efetivada }\end{array}$ \\
\hline 1991 & $\begin{array}{l}\text { Nenhuma ação para transportes e } \\
\text { mobilidade urbana prevista pela atual gestão } \\
\text { não foi efetivada }\end{array}$ \\
\hline 2001 & $\begin{array}{l}\text { Nenhuma ação para transportes e } \\
\text { mobilidade urbana prevista pela atual gestão } \\
\text { não foi efetivada }\end{array}$ \\
\hline 2011 & $\begin{array}{l}\text { Nenhuma ação para transportes e } \\
\text { mobilidade urbana prevista pela atual gestão } \\
\text { não foi efetivada }\end{array}$ \\
\hline
\end{tabular}

c) Escore e Normalização

\begin{tabular}{ccc}
\hline Cenário & Escore & Escore Normalizado \\
\hline 1980 & 0,00 & 0,00 \\
\hline 1991 & 0,00 & 0,00 \\
\hline 2001 & 0,00 & 0,00 \\
\hline 2011 & 0,00 & 0,00 \\
\hline
\end{tabular}

\begin{tabular}{cl}
\hline Escore & Valores de Referência \\
\hline 1,00 & $\begin{array}{l}\text { Grande parte das ações para transportes e } \\
\text { mobilidade urbana previstas pela atual gestão } \\
\text { foram efetivadas, tendo sido dada continuidade } \\
\text { às mesmas mesmo após mudanças no quadro } \\
\text { da administração municipal }\end{array}$ \\
\hline 0,75 & $\begin{array}{l}\text { Algumas ações para transportes e mobilidade } \\
\text { urbana previstas pela atual gestão foram } \\
\text { efetivadas, tendo sido dada continuidade às } \\
\text { mesmas mesmo após mudanças no quadro da } \\
\text { administração municipal }\end{array}$ \\
\hline 0,50 & $\begin{array}{l}\text { Grande parte das ações para transportes e } \\
\text { mobilidade urbana previstas pela atual gestão } \\
\text { foi efetivada, no entanto, grande parte foi } \\
\text { abandonada em função de mudanças no } \\
\text { quadro da administração municipal }\end{array}$ \\
\hline 0,25 & $\begin{array}{l}\text { Algumas ações para transportes e mobilidade } \\
\text { urbana previstas pela atual gestão foram } \\
\text { efetivadas, no entanto, grande parte foi } \\
\text { abandonada em função de mudanças no } \\
\text { quadro da administração municipal }\end{array}$ \\
\hline Tema & $\begin{array}{l}\text { Nenhuma ação para transportes e mobilidade } \\
\text { urbana prevista pela atual gestão foi efetivada }\end{array}$ \\
\hline Indicador & $\begin{array}{l}\text { 7.7. Planejamento da infraestrutura urbana e } \\
\text { equipamentos urbanos }\end{array}$ \\
\hline Definição & $\begin{array}{l}\text { Área urbana com cobertura vegetal (parques, } \\
\text { jardins, áreas verdes) por habitante. }\end{array}$ \\
\hline Domínio & Planejamento Integrado \\
\hline Then
\end{tabular}

\section{a) Fontes de Dados}

\begin{tabular}{ll}
\hline 1980 & Informação não disponível. \\
\hline 1991 & Informação não disponível. \\
\hline 2001 & Informação não disponível. \\
\hline 2011 & Informação não disponível. \\
\hline
\end{tabular}

\section{b) Método de Cálculo}

\begin{tabular}{ll}
\hline 1980 & n/a \\
\hline 1991 & n/a \\
\hline 2001 & n/a \\
\hline 2011 & n/a \\
\hline
\end{tabular}

\section{c) Escore e Normalização}

\begin{tabular}{ccc}
\hline Cenário & Escore & Escore Normalizado \\
\hline 1980 & $\mathrm{n} / \mathrm{a}$ & $\mathrm{n} / \mathrm{a}$ \\
\hline 1991 & $\mathrm{n} / \mathrm{a}$ & $\mathrm{n} / \mathrm{a}$ \\
\hline 2001 & $\mathrm{n} / \mathrm{a}$ & $\mathrm{n} / \mathrm{a}$ \\
\hline 2011 & $\mathrm{n} / \mathrm{a}$ & $\mathrm{n} / \mathrm{a}$ \\
\hline
\end{tabular}

\begin{tabular}{cl}
\hline Escore & $\begin{array}{l}\text { Valores de Referência } \\
\text { Área verde por habitante }\end{array}$ \\
\hline 1,00 & Igual ou superior a $25 \mathrm{~m}^{2}$ por habitante \\
\hline 0,75 & $20 \mathrm{~m}^{2}$ por habitante \\
\hline 0,50 & $15 \mathrm{~m}^{2}$ por habitante \\
\hline 0,25 & $10 \mathrm{~m}^{2}$ por habitante \\
\hline 0,00 & Igual ou inferior a $5 \mathrm{~m}^{2}$ por habitante \\
\hline
\end{tabular}




\begin{tabular}{ll}
\hline Domínio & Planejamento Integrado \\
\hline Tema & $\begin{array}{l}\text { Planejamento da infraestrutura urbana e } \\
\text { equipamentos urbanos }\end{array}$ \\
\hline Indicador & 7.7.2. Equipamentos urbanos (escolas) \\
\hline \multirow{2}{*}{ Definição } & $\begin{array}{l}\text { Número de escolas em nível de educação } \\
\text { infantil e ensino fundamental, públicas e } \\
\text { particulares, por 1000 habitantes. }\end{array}$ \\
\hline
\end{tabular}

\section{a) Fontes de Dados}

\begin{tabular}{ll}
\hline 1980 & Informação não disponível. \\
\hline 1991 & Informação não disponível. \\
\hline 2001 & $\begin{array}{l}\text { Censo 2000 (IBGE, 2001) e Sistema de } \\
\text { Estatísticas Educacionais (INEP, 2012) }\end{array}$ \\
\hline 2011 & $\begin{array}{l}\text { Censo 2010 (IBGE, 2011a) e página do IBGE } \\
\text { Cidades (IBGE, 2011b) }\end{array}$ \\
\hline
\end{tabular}

\section{b) Método de Cálculo}

\begin{tabular}{|c|c|}
\hline 1980 & $\mathrm{n} / \mathrm{a}$ \\
\hline 1991 & $\mathrm{n} / \mathrm{a}$ \\
\hline 2001 & $\begin{array}{l}\text { - Número de escolas de ensino pré-escolar: } 66 \\
\text { - Número de escolas de ensino fundamental: } \\
450 \\
\text { - População de Belém: } 1.279 .861 \text { habitantes } \\
\text { - Número de escolas por } 1000 \text { habitantes = } 66 \\
\text { + 450)/ } 1.279,861=0,40\end{array}$ \\
\hline 2011 & $\begin{array}{l}\text { - Número de escolas de ensino pré-escolar: } 274 \\
\text { - Número de escolas de ensino fundamental: } \\
457 \\
\text { - População de Belém: } 1.393 .399 \text { habitantes } \\
\text { - Número de escolas por } 1000 \text { habitantes = }(274 \\
+457) / 1.393,399=0,52\end{array}$ \\
\hline
\end{tabular}

c) Escore e Normalização

\begin{tabular}{ccc}
\hline Cenário & Escore & Escore Normalizado \\
\hline 1980 & $\mathrm{n} / \mathrm{a}$ & $\mathrm{n} / \mathrm{a}$ \\
\hline 1991 & $\mathrm{n} / \mathrm{a}$ & $\mathrm{n} / \mathrm{a}$ \\
\hline 2001 & 0,40 & 0,15 \\
\hline 2011 & 0,52 & 0,27 \\
\hline \multicolumn{3}{c}{ Valores de Referência } \\
Escore & $\begin{array}{l}\text { Número de escolas por 1000 habitantes no } \\
\text { município }\end{array}$ \\
\hline 1,00 & Igual ou superior a 1,25 \\
\hline 0,75 & 1,00 \\
\hline 0,50 & 0,75 \\
\hline 0,25 & 0,50 \\
\hline 0,00 & Igual ou inferior a 0,25 \\
\hline
\end{tabular}

\begin{tabular}{ll}
\hline Domínio & Planejamento Integrado \\
\hline Tema & $\begin{array}{l}\text { Planejamento da infraestrutura urbana e } \\
\text { equipamentos urbanos }\end{array}$ \\
\hline Indicador & $\begin{array}{l}\text { 7.7.3. Equipamentos urbanos (postos de } \\
\text { saúde) }\end{array}$ \\
\hline Definição & $\begin{array}{l}\text { Número de equipamentos de saúde ou } \\
\text { unidades de atendimento médico primário } \\
\text { (postos de saúde) por 100.000 habitantes. }\end{array}$ \\
\hline
\end{tabular}

a) Fontes de Dados

\begin{tabular}{cl}
\hline 1980 & $\begin{array}{l}\text { Dados do IBGE (2012) e página de Informações } \\
\text { de Saúde do DATASUS (2012) }\end{array}$ \\
\hline 1991 & $\begin{array}{l}\text { Dados do IBGE (2012) e página de Informações } \\
\text { de Saúde do DATASUS (2012) }\end{array}$ \\
\hline 2001 & $\begin{array}{l}\text { Censo 2000 (IBGE, 2001) e página de } \\
\text { Informações de Saúde do DATASUS (2012) }\end{array}$ \\
\hline 2011 & $\begin{array}{l}\text { Censo 2010 (IBGE, 2011a) e página de } \\
\text { Informações de Saúde do DATASUS (2012) }\end{array}$ \\
\hline
\end{tabular}

\section{b) Método de Cálculo}

- Os dados disponíveis no DATASUS mostram que em agosto de 2005 existia um total de 58 postos de saúde, valor que cresceu para 73 em dezembro de 2011. Como não foi possível

1980 encontrar dados para 1980, considerou-se que esse número seria menor ou igual a 58.

- População de Belém: 949.545 habitantes.

- Escore: 6,11

- Os dados disponíveis no DATASUS mostram que em agosto de 2005 existia um total de 58 postos de saúde, valor que cresceu para 73

1991 em dezembro de 2011. Como não foi possível encontrar dados para 1991, considerou-se que esse número seria menor ou igual a 58.

- População de Belém: 1.244.688 habitantes.

- Escore: 4,66

- Os dados disponíveis no DATASUS mostram que em agosto de 2005 existia um total de 58 postos de saúde, valor que cresceu para 73

em dezembro de 2011. Como não foi possível encontrar dados para 2001, considerou-se que esse número seria menor ou igual a 58.

- População de Belém: 1.279.861 habitantes.

- Escore: 4,53

- Número de estabelecimentos: 73

2011

- População de Belém: 1.393.399 habitantes

- Número de equipamentos de saúde por 100.000 habitantes $=73 / 13,93399=5,23$

\section{c) Escore e Normalização}

\begin{tabular}{ccc}
\hline Cenário & Escore & Escore Normalizado \\
\hline 1980 & $<6,11$ & 0,00 \\
\hline 1991 & $<4,66$ & 0,00 \\
\hline 2001 & $<4,53$ & 0,00 \\
\hline 2011 & 5,23 & 0,00 \\
\hline
\end{tabular}




\begin{tabular}{ll}
\hline Escore & $\begin{array}{l}\text { Valores de Referência } \\
\text { Número de postos de saúde por 100.000 } \\
\text { habitantes no município }\end{array}$ \\
\hline 1,00 & 50 ou mais \\
\hline 0,75 & 40 \\
\hline 0,50 & 30 \\
\hline 0,25 & 20 \\
\hline 0,00 & Até 10 \\
\hline
\end{tabular}

\begin{tabular}{ll}
\hline Domínio & Planejamento Integrado \\
\hline Tema & 7.8. Plano Diretor e legislação urbanística \\
\hline Indicador & 7.8.1. Plano Diretor \\
\hline Definição & $\begin{array}{l}\text { Existência e ano de elaboração/atualização } \\
\text { do Plano Diretor Municipal. }\end{array}$ \\
\hline
\end{tabular}

\section{a) Fontes de Dados}

\begin{tabular}{ll}
\hline 1980 & Klautau (1993) \\
\hline 1991 & Klautau (1993) \\
\hline 2001 & $\begin{array}{l}\text { Página de legislação da Prefeitura de Belém } \\
\text { (PMB, 2011b) e livro "Como andam Belém e } \\
\text { Goiânia" (MCIDADES, 2008a). }\end{array}$ \\
\hline 2011 & $\begin{array}{l}\text { Página de legislação da Prefeitura de Belém } \\
\text { (PMB, 2011b). }\end{array}$ \\
\hline
\end{tabular}

\section{b) Método de Cálculo}

\begin{tabular}{ll}
\hline \multirow{2}{*}{1980} & $\begin{array}{l}\text { Plano de Desenvolvimento da Grande Belém - } \\
\text { PDGB (PMB apud KLAUTAU, 1993)22 }\end{array}$ \\
\hline \multirow{2}{*}{1991} & $\begin{array}{l}\text { Plano de Desenvolvimento da Grande Belém - } \\
\text { PDGB (PMB apud KLAUTAU, 1993) }\end{array}$ \\
\hline 2001 & Plano Diretor Urbano (PMB, 1993) \\
\hline 2011 & Plano Diretor do Município de Belém (PMB, 2008) \\
\hline
\end{tabular}

c) Escore e Normalização

\begin{tabular}{ccc}
\hline Cenário & Escore & Escore Normalizado \\
\hline 1980 & 1,00 & 1,00 \\
\hline 1991 & 0,50 & 0,50 \\
\hline 2001 & 0,50 & 0,50 \\
\hline 2011 & 1,00 & 1,00 \\
\hline \multicolumn{3}{c}{ Valores de Referência } \\
Escore & $\begin{array}{l}\text { O município dispõe de Plano Diretor, } \\
\text { implantado ou atualizado há: }\end{array}$ \\
\hline 1,00 & Menos de 7 anos \\
\hline 0,50 & Mais de 7 anos \\
\hline 0,00 & O município não dispõe de Plano Diretor \\
\hline
\end{tabular}

\footnotetext{
22 - Plano de Desenvolvimento da Grande Belém - Prefeitura Municipal de Belém - 1975.
}

\begin{tabular}{ll}
\hline Domínio & Planejamento Integrado \\
\hline Tema & Plano Diretor e legislação urbanística \\
\hline Indicador & 7.8.2. Legislação urbanística \\
\hline Definição & Existência de legislação urbanística \\
\hline
\end{tabular}

\section{a) Fontes de Dados}

\begin{tabular}{ll}
\hline 1980 & $\begin{array}{l}\text { Legislação disponível na Internet (PMB, 2006b, } \\
\text { a, 2011b) }\end{array}$ \\
\hline 1991 & $\begin{array}{l}\text { Legislação disponível na Internet (PMB, 2006b, } \\
\text { a, 2011b) }\end{array}$ \\
\hline 2001 & $\begin{array}{l}\text { Legislação disponível na Internet (PMB, 2006b, } \\
\text { a, 2011b) }\end{array}$ \\
2011 & $\begin{array}{l}\text { Legislação disponível na Internet (PMB, 2006b, } \\
\text { a, 2011b) }\end{array}$ \\
\hline
\end{tabular}

\section{b) Método de Cálculo}

\begin{tabular}{|c|c|}
\hline 1980 & $\begin{array}{l}\text { - Lei do Perímetro Urbano: Não foram } \\
\text { encontradas informações sobre a existência } \\
\text { de uma lei específica, mas outras leis fazem } \\
\text { referência a áreas urbanas e rurais e a } \\
\text { divisão em bairros. Considerou-se, assim, que } \\
\text { o Perímetro Urbano estivesse legalmente } \\
\text { estabelecido. } \\
\text { - Lei de Zoneamento ou equivalente (PMB, } \\
\text { 1979) } \\
\text { - Lei de Uso e Ocupação do Solo (PMB, 1979) } \\
\text { - Código de Obras: Não foi encontrada a lei } \\
\text { referente a este assunto, mas a lei que trata } \\
\text { do Código de Posturas (PMB, 1977) faz se } \\
\text { remete a um "Código de Obras e Edificações } \\
\text { do Município de Belém". } \\
\text { - Código de Posturas (PMB, 1977) }\end{array}$ \\
\hline 1991 & $\begin{array}{l}\text { - Lei do Perímetro Urbano: Não foram } \\
\text { encontradas informações sobre a existência } \\
\text { de uma lei específica, mas outras leis fazem } \\
\text { referência a áreas urbanas e rurais e a } \\
\text { divisão em bairros. Considerou-se, assim, que } \\
\text { o Perímetro Urbano estivesse legalmente } \\
\text { estabelecido. } \\
\text { - Lei de Zoneamento ou equivalente (PMB, } \\
\text { 1988b) } \\
\text { - Lei de Uso e Ocupação do Solo (PMB, 1988b) } \\
\text { - Código de Obras (PMB, 1988a), } \\
\text { - Código de Posturas (PMB, 1977) }\end{array}$ \\
\hline 2001 & $\begin{array}{l}\text { - Lei do Perímetro Urbano (PMB; PMA, 1991; } \\
\text { PMB, 1996) } \\
\text { - Lei de Zoneamento ou equivalente (PMB, } \\
\text { 1999) } \\
\text { - Lei de Uso e Ocupação do Solo (PMB, 1999) } \\
\text { - Código de Obras (PMB, 1988a), } \\
\text { - Código de Posturas (PMB, 1977) } \\
\text { - Legislação Sobre Áreas de Interesse Especial } \\
\text { (PMB, 1994b, a, 1999, 2008) } \\
\text { - Legislação de Interesse Social (PMB, 1993) } \\
\text { - Instrumentos para o Parcelamento, Edificação } \\
\text { ou Utilização Compulsórios, Outorga Onerosa } \\
\text { do Direito de Construir, Operações Urbanas } \\
\text { Consorciadas ou outros instrumentos de } \\
\text { planejamento urbano (PMB, 1993) }\end{array}$ \\
\hline 2011 & $\begin{array}{l}\text { - Lei do Perímetro Urbano (PMB; PMA, 1991; } \\
\text { PMB, 1996) } \\
\text { - Lei de Zoneamento ou equivalente (PMB, } \\
\text { 1999) }\end{array}$ \\
\hline
\end{tabular}


- Lei de Uso e Ocupação do Solo (PMB, 1999)

- Código de Obras (PMB, 1988a),

- Código de Posturas (PMB, 1977)

- Legislação Sobre Áreas de Interesse Especial (PMB, 1994b, a, 1999, 2008)

- Legislação de Interesse Social (PMB, 2008)

- Instrumentos para o Parcelamento, Edificação ou Utilização Compulsórios, Outorga Onerosa do Direito de Construir, Operações Urbanas Consorciadas ou outros instrumentos de planejamento urbano (PMB, 2008)

\section{c) Escore e Normalização}

\begin{tabular}{ccc}
\hline Cenário & Escore & Escore Normalizado \\
\hline 1980 & 0,50 & 0,50 \\
\hline 1991 & 0,50 & 0,50 \\
\hline 2001 & 1,00 & 1,00 \\
\hline 2011 & 1,00 & 1,00 \\
\hline
\end{tabular}

\section{Escore Valores de Referência}

O município dispõe dos seguintes instrumentos:

Lei do Perímetro Urbano, Lei de Zoneamento ou equivalente, Lei de Uso e Ocupação do Solo, Código de Obras, Código de Posturas,

Legislação Sobre Áreas de Interesse Especial,

1,00 Legislação de Interesse Social, instrumentos para o Parcelamento, Edificação ou Utilização Compulsórios, Outorga Onerosa do Direito de Construir, Operações Urbanas Consorciadas ou outros instrumentos de planejamento urbano

Lei do Perímetro Urbano, Lei de Zoneamento ou equivalente, Lei de Uso e Ocupação do Solo, Código de Obras, Código de Posturas,

0,90 Legislação Sobre Áreas de Interesse Especial, Legislação de Interesse Social, instrumentos para o Parcelamento, Edificação ou Utilização Compulsórios e Outorga Onerosa do Direito de Construir

Lei do Perímetro Urbano, Lei de Zoneamento ou equivalente, Lei de Uso e Ocupação do Solo, Código de Obras, Código de Posturas,

0,80 Legislação Sobre Áreas de Interesse Especial, Legislação de Interesse Social, instrumento para o Parcelamento, Edificação ou Utilização Compulsórios

Lei do Perímetro Urbano, Lei de Zoneamento ou equivalente, Lei de Uso e Ocupação do Solo,

0,70 Código de Obras, Código de Posturas, Legislação Sobre Áreas de Interesse Especial, Legislação de Interesse Social

\begin{tabular}{cl}
\hline 0,60 & $\begin{array}{l}\text { Lei do Perímetro Urbano, Lei de Zoneamento ou } \\
\text { equivalente, Lei de Uso e Ocupação do Solo, } \\
\text { Código de Obras, Código de Posturas, } \\
\text { Legislação Sobre Áreas de Interesse Especial }\end{array}$ \\
\hline $0,50 \quad \begin{array}{l}\text { Lei do Perímetro Urbano, Lei de Zoneamento ou } \\
\text { equivalente, Lei de Uso e Ocupação do Solo, } \\
\text { Código de Obras, Código de Posturas }\end{array}$ \\
\hline $0,40 \quad \begin{array}{l}\text { Lei do Perímetro Urbano, Lei de Zoneamento ou } \\
\text { equivalente, Lei de Uso e Ocupação do Solo, } \\
\text { Código de Obras }\end{array}$ \\
\hline $0,30 \quad \begin{array}{l}\text { Lei do Perímetro Urbano, Lei de Zoneamento ou } \\
\text { equivalente, Lei de Uso e Ocupação do Solo }\end{array}$ \\
\hline 0,20 & $\begin{array}{l}\text { Lei do Perímetro Urbano, Lei de Zoneamento ou } \\
\text { equivalente }\end{array}$ \\
\hline
\end{tabular}

\begin{tabular}{ll}
\hline 0,10 & Lei do Perímetro Urbano \\
\hline 0,00 & O município não dispõe de legislação urbanística \\
\hline Domínio & Planejamento Integrado \\
\hline Tema & Plano Diretor e legislação urbanística \\
\hline Indicador & 7.8.3. Cumprimento da legislação urbanística \\
\hline Definição & $\begin{array}{l}\text { Fiscalização por parte da administração } \\
\text { municipal com relação ao cumprimento da } \\
\text { legislação urbanística vigente. }\end{array}$ \\
\hline
\end{tabular}

\section{a) Fontes de Dados}

\begin{tabular}{ll}
\hline 1980 & Informação não disponível. \\
\hline 1991 & Informação não disponível. \\
\hline 2001 & Informação não disponível. \\
\hline 2011 & Informação não disponível. \\
\hline
\end{tabular}

\section{b) Método de Cálculo}

\begin{tabular}{ll}
\hline 1980 & $\mathrm{n} / \mathrm{a}$ \\
\hline 1991 & $\mathrm{n} / \mathrm{a}$ \\
\hline 2001 & $\mathrm{n} / \mathrm{a}$ \\
\hline 2011 & $\mathrm{n} / \mathrm{a}$ \\
\hline
\end{tabular}

\section{c) Escore e Normalização}

\begin{tabular}{ccc}
\hline Cenário & Escore & Escore Normalizado \\
\hline 1980 & $\mathrm{n} / \mathrm{a}$ & $\mathrm{n} / \mathrm{a}$ \\
\hline 1991 & $\mathrm{n} / \mathrm{a}$ & $\mathrm{n} / \mathrm{a}$ \\
\hline 2001 & $\mathrm{n} / \mathrm{a}$ & $\mathrm{n} / \mathrm{a}$ \\
\hline 2011 & $\mathrm{n} / \mathrm{a}$ & $\mathrm{n} / \mathrm{a}$ \\
\hline
\end{tabular}

\section{\begin{tabular}{ll}
\multirow{2}{*}{ Escore } & $\begin{array}{l}\text { Valores de Referência } \\
\text { A administração municipal tem realizado: }\end{array}$ \\
\hline
\end{tabular}}

\begin{tabular}{cl}
\hline 1,00 & $\begin{array}{l}\text { Operaçães de fiscalização, notificação e } \\
\text { autuação dos responsáveis, incluindo aplicação } \\
\text { de sançes mais severas como paralisação das } \\
\text { obras ou demolição parcial ou total dos } \\
\text { empreendimentos }\end{array}$ \\
\hline $0,75 \quad \begin{array}{l}\text { Operaçães de fiscalização de obras e } \\
\text { empreendimentos em desacordo com a } \\
\text { legislação urbanística municipal, notificação e } \\
\text { autuação dos responsáveis, incluindo aplicação } \\
\text { de multas }\end{array}$ \\
\hline $0,50 \quad \begin{array}{l}\text { Operaçães de fiscalização de obras e } \\
\text { empreendimentos em desacordo com a } \\
\text { legislação urbanística municipal, porém não tem } \\
\text { autuado ou aplicado qualquer sanção aos } \\
\text { responsáveis, limitando-se a notificação dos } \\
\text { mesmos }\end{array}$ \\
\hline $0,25 \quad \begin{array}{l}\text { Operações de fiscalização de obras e } \\
\text { empreendimentos em desacordo com a } \\
\text { legislação urbanística municipal somente em } \\
\text { caso de denúncias }\end{array}$ \\
\hline $0,00 \quad \begin{array}{l}\text { A administração municipal não tem realizado } \\
\text { operaçães de fiscalização de obras e } \\
\text { empreendimentos em desacordo com a } \\
\text { legislação urbanística municipal }\end{array}$ \\
\hline
\end{tabular}




\begin{tabular}{ll}
\hline Domínio & 8. Tráfego e Circulação urbana \\
\hline Tema & 8.1. Acidentes de trânsito \\
\hline Indicador & 8.1.1. Acidentes de trânsito \\
\hline Definição & $\begin{array}{l}\text { Número de mortos em acidentes de trânsito } \\
\text { ocorridos em vias urbanas no ano de } \\
\text { referência, por 100.000 habitantes. }\end{array}$ \\
\hline
\end{tabular}

\section{a) Fontes de Dados}

\begin{tabular}{ll}
\hline 1980 & Informação não disponível. \\
\hline 1991 & Informação não disponível. \\
\hline & • Anuário Estatístico de Acidentes de Trânsito - \\
& 2001 do Departamento Nacional de Trânsito \\
2001 & (DENATRAN, 2002) \\
& População total do município de acordo com o \\
& Censo do IBGE (IBGE, 2001). \\
\hline 2011 & (IBGE, 2011a) e (DETRAN-PA, 2011a) \\
\hline
\end{tabular}

\section{b) Método de Cálculo}

\begin{tabular}{|c|c|}
\hline 1980 & $\mathrm{n} / \mathrm{a}$ \\
\hline 1991 & $\mathrm{n} / \mathrm{a}$ \\
\hline 2001 & $\begin{array}{l}\text { - Levantamento do número de mortos em } \\
\text { acidentes de trânsito ocorridos em vias } \\
\text { urbanas no ano de } 2001 \text { - } 62 \text { mortos; } \\
\text { - População total do município no ano de } \\
\text { referência - } 1.280 .614 \text { habitantes; } \\
\text { - O indicador é obtido através da equação: } \\
\text { I = } M \text { / ( } P \text { / 100.000) } \\
\text { Onde: } \\
I=\text { indicador referente a mortes e } \\
\text { feridos graves em acidentes de } \\
\text { trânsito; } \\
M=\text { número de mortos em acidentes } \\
\text { de trânsito ocorridos em vias urbanas } \\
\text { no ano de referência. }\end{array}$ \\
\hline 2011 & $\begin{array}{l}\text { - Número de mortos = } 108 \\
\text { - } \text { População = 1.393.399 habitantes }\end{array}$ \\
\hline
\end{tabular}

\section{c) Escore e Normalização}

\begin{tabular}{ccc}
\hline Cenário & Escore & Escore Normalizado \\
\hline 1980 & $\mathrm{n} / \mathrm{a}$ & $\mathrm{n} / \mathrm{a}$ \\
\hline 1991 & $\mathrm{n} / \mathrm{a}$ & $\mathrm{n} / \mathrm{a}$ \\
\hline 2001 & 4,84 & 0,88 \\
\hline 2011 & 7,75 & 0,81 \\
\hline
\end{tabular}

\begin{tabular}{ll}
\hline Escore & $\begin{array}{l}\text { Valores de Referência } \\
\text { Número de mortos em acidentes de trânsito } \\
\text { ocorridos em vias urbanas do município no ano } \\
\text { de referência por } 100.000 \text { habitantes }\end{array}$ \\
\hline 1,00 & Não houve \\
\hline 0,75 & 10 \\
\hline 0,50 & 20 \\
\hline 0,25 & 30 \\
\hline 0,00 & 40 ou mais \\
\hline
\end{tabular}

\begin{tabular}{ll}
\hline Domínio & Tráfego e Circulação urbana \\
\hline Tema & Acidentes de trânsito \\
\hline Indicador & 8.1.2. Acidentes com pedestres e ciclistas \\
\hline Definição & $\begin{array}{l}\text { Porcentagem dos acidentes de trânsito } \\
\text { ocorridos no ano de referência em vias } \\
\text { urbanas do município envolvendo pedestres e } \\
\text { ciclistas. }\end{array}$ \\
\hline
\end{tabular}

\section{a) Fontes de Dados}

\begin{tabular}{ll}
\hline 1980 & Informação não disponível. \\
\hline 1991 & Informação não disponível. \\
\hline 2001 & $\begin{array}{l}\text { Anuário Estatístico de Acidentes de Trânsito - } \\
\text { 2001 do Departamento Nacional de Trânsito } \\
\text { (DENATRAN, 2002). }\end{array}$ \\
\hline 2011 & (IBGE, 2011a) e (DETRAN-PA, 2011a) \\
\hline
\end{tabular}

\section{b) Método de Cálculo}

\begin{tabular}{|c|c|}
\hline 1980 & $\mathrm{n} / \mathrm{a}$ \\
\hline 1991 & $\mathrm{n} / \mathrm{a}$ \\
\hline 2001 & $\begin{array}{l}\text { - Não foi possível encontrar, no relatório do } \\
\text { DENATRAN, o número total de acidentes, já } \\
\text { que este tem o foco principal nos acidentes } \\
\text { com vítimas. } \\
\text { - Levantamento do número total de acidentes } \\
\text { com vítima, ocorridos no ano de 2001: } 1.095 \\
\text { acidentes; } \\
\text { - Levantamento do número total de mortos e } \\
\text { feridos, referentes aos acidentes ocorridos no } \\
\text { ano de } 2001: 62 \text { mortos e } 1226 \text { feridos; } \\
\text { - Levantamento do número de acidentes com } \\
\text { vítima, ocorridos no ano de } 2001 \text {, envolvendo } \\
\text { pedestres e ciclistas: } \\
\text { - Número de atropelamentos ocorridos no } \\
\text { ano - } 463 \text { atropelamentos; } \\
\text { - Número de acidentes envolvendo ciclistas - } \\
\text { o relatório não apresenta, separadamente, } \\
\text { o número de acidentes que envolvem } \\
\text { ciclistas. Se a prática for a mesma de } \\
\text { muitas cidades brasileiras, estes devem } \\
\text { estar classificados como atropelamentos. } \\
\text { - Estimativa do número total de acidentes. Não } \\
\text { existem informações sobre o número toral de } \\
\text { acidentes para o ano de } 2001 \text {. Consultando o } \\
\text { Relatório Estatístico do DETRAN-PA para o } \\
\text { período } 2007-2009 \text { (DETRAN-PA, } 2010 \text { ), } \\
\text { verifica-se que, em média, o número de } \\
\text { acidentes é igual a quatro vezes o número de } \\
\text { mortos e feridos. Ter-se-ia, então, um número } \\
\text { estimado de } 5100 \text { acidentes. } \\
\text { número de acidentes com pedestre e ciclistas } \\
\text { e o total de acidentes: } 463 / 5100=9 \% \\
\text { o } \text { - }\end{array}$ \\
\hline 2011 & $\begin{array}{l}\text { - Acidentes com pedestres e ciclistas: } 703+ \\
593=1296 \\
\text { - Total de acidentes: } 10506\end{array}$ \\
\hline
\end{tabular}

\section{c) Escore e Normalização}

\begin{tabular}{ccc}
\hline Cenário & Escore & Escore Normalizado \\
\hline 1980 & $\mathrm{n} / \mathrm{a}$ & $\mathrm{n} / \mathrm{a}$ \\
\hline 1991 & $\mathrm{n} / \mathrm{a}$ & $\mathrm{n} / \mathrm{a}$ \\
\hline 2001 & $9 \%$ & 0,80 \\
\hline 2011 & $12,34 \%$ & 0,63 \\
\hline
\end{tabular}




\begin{tabular}{|c|c|}
\hline Escore & $\begin{array}{l}\text { Valores de Referência } \\
\text { Porcentagem dos acidentes de trânsito } \\
\text { ocorridos em vias urbanas do município no ano } \\
\text { de referência envolvendo pedestres e ciclistas }\end{array}$ \\
\hline 1,00 & Até $5 \%$ \\
\hline 0,75 & $10 \%$ \\
\hline 0,50 & $15 \%$ \\
\hline 0,25 & $20 \%$ \\
\hline 0,00 & $25 \%$ ou mais \\
\hline Domínio & Tráfego e Circulação urbana \\
\hline Tema & Acidentes de trânsito \\
\hline Indicador & 8.1.3. Prevenção de acidentes \\
\hline Definição & $\begin{array}{l}\text { Porcentagem da extensão de vias locais com } \\
\text { dispositivos de moderação de tráfego em } \\
\text { relação à extensão total de vias locais do } \\
\text { sistema viário urbano. }\end{array}$ \\
\hline
\end{tabular}

a) Fontes de Dados

\begin{tabular}{ll}
\hline 1980 & Informação não disponível nos relatórios. \\
\hline 1991 & Informação não disponível no relatório. \\
\hline 2001 & Informação não disponível no relatório. \\
\hline 2011 & $\begin{array}{l}\text { Levantamentos de campo feitos pelo pessoal do } \\
\text { ITEP/UFPA e consulta à CTBel. }\end{array}$ \\
\hline
\end{tabular}

\section{b) Método de Cálculo}

\begin{tabular}{ll}
\hline 1980 & n/a \\
\hline 1991 & n/a \\
\hline 2001 & n/a \\
\hline 2011 & $\begin{array}{l}\text { Informações sobre a localização de alguns } \\
\text { dispositivos de controle de tráfego, tais como: } \\
\text { lombadas, platôs e estreitamento de vias. }\end{array}$ \\
\hline
\end{tabular}

c) Escore e Normalização

\begin{tabular}{ccc}
\hline Cenário & Escore & Escore Normalizado \\
\hline 1980 & $\mathrm{n} / \mathrm{a}$ & $\mathrm{n} / \mathrm{a}$ \\
\hline 1991 & $\mathrm{n} / \mathrm{a}$ & $\mathrm{n} / \mathrm{a}$ \\
\hline 2001 & $\mathrm{n} / \mathrm{a}$ & $\mathrm{n} / \mathrm{a}$ \\
\hline 2011 & $25 \%$ & 0,25 \\
\hline & \\
\hline & $\begin{array}{l}\text { Valores de Referência } \\
\text { Escore }\end{array}$ & $\begin{array}{l}\text { Porcentagem das vias locais do sistema viário } \\
\text { urbano que apresentam dispositivos de } \\
\text { moderação de tráfego }\end{array}$ \\
\hline 1,00 & $100 \%$ \\
\hline 0,75 & $75 \%$ \\
\hline 0,50 & $\begin{array}{l}50 \% \\
0,25\end{array}$ & $25 \%$ \\
\hline 0,00 & $\begin{array}{l}\text { As vias locais do sistema viário urbano não } \\
\text { apresentam dispositivos de moderação de } \\
\text { tráfego }\end{array}$ \\
\hline
\end{tabular}

\begin{tabular}{ll}
\hline Domínio & Tráfego e Circulação Urbana \\
\hline Tema & 8.2. Educação para o trânsito \\
\hline Indicador & 8.2.1. Educação para o trânsito \\
\hline & $\begin{array}{l}\text { Porcentagem de escolas de nível pré-escolar, } \\
\text { fundamental e médio, públicas e particulares, } \\
\text { promovendo aulas ou campanhas de } \\
\text { educação para o trânsito no ano de referência } \\
\text { no município. }\end{array}$ \\
\hline
\end{tabular}

a) Fontes de Dados

\begin{tabular}{ll}
\hline 1980 & Informação não disponível. \\
\hline 1991 & Informação não disponível. \\
\hline 2001 & Informação não disponível. \\
\hline 2011 & $\begin{array}{l}\text { Levantamento de informações feito pelo pessoal } \\
\text { do ITEP/UFPA. }\end{array}$ \\
\hline
\end{tabular}

\section{b) Método de Cálculo}

\begin{tabular}{ll}
\hline 1980 & n/a \\
\hline 1991 & n/a \\
\hline 2001 & n/a \\
\hline 2011 & O levantamento levou ao resultado de $25 \%$. \\
\hline
\end{tabular}

\section{c) Escore e Normalização}

\begin{tabular}{ccc}
\hline Cenário & Escore & Escore Normalizado \\
\hline 1980 & $\mathrm{n} / \mathrm{a}$ & $\mathrm{n} / \mathrm{a}$ \\
\hline 1991 & $\mathrm{n} / \mathrm{a}$ & $\mathrm{n} / \mathrm{a}$ \\
\hline 2001 & $\mathrm{n} / \mathrm{a}$ & $\mathrm{n} / \mathrm{a}$ \\
\hline 2011 & $25 \%$ & 0,25 \\
\hline
\end{tabular}

\begin{tabular}{ll}
\hline Escore & $\begin{array}{l}\text { Valores de Referência } \\
\text { Porcentagem das escolas públicas ou } \\
\text { particulares do município que implantaram } \\
\text { disciplinas ou programas de educação para o } \\
\text { trânsito no ano de referência }\end{array}$ \\
\hline 1,00 & $100 \%$ \\
\hline 0,75 & $75 \%$ \\
\hline 0,50 & $50 \%$ \\
\hline 0,25 & $25 \%$ \\
\hline 0,00 & 0 \\
\hline & \\
\hline Domínio & Tráfego e Circulação Urbana \\
\hline Tema & 8.3. Fluidez e circulação \\
\hline Indicador & 8.3.1. Congestionamento \\
\hline Definição & $\begin{array}{l}\text { Média diária mensal de horas de } \\
\text { congestionamento de tráfego em vias da rede } \\
\text { viária principal. }\end{array}$ \\
\hline
\end{tabular}

\section{a) Fontes de Dados}

\begin{tabular}{ll}
\hline 1980 & Informação não disponível. \\
\hline 1991 & Informação não disponível. \\
\hline \multirow{2}{*}{2001} & $\begin{array}{l}\text { Verificamos os dados das pesquisas de tempos } \\
\text { de viagem (velocidade-retardamento) do PDTU- } \\
\text { RMB (JICA, 2001). Essas pesquisas mostram } \\
\text { trechos com velocidades baixas, até menos de } \\
20 \mathrm{~km} / \mathrm{h}, \text { e citam congestionamentos entre as }\end{array}$ \\
\hline
\end{tabular}




\begin{tabular}{|c|c|}
\hline & $\begin{array}{l}\text { causas para os retardamentos, mas não foi } \\
\text { possível definir a duração dos períodos de } \\
\text { congestionamento. }\end{array}$ \\
\hline 2011 & $\begin{array}{l}\text { Experiência da equipe UFPA, nos principais } \\
\text { corredores de tráfego de Belém (área central). } \\
\text { Também dados do levantamento para o } \\
\text { indicador Velocidade de Tráfego (8.3.2). }\end{array}$ \\
\hline
\end{tabular}

b) Método de Cálculo

\begin{tabular}{ll}
\hline 1980 & n/a \\
\hline 1991 & n/a \\
\hline 2001 & n/a \\
\hline 2011 & Valor estimado em 3 horas. \\
\hline
\end{tabular}

c) Escore e Normalização

\begin{tabular}{ccc}
\hline Cenário & Escore & Escore Normalizado \\
\hline 1980 & $\mathrm{n} / \mathrm{a}$ & $\mathrm{n} / \mathrm{a}$ \\
\hline 1991 & $\mathrm{n} / \mathrm{a}$ & $\mathrm{n} / \mathrm{a}$ \\
\hline 2001 & $\mathrm{n} / \mathrm{a}$ & $\mathrm{n} / \mathrm{a}$ \\
\hline 2011 & 3,00 & 0,50 \\
\hline
\end{tabular}

\begin{tabular}{|c|c|}
\hline Escore & $\begin{array}{l}\text { Valores de Referência } \\
\text { Média diária mensal de horas de } \\
\text { congestionamento de tráfego em vias da rede } \\
\text { principal }\end{array}$ \\
\hline 1,00 & Até 1 hora/dia \\
\hline 0,75 & 2 horas/dia \\
\hline 0,50 & 3 horas/dia \\
\hline 0,25 & 4 horas/dia \\
\hline 0,00 & 5 horas/dia ou mais \\
\hline Domínio & Tráfego e Circulação Urbana \\
\hline Tema & Fluidez e Circulação \\
\hline Indicador & 8.3.2. Velocidade média do tráfego \\
\hline Definição & $\begin{array}{l}\text { Velocidade média de deslocamento em } \\
\text { transporte individual motorizado, observada } \\
\text { num circuito preestabelecido de vias (rede } \\
\text { viária principal), em horário de pico. }\end{array}$ \\
\hline
\end{tabular}

a) Fontes de Dados

\begin{tabular}{ll}
\hline 1980 & Relatório do TRANSCOL (GEIPOT, 1980) \\
\hline 1991 & Relatório do PDTU (JICA, 1991). \\
\hline $\begin{array}{l}\text { Dados das pesquisas de tempos de viagem } \\
\text { (velocidade-retardamento) do PDTU-RMB (JICA, } \\
\text { 2001), do arquivo "VELOCIDADE MEDIA } \\
\text { TOTAL.xIs" (CD 2). }\end{array}$ \\
\hline 2011 & $\begin{array}{l}\text { Levantamento de dados, feito pelo pessoal do } \\
\text { ITEP/UFPA, abrangendo uma amostra de vias } \\
\text { do sistema principal. }\end{array}$ \\
\hline
\end{tabular}

b) Método de Cálculo

O quadro C.4-1 apresenta os valores de velocidades médias do transporte coletivo para

1980 vários trechos da malha viária principal de Belém. Dependendo do sentido (bairro-centro ou centro-bairro) e do período (pico da manhã ou da tarde) os valores de velocidade variam de $10 \mathrm{a}$

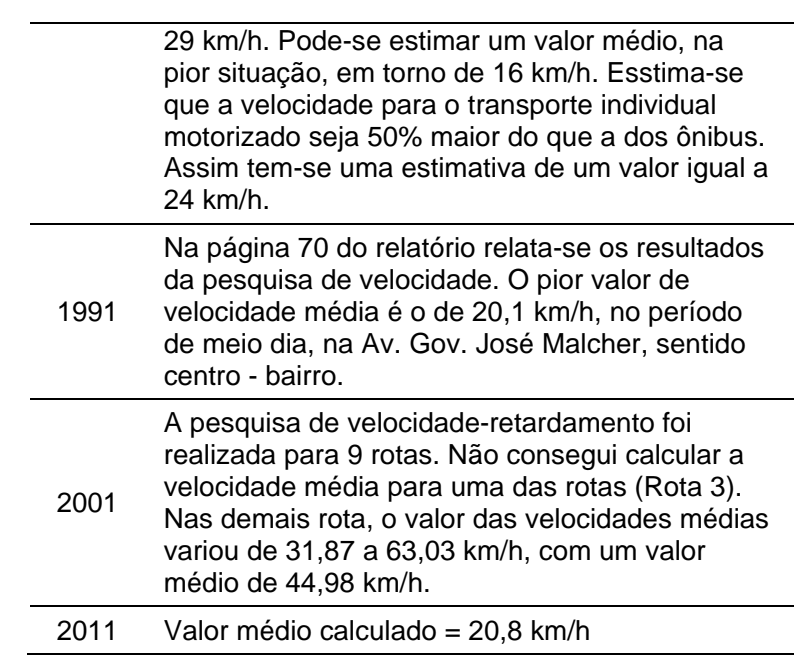

c) Escore e Normalização

\begin{tabular}{ccc}
\hline Cenário & Escore & Escore Normalizado \\
\hline 1980 & 24,0 & 0,70 \\
\hline 1991 & 20,1 & 0,51 \\
\hline 2001 & 31,9 & 1,00 \\
\hline 2011 & 20,8 & 0,54 \\
\hline
\end{tabular}

\begin{tabular}{|c|c|}
\hline & Valores de Referência \\
\hline Escore & $\begin{array}{l}\text { Velocidade média de tráfego, no pico, em vias } \\
\text { da rede principal }\end{array}$ \\
\hline 1,00 & Igual ou superior a $30 \mathrm{~km} / \mathrm{h}$ \\
\hline 0,75 & $25 \mathrm{~km} / \mathrm{h}$ \\
\hline 0,50 & $20 \mathrm{~km} / \mathrm{h}$ \\
\hline 0,25 & $15 \mathrm{~km} / \mathrm{h}$ \\
\hline 0,00 & Até $10 \mathrm{~km} / \mathrm{h}$ \\
\hline Domínio & Tráfego e Circulação Urbana \\
\hline Tema & 8.4. Operação e fiscalização de trânsito \\
\hline Indicador & 8.4.1. Violação das leis de trânsito \\
\hline Definição & $\begin{array}{l}\text { Porcentagem de condutores habilitados que } \\
\text { cometeram infrações em relação ao número } \\
\text { de condutores com habilitação no município } \\
\text { no ano de referência. }\end{array}$ \\
\hline
\end{tabular}

\section{a) Fontes de Dados}

\begin{tabular}{ll}
\hline 1980 & Informação não disponível. \\
\hline 1991 & Informação não disponível. \\
\hline 2001 & Informação não disponível. \\
\hline 2011 & Informação não disponível. \\
\hline
\end{tabular}

\section{b) Método de Cálculo}

\begin{tabular}{ll}
\hline 1980 & $\mathrm{n} / \mathrm{a}$ \\
\hline 1991 & $\mathrm{n} / \mathrm{a}$ \\
\hline 2001 & $\mathrm{n} / \mathrm{a}$ \\
\hline 2011 & $\mathrm{n} / \mathrm{a}$ \\
\hline
\end{tabular}


c) Escore e Normalização

\begin{tabular}{ccc}
\hline Cenário & Escore & Escore Normalizado \\
\hline 1980 & $\mathrm{n} / \mathrm{a}$ & $\mathrm{n} / \mathrm{a}$ \\
\hline 1991 & $\mathrm{n} / \mathrm{a}$ & $\mathrm{n} / \mathrm{a}$ \\
\hline 2001 & $\mathrm{n} / \mathrm{a}$ & $\mathrm{n} / \mathrm{a}$ \\
\hline 2011 & 2,60 & 0,93 \\
\hline
\end{tabular}

\begin{tabular}{|c|c|}
\hline Escore & $\begin{array}{l}\text { Valores de Referência } \\
\text { Porcentagem dos condutores com habilitação } \\
\text { que cometeram infrações gravíssimas ou } \\
\text { atingiram mais de } 20 \text { pontos no ano de } \\
\text { referência no município }\end{array}$ \\
\hline 1,00 & Até $2 \%$ \\
\hline 0,75 & $4 \%$ \\
\hline 0,50 & $6 \%$ \\
\hline 0,25 & $8 \%$ \\
\hline 0,00 & $10 \%$ ou mais \\
\hline Domínio & Tráfego e Circulação Urbana \\
\hline Tema & 8.5. Transporte individual \\
\hline Indicador & 8.5.1. Índice de Motorização \\
\hline Definição & $\begin{array}{l}\text { Número de automóveis registrados no } \\
\text { município por } 1.000 \text { habitantes no ano de } \\
\text { referência. }\end{array}$ \\
\hline
\end{tabular}

a) Fontes de Dados

\begin{tabular}{cl}
\hline \multirow{2}{1}{1980} & $\begin{array}{l}\text { Relatório do PDTU (JICA, 1991) e Anuário } \\
\text { Estatístico (PMB, 2011a). }\end{array}$ \\
\hline \multirow{2}{*}{1991} & $\begin{array}{l}\text { Relatório do PDTU (JICA, 1991) e Anuário } \\
\text { Estatístico (PMB, 2011a). }\end{array}$ \\
\hline 2001 & $\begin{array}{l}\text { Relatório do DENATRAN (DENATRAN, 2002) e } \\
\text { Censo 2000 (IBGE, 2001). }\end{array}$ \\
\hline 2011 & (IBGE, 2011a) e (DETRAN-PA, 2011b) \\
\hline
\end{tabular}

b) Método de Cálculo

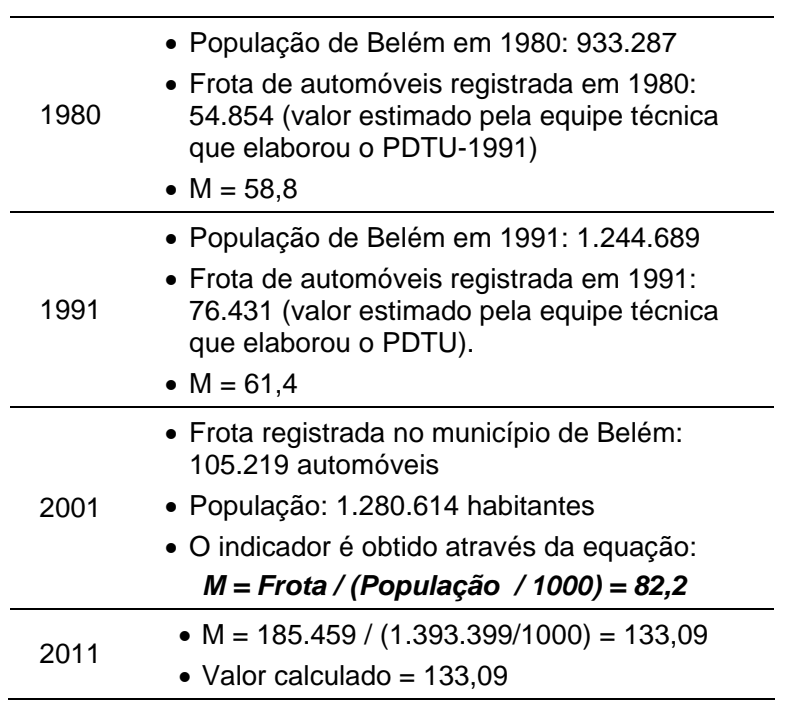

c) Escore e Normalização

\begin{tabular}{ccc}
\hline Cenário & Escore & Escore Normalizado \\
\hline 1980 & 58,8 & 1,00 \\
\hline 1991 & 61,4 & 1,00 \\
\hline 2001 & 82,2 & 1,00 \\
\hline 2011 & 133,1 & 1,00 \\
\hline
\end{tabular}

\begin{tabular}{ll}
\hline Escore & $\begin{array}{l}\text { Valores de Referência } \\
\text { Número de automóveis por } 1.000 \text { habitantes }\end{array}$ \\
\hline 1,00 & Até 250 \\
\hline 0,75 & 300 \\
\hline 0,50 & 350 \\
\hline 0,25 & 400 \\
\hline 0,00 & 450 ou mais \\
\hline
\end{tabular}

\begin{tabular}{ll}
\hline Domínio & Tráfego e Circulação Urbana \\
\hline Tema & Transporte individual \\
\hline Indicador & 8.5.2. Taxa de ocupação de veículos \\
\hline Definição & $\begin{array}{l}\text { Número médio de passageiros em } \\
\text { automóveis privados em deslocamentos feitos } \\
\text { na área urbana do município, para todos os } \\
\text { motivos de viagem. }\end{array}$ \\
\hline
\end{tabular}

a) Fontes de Dados

\begin{tabular}{ll}
\hline 1980 & Dados não disponíveis. \\
\hline 1991 & Dados não disponíveis. \\
\hline 2001 & Relatório Final do PDTU-RMB (JICA, 2001). \\
\hline 2011 & $\begin{array}{l}\text { Levantamento feito pela equipe do ITEP/UFPA } \\
\text { em corredor da área central de Belém }\end{array}$ \\
\hline
\end{tabular}

\section{b) Método de Cálculo}

\begin{tabular}{ll}
\hline 1980 & n/a \\
\hline 1991 & n/a \\
\hline \multicolumn{1}{c}{$\begin{array}{l}\text { Na página 32 do relatório, apresentam-se os } \\
\text { resultados para a taxa de ocupação para as } \\
\text { screen-lines 1 e 2, com valores de 1,90 e 2,00, } \\
\text { respectivamente. } \\
\text { O Escore foi obtido através do cálculo da média } \\
\text { desses dois valores: 1,95. }\end{array}$} \\
\hline 2011 & $\begin{array}{l}\text { Valor médio encontrado de 1,45 passageiros por } \\
\text { veículo }\end{array}$ \\
\hline
\end{tabular}

c) Escore e Normalização

\begin{tabular}{ccc}
\hline Cenário & Escore & Escore Normalizado \\
\hline 1980 & $\mathrm{n} / \mathrm{a}$ & $\mathrm{n} / \mathrm{a}$ \\
\hline 1991 & $\mathrm{n} / \mathrm{a}$ & $\mathrm{n} / \mathrm{a}$ \\
\hline 2001 & 1,95 & 0,31 \\
\hline 2011 & 1,45 & 0,15 \\
\hline
\end{tabular}




\begin{tabular}{|c|c|}
\hline & Valores de Referência \\
\hline Escore & $\begin{array}{l}\text { Taxa de ocupação média em deslocamentos na } \\
\text { área urbana }\end{array}$ \\
\hline 1,00 & 4 passageiros/automóvel \\
\hline 0,66 & 3 passageiros/automóvel \\
\hline 0,33 & 2 passageiros/automóvel \\
\hline 0,00 & 1 passageiro/automóvel \\
\hline Domínio & 9. Sistemas de Transporte Urbano \\
\hline Tema & $\begin{array}{l}\text { 9.1. Disponibilidade e qualidade do transporte } \\
\text { público }\end{array}$ \\
\hline Indicador & 9.1.1. Extensão da rede de transporte público \\
\hline Definição & $\begin{array}{l}\text { Extensão total da rede de transporte público } \\
\text { em relação à extensão total do sistema viário } \\
\text { urbano. }\end{array}$ \\
\hline
\end{tabular}

a) Fontes de Dados

\begin{tabular}{|c|c|}
\hline 1980 & Informações não disponíveis. \\
\hline 1991 & Relatório do PDTU (JICA, 1991). \\
\hline 2001 & $\begin{array}{l}\text { Base georreferenciada da área de estudo do } \\
\text { PDTU (JICA, 2001), incluindo as camadas do } \\
\text { sistema viário total e a das vias utilizadac pelo } \\
\text { sistema de transporte coletivo. }\end{array}$ \\
\hline 2011 & Informações não disponíveis. \\
\hline
\end{tabular}

b) Método de Cálculo

\begin{tabular}{ll}
\hline 1980 & n/a \\
\hline 1991 & $\begin{array}{l}\text { A informação que consta da página } 55 \text { do } \\
\text { relatório é de que existia um total de } 443 \mathrm{~km} \\
\text { de vias urbanas, mas não existe informação } \\
\text { sobre a extensção da malha de transporte } \\
\text { coletivo. }\end{array}$ \\
\hline $\begin{array}{l}\text { - Filtragem da base total para a eliminação } \\
\text { dos links de centroides e aquavias; }\end{array}$ \\
$\begin{array}{l}\text { - Cálculo da extensão total do sistema viário } \\
\text { na área urbana - 829 km; } \\
\text { • Cálculo da extensão total da rede de } \\
\text { transporte público - 437 km. }\end{array}$ \\
\hline 2011 & \\
\hline
\end{tabular}

c) Escore e Normalização

\begin{tabular}{ccc}
\hline Cenário & Escore & Escore Normalizado \\
\hline 1980 & $\mathrm{n} / \mathrm{a}$ & $\mathrm{n} / \mathrm{a}$ \\
\hline 1991 & $\mathrm{n} / \mathrm{a}$ & $\mathrm{n} / \mathrm{a}$ \\
\hline 2001 & $53 \%$ & 0,41 \\
\hline 2011 & $\mathrm{n} / \mathrm{a}$ & $\mathrm{n} / \mathrm{a}$ \\
\hline
\end{tabular}

\begin{tabular}{ll}
\hline Escore & $\begin{array}{l}\text { Valores de Referência } \\
\text { Extensão da rede de transporte público em } \\
\text { relação a extensão do sistema viário }\end{array}$ \\
\hline 1,00 & Igual ou superior \\
\hline 0,75 & $80 \%$ \\
\hline 0,50 & $60 \%$ \\
\hline 0,25 & $40 \%$ \\
\hline 0,00 & Até $20 \%$ \\
\hline
\end{tabular}

\begin{tabular}{ll}
\hline Domínio & Sistemas de Transporte Urbano \\
\hline Tema & $\begin{array}{l}\text { Disponibilidade e qualidade do transporte } \\
\text { público }\end{array}$ \\
\hline Indicador & $\begin{array}{l}\text { 9.1.2. Frequência de atendimento do } \\
\text { transporte público }\end{array}$ \\
\hline Definiçãoo & $\begin{array}{l}\text { Frequência média de veículos de transporte } \\
\text { coletivo por ônibus em linhas urbanas no } \\
\text { município, nos dias úteis e períodos de pico. }\end{array}$ \\
\hline
\end{tabular}

a) Fontes de Dados

\begin{tabular}{ll}
\hline 1980 & Relatório do TRANSCOL (GEIPOT, 1980) \\
\hline 1991 & Relatório do PDTU (JICA, 1991) \\
\hline 2001 & $\begin{array}{l}\text { Planilha "Dados Operacionais.xIs" do CD 2 do } \\
\text { PDTU-RMB (JICA, 2001). }\end{array}$ \\
\hline 2011 & $\begin{array}{l}\text { Relatórios de planos e estudos da RMB (JICA, } \\
\text { 2003; PARÁ, 2006; JICA, 2010) }\end{array}$ \\
\hline
\end{tabular}

\section{b) Método de Cálculo}

\begin{tabular}{ll}
\hline \multirow{2}{*}{1980} & $\begin{array}{l}\text { No quadro C.5-1, na página 32 do relatório, } \\
\text { encontra-se o valor do intervalo, no horário de } \\
\text { pico, para cada linha. O valor médio fica em } \\
\text { torno de } 6 \text { minutos. }\end{array}$ \\
\hline \multirow{2}{*}{$\begin{array}{l}\text { Na tabela 6.2-3 do relatório, encontra-se o } \\
\text { valor entre } 5 \text { (área central) e } 6 \text { min. (área de } \\
\text { transição). Para as linhas classificadas como } \\
\text { suburbanas o intervalo é de } 11 \text { minutos. } \\
\text { Adotou-se o valor de 5,5 min. }\end{array}$} \\
\hline \multirow{2001}{*}{$\begin{array}{l}\text { Verificação dos intervalos médios entre } \\
\text { viagens de cada linha, no período de pico; } \\
\text { Cálculo da média das médias desses valores. }\end{array}$} \\
\hline $\begin{array}{l}\text { Não foi encontrada a informação explícita que } \\
\text { permitisse o cálculo do valor médio do } \\
\text { intervalo, mas baseado na leitura dos } \\
\text { relatórios pode-se deduzir que o intervalo } \\
\text { médio fica abaixo de 15 minutos. }\end{array}$ \\
\hline
\end{tabular}

\section{c) Escore e Normalização}

\begin{tabular}{ccc}
\hline Cenário & Escore & Escore Normalizado \\
\hline 1980 & 6,0 & 1,00 \\
\hline 1991 & 5,5 & 1,00 \\
\hline 2001 & 5,4 & 1,00 \\
\hline 2011 & $<15$ & 1,00 \\
\hline
\end{tabular}

\begin{tabular}{cl}
\hline Escore & $\begin{array}{l}\text { Valores de Referência } \\
\text { Frequência média de atendimento do serviço de } \\
\text { transporte público por ônibus nos horários de } \\
\text { pico }\end{array}$ \\
\hline 1,00 & Até 15 minutos ou 4,00 ônibus/hora \\
\hline 0,75 & 20 minutos ou 3,00 ônibus/hora \\
\hline 0,50 & 25 minutos ou 2,4 ônibus/hora \\
\hline 0,25 & 30 minutos ou 2 ônibus/hora \\
\hline 0,00 & 35 minutos ou mais, ou 1,7 ônibus/hora \\
\hline
\end{tabular}




\begin{tabular}{ll}
\hline Domínio & Sistemas de Transporte Urbano \\
\hline Tema & $\begin{array}{l}\text { Disponibilidade e qualidade do transporte } \\
\text { público }\end{array}$ \\
\hline Indicador & 9.1.3. Pontualidade \\
\hline Definição & $\begin{array}{l}\text { Porcentagem das viagens em veículos de } \\
\text { transporte coletivo por ônibus respeitando a } \\
\text { programação horária. }\end{array}$ \\
\hline
\end{tabular}

\section{a) Fontes de Dados}

\begin{tabular}{ll}
\hline 1980 & Informação não disponível. \\
\hline 1991 & Informação não disponível. \\
\hline 2001 & Informação não disponível. \\
\hline 2011 & Informação não disponível. \\
\hline
\end{tabular}

\section{b) Método de Cálculo}

\begin{tabular}{ll}
\hline 1980 & n/a \\
\hline 1991 & $\mathrm{n} / \mathrm{a}$ \\
\hline 2001 & $\mathrm{n} / \mathrm{a}$ \\
\hline 2011 & $\mathrm{n} / \mathrm{a}$ \\
\hline
\end{tabular}

\section{c) Escore e Normalização}

\begin{tabular}{ccc}
\hline Cenário & Escore & Escore Normalizado \\
\hline 1980 & $\mathrm{n} / \mathrm{a}$ & $\mathrm{n} / \mathrm{a}$ \\
\hline 1991 & $\mathrm{n} / \mathrm{a}$ & $\mathrm{n} / \mathrm{a}$ \\
\hline 2001 & $\mathrm{n} / \mathrm{a}$ & $\mathrm{n} / \mathrm{a}$ \\
\hline 2011 & $\mathrm{n} / \mathrm{a}$ & $\mathrm{n} / \mathrm{a}$ \\
\hline
\end{tabular}

\begin{tabular}{|c|c|}
\hline Escore & $\begin{array}{l}\text { Valores de Referência } \\
\text { Porcentagem das viagens por transporte } \\
\text { coletivo por ônibus no mês analisado que } \\
\text { respeitaram os horários programados }\end{array}$ \\
\hline 1,00 & $100 \%$ \\
\hline 0,75 & $95 \%$ \\
\hline 0,50 & $90 \%$ \\
\hline 0,25 & $85 \%$ \\
\hline 0,00 & $80 \%$ ou menos \\
\hline Domínio & Sistemas de Transporte Urbano \\
\hline Tema & $\begin{array}{l}\text { Disponibilidade e qualidade do transporte } \\
\text { público }\end{array}$ \\
\hline Indicador & 9.1.4. Velocidade média do transporte público \\
\hline Definição & $\begin{array}{l}\text { Velocidade média de deslocamento em } \\
\text { transporte público por ônibus (velocidade } \\
\text { comercial). }\end{array}$ \\
\hline
\end{tabular}

\section{a) Fontes de Dados}

\begin{tabular}{ll}
\hline 1980 & $\begin{array}{l}\text { Relatório do estudo de racionalização (GEIPOT, } \\
\text { 1986). }\end{array}$ \\
\hline 1991 & Relatório do PDTU (JICA, 1991). \\
\hline 2001 & $\begin{array}{l}\text { Planilha "Dados Operacionais.xIs" do CD 2 do } \\
\text { PDTU-RMB (JICA, 2001). }\end{array}$ \\
\hline 2011 & $\begin{array}{l}\text { Levantamento feito pela equipe do ITEP/UFPA } \\
\text { em uma amostra de 10\% das linhas de ônibus } \\
\text { urbano. }\end{array}$ \\
\hline
\end{tabular}

b) Método de Cálculo

\begin{tabular}{cl}
\hline 1980 & $\begin{array}{l}\text { Na página 21 do relatório existe uma tabela com } \\
\text { a velocidade média de cada linha e do conjunto } \\
\text { como o todo, com um valor de } 22,7 \mathrm{~km} / \mathrm{h} .\end{array}$ \\
\hline 1991 & $\begin{array}{l}\text { Na página } 119 \text { do relatório final, existe a } \\
\text { informação de velocidade média entre } 18,9 \mathrm{e} \\
21,2 \mathrm{~km} / \mathrm{h} \text {. Adotou-se aqui o valor de } 20 \mathrm{~km} / \mathrm{h} .\end{array}$ \\
\hline 2001 & $\begin{array}{l}\text { Cálculo da velocidade média comercial de cada } \\
\text { linha apresentada na planilha; } \\
\text { Adoção da média dos valores das velocidades } \\
\text { médias de cada linha. }\end{array}$ \\
\hline 2011 & $\begin{array}{l}\text { Valor da velocidade média calculado em } 19,6 \\
\mathrm{~km} / \mathrm{h}\end{array}$ \\
\hline
\end{tabular}

c) Escore e Normalização

\begin{tabular}{ccc}
\hline Cenário & Escore & Escore Normalizado \\
\hline 1980 & 22,7 & 0,64 \\
\hline 1991 & 20,0 & 0,50 \\
\hline 2001 & 24,0 & 0,70 \\
\hline 2011 & 19,6 & 0,48 \\
\hline
\end{tabular}

\begin{tabular}{cl}
\hline Escore & $\begin{array}{l}\text { Valores de Referência } \\
\text { Velocidade média do serviço de transporte } \\
\text { coletivo por ônibus em horário de pico }\end{array}$ \\
\hline 1,00 & Mais de $25 \mathrm{~km} / \mathrm{h}$ \\
\hline 0,75 & $25 \mathrm{~km} / \mathrm{h}$ \\
\hline 0,50 & $20 \mathrm{~km} / \mathrm{h}$ \\
\hline 0,25 & $15 \mathrm{~km} / \mathrm{h}$ \\
\hline 0,00 & Igual ou inferior a $10 \mathrm{~km} / \mathrm{h}$ \\
\hline \multicolumn{1}{c}{ Domínio } & Sistemas de Transporte Urbano \\
\hline Tema & $\begin{array}{l}\text { Disponibilidade e qualidade do transporte } \\
\text { público }\end{array}$ \\
\hline Indicador & $\begin{array}{l}\text { 9.1.5. Idade média da frota de transporte } \\
\text { público }\end{array}$ \\
\hline Definição & $\begin{array}{l}\text { Idade média da frota de ônibus e micro- } \\
\text { município. }\end{array}$ \\
\hline
\end{tabular}

a) Fontes de Dados

\begin{tabular}{ll}
\hline 1980 & Relatório do TRANSCOL (GEIPOT, 1980) \\
\hline 1991 & Relatório do PDTU (JICA, 1991) \\
\hline 2001 & $\begin{array}{l}\text { O relatório do PDTU (JICA, 2001) não contém } \\
\text { esta informação, mas ela existe no estudo } \\
\text { desenvolvido, dois anos depois, para detalhar a } \\
\text { proposta de transporte coletivo (JICA, 2003). }\end{array}$ \\
\hline 2011 & CTBel \\
\hline
\end{tabular}

\section{b) Método de Cálculo}

\begin{tabular}{ll}
\hline 1980 & $\begin{array}{l}\text { No Quadro D.2-II, página 46, encontra-se a } \\
\text { informação de idade média = 2,9 anos. }\end{array}$ \\
\hline 1991 & $\begin{array}{l}\text { Na Tabela 12.6-1, página 331, encontram-se os } \\
\text { dados com a quantidade de veículos com idades } \\
\text { entre 0 e 14 anos. Calculando-se a média, } \\
\text { obtem-se o valor de 4,0 anos. }\end{array}$ \\
\hline 2001 & $\begin{array}{l}\text { Na Tabela 11.3-2, na página 331 do estudo } \\
\text { (JICA, 2003), encontram-se os dados sobre a }\end{array}$ \\
\hline
\end{tabular}




\begin{tabular}{ll}
\hline & $\begin{array}{l}\text { distribuição das idades dos ônibus. A média de } \\
\text { idade calculada foi de 5,3 anos. }\end{array}$ \\
\hline 2011 & Valor da idade média informado = 4,2 anos \\
\hline
\end{tabular}

c) Escore e Normalização

\begin{tabular}{ccc}
\hline Cenário & Escore & Escore Normalizado \\
\hline 1980 & 2,9 & 1,00 \\
\hline 1991 & 4,0 & 1,00 \\
\hline 2001 & 5,3 & 0,94 \\
\hline 2011 & 4,2 & 1,00 \\
\hline
\end{tabular}

\begin{tabular}{|c|c|}
\hline Escore & $\begin{array}{l}\text { Valores de Referência } \\
\text { Idade média da frota de ônibus e micro-ônibus } \\
\text { urbanos }\end{array}$ \\
\hline 1,00 & Até 5 anos \\
\hline 0,66 & 7 anos \\
\hline 0,33 & 9 anos \\
\hline 0,00 & 11 anos ou mais \\
\hline Domínio & Sistemas de Transporte Urbano \\
\hline Tema & $\begin{array}{l}\text { Disponibilidade e qualidade do transporte } \\
\text { público }\end{array}$ \\
\hline Indicador & 9.1.6. Índice de passageiros por quilômetro \\
\hline Definição & $\begin{array}{l}\text { Razão entre o número total de passageiros } \\
\text { transportados e a quilometragem percorrida } \\
\text { pela frota de transporte púbico do município. }\end{array}$ \\
\hline
\end{tabular}

\section{a) Fontes de Dados}

\begin{tabular}{cl}
\hline 1980 & $\begin{array}{l}\text { Relatório do Estudo de Racionalização do } \\
\text { Transporte Coletivo da RMB (GEIPOT, 1986) }\end{array}$ \\
\hline 1991 & Relatório do PDTU (JICA, 1991) \\
\hline 2001 & $\begin{array}{l}\text { Planilha "Dados Operacionais.xls" do CD 2 do } \\
\text { PDTU-RMB (JICA, 2001). }\end{array}$ \\
\hline 2011 & (ESPIRITO SANTO, 2010) \\
\hline
\end{tabular}

\section{b) Método de Cálculo}

\begin{tabular}{|c|c|}
\hline 1980 & $\begin{array}{l}\text { No quadro 3.2, página } 21 \text { do relatório, encontra- } \\
\text { se a informação de IPK }=4,13\end{array}$ \\
\hline 1991 & $\begin{array}{l}\text { - Passageiros transportados por dia: } 1.214 .014 \\
\text { passageiros } \\
\text { - Quilometragem percorrida por dia: } 235.632 \mathrm{~km} \\
\text { - IPK = } 5\end{array}$ \\
\hline 2001 & $\begin{array}{l}\text { Levantamento do IPK médio do serviço de } \\
\text { transporte coletivo urbano. }\end{array}$ \\
\hline 2011 & $\begin{array}{l}\text { - } \text { Passageiros transportados } / \mathrm{dia}=34.160 .793 \\
\text { - } \text { Quilometragem/dia = 12.182.870 } \\
\text { - IPK }=2,8\end{array}$ \\
\hline
\end{tabular}

\section{c) Escore e Normalização}

\begin{tabular}{ccc}
\hline Cenário & Escore & Escore Normalizado \\
\hline 1980 & 4,13 & 0,82 \\
\hline 1991 & 5,00 & 1,00 \\
\hline 2001 & 2,74 & 0,12 \\
\hline 2011 & 2,80 & 0,15 \\
\hline
\end{tabular}

\begin{tabular}{|c|c|}
\hline Escore & $\begin{array}{l}\text { Valores de Referência } \\
\text { IPK do serviço de transporte público por ônibus } \\
\text { no ano de referência (ou mês observado) }\end{array}$ \\
\hline 1,00 & $\begin{array}{l}\text { Igual ou superior a } 4,5 \text { até o limite de } 5 \\
\text { passageiros } / \mathrm{km}\end{array}$ \\
\hline 0,75 & 4 passageiros $/ \mathrm{km}$ \\
\hline 0,50 & 3,5 passageiros $/ \mathrm{km}$ \\
\hline 0,25 & 3 passageiros $/ \mathrm{km}$ \\
\hline 0,00 & Até 2,5 ou superior a 5 passageiros $/ \mathrm{km}$ \\
\hline Domínio & Sistemas de Transporte Urbano \\
\hline Tema & $\begin{array}{l}\text { Disponibilidade e qualidade do transporte } \\
\text { público }\end{array}$ \\
\hline Indicador & 9.1.7. Passageiros transportados anualmente \\
\hline Definição & $\begin{array}{l}\text { Variação em termos percentuais do número } \\
\text { de passageiros transportados pelos serviços } \\
\text { de transporte público urbano no município } \\
\text { para um período de } 2 \text { anos. }\end{array}$ \\
\hline
\end{tabular}

\section{a) Fontes de Dados}

\begin{tabular}{cl}
\hline 1980 & Relatórios dos estudos do GEIPOT $(1980,1986)$ \\
\hline 1991 & $\begin{array}{l}\text { Relatórios do GEIPOT }(1980,1986) \text { e da JICA } \\
(1991)\end{array}$ \\
\hline 2001 & Relatórios dos estudos da JICA (1991, 2001) \\
\hline 2011 & $\begin{array}{l}\text { Sistema de Informações da Mobilidade Urbana } \\
\text { (ANTP, 2008, 2010b, 2011a) }\end{array}$ \\
\hline
\end{tabular}

b) Método de Cálculo

- Passageiros transportados em 1980: 660.637

- Passageiros transportados em 1986: 863.485

- Diferença em 6 anos: 202.848 (crescimento de $30,7 \%)$

- Taxa anual equivalente: $4,6 \%$ aa

- Taxa de crescimento equivalente para 2 anos: 9,3\%

- Passageiros transportados em 1986: 863.485

- Passageiros transportados por dia em 1991: 1.214.014

1991 - Diferença em 5 anos: 350.529 (crescimento de $40,6 \%)$

- Taxa anual equivalente: $7,1 \%$ aa

- Taxa de crescimento equivalente para 2 anos: $14,6 \%$

- Passageiros transportados por dia em 1991: 1.214.014

- Passageiros transportados por dia em 2001: 1.328.088

2001 - Diferença em 10 anos: 114.074 passageiros

- Taxa de crescimento em 10 anos: 9,4\%

- Taxa de crescimento anual: 0,9\% aa

- Taxa de crescimento equivalente para 2 anos: $1,8 \%$

\begin{tabular}{cccc}
\hline \multirow{2}{*}{2011} & ano & passageiros & variação \\
\cline { 2 - 4 } & 2007 & 250949084 & \\
\cline { 2 - 4 } & 2009 & 256070613 & $2,0 \%$ \\
\hline & 2010 & 269413037 & $5,2 \%$ \\
\hline
\end{tabular}


c) Escore e Normalização

\begin{tabular}{ccc}
\hline Cenário & Escore & Escore Normalizado \\
\hline 1980 & 0,75 & 0,75 \\
\hline 1991 & 0,75 & 0,75 \\
\hline 2001 & 0,75 & 0,75 \\
\hline 2011 & 0,75 & 0,75 \\
\hline
\end{tabular}

\begin{tabular}{cl}
\hline Escore & $\begin{array}{l}\text { Valores de Referência } \\
\text { Foi observado para o número de passageiros } \\
\text { transportados em dois anos distintos no } \\
\text { município: }\end{array}$ \\
\hline 1,00 & Crescimento superior a 25\% \\
\hline 0,75 & Crescimento inferior a 25\% \\
\hline 0,50 & $\begin{array}{l}\text { O número de passageiros transportados } \\
\text { permaneceu constante }\end{array}$ \\
\hline 0,25 & Decréscimo inferior a 25\% \\
\hline 0,00 & Decréscimo superior a 25\% \\
\hline Domínio & Sistemas de Transporte Urbano \\
\hline Tema & $\begin{array}{l}\text { Disponibilidade e qualidade do transporte } \\
\text { público }\end{array}$ \\
\hline Indicador & $\begin{array}{l}\text { 9.1.8. Satisfação do usuário com o serviço de } \\
\text { transporte público }\end{array}$ \\
\hline Definição & $\begin{array}{l}\text { Porcentagem da população satisfeita com o } \\
\text { serviço de transporte público urbano e } \\
\text { metropolitano em todas as suas modalidades. }\end{array}$ \\
\hline
\end{tabular}

a) Fontes de Dados

\begin{tabular}{ll}
\hline 1980 & Informação não disponível. \\
\hline 1991 & Informação não disponível. \\
\hline 2001 & $\begin{array}{l}\text { Pesquisa de opinião apresentada no relatório do } \\
\text { PDTU-RMB (JICA, 2001), pág. 67. }\end{array}$ \\
\hline 2011 & (ESPIRITO SANTO, 2010) \\
\hline
\end{tabular}

\section{b) Método de Cálculo}

\begin{tabular}{|c|c|}
\hline 1980 & $\mathrm{n} / \mathrm{a}$ \\
\hline 1991 & $\mathrm{n} / \mathrm{a}$ \\
\hline 2001 & $\begin{array}{l}\text { - Consideradas duas questões repondidas } \\
\text { pelos usuários: } \\
\text { - Qual a lotação dos ônibus nos } \\
\text { deslocamentos diários? } \\
\text { - percentual de "superlotados": } 40,1 \% \\
\text { - percentual de "cheios": } 25,0 \% \\
\text { - Somando essas duas opções: } 65,1 \% \\
\text { - Qual é o número de ônibus disponíveis para } \\
\text { os deslocamentos diários? } \\
\text { - Percentual de "muito pequeno": } 26,7 \% \\
\text { - Percentual de "pequeno": } 38,7 \% \\
\text { - Somando essas duas opções: } 65,4 \% \\
\text { - Consideramos que } 65 \% \text { dos usuários estão } \\
\text { insatisfeitos com o sistema. }\end{array}$ \\
\hline 2011 & $\begin{array}{l}\text { Média dos percentuais da pesquisa de opinião, } \\
\text { apresentada por Espírito Santo (2010), } \\
\text { considerando: conforto, conservação, limpeza, } \\
\text { horário, acessibilidade, tempo de viagem, } \\
\text { lotação e cumprimento de horário. }\end{array}$ \\
\hline
\end{tabular}

c) Escore e Normalização

\begin{tabular}{ccc}
\hline Cenário & Escore & Escore Normalizado \\
\hline 1980 & $\mathrm{n} / \mathrm{a}$ & $\mathrm{n} / \mathrm{a}$ \\
\hline 1991 & $\mathrm{n} / \mathrm{a}$ & $\mathrm{n} / \mathrm{a}$ \\
\hline 2001 & $35 \%$ & 0,35 \\
\hline 2011 & $31 \%$ & 0,31 \\
\hline
\end{tabular}

\begin{tabular}{ll}
\hline Escore & $\begin{array}{l}\text { Valores de Referência } \\
\text { Porcentagem da população (ou dos } \\
\text { entrevistados) que está totalmente satisfeita (ou } \\
\text { percebe o serviço como excelente) com o } \\
\text { sistema de transporte público urbano e } \\
\text { metropolitano }\end{array}$ \\
\hline 1,00 & $100 \%$ \\
\hline 0,75 & $75 \%$ \\
\hline 0,50 & $50 \%$ \\
\hline 0,25 & $25 \%$ \\
\hline 0,00 & 0 \\
\hline \multicolumn{2}{|c}{} \\
\hline Domínio & Sistemas de Transporte Urbano \\
\hline Tema & 9.2 . Diversificação modal \\
\hline Indicador & 9.2 .1 . Diversidade de modos de transporte \\
\hline Definição & $\begin{array}{l}\text { Número de modos de transporte disponíveis } \\
\text { na cidade. }\end{array}$ \\
\hline
\end{tabular}

\section{a) Fontes de Dados}

\begin{tabular}{ll}
\hline 1980 & $\begin{array}{l}\text { Relatórios dos planos e estudos desenvolvidos } \\
\text { pelo GEIPOT }(1978,1979,1980,1986)\end{array}$ \\
\hline 1991 & Relatório do PDTU (JICA, 1991) \\
\hline 2001 & PDTU (JICA, 2001) na página 18. \\
\hline 2011 & Observação local \\
\hline
\end{tabular}

\section{b) Método de Cálculo}

\begin{tabular}{l}
1980 a pé, bicicleta, automóvel, taxi, ônibus e fluvial $=6$ \\
\hline 1991 a pé, bicicleta, automóvel, taxi, ônibus e fluvial $=6$ \\
\hline 2001 a pé, bicicleta, automóvel, taxi, ônibus e fluvial $=6$ \\
\hline 2011 a pé, bicicleta, automóvel, taxi, ônibus e fluvial $=6$
\end{tabular}

\section{c) Escore e Normalização}

\begin{tabular}{ccc}
\hline Cenário & Escore & Escore Normalizado \\
\hline 1980 & 6 & 0,75 \\
\hline 1991 & 6 & 0,75 \\
\hline 2001 & 6 & 0,75 \\
\hline 2011 & 6 & 0,75 \\
\hline
\end{tabular}




\begin{tabular}{|c|c|}
\hline & Valores de Referência \\
\hline Escore & $\begin{array}{l}\text { Número de modos de transporte (público, semi- } \\
\text { público e privado) que a cidade dispõe }\end{array}$ \\
\hline 1,00 & $\begin{array}{l}7 \text { ou mais - a pé, bicicleta, automóvel, taxi, } \\
\text { ônibus, ferroviário (bonde, metro ou trem de } \\
\text { subúrbio), serviços especiais (car sharing) e } \\
\text { aquaviário (ferryboats e outros barcos). }\end{array}$ \\
\hline 0,75 & $\begin{array}{l}6 \text { - a pé, bicicleta, automóvel, taxi, ônibus e } \\
\text { ferroviário (bonde, metro ou trem de subúrbio). }\end{array}$ \\
\hline 0,50 & 5 - a pé, bicicleta, automóvel, taxi e ônibus. \\
\hline 0,25 & 4 - a pé, bicicleta, automóvel e taxi. \\
\hline 0,00 & 3 - a pé, bicicleta e automóvel. \\
\hline Domínio & Sistemas de Transporte Urbano \\
\hline Tema & Diversificação modal \\
\hline Indicador & $\begin{array}{l}\text { 9.2.2. Transporte coletivo } x \text { transporte } \\
\text { individual }\end{array}$ \\
\hline Definição & $\begin{array}{l}\text { Razão entre o número diário de viagens na } \\
\text { área urbana ou metropolitana feitas por } \\
\text { modos coletivos de transporte e o número } \\
\text { diário de viagens feitas por modos } \\
\text { individuais de transporte motorizados. }\end{array}$ \\
\hline
\end{tabular}

\section{a) Fontes de Dados}

\begin{tabular}{ll}
\hline 1980 & $\begin{array}{l}\text { Relatórios dos planos e estudos desenvolvidos } \\
\text { pelo GEIPOT }(1978,1979,1980,1986)\end{array}$ \\
\hline 1991 & Relatório do PDTU (JICA, 1991) \\
\hline 2001 & Relatório do PDTU (JICA, 2001) na página 233. \\
\hline 2011 & $\begin{array}{l}\text { Estudo Preparatório para o Projeto de Sistema } \\
\text { de Transporte de Ônibus da Região } \\
\text { Metropolitana de Belém (JICA, 2010) }\end{array}$ \\
\hline
\end{tabular}

\section{b) Método de Cálculo}

\begin{tabular}{|c|c|}
\hline 1980 & $\begin{array}{l}\text { - Viagens por transporte coletivo: } 56,7 \% \\
\text { - Viagens por transporte privado: } 39,3 \% \\
\text { - Razão }=56,7 / 39,3=1,44\end{array}$ \\
\hline 1991 & $\begin{array}{l}\text { - Viagens por transporte coletivo: } 1.544 .975 \\
\text { - Viagens por transporte privado: } 366.190 \\
\text { (carro) + } 38.831 \text { (Táxi) = 405.021 } \\
\text { - Razão }=1.544 .975 / 405.021=3,81 \\
\end{array}$ \\
\hline 2001 & $\begin{array}{l}\text { - Identificação do valor do percentual de } \\
\text { viagens realizadas em apenas um dia na } \\
\text { área urbana feita com veículos motorizados } \\
\text { individuais: } 12,1 \% \text {; } \\
\text { - Identificação do valor do percentual de } \\
\text { viagens feitas por modos coletivos de } \\
\text { transporte: } 44,6 \% \text {; } \\
\text { - O indicador é obtido pela razão do percentual } \\
\text { de viagens feitas por modos coletivos pelo } \\
\text { percentual daquelas realizadas por modos } \\
\text { individuais de transportes motorizados: } 44,6 \text { / } \\
12,1=3,69 \text {. }\end{array}$ \\
\hline 2011 & $\begin{array}{l}\text { - Viagens por transporte coletivo: } 1.724 .093 \\
\text { - Viagens por transporte privado: } 1.043 .252 \\
\text { - Razão }=1.724 .093 / 1.043 .252=1,65\end{array}$ \\
\hline
\end{tabular}

\section{c) Escore e Normalização}

\begin{tabular}{ccc}
\hline Cenário & Escore & Escore Normalizado \\
\hline 1980 & 1,44 & 0,11 \\
\hline 1991 & 3,81 & 0,71 \\
\hline 2001 & 3,69 & 0,68 \\
\hline 2011 & 1,65 & 0,16 \\
\hline
\end{tabular}

\begin{tabular}{cl}
\hline Escore & $\begin{array}{l}\text { Valores de Referência } \\
\text { Razão entre o número diário de viagens na } \\
\text { área urbana feitas por modos coletivos e o } \\
\text { número diário de viagens feitas por modos } \\
\text { individuais de transporte motorizados }\end{array}$ \\
\hline 1,00 & Igual ou superior a 5 \\
\hline 0,75 & 4 \\
\hline 0,50 & 3 \\
\hline 0,25 & 2 \\
\hline 0,00 & Igual ou inferior a 1 \\
\hline Domínio & Sistemas de Transporte Urbano \\
\hline Tema & Diversificação modal \\
\hline Indicador & $\begin{array}{l}\text { 9.2.3. Modos não-motorizados x modos } \\
\text { motorizados }\end{array}$ \\
\hline & $\begin{array}{l}\text { Razão entre o número diário de viagens na } \\
\text { área urbana ou metropolitana feitas por } \\
\text { modos não-motorizados de transporte e } \\
\text { número diário de viagens feitas por modos } \\
\text { motorizados de transporte. }\end{array}$ \\
\hline
\end{tabular}

\section{a) Fontes de Dados}

\begin{tabular}{ll}
\hline 1980 & $\begin{array}{l}\text { Relatórios dos planos e estudos desenvolvidos } \\
\text { pelo GEIPOT }(1978,1979,1980,1986)\end{array}$ \\
\hline 1991 & Relatório do PDTU (JICA, 1991) \\
\hline 2001 & PDTU (JICA, 2001) na página 18. \\
\hline 2011 & Informação não disponível \\
\hline
\end{tabular}

\section{b) Método de Cálculo}

- A pé: não informado

- Bicicleta: $1,7 \%$

- Automóvel: $29,4 \%$ + 9,9\% (táxi)

- Ônibus: $56,7 \%$

1980 - Não motorizado:

- Motorizado: $96 \%$

- Escore $=4$ / $96=0,04$ (este não deve ser um valor real, mas ele era, certamente, menor do que 1.

- A pé + bicicleta: $29 \%$

- Automóvel: $17 \%$

- Ônibus: $54 \%$

1991 • Não motorizado: 29\%

- Motorizado: $71 \%$

- Escore = $29 / 71=0,41$

- Identificação do valor do percentual de viagens feitas por modos não-motorizados de transporte: a pé $(34,6 \%)+$ bicicleta $(7,6 \%)=$ $42,2 \%$;

- Identificação do valor do percentual de viagens realizadas por modos motorizados 


\begin{tabular}{|c|c|}
\hline & $\begin{array}{l}\text { de transportes: ônibus }(44,6)+\text { automóvel } \\
(12,1 \%)+\text { outros }(1,1 \%)=57,8 ; \\
\text { - O indicador é obtido pela razão do primeiro } \\
\text { pelo segundo item }=42,2 / 57.8=0,73 ;\end{array}$ \\
\hline 2011 & $\mathrm{n} / \mathrm{a}$ \\
\hline
\end{tabular}

c) Escore e Normalização

\begin{tabular}{ccc}
\hline Cenário & Escore & Escore Normalizado \\
\hline 1980 & 0,04 & 0,00 \\
\hline 1991 & 0,41 & 0,00 \\
\hline 2001 & 0,73 & 0,00 \\
\hline 2011 & $\mathrm{n} / \mathrm{a}$ & $\mathrm{n} / \mathrm{a}$ \\
\hline
\end{tabular}

\begin{tabular}{|c|c|}
\hline Escore & $\begin{array}{l}\text { Valores de Referência } \\
\text { Razão entre o número diário de viagens na } \\
\text { área urbana feitas por modos não-motorizados } \\
\text { e o número diário de viagens feitas por modos } \\
\text { motorizados de transporte }\end{array}$ \\
\hline 1,00 & Igual ou superior a 2 \\
\hline 0,75 & 1,75 \\
\hline 0,50 & 1,50 \\
\hline 0,25 & 1,25 \\
\hline 0,00 & Igual ou inferior 1 \\
\hline Domínio & Sistemas de Transporte Urbano \\
\hline Tema & $\begin{array}{l}\text { 9.3. Regulação e fiscalização do transporte } \\
\text { público }\end{array}$ \\
\hline Indicador & 9.3.1. Contratos e licitações \\
\hline Definição & $\begin{array}{l}\text { Porcentagem dos contratos de operação de } \\
\text { serviços de transporte público que se } \\
\text { encontram regularizados. }\end{array}$ \\
\hline
\end{tabular}

\section{a) Fontes de Dados}

\begin{tabular}{ll}
\hline 1980 & $\begin{array}{l}\text { Relatórios dos planos e estudos desenvolvidos } \\
\text { pelo GEIPOT }(1978,1979,1980,1986)\end{array}$ \\
\hline 1991 & Relatório do PDTU (JICA, 1991) \\
\hline 2001 & $\begin{array}{l}\text { Documento “Linhas por Empresa.doc" incluído } \\
\text { no CD 2 do PDTU-RMB (JICA, 2001). }\end{array}$ \\
\hline 2011 & $\begin{array}{l}\text { A equipe UFPA, baseada nas informações da } \\
\text { Câmara Municipal de Vereadores, em 2011, na } \\
\text { sessão sobre situação das empresas de } \\
\text { transporte coletivo de Belém. }\end{array}$ \\
\hline
\end{tabular}

\section{b) Método de Cálculo}

\begin{tabular}{ll}
\hline \multirow{2}{*}{1980} & $\begin{array}{l}\text { A legislação brasileira só ficou mais rigorosa } \\
\text { quanto a licitações desses serviços a partir da } \\
\text { atual Constituição Brasileira (BRASIL, 1988). As } \\
\text { empresas estavam operando de acordo com } \\
\text { permissões ou concessões da Prefeitura de } \\
\text { Belém. }\end{array}$ \\
\hline \multirow{2}{1991}{$\begin{array}{l}\text { A legislação brasileira só ficou mais rigorosa } \\
\text { quanto a licitações desses serviços a partir da } \\
\text { atual Constituição Brasileira (BRASIL, 1988) e } \\
\text { os contratos anteriores puderam ser renovados, } \\
\text { antes de novas licitações. As empresas estavam } \\
\text { operando de acordo com permissões ou } \\
\text { concessões da Prefeitura de Belém. }\end{array}$} \\
\hline $\begin{array}{l}\text { O documento "Linhas por Empresa.doc" incluido } \\
\text { no CD 2 do PDTU-RMB (JICA, 2001) apresenta }\end{array}$
\end{tabular}

\begin{tabular}{ll}
\hline a relação das linhas operadas pelas empresas. \\
Embora o assunto seja controverso (MERCÊS, \\
2004), considerou-se que todas as empresas \\
estavam operando regularmente.
\end{tabular}

\section{c) Escore e Normalização}

\begin{tabular}{ccc}
\hline Cenário & Escore & Escore Normalizado \\
\hline 1980 & $100 \%$ & 1,00 \\
\hline 1991 & $100 \%$ & 1,00 \\
\hline 2001 & $100 \%$ & 1,00 \\
\hline 2011 & $0 \%$ & 0,00 \\
\hline
\end{tabular}

\begin{tabular}{ll}
\hline Escore & $\begin{array}{l}\text { Valores de Referência } \\
\text { Porcentagem dos contratos de prestação de } \\
\text { serviços de transportes que se encontram } \\
\text { regularizados }\end{array}$ \\
\hline 1,00 & $100 \%$ \\
\hline 0,75 & $75 \%$ \\
\hline 0,50 & $50 \%$ \\
\hline 0,25 & $25 \%$ \\
\hline 0,00 & 0 \\
\hline
\end{tabular}

\begin{tabular}{|c|c|}
\hline Domínio & Sistemas de Transporte Urbano \\
\hline Tema & $\begin{array}{l}\text { Regulação e fiscalização do transporte } \\
\text { público }\end{array}$ \\
\hline Indicador & 9.3.2. Transporte clandestino \\
\hline Definição & $\begin{array}{l}\text { Participação do transporte clandestino ou } \\
\text { irregular nos deslocamentos urbanos. }\end{array}$ \\
\hline
\end{tabular}

\section{a) Fontes de Dados}

\begin{tabular}{ll}
\hline 1980 & Informação não disponível. \\
\hline 1991 & Informação não disponível. \\
\hline 2001 & Informação não disponível. \\
\hline 2011 & SETRANSBEL $^{23}$ \\
\hline
\end{tabular}

\section{b) Método de Cálculo}

\begin{tabular}{ll}
\hline 1980 & n/a \\
\hline 1991 & n/a \\
\hline 2001 & n/a \\
\hline 2011 & $\begin{array}{l}\text { Expressiva, predominando os serviços de vans } \\
\text { e peruas irregulares, mototáxi e táxi-lotação }\end{array}$ \\
\hline
\end{tabular}

\section{c) Escore e Normalização}

\begin{tabular}{ccc}
\hline Cenário & Escore & Escore Normalizado \\
\hline 1980 & $\mathrm{n} / \mathrm{a}$ & $\mathrm{n} / \mathrm{a}$ \\
\hline 1991 & $\mathrm{n} / \mathrm{a}$ & $\mathrm{n} / \mathrm{a}$ \\
\hline 2001 & $\mathrm{n} / \mathrm{a}$ & $\mathrm{n} / \mathrm{a}$ \\
\hline 2011 & 0,25 & 0,25 \\
\hline
\end{tabular}

${ }^{23}$ Sindicato das Empresas de Transporte de Belém 


\begin{tabular}{|c|c|}
\hline & Valores de Referência \\
\hline Escore & $\begin{array}{l}\text { A participação do transporte clandestino no } \\
\text { sistema de transporte público urbano é: }\end{array}$ \\
\hline 1,00 & $\begin{array}{l}\text { Inexpressiva ou inexistente, tendo sido } \\
\text { combatidos, regulamentados ou incorporados } \\
\text { ao sistema formal }\end{array}$ \\
\hline 0,75 & $\begin{array}{l}\text { Pequena, predominando os serviços de vans e } \\
\text { peruas irregulares }\end{array}$ \\
\hline 0,50 & $\begin{array}{l}\text { Pequena, predominando os serviços de vans e } \\
\text { peruas irregulares e mototáxi }\end{array}$ \\
\hline 0,25 & $\begin{array}{l}\text { Expressiva, predominando os serviços de vans } \\
\text { e peruas irregulares, mototáxi e táxi-lotação }\end{array}$ \\
\hline 0,00 & $\begin{array}{l}\text { Expressiva, existindo serviços de natureza } \\
\text { diversa como vans e peruas irregulares, } \\
\text { mototáxi, táxi-lotação, ônibus piratas e } \\
\text { automóveis }\end{array}$ \\
\hline Domínio & Sistemas de Transporte Urbano \\
\hline Tema & 9.4. Integração do transporte público \\
\hline Indicador & 9.4.1. Terminais intermodais \\
\hline Definição & $\begin{array}{l}\text { Porcentagem dos terminais de transporte } \\
\text { urbano/metropolitano de passageiros que } \\
\text { permitem a integração física de dois ou mais } \\
\text { modos de transporte público. }\end{array}$ \\
\hline
\end{tabular}

\section{a) Fontes de Dados}

\begin{tabular}{ll}
\hline 1980 & $\begin{array}{l}\text { Relatórios dos planos e estudos desenvolvidos } \\
\text { pelo GEIPOT }(1978,1979,1980,1986)\end{array}$ \\
\hline 1991 & Relatório do PDTU (JICA, 1991) \\
\hline 2001 & Relatório final do PDTU-RMB (JICA, 2001). \\
\hline 2011 & Observação local \\
\hline
\end{tabular}

\section{b) Método de Cálculo}

\begin{tabular}{ll}
\hline 1980 & $\begin{array}{l}\text { Conforme pode-se verificar nos relatórios, não } \\
\text { existia este tipo de terminal. }\end{array}$ \\
\hline 1991 & $\begin{array}{l}\text { Conforme pode-se verificar no relatório, não } \\
\text { existia este tipo de terminal. }\end{array}$ \\
\hline 2001 & $\begin{array}{l}\text { No relatório final do PDTU-RMB (JICA, 2001) } \\
\text { não foram encontradas referências a terminais } \\
\text { de integração, a não ser o Terminal Rodoviário } \\
\text { Intermunicipal. Considerou-se como 0 (zero) } \\
\text { terminais. }\end{array}$ \\
\hline 2011 & $\begin{array}{l}\text { Belém não dispõe de terminais de integração } \\
\text { intermodal }\end{array}$ \\
\hline
\end{tabular}

c) Escore e Normalização

\begin{tabular}{ccc}
\hline Cenário & Escore & Escore Normalizado \\
\hline 1980 & 0 & 0,00 \\
\hline 1991 & 0 & 0,00 \\
\hline 2001 & 0 & 0,00 \\
\hline 2011 & 0 & 0,00 \\
\hline
\end{tabular}

\begin{tabular}{cl}
\hline Escore & $\begin{array}{l}\text { Valores de Referência } \\
\text { Porcentagem dos terminais de transporte } \\
\text { público urbano que permitem integração } \\
\text { entre dois os mais modos de transporte } \\
\text { público }\end{array}$ \\
\hline 1,00 & Mais de $75 \%$ \\
\hline 0,75 & $75 \%$ \\
\hline 0,50 & $50 \%$ \\
\hline 0,25 & $25 \%$ \\
\hline 0,00 & 0 \\
\hline & \\
\hline Domínio & Sistemas de Transporte Urbano \\
\hline Tema & Integração do transporte público \\
\hline Indicador & 9.4.2. Integração do transporte público \\
\hline Definição & $\begin{array}{l}\text { Grau de integração do sistema de transporte } \\
\text { público urbano e metropolitano. }\end{array}$ \\
\hline
\end{tabular}

\section{a) Fontes de Dados}

\begin{tabular}{ll}
\hline 1980 & $\begin{array}{l}\text { Relatórios dos planos e estudos desenvolvidos } \\
\text { pelo GEIPOT }(1978,1979,1980,1986)\end{array}$ \\
\hline 1991 & Relatório do PDTU (JICA, 1991) \\
\hline 2001 & Relatório do PDTU (JICA, 2001) \\
\hline 2011 & Experiência local da equipe do ITEP/UFPA \\
\hline
\end{tabular}

\section{b) Método de Cálculo}

\begin{tabular}{cl}
\hline 1980 & $\begin{array}{l}\text { Pelo diagnóstico do sistema, apresentado nos } \\
\text { relatórios, verifica-se a inexistência de } \\
\text { integração física ou tarifária. }\end{array}$ \\
\hline 1991 & $\begin{array}{l}\text { Pelo diagnóstico do sistema, apresentado nos } \\
\text { relatórios, verifica-se a inexistência de } \\
\text { integração física ou tarifária. }\end{array}$ \\
\hline 2001 & $\begin{array}{l}\text { Pela informações continas no item (3) da página } \\
\text { "S 15" do relatório final do PDTU-RMB (JICA, } \\
\text { 2001) “... não existe integração física, } \\
\text { operacional e tarifária na rede de transporte } \\
\text { público, ...". }\end{array}$ \\
\hline 2011 & $\begin{array}{l}\text { É praticada somente a integração física em } \\
\text { terminais fechados do sistema de transporte } \\
\text { público urbano, para o mesmo modo de } \\
\text { transporte (transferências intramodais) }\end{array}$ \\
\hline
\end{tabular}

c) Escore e Normalização

\begin{tabular}{ccc}
\hline Cenário & Escore & Escore Normalizado \\
\hline 1980 & 0,00 & 0,00 \\
\hline 1991 & 0,00 & 0,00 \\
\hline 2001 & 0,00 & 0,00 \\
\hline 2011 & 0,25 & 0,25 \\
\hline
\end{tabular}




\begin{tabular}{|c|c|}
\hline Escore & Valores de Referência \\
\hline 1,00 & $\begin{array}{l}\text { O sistema de transporte público é totalmente } \\
\text { integrado com o uso de bilhete eletrônico para } \\
\text { integração intermodal e de sistemas adjacentes } \\
\text { (intermunicipais ou metropolitanos) }\end{array}$ \\
\hline 0,75 & $\begin{array}{l}\text { É praticada a integração física e tarifária } \\
\text { temporal em terminais fechados e em qualquer } \\
\text { ponto do sistema de transporte público urbano, } \\
\text { para o mesmo modo de transporte e entre } \\
\text { diferentes modos (transferências intramodais e } \\
\text { intermodais) }\end{array}$ \\
\hline 0,50 & $\begin{array}{l}\text { É praticada a integração física e tarifária } \\
\text { temporal somente em terminais fechados do } \\
\text { sistema de transporte público urbano, para o } \\
\text { mesmo modo de transporte (transferências } \\
\text { intramodais) }\end{array}$ \\
\hline 0,25 & $\begin{array}{l}\text { É praticada somente a integração física em } \\
\text { terminais fechados do sistema de transporte } \\
\text { público urbano, para o mesmo modo de } \\
\text { transporte (transferências intramodais) }\end{array}$ \\
\hline 0,00 & $\begin{array}{l}\text { Não é praticada nenhuma forma de integração } \\
\text { física ou tarifária no sistema de transporte } \\
\text { público urbano }\end{array}$ \\
\hline Domínio & Sistemas de Transporte Urbano \\
\hline Tema & 9.5. Política Tarifária \\
\hline Indicador & 9.5.1. Descontos e gratuidades \\
\hline Definição & $\begin{array}{l}\text { Porcentagem dos usuários do sistema de } \\
\text { transporte público que usufruem de descontos } \\
\text { ou gratuidade do valor da tarifa. }\end{array}$ \\
\hline
\end{tabular}

\section{a) Fontes de Dados}

\begin{tabular}{ll}
\hline 1980 & $\begin{array}{l}\text { Relatórios de estudos e planos desenvolvidos } \\
\text { pelo GEIPOT }(1978,1979,1980,1986)\end{array}$ \\
\hline 1991 & Relatório do PDTU (JICA, 1991). \\
\hline 2001 & $\begin{array}{l}\text { Planilha "IPK MAIO 2000.xIs" que consta do CD } \\
2 \text { do PDTU-RMB (JICA, 2001). }\end{array}$ \\
\hline 2011 & (ESPIRITO SANTO, 2010) \\
\hline
\end{tabular}

\section{b) Método de Cálculo}

\begin{tabular}{|c|c|}
\hline 1980 & Informação não disponível. \\
\hline 1991 & Informação não disponível. \\
\hline \multirow[b]{2}{*}{2001} & $\begin{array}{l}\text { - Na planilha referida acima temos a utilização } \\
\text { de um fator igual a 0,85 que é utilizado para o } \\
\text { cálculo do passageiro equivalente. }\end{array}$ \\
\hline & $\begin{array}{l}\text { - Não foram encontradas mais informações, } \\
\text { mas considerando que essa diminuiçao se } \\
\text { deve à meia passagem paga pelos } \\
\text { estudantes teríamos um total de } 30 \% \text { dos } \\
\text { usuários beneficiados. Considerou-se } \\
\text { também que as gratuidade não devem ser } \\
\text { registradas (passarem pela catraca). }\end{array}$ \\
\hline \multirow{3}{*}{2011} & Passageiros com desconto $=10.098 .212$ \\
\hline & Passageiros isentos $=6.326 .691$ \\
\hline & Total de passageiros $=34.160 .793$ \\
\hline
\end{tabular}

\section{c) Escore e Normalização}

\begin{tabular}{ccc}
\hline Cenário & Escore & Escore Normalizado \\
\hline 1980 & $\mathrm{n} / \mathrm{a}$ & $\mathrm{n} / \mathrm{a}$ \\
\hline 1991 & $\mathrm{n} / \mathrm{a}$ & $\mathrm{n} / \mathrm{a}$ \\
\hline 2001 & $30 \%$ & 0,50 \\
\hline 2011 & $48 \%$ & 0,05 \\
\hline
\end{tabular}

\begin{tabular}{|c|c|}
\hline Escore & $\begin{array}{l}\text { Valores de Referência } \\
\text { Porcentagem dos embarques (ou usuários) } \\
\text { do sistema de transporte público no período } \\
\text { de análise que tiveram desconto ou } \\
\text { gratuidade da tarifa }\end{array}$ \\
\hline 1,00 & Até $10 \%$ \\
\hline 0,75 & $20 \%$ \\
\hline 0,50 & $30 \%$ \\
\hline 0,25 & $40 \%$ \\
\hline 0,00 & $50 \%$ ou mais \\
\hline Domínio & Sistemas de Transportes Urbanos \\
\hline Tema & Política tarifária \\
\hline Indicador & 9.5.2. Tarifas de transporte \\
\hline Definição & $\begin{array}{l}\text { Variação percentual dos valores de tarifa de } \\
\text { transporte público urbano para um período de } \\
\text { análise, comparada a índices inflacionários } \\
\text { para o mesmo período. }\end{array}$ \\
\hline
\end{tabular}

\section{a) Fontes de Dados}

\begin{tabular}{ll}
\hline 1980 & Informação não encontrada. \\
\hline 1991 & Informação não encontrada. \\
\hline 2001 & $\begin{array}{l}\text { Relatório do Ministério das Cidades sobre a } \\
\text { evolução dos valores da tarifa (MCIDADES, } \\
\text { 2004). }\end{array}$ \\
\hline 2011 & CTBel e DIEESE ${ }^{24}$ \\
\hline
\end{tabular}

\section{b) Método de Cálculo}

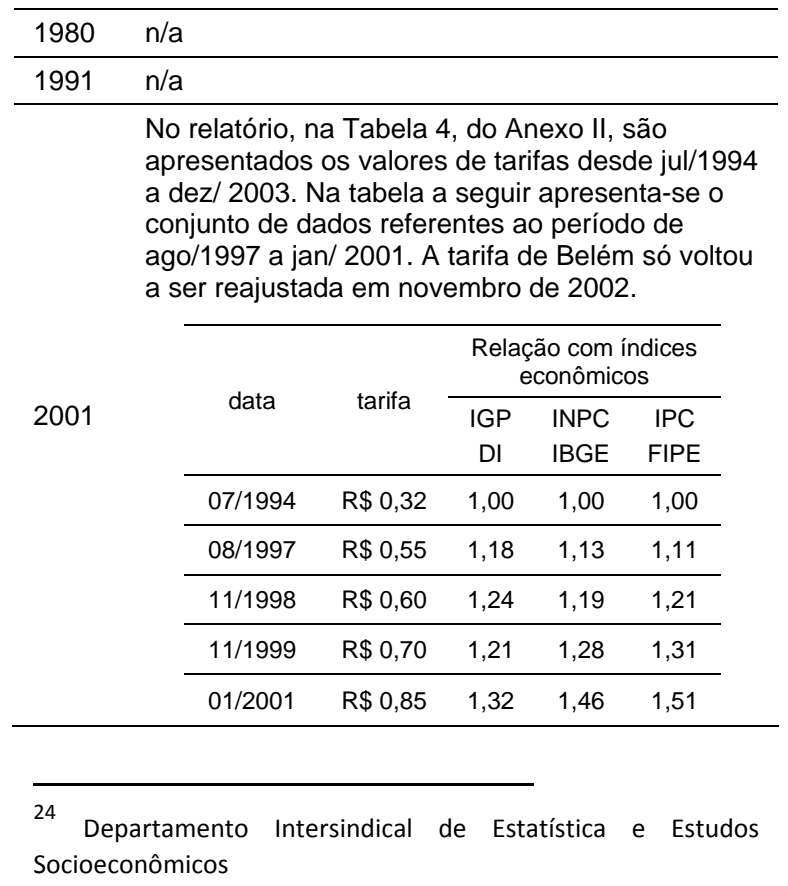


- Tarifa em 2010 - R\$1,85

- Índice inflacionário (DIEESE, 2010) = 6\%

2011 - Reajuste: Fevereiro 2010 - de R\$ 1,70 para $\mathrm{R} \$ 1,85$

- Variação: 8,11\% (acima do índice)

c) Escore e Normalização

\begin{tabular}{ccc}
\hline Cenário & Escore & Escore Normalizado \\
\hline 1980 & $\mathrm{n} / \mathrm{a}$ & $\mathrm{n} / \mathrm{a}$ \\
\hline 1991 & $\mathrm{n} / \mathrm{a}$ & $\mathrm{n} / \mathrm{a}$ \\
\hline 2001 & 0,00 & 0,00 \\
\hline 2011 & 0,00 & 0,00 \\
\hline
\end{tabular}

\begin{tabular}{cl}
\hline Escore & $\begin{array}{l}\text { Valores de Referência } \\
\text { As tarifas de transporte público } \\
\text { apresentaram, em relação ao índice } \\
\text { inflacionário selecionado: }\end{array}$ \\
\hline 1,00 & Não houve aumento da tarifa \\
\hline 0,66 & Aumento inferior ao índice \\
\hline 0,33 & Aumento equivalente ao índice \\
\hline 0,00 & Aumento superior ao índice \\
\hline Domínio & Sistemas de Transporte Urbano \\
\hline Tema & Política tarifária \\
\hline Indicador & 9.5.3. Subsídios públicos \\
\hline Definição & $\begin{array}{l}\text { Subsídios públicos oferecidos aos sistemas } \\
\text { de transporte urbano/metropolitano. }\end{array}$ \\
\hline
\end{tabular}

\section{a) Fontes de Dados}

\begin{tabular}{cl}
\hline 1980 & $\begin{array}{l}\text { Não existia subsídio público. A tarifa era } \\
\text { praticamente unificada (apenas } 3 \text { linhas estavam } \\
\text { fora do mesmo valor), mas era mantida através } \\
\text { de subsídio cruzado. }\end{array}$ \\
\hline 1991 & $\begin{array}{l}\text { Não existia subsídio público. A tarifa única existe, } \\
\text { mas através de subsídio cruzado. }\end{array}$ \\
\hline 2001 & $\begin{array}{l}\text { Não existia subsídio público. A tarifa única } \\
\text { existia, mas neste caso trata-se de subsídio } \\
\text { cruzado. }\end{array}$ \\
\hline 2011 & $\begin{array}{l}\text { Não existie subsídio público. A tarifa única existe, } \\
\text { mas neste caso trata-se de subsídio cruzado. }\end{array}$ \\
\hline
\end{tabular}

b) Método de Cálculo

\begin{tabular}{ll}
\hline 1980 & n/a \\
\hline 1991 & n/a \\
\hline 2001 & n/a \\
\hline 2011 & n/a \\
\hline
\end{tabular}

c) Escore e Normalização

\begin{tabular}{ccc}
\hline Cenário & Escore & Escore Normalizado \\
\hline 1980 & 0,00 & 0,00 \\
\hline 1991 & 0,00 & 0,00 \\
\hline 2001 & 0,00 & 0,00 \\
\hline 2011 & 0,00 & 0,00 \\
\hline
\end{tabular}

\begin{tabular}{cl}
\hline Escore & $\begin{array}{l}\text { Valores de Referência } \\
\text { Há subsídios: }\end{array}$ \\
\hline 1,00 & $\begin{array}{l}\text { Públicos para a totalidade do sistema de } \\
\text { transporte público urbano e metropolitano, } \\
\text { visando a redução da tarifa de transporte }\end{array}$ \\
\hline 0,75 & $\begin{array}{l}\text { Públicos para serviços deficitários (alta } \\
\text { capacidade ou metro-ferroviários) e serviços } \\
\text { especiais de transporte (pessoas com } \\
\text { necessidades especiais, etc) }\end{array}$ \\
\hline 0,50 & $\begin{array}{l}\text { Público somente para serviços deficitários } \\
\text { (alta capacidade ou metro-ferroviários) }\end{array}$ \\
\hline 0,25 & $\begin{array}{l}\text { Há somente mecanismos de subsídio } \\
\text { interno para compensação em sistema de } \\
\text { transporte urbano com tarifa única }\end{array}$ \\
\hline 0,00 & $\begin{array}{l}\text { Não há qualquer subsídio público ou } \\
\text { mecanismos de compensação para os } \\
\text { sistemas de transporte } \\
\text { urbano/metropolitano }\end{array}$ \\
\hline
\end{tabular}

